Published in final edited form as:

Cochrane Database Syst Rev. ; 8: CD007675. doi:10.1002/14651858.CD007675.pub2.

\title{
Interactive computer-based interventions for weight loss or weight maintenance in overweight or obese people
}

\author{
L. Susan Wieland ${ }^{1}$, Louise Falzon ${ }^{2}$, Chris N Sciamanna ${ }^{3}$, Kimberlee $\mathrm{J} \mathrm{Trudeau}^{4}$, Suzanne \\ Brodney Folse $^{5}$, Joseph E Schwartz ${ }^{6}$, and Karina W Davidson ${ }^{7}$
}

${ }^{1}$ Center for Integrative Medicine, University of Maryland School of Medicine, Baltimore, Maryland, USA ${ }^{2}$ Center for Behavioral Cardiovascular Health, Columbia University Medical Center, New York, NY, USA ${ }^{3}$ Chief, Division of General Internal Medicine, Penn State College of Medicine, Hershey, USA ${ }^{4}$ Inflexxion, Inc., Newton, MA, USA ${ }^{5}$ The Health \& Wellness Institute, Providence, Rhode Island, USA ${ }^{6}$ Psychiatry and Behavioral Sciences, Stony Brook University, Stony Brook, USA ${ }^{7}$ Behavioral Cardiovascular Health \& Hypertension Program, Columbia College of Physicians \& Surgeons, New York, New York, USA

\section{Abstract \\ Background-The World Health Organization (WHO) estimates that the number of obese or overweight individuals worldwide will increase to 1.5 billion by 2015. Chronic diseases associated with overweight or obesity include diabetes, heart disease, hypertension and stroke.}

Copyright @ 2012 The Cochrane Collaboration. Published by John Wiley \& Sons, Ltd.

Contact address: Louise Falzon, Center for Behavioral Cardiovascular Health, Columbia University Medical Center, PH9 Room E319, 622 West 168th St, New York, NY, 10032, USA. af2215@ columbia.edu.

CONTRIBUTIONS OF AUTHORS

L. Susan Wieland: trial selection, data extraction, data analysis, data interpretation, draft manuscript, review final draft.

Louise Falzon: protocol draft, search strategy development, trial selection, data extraction, 'Risk of bias' assessment, draft manuscript, review final draft.

Chris N. Sciamanna: protocol draft, 'Risk of bias' assessment, draft manuscript, review final draft.

Kimberlee J. Trudeau: protocol draft, study selection, 'Risk of bias' assessment, review final draft.

Suzanne Brodney: protocol draft, data extraction, review final draft.

Joseph E Schwartz: data analysis, review final draft.

Karina W Davidson: protocol draft, review final draft.

\section{DIFFERENCES BETWEEN PROTOCOL AND REVIEW}

TITLE: changed from "Computer-based interventions for weight loss or weight maintenance in overweight or obese people" to "Interactive computer-based interventions for weight loss or weight maintenance in overweight or obese people".

OBJECTIVES: changed to "To assess the effects of interactive computer-based interventions for weight loss or weight maintenance in overweight or obese people".

TYPES OF STUDIES: quasi-randomized controlled trials (quasi-RCTs) added.

ELECTRONIC SEARCHES: CRISP deleted from list of databases searched.

SELECTION OF STUDIES: LSW added for selection of studies.

DATA EXTRACTION AND MANAGEMENT: LF replaced by LSW for data extraction.

RISK OF BIAS IN INCLUDED STUDIES: CS added for risk of bias assessment.

DECLARATIONS OF INTEREST

L. Susan Wieland: none known.

Louise Falzon: none known.

Chris N. Sciamanna is developing and testing a web-based weight loss program. It is a university-based, grant-funded project.

Kimberlee J. Trudeau: none known.

Suzanne Brodney: none known.

Joseph E. Schwartz: none known.

Karina W. Davidson: none known. 
Objectives-To assess the effects of interactive computer-based interventions for weight loss or weight maintenance in overweight or obese people.

Search methods-We searched several electronic databases, including CENTRAL, MEDLINE, EMBASE, CINAHL, LILACS and PsycINFO, through 25 May 2011. We also searched clinical trials registries to identify studies. We scanned reference lists of included studies and relevant systematic reviews.

Selection criteria-Studies were included if they were randomized controlled trials or quasirandomized controlled trials that evaluated interactive computer-based weight loss or weight maintenance programs in adults with overweight or obesity. We excluded trials if the duration of the intervention was less than four weeks or the loss to follow-up was greater than $20 \%$ overall.

Data collection and analysis-Two authors independently extracted study data and assessed risk of bias. Where interventions, control conditions, outcomes and time frames were similar between studies, we combined study data using meta-analysis.

Main results-We included 14 weight loss studies with a total of 2537 participants, and four weight maintenance studies with a total of 1603 participants. Treatment duration was between four weeks and 30 months. At six months, computer-based interventions led to greater weight loss than minimal interventions (mean difference (MD) $-1.5 \mathrm{~kg}$; 95\% confidence interval (CI) -2.1 to -0.9 ; two trials) but less weight loss than in-person treatment (MD $2.1 \mathrm{~kg}$; 95\% CI 0.8 to 3.4; one trial). At six months, computer-based interventions were superior to a minimal control intervention in limiting weight regain (MD $-0.7 \mathrm{~kg} ; 95 \% \mathrm{CI}-1.2$ to -0.2 ; two trials), but not superior to infrequent in-person treatment (MD $0.5 \mathrm{~kg} ; 95 \%-0.5$ to 1.6; two trials). We did not observe consistent differences in dietary or physical activity behaviors between intervention and control groups in either weight loss or weight maintenance trials. Three weight loss studies estimated the costs of computer-based interventions compared to usual care, however two of the studies were 11 and 28 years old, and recent advances in technology render these estimates unlikely to be applicable to current or future interventions, while the third study was conducted in active duty military personnel, and it is unclear whether the costs are relevant to other settings. One weight loss study reported the cost-effectiveness ratio for a weekly in-person weight loss intervention relative to a computer-based intervention as USD 7177 (EUR 5678) per life year gained (80\% CI USD 3055 to USD 60,291 (EUR 2417 to EUR 47,702)). It is unclear whether this could be extrapolated to other studies. No data were identified on adverse events, morbidity, complications or health-related quality of life.

Authors' conclusions-Compared to no intervention or minimal interventions (pamphlets, usual care), interactive computer-based interventions are an effective intervention for weight loss and weight maintenance. Compared to in-person interventions, interactive computer-based interventions result in smaller weight losses and lower levels of weight maintenance. The amount of additional weight loss, however, is relatively small and of brief duration, making the clinical significance of these differences unclear.

\section{INDEX TERMS: Medical Subject Headings (MeSH)}

*Weight Loss; Obesity [*therapy]; Overweight [therapy]; Randomized Controlled Trials as Topic; Therapy; Computer-Assisted [*methods] 


\section{MeSH check words}

Adult; Female; Humans; Male

\section{PLAIN LANGUAGE SUMMARY \\ Interactive computer-based interventions for weight loss or weight maintenance in overweight or obese people}

Overweight and obesity are common health problems and increase the risk of developing several serious health conditions. The standard treatment for overweight and obesity is to help patients change their diet and exercise habits. Treatment programs in which patients interact with a computer may help people make these changes, and improve their ability to lose weight and keep it off. We looked for randomized or quasi-randomized trials in which an interactive computer intervention was compared with no treatment, a limited treatment such as usual care or paper materials, or an in-person treatment to help people lose weight or keep it off. We included 14 weight loss studies with a total of 2537 participants, and four weight maintenance studies with a total of 1603 participants. The length of treatment ranged from four weeks to 30 months. At six months, computer-based interventions led to greater weight loss than minimal interventions (mean difference $-1.5 \mathrm{~kg}$; $95 \%$ confidence interval (CI) -2.1 to -0.9 ; two trials) but less than in-person treatment (mean difference $2.1 \mathrm{~kg} ; 95 \%$ CI 0.8 to 3.4; one trial). At six months, computer-based interventions were superior to a minimal control intervention in limiting weight regain (mean difference $-0.7 \mathrm{~kg} ; 95 \% \mathrm{CI}$ -1.2 to -0.2 ; two trials), but not superior to infrequent in-person treatment (mean difference $0.5 \mathrm{~kg} ; 95 \%-0.5$ to 1.6 ; two trials).

Three weight loss studies estimated the costs of computer-based interventions compared to usual care, however two of the studies were 11 and 28 years old, and these estimates are probably not relevant to interventions using current technology, while the third study was carried out in active duty military personnel, and it is unclear whether costs would be similar in other settings. One weight loss study reported the cost-effectiveness ratio for a weekly inperson weight loss intervention relative to a computer-based intervention as USD 7177 (EUR 5678) per life year gained (80\% CI USD 3055 to USD 60,291 (EUR 2417 to EUR $47,702)$ ). It is unclear whether this is relevant to other studies. No studies had information on health-related quality of life, morbidity, complications or adverse effects.

Compared to no intervention or minimal interventions (pamphlets, usual care), interactive computer-based interventions are an effective intervention for weight loss and weight maintenance. Compared to in-person interventions, interactive computer-based interventions result in smaller weight losses and lower levels of weight maintenance. The amount of additional weight loss, however, is relatively small and of brief duration, making the clinical significance of these differences unclear. 
SUMMARY OF FINDINGS FOR THE MAIN COMPARISON [Explanation]

\begin{tabular}{|c|c|c|c|c|c|c|}
\hline \multicolumn{7}{|c|}{$\begin{array}{l}\text { Patient or population: adults with overweight or obesity } \\
\text { Settings: community } \\
\text { Intervention: interactive computer intervention } \\
\text { Comparison: usual care }\end{array}$} \\
\hline \multirow[t]{3}{*}{ Outcomes } & \multicolumn{2}{|c|}{ Illustrative comparative risks ${ }^{*}(95 \% \mathrm{CI})$} & \multirow{3}{*}{$\begin{array}{l}\text { Relative } \\
\text { effect }(95 \% \\
\text { CI) }\end{array}$} & \multirow{3}{*}{$\begin{array}{l}\text { No of } \\
\text { participants } \\
\text { (studies) }\end{array}$} & \multirow{3}{*}{$\begin{array}{l}\text { Quality of } \\
\text { the evidence } \\
\text { (GRADE) }\end{array}$} & \multirow[t]{3}{*}{ Comments } \\
\hline & Assumed risk & Corresponding risk & & & & \\
\hline & Usual care & Interactive computer intervention & & & & \\
\hline Health-related quality of life & See comment & See comment & Not estimable & See comment & See comment & Not investigated \\
\hline Adverse effects & See comment & See comment & Not estimable & See comment & See comment & $\begin{array}{l}\text { One weight } \\
\text { maintenance } \\
\text { study stated that } \\
\text { no serious } \\
\text { adverse events } \\
\text { occurred. No } \\
\text { other study } \\
\text { investigated } \\
\text { adverse events }\end{array}$ \\
\hline $\begin{array}{l}\text { Weight loss (change in kg weight) } \\
\text { Follow-up: } 6 \text { months }\end{array}$ & $\begin{array}{l}\text { The mean } \\
\text { weight loss in } \\
\text { the control } \\
\text { groups ranged } \\
\text { from } 3.5 \mathrm{~kg} \\
\text { lost to } 0.5 \mathrm{~kg} \\
\text { gained }\end{array}$ & $\begin{array}{l}\text { The mean weight loss in the } \\
\text { intervention groups was } 1.5 \mathrm{~kg}(0.9 \\
\text { to } 2.1) \text { greater }\end{array}$ & & 511 (2 studies) & $\begin{array}{l}\oplus \oplus \oplus \circ \\
3 \text { moderate } l\end{array}$ & \\
\hline $\begin{array}{l}\text { Weight regain (change in kg } \\
\text { weight) } \\
\text { Follow-up: } 12 \text { months }\end{array}$ & $\begin{array}{l}\text { The mean } \\
\text { weight regain } \\
\text { in the control } \\
\text { groups ranged } \\
\text { from } 0.6 \mathrm{~kg} \text { to } \\
3.0 \mathrm{~kg}\end{array}$ & $\begin{array}{l}\text { The mean weight regain in the } \\
\text { intervention groups was } 0.8 \mathrm{~kg}(0.2 \\
\text { to } 1.4) \text { lower }\end{array}$ & & 1004 (3 studies) & $\begin{array}{l}\oplus \oplus \oplus \circ \\
3 \text { moderate } 2\end{array}$ & \\
\hline Physical-activity related outcomes & See comment & See comment & Not estimable & See comment & See comment & $\begin{array}{l}\text { Few studies } \\
\text { investigated } \\
\text { these outcomes, } \\
\text { and no } \\
\text { individual } \\
\text { studies or } \\
\text { pooled analyses } \\
\text { identified } \\
\text { clinically or } \\
\text { statistically } \\
\text { significant } \\
\text { physical- } \\
\text { activity effects }\end{array}$ \\
\hline Cost-effectiveness & See comment & See comment & Not estimable & See comment & See comment & $\begin{array}{l}\text { Two weight } \\
\text { loss studies } \\
\text { estimated the } \\
\text { costs of the } \\
\text { intervention, } \\
\text { howevert the } \\
\text { studies were } 11 \\
\text { and } 28 \text { years } \\
\text { old. Recent } \\
\text { advances in } \\
\text { technology } \\
\text { render these } \\
\text { estimates un- } \\
\text { likely to be } \\
\text { applicable to } \\
\text { current or future } \\
\text { interventions. A } \\
\text { companion } \\
\text { publication to a } \\
\text { thirs study } \\
\text { estimated the } \\
\text { costs of the } \\
\text { intervention, } \\
\text { but this study } \\
\text { was conducted } \\
\text { in active duty } \\
\text { military } \\
\text { personel, and } \\
\text { it is unclear } \\
\text { whether costs } \\
\text { could be be } \\
\text { extrapolated to } \\
\text { other settings }\end{array}$ \\
\hline
\end{tabular}

The basis for the assumed risk (e.g. the median control group risk across studies) is provided in footnotes. The corresponding risk (and its 95\% confidence interval) is based on the assumed risk in the comparison group and the relative effect of the intervention (and its 95\% CI).

CI: confidence interval 
GRADE Working Group grades of evidence

High quality: Further research is very unlikely to change our confidence in the estimate of effect.

Moderate quality: Further research is likely to have an important impact on our confidence in the estimate of effect and may change the estimate.

Low quality: Further research is very likely to have an important impact on our confidence in the estimate of effect and is likely to change the estimate. Very low quality: We are very uncertain about the estimate.

$\overline{1}$ One study stated that study staff could not be blinded. There was therefore a risk of bias in assessing outcome measurements. The same study was also unclear about allocation concealment.

2 Two studies were unclear about details of randomization, unclear about allocation concealment and unclear about blinding.

\section{BACKGROUND}

\section{Description of the condition}

Prevalence-Once considered a problem only in high-income countries, overweight and obesity are now dramatically on the rise in low- and middle-income countries, particularly in urban settings (World Health Organization 2011). The World Health Organization estimates that, without action, the number of overweight and obese individuals worldwide will increase from 1 billion in 2010 to 1.5 billion in 2015 (World Health Organization 2011). Overweight and obesity increase the risks for many chronic medical conditions, including diabetes, heart disease, hypertension and stroke (National Institutes of Health 2000), though modest reductions in weight can lead to important health benefits (Pi-Sunyer 2007; Stevens 2001).

Aetiology-The fundamental cause of obesity and overweight is an energy imbalance between calories consumed and calories expended (World Health Organization 2004). Global increases in overweight and obesity are attributable to a number of factors including a global shift in diet towards increased intake of energy-dense foods that are high in fat and sugars but low in vitamins, minerals and other micronutrients and a trend towards decreased physical activity due to the increasingly sedentary nature of many forms of work, changing modes of transportation and increasing urbanization (World Health Organization 2011).

Costs-Obesity accounts for $2 \%$ to $6 \%$ of total healthcare costs in several developed countries; some estimates put the figure as high as 7\% (Withrow 2011). The true costs are undoubtedly much greater as not all obesity-related conditions are included in the calculations. According to a study of national costs attributed to overweight and obesity, related medical expenditures accounted for 9.1 percent of the total U.S. medical costs in 1998 and may have reached as high as USD 78.5 billion (USD 92.6 billion in 2002 dollars) (Finkelstein 2003; see also http://www.cdc.gov/nccdphp/dnpa/obesity/ economic_consequences.htm). Private employers alone are estimated to spend USD 45 billion per year paying for the direct and indirect costs of obesity (Finkelstein 2003).

A major issue is that overweight and obesity affects a great number of people, which means that any potential intervention needs to be highly cost-effective. A quick calculation shows that, assuming that in-person sessions cost USD 10 each and an individual attends 24 biweekly weight maintenance sessions per year, treatment of the 145 million U.S. adults who are overweight or obese would cost approximately USD 35 billion per year, an amount 
similar to the total annual budget of the U.S. National Institutes of Health (NIH) (Heinen 2009).

As computer and web-based interventions have the potential to be cost-effective or even free to the end-user, supported by advertising, they have the potential for a significant public health impact (Mitchell 2008; Tate 2009). Due to this potentially great public health impact, understanding the impact of these interventions is critical in formulating a public health strategy for addressing the epidemic of overweight and obesity.

Diagnostic criteria-Body mass index (BMI) is an index of weight-for-height that is commonly used in classifying overweight and obesity in adult populations and individuals. It is defined as the weight in kilograms divided by the square of the height in meters $\left(\mathrm{kg} / \mathrm{m}^{2}\right)$. The World Health Organization characterizes 'overweight' (a BMI greater than or equal to $25 \mathrm{~kg} / \mathrm{m}^{2}$ ) and 'obesity' (a BMI greater than or equal to $30 / \mathrm{m}^{2}$ ) as "abnormal or excessive body weight that may impair health.” (World Health Organization 2011).

\section{Description of the intervention}

The U.S. National Institutes of Health (NIH) recommend that weight loss programs include dietary therapy, physical activity and behavior therapy. The results of the National Weight Control Registry (Wing 2005) indicate four types of behavior common to the National Weight Control Registry participants:

1. eating a low-fat, high-carbohydrate diet;

2. eating breakfast almost every day;

3. frequent self monitoring of weight; and

4. participation in a high level of physical activity.

These behaviors may be supported by computer or Internet-based programs. Today many people conduct their information-seeking online, particularly information about health. Individuals who seek out that information are often motivated to learn about a health condition and many are particularly interested in self management of their health. Consequently, computer and/or Internet-based interventions are associated with improved knowledge and/ or behavioral outcomes (Wantland 2004).

Over the past decade, web-based interventions have been developed and tested for a range of behaviors and chronic conditions, including weight control. Websites that attract enough users can be provided at no cost to those users and remain profitable when supported by advertising (Meenan 2009; Miller 2008; Mitchell 2008). In addition, web-based programs overcome the time and travel barriers of face to-face interventions, and increasingly include social features similar to the in-person experience. If it were possible to create effective web-based tools that were able to engage individuals for the long term, the reach of the Internet would give these interventions the ability to have a major public health impact (Glasgow 2007). 


\section{How the intervention might work}

Behavioral weight control is the sum total of a great number of practices that each influence caloric intake, caloric expenditure, or both (Foster 2005). Traditional behavioral weightmanagement programs typically include multiple components from multiple theoretical approaches (e.g. cognitive-behavioral therapy, self regulation theory) (Brownell 2000; DPP Research Group 2002; Foster 2005). Participants are taught a number of recommended practices such as stimulus control, self monitoring (e.g. food records) and identification of high-risk situations for relapse (Brownell 2000; DPP Research Group 2002; National Institutes of Health 2000). Weight loss maintenance interventions typically include a focus on the same set of weight control practices as in weight loss interventions (Rothman 2000), and reinforce the long-term use of these practices by building problem-solving skills (Perri 1992; Perri 2001; Perri 2008; Svetkey 2008).

As a result, interactive weight management interventions include features that mimic these components that would traditionally be provided in-person, such as online goal-setting as opposed to face-to-face goal setting. While face-to-face interventions often include diaries of caloric intake and exercise and a therapist compares these to the recommendations and goals for the patient, this feedback can be computerized and provided online without a therapist involved. Most of what is available, therefore, in interactive interventions has been a computerization of what is available face-to-face. This includes online chat sessions and message boards which are designed to replicate what might happen in a group counseling session.

Adverse effects of intervention-There are no known adverse effects of interactive computer-based interventions for weight loss or weight maintenance.

\section{Why it is important to do this review}

As the prevalence of obesity continues to rise, the need for practical, easily disseminated and effective weight loss and weight maintenance programs has become increasingly important. Computer-based interventions may serve as an efficient and cost-effective method to meet this growing public health need (World Health Organization 2011).

For example, in 2001, Tate and colleagues published the results of a randomized trial that studied the impact of an interactive weight control website with the following features: 24 weekly lessons, weekly submission of self monitoring diaries, weekly recommendations from a therapist, and the opportunity for social support among group members (Tate 2001). The behavior therapy group lost a mean (standard deviation (SD)) of 4.0 (2.8) $\mathrm{kg}$ by three months and 4.1 (4.5) kg by six months. Since this first study, a large number of other studies have been published using a variety of interactive computer intervention features.

A Cochrane systematic review concluded that in people with chronic diseases, interactive health communication applications can help increase knowledge and social support and result in improved behavioral and clinical outcomes (Murray 2005). Two systematic reviews on computer-based interventions to modify physical activity and dietary behaviors (Kroeze 2006; Wantland 2004) concluded that there is potential for the application of computer 
tailoring for promoting healthy diets. In addition, a recent review by Neve and colleagues excluded a number of studies that used interactive health communication methods that were not conducted over the Internet (Neve 2010). This distinction is important as most of the studies that have utilized the Internet could have been performed using computer-tailored messages stored on the computer's hard drive, rather than on a server at some distant location. For that reason, what was learned in studies that used interactive computer-tailored messages stored locally is important for understanding what types of interactive interventions are effective. We have therefore included them in this review, rather than including only 'web-based' interventions. This systematic review provides current evidence on all interactive computer-based weight loss or weight maintenance interventions.

\section{OBJECTIVES}

To assess the effects of interactive computer-based interventions for weight loss or weight maintenance in overweight or obese people.

\section{METHODS}

\section{Criteria for considering studies for this review}

Types of studies-We included randomized controlled trials (RCTs) and quasirandomized controlled trials (quasi-RCTs). We did not restrict by language or publication status (e.g. unpublished, abstract only or full journal publication).

Types of participants-We included studies with adult participants who were overweight or obese. Diagnostic criteria for overweight were usually based on the common body mass index (BMI) guidelines for adults, but we did not exclude studies that used other criteria (e.g. 10 pounds overweight). We excluded studies in which participants were not stated to be overweight or obese. We excluded studies including a mix of overweight and normal weight participants unless we were able to obtain data for the subgroup of overweight participants.

Types of interventions-We included trials evaluating computer-based weight loss or weight maintenance programs that require the user to interact directly with the computer. We excluded trials in which the duration of the intervention was less than four weeks. We also excluded trials in which the loss to follow-up was greater than $20 \%$ overall. The control interventions were usual care, educational materials (either online or paper), telephone interventions and in-person interventions.

We excluded studies using personal digital assistants (PDAs) or other communication media (e.g. interactive voice response) because computers allow by far the most rich set of possible interactions. At the time that this review was planned, PDAs and mobile telephones had lesser interactive potential due to their limited screen size and software functionality. However, we note that smartphones now have the capacity to function as fully mobile computers with interactive potential similar to that of laptops and desktops. We are not aware of any randomized trials of interactive weight loss programs on smartphones, but plan to search for and include trials of smartphones for the update of this review. 


\section{Types of outcome measures \\ Primary outcomes}

- Body weight (measured in kilograms or pounds) or body mass index (BMI). Body weight and BMI could be measured at endpoint, as absolute change from baseline, or as percentage change from baseline.

- Waist circumference (measured in inches or centimeters). Waist circumference could be measured at endpoint, as absolute change from baseline, or as percentage change from baseline.

- Health-related quality of life, well-being and patient satisfaction, as measured by any instrument.

\section{Secondary outcomes}

- Physical activity-related outcomes, such as steps per day, kilocalories per week, or any other measure of energy expenditure.

- Diet-related outcomes such as total fat intake, total calories, total fibre and number of servings of fruits/vegetables.

- Cost-effectiveness.

- $\quad$ Adverse events.

\section{Covariates, effect modifiers and confounders}

- Adherence.

Timing of outcome measurement: We assessed outcomes at short-term (defined as four months or less), medium-term (defined as greater than four months and less than 12 months) and long-term (defined as 12 months or more) follow-up. In studies with multiple short-term times of outcome measurement, we chose to include the outcome measured at the time closest to the end of treatment. In studies where initiation of treatment was delayed substantially after randomization, we considered the starting point for follow-up to be initiation of treatment rather than randomization.

\section{Search methods for identification of studies}

Electronic searches-We first searched the following databases from inception to April 2009, and then re-ran the searches up to May 2011 for the identification of trials:

- The Cochrane Library

- Ovid MEDLINE(R)

- Ovid MEDLINE(R) In-Process \& Other Non-Indexed Citations

- Ovid EMBASE

- EBSCOHost CINAHL

- Web of Science 
- Dissertation Abstracts

- $\quad$ Ovid PsycINFO

- $\quad$ LILACS

- Cochrane Behavioral Medicine Field Specialized Register

We searched databases on 14 and 15 April 2009 and on 25 May 2011. There were no language restrictions applied to any of the search strategies.

After the searches in these databases had been run, we set up for weekly alerts MEDLINE and PsycINFO and scanned the contents of key journals on a weekly basis up until September 2011 to check for any newly published studies.

Details of all search strategies are given in Appendix 1.

Searching other resources-To identify ongoing studies, we searched the CRISP database and Current Controlled Trials registries. We searched the reference lists of review articles and of all included studies in order to find other potentially eligible trials or ancillary publications.

We contacted several experts in this field (including authors of some of the included studies) to ensure that no other ongoing or unpublished studies had been missed.

\section{Data collection and analysis}

Selection of studies-To determine the studies to be assessed further, two authors (KJT and LF for the original search results, and LF and LSW for the updated search results) independently scanned the abstract, title or both sections of every record retrieved. We investigated all potentially relevant articles as full text. We measured interrater agreement for study selection using the kappa statistic (Cohen 1960). Where differences in opinion existed, they were resolved by a third party. If resolving disagreement was not possible, we added the article to those 'awaiting assessment' and contacted authors for clarification. An adapted PRISMA (preferred reporting items for systematic reviews and meta-analyses) flow-chart of study selection shown in Figure 1 (Liberati 2009).

Data extraction and management-Two review authors (LSW, SBF) independently abstracted relevant population and intervention characteristics using standard data extraction templates (for details see Characteristics of included studies; Table 1; Appendix 2;

Appendix 3; Appendix 4; Appendix 5). We resolved all disagreements by discussion. Extracted data included year and country of study, study design, participant characteristics, inclusion and exclusion criteria, description of intervention and control conditions, duration of intervention, study outcomes and duration of follow-up. We sought any missing information on key study characteristics or weight outcomes from the corresponding author of the article.

Dealing with duplicate publications-In the case of duplicate publications and companion papers of a primary study, we tried to maximize yield of information by 
simultaneous evaluation of all available data. In cases of doubt, the original publication (usually the oldest version) was given priority.

Assessment of risk of bias in included studies-Two authors (KJT, LF) assessed each trial independently. Disagreements were resolved by consensus, or by consultation with a third party. We calculated interrater agreement for key bias indicators (e.g. allocation concealment, incomplete outcome data) using the kappa statistic (Cohen 1960). In cases of disagreement, the rest of the group was consulted and a judgement was made based on consensus.

We assessed risk of bias using the Cochrane Collaboration's tool (Higgins 2009), which includes the following items.

- Was the allocation sequence adequately generated?

- Was the allocation adequately concealed?

- Was knowledge of the allocated intervention adequately prevented during the study?

- Were incomplete outcome data adequately addressed?

- Were reports of the study free of suggestion of selective outcome reporting?

- Was the study apparently free of other problems that could put it at a high risk of bias?

We judged risk of bias criteria as 'low risk', 'high risk' or 'unclear risk' and evaluated individual bias items as described in the Cochrane Handbook for Systematic Reviews of Interventions (Higgins 2009).

\section{Measures of treatment effect}

Dichotomous data: We expressed dichotomous outcomes (e.g. weight loss yes/no) as odds ratios (OR) or risk ratios (RR) with $95 \%$ confidence intervals (CI), where deemed clinically relevant and appropriate.

Continuous data: For continuous outcomes (e.g. weight) on the same scale, we calculated the weighted mean difference (MD) and 95\% confidence intervals. We calculated pooled continuous outcomes from different scales used to measure the same underlying concept (e.g. different measures of physical activity) using the standardized mean difference (SMD) and $95 \%$ confidence intervals. We extracted outcomes as change from baseline when possible, otherwise we extracted outcomes at endpoint. We combined change and endpoint outcomes in the calculation of weighted mean differences if necessary, however we did not mix endpoint and change outcomes in calculation of standardized mean differences. Studies that reported outcomes using Imperial measures (pounds rather than kilograms, and inches rather than centimeters) had their results converted to the metric standard (kilograms and centimeters) prior to performing all analyses. 
Unit of analysis issues: For cluster-randomized trials which did not adjust for clustering in reporting their results, we followed the guidance in chapter 16.3 of the Cochrane Handbook for Systematic Reviews of Interventions (Higgins 2009). We used an estimate of the intra class correlation coefficient (ICC) to calculate a design effect for each cluster-randomized trial. The design effect was used to divide the sample size in the experimental and control groups for analyses using continuous data, and to divide the standard error for analyses using generic inverse variance data.

Dealing with missing data: We contacted the corresponding author of the study report to obtain any relevant missing data for key study characteristics (e.g. sample size) or weight outcomes. In cases where study participants were lost to follow-up, and intention-to-treat analyses were conducted using baseline observation carried forward (BOCF) or other methods were used to impute the missing values, we used the imputed data for our primary analysis, and conducted a sensitivity analysis using available case data. When an individual study report used multiple methods of imputation, we used the data created using the most conservative method (e.g. BOCF for a weight loss trial). When statistics such as standard deviations were not present in the study report, we used the methods outlined in chapter 7 of the Cochrane Handbook for Systematic Reviews of Interventions (Higgins 2009) to calculate the missing statistics. Whenever possible, we used the procedures outlined in chapters 7 and 16 of the Cochrane Handbook for Systematic Reviews of Interventions (Higgins 2009) to calculate change outcomes from extracted baseline and endpoint outcomes. When standard deviations were present for the baseline and endpoint measurements, but not for the mean change from baseline, we followed the procedures described in chapter 16.1.3.2 of the Cochrane Handbook for Systematic Reviews of Interventions (Higgins 2009). We calculated the correlation co-efficient from a similar study reporting standard deviations for baseline, endpoint and change values of the same variable (e.g. weight, BMI), and used the calculated correlation coefficient to impute the missing standard deviation for the change from baseline.

Assessment of heterogeneity: In the event of substantial clinical or methodological heterogeneity we did not combine study results in a meta-analysis. We identified statistical heterogeneity by visual inspection of the forest plots, by using a standard $\mathrm{Chi}^{2}$ test and a significance level of $a=0.1$, in view of the low power of this test, and by using the $\mathrm{I}^{2}$ statistic (Higgins 2002), where $\mathrm{I}^{2}$ values of 50\% and more indicate a substantial level of heterogeneity (Higgins 2003; Higgins 2009). When substantial statistical heterogeneity was found, we attempted to determine potential reasons for it by examining individual study and subgroup characteristics.

Assessment of reporting biases: For analyses including at least 10 trials, we used funnel plots to assess for the potential existence of small study bias. In light of the many possible explanations for funnel plot asymmetry, we were cautious in our interpretation of the results (Lau 2006; Sterne 2001).

Data synthesis: We combined data from individual studies when the trials were sufficiently similar in terms of the intervention goal (weight loss or weight maintenance), the treatment 
(e.g. computer-based intervention as a sole intervention, computer-based intervention as an adjunct to another intervention), the control intervention (e.g. minimal or no intervention, intensive in-person intervention), outcome measures (e.g. weight, BMI, waist circumference) and timing of outcome assessment (short-term, medium-term or long-term). For pooled data, we calculated summary test statistics using a random-effects effect model to account for expected heterogeneity between studies. If the $\mathrm{I}^{2}$ statistic was greater than or equal to $50 \%$, we interpreted the summary measures of effect with caution, and investigated heterogeneity between trials.

Subgroup analysis and investigation of heterogeneity: We planned to carry out subgroup analyses if one of the primary outcome parameters demonstrated statistically significant differences between intervention groups.

We planned to carry out subgroup analyses on the following subgroups if data were available:

- overweight and obese participants;

- gender;

- younger and older persons.

Sensitivity analysis: When data were available, we performed sensitivity analyses to explore the influence of the following factors on effect size:

- repeating the analysis excluding unpublished studies;

- repeating the analysis taking account of risk of bias, as specified above;

- repeating the analysis excluding any very long or large studies to establish how much they dominate the results;

- repeating the analysis excluding studies using the following filters: diagnostic criteria, language of publication, source of funding (industry versus other), country.

We also tested the robustness of the results by repeating the analysis using different methods for obtaining outcome data (available case data, ITT analysis using imputed data) and different statistical models (fixed-effect model and random-effects model).

\section{RESULTS}

\section{Description of studies}

See: Characteristics of included studies; Characteristics of excluded studies; Characteristics of ongoing studies.

See Characteristics of included studies; Characteristics of excluded studies; Characteristics of studies awaiting classification; Characteristics of ongoing studies; and Table 1.

Results of the search-The electronic search strategies, weekly updates and additional searching of resources yielded 9195 abstracts retrieved between 14 April 2009 and 25 May 2011. From the potentially eligible 376 titles, we excluded 184 and retrieved 105 in full text 
for further examination. A total of 18 studies met the inclusion criteria and were included in the review. See Figure 1. The kappa statistic for trial selection was 0.61 (95\% confidence interval (CI) is 0.42 to 0.80 ). The details of these studies are described in Characteristics of included studies.

Included studies-We included 18 studies (Bennett 2010; Cussler 2008; DeLucia 1988; Gabriele 2011; Harvey-Berino 2002; Harvey-Berino 2010; Hunter 2008; Morgan 2009; Morgan 2011; Schroder 2010; Svetkey 2008; Tate 2001; Tate 2003; Tate 2006; Threlfall 1984; Webber 2008; Wing 2006; Wylie-Rosett 2001), of which 14 focused on weight loss and four focused on weight maintenance. In these 18 trials, 2452 people were in the computer treatment groups and 1688 people in one of the comparison groups. The earliest study report was a PhD dissertation (Threlfall 1984) from 1984, and the most recent study reports were published in 2011 (Gabriele 2011; Morgan 2011). All reports were in English, and with the exception of the $\mathrm{PhD}$ dissertation, all studies were published in peer-reviewed journals. Aside from two trials which were conducted in Australia (Morgan 2009; Morgan 2011), all trials were conducted in the USA. All interventions were carried out in outpatient or community settings. Two studies (Harvey-Berino 2010; Svetkey 2008) were multi-centre trials. Study sample sizes ranged from 29 participants (DeLucia 1988) to 1032 participants (Svetkey 2008). Seven trials included fewer than 100 participants (DeLucia 1988; Morgan 2009; Schroder 2010; Tate 2001; Tate 2003; Threlfall 1984; Webber 2008), six trials included between 100 and 150 participants (Bennett 2010; Cussler 2008; Gabriele 2011; Harvey-Berino 2002; Morgan 2011; Tate 2006), four trials included between 200 and 600 participants (Harvey-Berino 2010; Hunter 2008; Wing 2006; Wylie-Rosett 2001) and one trial included over 1000 participants (Svetkey 2008). As required by our review inclusion criteria, all studies collected follow-up data from at least $80 \%$ of participants.

Design-Seventeen studies were randomized controlled trials (RCTs) and one study (Schroder 2010) was a quasi-randomized controlled trial (quasi-RCT). All studies were parallel-arm trials in which individuals were allocated to study arms, with the exception of Cussler 2008 and Morgan 2011, in which groups were cluster-randomized to parallel study arms.

Participants-There were a total of 4140 participants in the 18 trials. All trials were conducted in adults.

Two trials (Cussler 2008; Webber 2008) included solely women and two trials (Morgan 2009; Morgan 2011) included solely men. The remaining 14 studies contained both men and women. Across all participants $27 \%$ were men and $73 \%$ were women. In the trials which included both men and women (3759 participants in total) the gender percentages were $26 \%$ men and $74 \%$ women.

Most inclusion criteria were based on body mass index (BMI). Participants in Wylie-Rosett 2001 had a BMI of at least $25 \mathrm{~kg} / \mathrm{m}^{2}$, or a BMI of at least 24 with at least one risk factor for cardiovascular disease, and Schroder 2010 included people with a BMI $\geq 27 \mathrm{~kg} / \mathrm{m}^{2}$. Hunter 2008 included participants with a BMI of $\geq 25$ for women and BMI $\geq 27.5$ for men. BMI ranges for participants in the other studies were: 25 to $36 \mathrm{~kg} / \mathrm{m}^{2}$ (Tate 2001), 25 to $37 \mathrm{~kg} / \mathrm{m}^{2}$ 
(Morgan 2009), 25 to $40 \mathrm{~kg} / \mathrm{m}^{2}$ (Gabriele 2011; Morgan 2011; Webber 2008), 25 to 50 $\mathrm{kg} / \mathrm{m}^{2}$ (Harvey-Berino 2010), 27 to $40 \mathrm{~kg} / \mathrm{m}^{2}$ (Tate 2003; Tate 2006) and 30 to $40 \mathrm{~kg} / \mathrm{m}^{2}$ (Bennett 2010). Study participants in the DeLucia 1988 trial were least $10 \mathrm{lb}$ overweight. The Threlfall1984 study included participants who had a body weight of at least $10 \%$ over the midpoint of the desired weight range on the Metropolitan Life Insurance Company table of recommended weights based on gender, height and body frame size.

In three of the four included weight maintenance trials, participants met BMI criteria at the beginning of the weight loss segment of the study. Participants in Cussler 2008 had a BMI of 25 to $38 \mathrm{~kg} / \mathrm{m}^{2}$ and participants in Harvey-Berino $2002 \mathrm{had}$ a BMI of $25 \mathrm{~kg} / \mathrm{m}^{2}$ or greater. Participants in Svetkey 2008 had BMIs of 25 to $40 \mathrm{~kg} / \mathrm{m}^{2}$ at the beginning of weight loss and had lost at least $4 \mathrm{~kg}$ during the weight loss phase of the study. In the fourth weight maintenance trial (Wing 2006), participants had to have lost at least $10 \%$ of their body weight during the previous two years to qualify for study entry.

Interventions-We analyzed studies focusing on interventions for weight loss and studies focusing on interventions for weight maintenance separately. The rationale for this was that, although the practices that contribute to weight loss and weight loss maintenance are hypothesized to be the same (Rothman 2000; Rothman 2009), the rates of weight change are very different in weight loss versus weight loss maintenance studies, making them difficult to combine statistically. Rates of weight loss are rapid in the initial six months, after which point a significantly slower process of weight regain typically occurs (Franz 2007). Most studies that focus on weight loss maintenance enroll people after the period of most rapid weight regain (months six to 12), so that the rate of regain in those studies is, on average, even slower. For example, in Foster behavioral treatment produces weight loss of approximately $10 \mathrm{~kg}$ during the first six months of treatment (Foster 2005), yet a recent weight loss maintenance study by Perri and colleagues observed a weight regain of only 3.7 $\mathrm{kg}$ in the control group over 12 months (Perri 2008). This different rate of weight change suggests that weight loss and weight loss maintenance interventions need to be considered separately. Each study included in this review tested the effect of a computer-based intervention for either weight loss or weight maintenance, with the exception of Hunter 2008, which began by focusing on weight-gain prevention in overweight individuals but shifted, in response to participant motivations for participating in the trial, to a focus on weight loss. We classified Hunter 2008 as a weight-loss trial in this review.

A total of 14 studies with 2537 participants assessed the effectiveness of interactive computer-based interventions on achievement of weight loss (Bennett 2010; DeLucia 1988; Gabriele 2011; Harvey-Berino 2010; Hunter 2008; Morgan 2009; Morgan 2011; Schroder 2010; Tate 2001; Tate 2003; Tate 2006; Threlfall 1984; Webber 2008; Wylie-Rosett 2001). The duration of the intervention ranged from 10 weeks to 12 months (see Appendix 4).

Seven of the weight loss studies (Bennett 2010; Hunter 2008; Morgan 2009; Morgan 2011; Schroder 2010; Threlfall 1984; Wylie-Rosett 2001) compared an interactive computer-based intervention with a minimal or no treatment control condition. In two trials (Threlfall 1984; Wylie-Rosett 2001) the control condition was a weight loss workbook or manual, in two trials (Bennett 2010; Morgan 2009) the control condition was a booklet or leaflet, in one 
trial (Hunter 2008) the control condition was usual care on a military base, and in two trials (Morgan 2011; Schroder 2010) the control condition was a wait list. Two of the studies comparing an interactive computer-based intervention with a minimal or no treatment control condition (Schroder 2010; Wylie-Rosett 2001) were three-arm trials, in which a third treatment arm supplemented the computer-based intervention with an in-person treatment component. Both studies reported that there was not a significant difference between the two computer intervention arms. We therefore combined the two computer intervention arms for our main analyses, and conducted sensitivity analyses omitting the arms with the in-person treatment component.

One weight loss study (Harvey-Berino 2010) compared an interactive computer-based intervention with an in-person intervention. This study randomized participants to one of three treatment conditions: Internet-based treatment with access to a website and weekly online chats, in-person treatment with paper materials and a weekly in-person group session, and a hybrid condition which was Internet-based but in which in-person group sessions supplanted some of the weekly online chats. We compared the Internet-based treatment to each of the comparison treatments (in-person and hybrid) separately.

Five of the weight loss studies (Gabriele 2011; Tate 2001; Tate 2003; Tate 2006; Webber 2008) evaluated the effect of an interactive computer-based intervention as an adjunct or supplement to an Internet-delivered weight-loss intervention. In Gabriele 2011, all participants received an Internet-based weight loss program with weekly lessons and feedback delivered by e-mail. Participants were randomized to one of three groups: no individualized support, directive e-mail coaching or non-directive e-mail coaching. We analyzed the directive and non-directive e-mail coaching separately because they were based upon different theoretical approaches to counseling and the trial found important differences in the efficacy of the two conditions. In Tate 2001, following an in-person one-hour behavioral weight loss session, participants were randomized to either online education or online behavior therapy. The online education group received online information about weight loss, and was also encouraged to use the online resources to track their diet and exercise. The interactive computer intervention group submitted individual weight, calorie and fat intake, exercise data and questions or comments online, and also had access to an electronic bulletin board. A behavioral therapist e-mailed individualized feedback to the interactive group participants weekly. In Tate 2003, the control group submitted their weight and received weight loss information online, while an interactive intervention group submitted weight, calorie and fat intake, exercise information, and any comments or questions and received e-mailed feedback from investigators. In Tate 2006, all intervention groups were instructed in the use of an interactive website. The control group received no further feedback. Two additional intervention groups received weekly feedback that was either 1) e-mail counseling from a human weight loss counselor or 2) tailored feedback from an automated computer program. We analyzed the e-mail counseling and automated feedback both combined and separately. In Webber 2008, both the intervention and control groups were assigned to 16 weeks of online self monitoring, but the intervention group participated in weekly online group chats in addition to the online self monitoring. We analyzed the e-mail counseling trials (Gabriele 2011; Tate 2001; Tate 2003; Tate 2006) and the group chats trial (Webber 2008) separately. One weight loss study (DeLucia 1988) 
evaluated the effect of an interactive computer-based intervention as an adjunct to an inperson weight loss intervention. All study participants received a standard in-person behavioral intervention program (Ferguson 1975) from counselors. There were a total of three treatment conditions: the behavioral intervention alone, and the behavioral intervention plus one of two different nutritional software programs. The study reported that there was no difference between the effects of the two computer intervention arms, and we therefore combined these two intervention arms for our analyses.

Four studies (Cussler 2008; Harvey-Berino 2002; Svetkey 2008; Wing 2006) with a total of 1603 participants assessed the effectiveness of interactive computer-based interventions in maintenance of weight loss. The duration of the intervention ranged from 12 months to 30 months (see Appendix 4). Three of these studies (Cussler 2008; Harvey-Berino 2002; Svetkey 2008) began with a weight loss intervention, randomly assigned participants to computer-based or a control intervention for weight maintenance, and then followed the participants for at least 12 months to assess the amount of weight regain. The fourth study (Wing 2006) recruited participants who had lost at least $10 \%$ of their body weight during the last two years, randomly assigned the participants to computer-based or control intervention groups, and followed them for 18 months.

Three of the weight maintenance studies (Cussler 2008; Svetkey 2008; Wing 2006) compared an interactive computer-based intervention with a minimal or no treatment control condition, such as printed newsletters. In the Cussler 2008 study staff did not counsel the control group participants, although the participants could continue to meet in the groups they had formed during the preceding weight loss segment of the trial. In Svetkey 2008 and Wing 2006, control group participants were given printed guidelines or printed newsletters. The computer-based interventions in these studies were an interactive website with occasional chat-room sessions and e-mail responses to questions (Cussler 2008), unlimited access to an interactive website and online bulletin board plus e-mail or telephone reminders for participants who did not log on (Svetkey 2008), and access to an interactive website plus online group meetings and message boards (Wing 2006).

Three studies (Harvey-Berino 2002; Svetkey 2008; Wing 2006) compared a computer-based intervention to a face-to-face treatment control condition. The computer-based interventions were biweekly Internet chat sessions with e-mails from therapists on non-chat weeks, combined with web-based data entry (Harvey-Berino 2002), an interactive website plus online bulletin board and e-mail reminders (Svetkey 2008), and an interactive website plus online group meetings and message boards (Wing 2006). Each of the three studies in this group compared the computer-based intervention to a minimal (defined as contact monthly or less often) face-to-face treatment intervention. One study (Harvey-Berino 2002) also compared the computer-based intervention to a frequent (defined as contact more often than monthly) face-to-face treatment intervention. The minimal face-to-face intervention in Wing 2006 was weekly meetings for the first month (only) of the trial, then monthly meetings until the end of follow-up at 18 months. The minimal face-to-face intervention in Svetkey 2008 was monthly telephone support, with in-person meetings substituted every four months. The minimal face-to-face intervention in Harvey-Berino 2002 was monthly inperson contact for the first six months of weight maintenance, followed by no contact from 
month seven to 12. The frequent face-to-face intervention in Harvey-Berino 2002 was inperson meetings every two weeks for the entire 12 months of weight maintenance, supplemented by phone calls from a therapist during non-meeting weeks and regular submission of self monitoring data by postal mail.

Outcomes-All studies included weight outcomes in kilograms or pounds of body weight. The inclusion of other outcomes varied between studies, and there was no other outcome found in all studies. Weight, height (if assessed for purposes of calculating BMI) and waist circumference (if assessed) were measured by study personnel. When dietary intake was measured, it was always by means of dietary questionnaires completed by the participants. When physical activity was measured, it was by means of physical activity questionnaires completed by the participants, with the exception of Morgan 2009, in which physical activity was measured using pedometers, and Svetkey 2008, in which physical activity was measured by accelerometry.

Excluded studies-Nineteen studies were not randomized or quasi-randomized controlled trials and so we excluded them on the grounds of study design (Burnett 1984; Cange 2008; Collinson 2011; Cousineau 2008; Faghri 2008; Haugen 2007; James 2001; Joo 2010; Liou 2006; McHugh 2008; McTigue 2009; Nieto 2010; Park 2009; Petersen 2008; Riva 2000; Thurston 1991; Touger-Decker 2010; van der Mark 2009; Verheijden 2007).

There were 23 studies which we excluded due to the participant dropout rate being higher than specified in our inclusion criteria (Booth 2008; Brantley 2008; Burnett 1992; Carr 2008; Castelnuovo 2011; Gold 2007; Heetderks-Cox 2001; Jones 1997; Kerr 2008; McConnon 2007; McDoniel 2010; Micco 2007; Mobley 2006; Pullen 2008; Rothert 2006; Ryan 2010; Sartor 1991; Shay 2009; Turnin 2001; van Wier 2009; Wing 2009; Womble 2004). Studies which we excluded for other reasons were either because none or not all participants were overweight or obese (16 in total: Anderson-Bill 2011; Carr 2009; Cook 2007; De Bourdeaudhuij 2007; Dekkers 2011; Gow 2010; Herrick 2009; Kroeze 2008; Kroeze 2008a; Marcus 2007; Smeets 2007; Southard 2003; Vandelanotte 2005; Vandelanotte 2008; Werkman 2010; Winett 2007) and in one case because the focus was diabetes management (Kalten 2000), and in another because the focus was treatment of binge eating disorder (Carrard 2011). Thirteen studies were excluded on the grounds that the interventions were not interactive or the interactive component of the intervention was not computer-based (Adachi 2007; Campbell 2002; Christian 2011; Cook 2007; Foree-Gavert 1980; Jacobs 2010; Kremers 2005; Kristal 2000; Lohof 2007; Polzien 2007; Sbrocco 1999; Tanaka 2010; Vandelanotte 2008). A further three were not computer-based (Fitzgibbon 1995; Harvey-Berino 1998; Weinstock 1998); five studies involved hand-held or pocket computer-based interventions (Agras 1990; Burke 2011; Sbrocco 2005; Taylor 1991; Yon 2007). Four studies had interventions which were designed to promote physical activity rather than specifically to increase weight loss (Bischoff 2010; Carr 2009; Smith 2009; Steele 2007) and one study compared two interactive computer-based interventions (Webber 2010).

Finally one study had to be excluded because we were unable to contact the author to obtain the necessary information for data extraction (Harvey-Berino 2002a). Another study by the 
same author was excluded from this review because the study did not meet the $80 \%$ followup inclusion criterion at 12 months, there were no extractable data for earlier follow-up points, and we were unable to contact the author to obtain data for the earlier follow-up time points (Harvey-Berino 2004).

Two potential studies were identified but are awaiting classification. One is an ongoing study (Harvey-Berino NCT01232699) and one is a conference abstract which does not give sufficient information to determine eligibility and whose author could not yet be contacted for further information (Magnusdottir 2010).

\section{Risk of bias in included studies}

The methodological quality of included studies is described in Characteristics of included studies. Interrater agreement for risk of bias assessment was measured as 0.51 using the kappa statistic (Cohen 1960). This measure relates only to the 15 included studies retrieved from the original search results; the measure was not recalculated to incorporate the three studies from the updated search in 2011. See Figure 2 ('Risk of bias' graph) and Figure 3 ('Risk of bias' summary).

Allocation-Three trials (Morgan 2009; Morgan 2011; Svetkey 2008) clearly reported adequate methods of randomization and allocation concealment, and a further five trials (Gabriele 2011; Harvey-Berino 2010; Hunter 2008; Tate 2003; Tate 2006) adequately randomized participants but were unclear about whether allocation was adequately concealed. One trial (Bennett 2010) did not describe the method of randomization, but did state that assignments were enclosed in nontransparent envelopes, and we therefore judged that allocation was adequately concealed. Methods of both randomization and allocation concealment were either not described or unclear in eight trials (Cussler 2008; DeLucia 1988; Harvey-Berino 2002; Tate 2001; Threlfall 1984; Webber 2008; Wing 2006; WylieRosett 2001). One trial (Schroder 2010) was a quasi-randomized controlled trial which assigned every third participant, hence investigators and participants could potentially have foreseen assignments and we judged that allocation was not adequately concealed.

Blinding-None of the following studies stated whether any of the parties were blinded to treatment allocation: Cussler 2008; DeLucia 1988; Harvey-Berino 2010; Tate 2003; Threlfall 1984; Wing 2006; Wylie-Rosett 2001.

Bennett 2010 stated that research staff collecting evaluation data were blinded to randomization status. In Gabriele 2011 participants were reported to be blinded to treatment condition. Hunter 2008 stated that the study could not be blinded. The Morgan 2009 trial reported that participants were blind to group allocation at baseline assessment and that assessors were blinded to treatment allocation at all points. Morgan 2011 stated that participants and assessors were blind to treatment allocation at baseline, but did not report whether they were still blinded at follow-up. Research team members were blind to the type of intervention assignments in the Schroder 2010 study. In Svetkey 2008 and Webber 2008 outcome measurements were taken by staff members masked to treatment assignment. The Tate 2006 study reported that non-intervention staff weighed participants at baseline and at three and six months, but there is no specific statement of whether or not they were blinded. 
Participants were aware of randomization assignment, but their knowledge of the other interventions is unclear. It was stated that human e-counselors were blinded to the algorithms used to program the automated feedback counselor, but it is unclear whether they were aware of assignment of participants across all three groups.

Incomplete outcome data-All included studies had a loss to follow-up of less than $20 \%$ as specified in the inclusion criteria for the review.

We assessed attrition rates, noted whether reasons for dropout were given, and whether methods of handling missing data were stated. DeLucia 1988 and Threlfall 1984 presented data for completers only and did not use any methods to handle missing data.

All other studies used an intention-to treat analysis. Bennett 2010; Cussler 2008; Gabriele 2011; Harvey-Berino 2002; Harvey-Berino 2010; Hunter 2008; Morgan 2011; Tate 2001; Tate 2003 and Tate 2006 all used a baseline observation carried forward approach (BOCF). Tate 2006 also used last observation carried forward, expectation maximization and regression to impute missing values, and stated that the pattern of statistical significance using observed data and imputed data was identical with all methods. Morgan 2009 used linear mixed models to assess the primary analysis of effects of losses to follow-up. Schroder 2010 replaced missing data points with pre-intervention scores. Svetkey 2008 used multiple imputation to replace missing end-of-study weights, missing interim weights and other measures (apart from weights missing due to participant death). Wing 2006 assumed all dropouts regained $2.3 \mathrm{~kg}$ or more for their analysis. Wylie-Rosett 2001 reported that the study completers did not differ significantly from the dropouts with respect to baseline characteristics, but did not otherwise state how missing data were handled.

Selective reporting - Six of the included studies had protocols: Harvey-Berino 2010; Morgan 2009; Morgan 2011; Svetkey 2008; Tate 2006; Wing 2006. The primary outcome in the protocol was the same as the primary outcome in the methods section for each of these studies. Based on the available information all the trials appear to be free of selective reporting.

Other potential sources of bias-We assessed studies for any additional potential sources of bias in studies. These included: discrepancies between pre-specified questions/ entries in study protocols and the published reports; treatment variation or additional treatment in the intervention group; differences in groups at baseline; conflicts of authors and funding sources. None of the included studies appeared to have any other potential sources of bias.

\section{Effects of interventions}

See: Summary of findings for the main comparison Interactive computer intervention compared to usual care for weight loss or maintenance of weight loss in adults; Summary of findings 2 Interactive computer intervention compared to in-person interventions for weight loss or maintenance of weight loss in adults 
The primary outcomes of this review were changes in body weight, BMI, waist circumference and health-related quality of life. Secondary outcomes were changes in physical activity or diet, relative cost-effectiveness of interventions and adverse effects.

\section{Weight loss studies}

Computer-based intervention versus minimal treatment control for weight loss: Seven studies (Bennett 2010; Hunter 2008; Morgan 2009; Morgan 2011; Schroder 2010; Threlfall 1984; Wylie-Rosett 2001) with a combined total of 1367 participants included data on the effect of computer-based interventions versus a minimal intervention or no treatment upon weight loss. Two of the trials (Schroder 2010; Wylie-Rosett 2001) were three-arm studies in which one of the computer-based intervention arms was supplemented with an in-person intervention. In all analyses incorporating these studies, we conducted main analyses by combining the two computer-based intervention arms and then carried out subgroup analyses in which the study arm supplemented with in-person contact was excluded.

\section{Primary outcomes}

Weight loss outcomes: After 10 to 14 weeks of treatment, the five individual trials with weight loss measurements at three months (Bennett 2010; Morgan 2009; Morgan 2011; Schroder 2010; Threlfall 1984) showed that participants in the computer-based intervention groups lost more weight than participants in the minimal intervention control groups (mean difference (MD) $-2.5 \mathrm{~kg}$ (95\% confidence interval (CI) -3.4 to -1.6$), \mathrm{P}<0.00001 ; 430$ participants; five trials; Analysis 1.1: primary analysis 1.1.1. The heterogeneity in this analysis $\left(\mathrm{I}^{2}=44 \%\right)$ was unsurprising given the heterogeneity of interventions and comparisons. When we omitted the sole quasi-randomized trial (Schroder 2010), which was also the only trial that included an ongoing in-support arm as one component of the computer intervention, results were again similar to the initial analysis (MD $-2.8 \mathrm{~kg}(95 \%$ CI -3.7 to -1.9$), \mathrm{P}<0.00001 ; 339$ participants; four trials; Analysis 1.1: sensitivity analysis 1.1.2), although heterogeneity remained moderate $\left(\mathrm{I}^{2}=31 \%\right)$. When we repeated the analysis omitting only the ongoing in-person support arm from the quasi-randomized trial, results were similar to the initial comparison (MD $-2.5 \mathrm{~kg}$ (95\% CI -3.4 to -1.6$), \mathrm{P}<$ 0.00001; 399 participants; five trials; Analysis 1.1: sensitivity analysis 1.1.3), and heterogeneity was intermediate $\left(\mathrm{I}^{2}=39 \%\right)$. When we omitted the sole trial conducted in a workplace setting, which was also a cluster-randomized trial, and one of the two trials conducted in men only (Morgan 2011), from the analysis, weight loss was slightly less (MD $-2.2 \mathrm{~kg}$ ) and heterogeneity was greatly decreased $\left(\mathrm{I}^{2}=0 \%\right.$ ) (Analysis 1.1 : sensitivity analysis 1.1.4).

Two trials presented weight loss outcomes at six months (Hunter 2008; Morgan 2009). After six months of treatment, participants in the computer-based intervention lost more weight than participants in the control intervention (MD $-1.5 \mathrm{~kg}(95 \% \mathrm{CI}-2.1$ to -0.9$)$; $\mathrm{P}<$ 0.00001; 511 participants; two trials; Analysis 1.2) (Figure 4).

Only one trial (Wylie-Rosett 2001) examined weight loss outcomes at 12 months of followup. After 12 months of treatment, participants in the computer-based intervention lost more weight than participants in the control intervention (MD $-1.8 \mathrm{~kg}(95 \% \mathrm{CI}-3.1$ to -0.5$) ; \mathrm{P}=$ 
0.009; 474 participants; one trial; Analysis 1.3: primary analysis 1.3.1). This trial also contained an intervention arm with an in-person component, and when that arm was excluded from the comparison, the effect was smaller and no longer statistically significant (MD $-1.1 \mathrm{~kg}$ (95\% CI -2.6 to 0.3); $\mathrm{P}=0.12 ; 280$ participants; one trial, Analysis 1.3: sensitivity analysis 1.3.2).

Results were similar when percent weight lost and change in BMI rather than change in kilograms body weight were the weight-related outcomes. In the one study reporting percent weight loss at three months (Bennett 2010), participants in the computer intervention lost $3 \%$ more body weight (or approximately $2.5 \mathrm{~kg}$ ) compared to participants in the control group (MD -3.0\% (95\% CI -4.1 to - 1.9); $\mathrm{P}<0.00001 ; 101$ participants, one trial, Analysis 1.4). In the single study reporting percent weight loss at 12 months (Wylie-Rosett 2001), participants in the computer intervention lost a greater percentage of body weight than participants in the control group (MD -2.0\% (95\% CI -3.1 to -0.8); $\mathrm{P}=0.0008 ; 474$ participants; Analysis 1.5; primary analysis 1.5.1), although this effect was smaller and no longer statistically significant when participants receiving additional in-person consultations were excluded from the analysis (MD $-1.3 \%$ (95\% CI -2.7 to 0.1 ); $\mathrm{P}=0.07 ; 280$ participants; Analysis 1.5: sensitivity analysis 1.5.2). In the trials reporting BMI outcomes at three months, there was a larger decrease in BMI among participants in the computer intervention groups (MD $-1.0 \mathrm{~kg} / \mathrm{m}^{2}$ (95\% CI -1.4 to -0.6$), \mathrm{P}<0.00001 ; 367$ participants; four trials; Analysis 1.6; primary analysis 1.6.1). When intervention participants receiving some in-person contacts were excluded from the analysis, the mean difference in percentage weight lost remained similar (MD $-1.0 \mathrm{~kg} / \mathrm{m}^{2}$ (95\% CI -1.4 to -0.6$) ; \mathrm{P}<0.00001 ; 336$ participants; four trials; Analysis 1.6; sensitivity analysis 1.6.2). At six months the mean difference in BMI was smaller (MD $-0.7 \mathrm{~kg} / \mathrm{m}^{2}(95 \%$ CI -0.9 to -0.5$)$; $\mathrm{P}<0.00001 ; 464$ participants; two trials; Analysis 1.7). At 12 months the mean difference was similar to that at six months (MD $-0.6 \mathrm{~kg} / \mathrm{m}^{2}(95 \% \mathrm{CI}-1.1$ to -0.1$) ; \mathrm{P}=0.01 ; 474$ participants; one trial; Analysis 1.8; primary analysis 1.8.1), although the difference was smaller and not statistically significant when intervention participants receiving supplementary in-person contact were excluded from the analysis (MD $-0.4 \mathrm{~kg} / \mathrm{m}^{2}$ (95\% CI -0.9 to 0.1 ), $\mathrm{P}=0.14$; 280 participants; one trial; Analysis 1.8: sensitivity analysis 1.8.2).

Waist circumference outcomes: Five studies (Bennett 2010; Hunter 2008; Morgan 2009; Morgan 2011; Wylie-Rosett 2001) with a combined total of 1200 participants included data on the effect of computer-based interventions versus a minimal or no treatment intervention upon waist circumference. At three months, the pooled analysis favored the computer intervention group (MD $-3.0 \mathrm{~cm}(95 \% \mathrm{CI}-6.2$ to 0.3$) ; \mathrm{P}=0.07 ; 276$ participants; three trials; Analysis 1.9; primary analysis 1.9 .1$)$. This analysis was extremely heterogenous $\left(\mathrm{I}^{2}=\right.$ 86\%), due to the inclusion of the Morgan 2011 trial, which displayed a mean difference in waist circumference that was almost three times greater than that seen in any of the other trials. When we removed the Morgan 2011 trial from the meta-analysis, the pooled estimate of effect was smaller (MD $-1.4 \mathrm{~cm}$ (95\% CI -3.1 to 0.2$)$ ) $\mathrm{P}=0.08$; 166 participants; two trials; Analysis 1.9: sensitivity analysis 1.9.2). At six months the computer intervention group had a greater decrease in waist measurement (MD $-1.7 \mathrm{~cm}(95 \% \mathrm{CI}-2.5$ to -0.9$)$ ) $\mathrm{P}<$ 0.00001; 464 participants; two trials; Analysis 1.10) but this difference decreased and was 
not statistically significant at 12 months (MD $-0.9 \mathrm{~cm}(95 \% \mathrm{CI}-2.2$ to 0.5$) ; \mathrm{P}=0.20 ; 474$ participants; one trial; Analysis 1.11).

Health-related quality of life outcomes: No study included data on health-related quality of life outcomes.

\section{Secondary outcomes}

Dietary outcomes: Four studies (Hunter 2008; Morgan 2009; Morgan 2011; Wylie-Rosett 2001) with a combined total of 1099 participants included data on the effect of computerbased interventions versus a minimal or no treatment intervention upon diet-related outcomes. Diet-related outcomes were generally expressed as kilocalories (kcal) per day. There were no outcomes examined at the same time point in more than one study, therefore we performed no meta-analyses.

In one study (Morgan 2009) participants in the computer intervention arm decreased their caloric intake more than participants in the control arm at the three-month follow-up (MD $-269 \mathrm{kcal} /$ day (95\% CI -592 to 54); $\mathrm{P}=0.1 ; 65$ participants; Analysis 1.12) and this difference increased and became statistically significant at the six-month follow-up (MD $-421 \mathrm{kcal} /$ day (95\% CI -799 to -42 ); $\mathrm{P}=0.03 ; 65$ participants; Analysis 1.13). A later study by the same investigators (Morgan 2011) observed that the computer intervention arm had a greater decrease in self reported intake of cola and other soda drinks than did the control group, but did not report data on overall energy intake. In a third study (WylieRosett 2001), which followed participants to 12 months, participants in the control arm decreased their caloric intake slightly more than participants in the computer intervention arm at 12 months follow-up, although the difference was small and not significant at $\mathrm{P}<$ 0.05 for the analysis including all participants (MD $94 \mathrm{kcal} / \mathrm{day}$ (95\% CI -29 to 217); $\mathrm{P}=$ 0.14 ; 474 participants; Analysis 1.14; primary analysis 1.14.1) or for the analysis excluding intervention participants receiving in-person intervention components (MD $115 \mathrm{kcal} / \mathrm{day}$ (95\% CI -21 to 250 ); $\mathrm{P}=0.14 ; 280$ participants; Analysis 1.14; sensitivity analysis 1.14.2).

The decrease in percent calories from fat at six months was slightly greater in the computer intervention arm than the control arm of one study (Hunter 2008) (MD -1.1\% (95\% CI -2.0 to -0.2); $\mathrm{P}=0.02 ; 399$ participants; Analysis 1.15). In a second study (Wylie-Rosett 2001), the decrease in percent calories from fat at 12 months was not significantly different between intervention arms, whether all computer intervention participants were included in the analysis (MD 0.6\% (95\% CI -1.0 to 2.3); $\mathrm{P}=0.45 ; 474$ participants; Analysis 1.16; primary analysis 1.16 .1$)$ or those receiving in-person treatment components were excluded from the analysis (MD 1.4\% (95\% CI -0.4 to 3.2); $\mathrm{P}=0.12 ; 280$ participants; one trial; Analysis 1.16; sensitivity analysis 1.16.1).

Dietary fibre intake was examined in a single study (Hunter 2008), which found that at six months participants in the computer intervention arm improved their fibre intake more than participants in the control arm, as measured by the dietary fibre score (Block 2000) (MD 1.3 (95\% 0.5 to 2.1); $\mathrm{P}=0.001 ; 399$ participants; Analysis 1.17). 
Physical activity outcomes: Four studies (Hunter 2008; Morgan 2009; Morgan 2011; Wylie-Rosett 2001) with a combined total of 1099 participants included data on the effect of computer-based interventions versus a minimal or no treatment intervention upon physical activity-related outcomes. Physical activity was measured as steps per day (Morgan 2009), total metabolic equivalent (MET) minutes (Hunter 2008), total log-transformed MET minutes (Morgan 2011) and minutes walked continuously (Wylie-Rosett 2001). At three months, the computer intervention group had greater mean log-transformed MET minutes in one trial (MD $0.30 \log$-transformed MET minutes (95\% CI 0.0 to 0.6 ); $\mathrm{P}=0.03 ; 71$ participants; Analysis 1.18; analysis 1.18.1) but there was no difference in mean steps per day in a second trial (MD 208 mean steps/day (95\%-1111 to 1527); $\mathrm{P}=0.76 ; 65$ participants; Analysis 1.18; analysis 1.18.1). There was no difference in physical activity change between intervention and control groups at six months (standardized mean difference (SMD) -0.0 mean steps/day (95\% CI -0.2 to 0.1 ); $\mathrm{P}=0.69 ; 464$ participants; two trials; Analysis 1.19). There was also no difference in physical activity between computer and control groups at 12 months, whether all computer intervention participants were included (MD 0 minutes walked continuously (95\% CI -3 to 3 ); $\mathrm{P}=0.97 ; 474$ participants; one trial; Analysis 1.20; primary analysis 1.20.1) or computer intervention participants with added inperson contacts were excluded (MD 0 minutes walked continuously (95\% CI -4 to 4 ); $\mathrm{P}=$ 1.00; 280 participants; one trial; Analysis 1.20; sensitivity analysis 1.20.2).

Cost-effectiveness outcomes: Only two studies comparing computer-based interventions to a minimal intervention addressed the cost-effectiveness of the computer intervention (Threlfall 1984; Wylie-Rosett 2001). The cost-effectiveness of the intervention in the Hunter 2008 study was examined in a companion publication (Rasu 2010). Based on 2010 Euros, the intervention from Threlfall cost EUR 55.6 per participant and led to an average participant loss of $4.8 \%$ of body weight. The intervention from Wylie-Rosett and colleagues cost EUR 38.6 per participant and led to an average participant loss of $4.0 \%$ of body weight. The intervention by Hunter and colleagues led to an increase in weight loss by approximately $2.1 \%$ for a cost of EUR 65.5 per participant.

Adverse effects outcomes: No study reported assessing adverse effects of the intervention.

\section{Covariates}

Adherence: Several trials (Bennett 2010; Hunter 2008; Morgan 2009; Morgan 2011; WylieRosett 2001) tested for and demonstrated statistically significant positive associations between amount of computer use, measured in a variety of ways, and amount of weight loss in the intervention group.

Computer-based intervention versus in-person treatment for weight loss: One study (Harvey-Berino 2010) with a total of 481 participants assessed the effects of an interactive computer-based intervention versus an in-person intervention, versus an interactive computer-based intervention with some in-person contacts (hybrid intervention). 


\section{Primary outcomes}

Weight loss outcomes: At the completion of the six-month intervention, participants in the interactive computer-based intervention group lost less weight than the participants in the inperson intervention group (MD $2.1 \mathrm{~kg}(95 \%$ CI $95 \% \mathrm{CI} 0.8$ to 3.4) $\mathrm{P}=0.002 ; 319$ participants, one trial, Analysis 2.1; analysis 2.1.1). When the interactive computer-based intervention group was compared to the hybrid intervention group, there was no statistically significant difference in weight loss (MD $0.2 \mathrm{~kg}(95 \% \mathrm{CI}-1.0$ to 1.4$) \mathrm{P}=0.75 ; 323$

participants; Analysis 2.1; analysis 2.1.2). Results were similar when percent weight change rather than kilograms change was the outcome (MD 2.2\% (95\% CI 0.9 to 3.5); $\mathrm{P}=0.0007$; 319 participants; Analysis 2.2; analysis 2.2.1) and (MD 0.3\% (95\% CI -0.9 to 1.5 ); $\mathrm{P}=$ $0.63 ; 323$ participants; Analysis 2.2; analysis 2.2.2)).

Waist circumference outcomes: No waist circumference outcomes were reported.

Health-related quality of life outcomes: No study included data on health-related quality of life outcomes.

\section{Secondary outcomes}

Dietary and physical activity outcomes: Dietary and physical activity outcomes (kcal/day intake, $\mathrm{kcal} /$ day expenditure, $\%$ fat intake) were reported but we were unable to extract data from the trial report due to incomplete information on sample size for reported outcomes. The authors reported that there were no differences in dietary and physical activity effects between treatment conditions.

Cost-effectiveness outcomes: Cost-effectiveness for the Internet and in-person arms of Harvey-Berino 2010 was examined in a companion publication (Krukowski 2010). The Internet intervention cost EUR 288 per participant and led to a loss of $5.6 \%$ of body weight, while the in-person intervention in the same trial cost EUR 549 to deliver and led to an average weight loss of 8.2\% (Harvey-Berino 2010; Krukowski 2010). Assuming a 50\% weight regain at one year post-treatment, Krukowski and colleagues calculated the cost per (discounted) year of life gained to be USD 2160 for the Internet intervention versus a hypothesized no treatment, no costs, no weight loss condition, and USD 7177 (80\% CI USD 3055 to USD 60,291) per (discounted) year of life gained for the in-person relative to the Internet intervention (Harvey-Berino 2010; Krukowski 2010).

Adverse effects outcomes: No study reported assessing adverse effects of the intervention.

\section{Covariates}

Adherence: The proportion of online chats or in-person groups attended was measured, as was the percent of weeks that participants submitted a journal (either online or paper, depending on the treatment group). There was not a statistically significant difference between intervention groups in attendance or journal submission, and the authors did not test for associations between attendance or compliance and weight loss within intervention groups. 
Computer-based intervention as adjunct to an Internet intervention: Five studies (Gabriele 2011; Tate 2001; Tate 2003; Tate 2006; Webber 2008) with a combined total of 441 participants assessed the effects of an interactive computer-based intervention as an adjunct or supplement to an Internet intervention. Each study compared an Internet intervention with the same or similar intervention supplemented by a computer interaction. In Gabriele 2011; Tate 2001; Tate 2003 and Tate 2006, the interaction was individual e-mail counseling, ecoaching or automated computer feedback. In Webber 2008, the interaction was an online chat group. We analyzed the chat group trial separately from the trials using individualized e-mail or automated feedback.

Gabriele 2011 compared both non-directive e-coaching and directive e-coaching to minimal support. We initially combined the directive and non-directive arms of the trial, compared the combined arms with the minimal support arm, and analyzed the Gabriele trial together with the Tate trials (Tate 2001; Tate 2006). All analyses incorporating the Gabriele trial showed high heterogeneity, however. Furthermore, the authors found more differences between the directive and non-directive intervention arms than between either arm and the control intervention. We therefore redid the analyses combining the directive arm of the Gabriele trial with the Tate trials, as we believed that the counseling in the Tate trials was more similar to the directive intervention than to the non-directive intervention.

Tate 2006 compared both e-mail counseling and automated tailored computer feedback to an Internet program alone. In all analyses incorporating data from Tate 2006 we therefore conducted the main analysis by combining the two intervention arms of the trial (e-mail counseling and automated feedback) and then conducted additional analyses for e-mail counseling only and automated counseling only.

The intervention duration was 12 weeks in Gabriele 2011, 16 weeks in Webber 2008, six months in Tate 2001 and Tate 2006, and 12 months in Tate 2003. Because follow-up in Tate 2001 was above $80 \%$ at three months follow-up and less than $80 \%$ at six months follow-up, only the data from the three-month follow-up were eligible for inclusion in this review.

\section{Primary outcomes}

Weight loss outcomes: Four trials (Gabriele 2011; Tate 2001; Tate 2006; Webber 2008) presented data on weight loss outcomes at three to four months, one trial (Tate 2006) presented data on weight loss at six months, and one trial (Tate 2003) presented data on weight loss at 12 months. At three months, participants receiving individualized feedback lost more weight than participants receiving no additional feedback (MD $-2.1 \mathrm{~kg}$ (95\% CI -2.9 to -1.4$)$; $\mathrm{P}<0.00001 ; 352$ participants; three trials; Analysis 3.1 ; main comparison 3.1.1). The effect was slightly greater for e-mail counseling (MD $-2.3 \mathrm{~kg}(95 \% \mathrm{CI}-3.1$ to $-1.5)$; $\mathrm{P}<0.00001$; 291 participants; three trials; Analysis 3.1; subgroup analysis 3.1.2) than for automated feedback (MD $-1.8 \mathrm{~kg}(95 \% \mathrm{CI}-3.2$ to -0.5$)$; $\mathrm{P}=0.009 ; 128$ participants; one trial; Analysis 3.1; subgroup analysis 3.1.3). Non-directive e-mail counseling did not appear effective (MD $-0.3 \mathrm{~kg}$ (95\% CI -2.2 to 1.7); $\mathrm{P}=0.80 ; 69$ participants; one trial; Analysis 3.1; secondary comparison 3.1.4). 
In contrast to the effects seen with most forms of individualized counseling or feedback, participants receiving a group chat intervention in addition to online self monitoring (Webber 2008) lost less weight at four months than participants who did not receive the group chat intervention (MD $1.5 \mathrm{~kg}$ (95\% CI -0.7 to 3.7); $\mathrm{P}=0.18$; 66 participants; one trial; Analysis 3.1; analysis 3.1.5). The group chat intervention was not followed past four months. At six months, participants receiving individualized feedback lost more weight than participants not receiving such feedback (MD $-2.4 \mathrm{~kg}$ (95\% CI -4.1 to -0.8$) ; \mathrm{P}=0.004 ; 192$ participants; one trial; 192 participants; Analysis 3.2; main comparison 3.2.1), but this overall difference was composed of a large difference for e-mail counseling $(-3.6 \mathrm{~kg}(95 \%$ $\mathrm{CI}-5.6$ to -1.6$)$; $\mathrm{P}=0.0004 ; 131$ participants; one trial; Analysis 3.2; subgroup analysis 3.2.2) and a smaller difference for automated feedback that was not statistically significant (MD -1.2 (95\% CI -3.1 to 0.7); $\mathrm{P}=0.21 ; 128$ participants; one trial; Analysis 3.2; subgroup analysis 3.2.3). At 12 months, participants receiving individualized e-mail feedback lost more weight than participants who did not (MD $-2.4 \mathrm{~kg}(95 \% \mathrm{CI}-4.8 \mathrm{~kg}$ to $0.0 \mathrm{~kg}) ; \mathrm{P}=$ 0.05; 92 participants; one trial; Analysis 3.3).

Results were similar when percent weight lost and change in BMI rather than change in kilograms body weight were the weight-related outcomes. At three months, participants receiving individualized feedback or support lost a greater percentage of their body weight (MD -2.5\% (95\% CI -4.1 to -0.9); $\mathrm{P}=0.003 ; 227$ participants; two trials; Analysis 3.4: main comparison 3.4.1). When types of feedback or support were examined separately, a similar percentage weight loss was observed for e-mail feedback, including the directive email coaching in the Gabriele 2011 trial (MD $-2.7 \%$ (95\% CI -4.7 to -0.6$) ; \mathrm{P}=0.01 ; 180$ participants; two trials; Analysis 3.4: subgroup analysis 3.4.2), and automated feedback (MD $-2.6 \%$ (95\% -4.2 to -1.0$)$; $\mathrm{P}=0.001 ; 102$ participants; one trial; Analysis 3.4: subgroup analysis 3.4.3). However, the analyses combining Gabriele 2011 and Tate 2006 showed moderate to high heterogeneity $\left(\mathrm{I}^{2}=49 \%\right.$ and $\left.\mathrm{I}^{2}=66 \%\right)$, as the Gabriele trial consistently showed a smaller effect size than the Tate trial. Meanwhile, non-directive e-mail coaching as conducted in the Gabriele 2011 trial did not result in greater weight loss (MD - $0.2 \%$ (95\% CI -2.3 to 2.0 ); $\mathrm{P}=0.89 ; 69$ participants; one trial; Analysis 3.4: secondary comparison 3.4.4).

In the studies reporting percent weight loss at six or 12 months, participants receiving individualized feedback lost a larger percentage of their body weight at six months (MD $-4.0 \%$ (95\% CI -6.0 to -2.0 ); $\mathrm{P}<0.0001 ; 155$ participants; one trial; Analysis 3.5: main comparison 3.5.1) and 12 months (MD $-2.6 \%$ (95\% CI -4.9 to -0.3$) ; \mathrm{P}=0.03 ; 92$ participants; one trial; Analysis 3.6). At six months, the effect was greater among participants receiving e-mail feedback than among participants receiving automated feedback (Analysis 3.5; subgroup analyses 3.5.2 and 3.5.3).

In the single study reporting change in BMI (Tate 2003), the reduction in BMI at 12 months was not statistically significantly greater among participants in the e-counseling group (MD $-0.8 \mathrm{~kg} / \mathrm{m}^{2}$ (95\% CI -1.7 to 0.1 ); $\mathrm{P}=0.07 ; 92$ participants; one trial; Analysis 3.7 ).

Waist circumference outcomes: Gabriele 2011; Tate 2001 and Tate 2003 reported waist circumference outcomes. At three months, compared to the participants in the control group, 
participants in e-counseling or directive e-coaching had a greater reduction in mean waist circumference compared to participants in the control groups (MD $-2.6 \mathrm{~cm}$ (95\% CI -4.0 to $-1.2) ; \mathrm{P}=0.0003 ; 160$ participants; two trials; Analysis 3.8: main comparison 3.8.1), however non-directive e-coaching was not effective ( $\mathrm{MD}-0.3 \mathrm{~cm}(95 \% \mathrm{CI}-2.8$ to 2.2$) ; \mathrm{P}=$ 0.80; 69 participants; one trial; Analysis 3.8: secondary comparison 3.8.2). At 12 months, participants in the e-counseling group lost an average of $2.8 \mathrm{~cm}$ more from their waist (95\% CI -5.5 to $-0.1 ; \mathrm{P}=0.04 ; 92$ participants; one trial; Analysis 3.9).

Health-related quality of life outcomes: No study included data on health-related quality of life outcomes.

\section{Secondary outcomes}

Dietary outcomes: Tate 2006 and Webber 2008 reported data on change in total kilocalories per day, and Tate 2003; Tate 2006 and Webber 2008 reported data on change in percent calories from fat.

Individualized computer-based feedback was not associated with statistically significant decreases in caloric intake at three months (MD -115 calories/day (95\% CI -308 to 78 ); $\mathrm{P}=$ 0.24; 155 participants; one trial; Analysis 3.10: main comparison 3.10.1) or six months (MD $-117 \mathrm{kcal} / \mathrm{day}$ (95\% CI -359 to 125 ); $\mathrm{P}=0.34 ; 146$ participants; one trial; Analysis 3.11 : main comparison 3.11.1). Individualized feedback was associated with decreases in percent fat intake at three months (MD $-2.9 \%(95 \% \mathrm{CI}-5.0$ to -0.8$)$ ) $\mathrm{P}=0.007 ; 155$ participants; one trial; Analysis 3.12: main comparison 3.12.1) and six months (MD -3.8\% (95\% CI -5.9 to -1.7$) ; \mathrm{P}=0.0004 ; 146$ participants; one trial; Analysis 3.13: main comparison 3.13.1). At 12 months, the decrease in percentage dietary fat intake was three percent greater in the ecounseling group than the control group (95\% CI -6.1 to 0.1 ); $\mathrm{P}=0.06$; 92 participants; one trial; Analysis 3.14).

In contrast to individual support or feedback interventions, online group chats were associated with smaller (not greater) non-significant decreases in caloric intake at four months (MD $235 \mathrm{kcal} /$ day (95\% -156 to 626); $\mathrm{P}=0.24 ; 65$ participants; one trial; Analysis 3.10: secondary comparison 3.10.4), and there was no difference between intervention and control group participants in percentage fat intake (MD $-0.1 \%$ (95\% CI -3.2 to 3.0$)$; $\mathrm{P}=$ 0.95; 65 participants; one trial; Analysis 3.12: secondary comparison 3.12.4).

Physical activity outcomes: Tate 2003; Tate 2006 and Webber 2008 reported data on physical activity at three to four months, while Tate 2006 reported physical activity at six months and Tate 2003 reported physical activity at 12 months. At three months, participants receiving individualized feedback increased their energy expenditure more than did participants without such feedback (MD $347 \mathrm{kcal} /$ week (95\% CI 94 to 600); $\mathrm{P}=0.0007 ; 250$ participants; two trials; Analysis 3.15: main comparison 3.15.1). A similar effect was also observed when the analysis was restricted to trial arms with e-mail feedback, but the difference was much smaller and not statistically significant when the intervention was restricted to automated feedback (Analysis 3.15: subgroup analysis 3.15.3). Participants receiving individualized feedback had statistically non-significant greater increases in energy expenditure at six months (MD $294 \mathrm{kcal} /$ week (95\% CI -96 to 684); P = 0.14; 152 
participants; one trial; Analysis 3.16: main comparison 3.16.1) and 12 months (MD 279 $\mathrm{kcal} /$ week (95\% CI -165 to 723); $\mathrm{P}=0.22 ; 92$ participants; one trial; Analysis 3.17).

Online group chats were not associated with statistically significant increases in physical activity at four months (MD $498 \mathrm{kcal} /$ week (95\% CI -511 to 1507 ); $\mathrm{P}=0.33 ; 65$ participants; one trial; Analysis 3.15: secondary comparison 3.15.4).

Cost-effectiveness outcomes: None of the studies collected information on costs.

Adverse effects outcomes: Tate 2006 reported that no serious adverse events had occurred. No other study reported assessing adverse effects of the intervention.

\section{Covariates}

Adherence: Gabriele 2011 collected information on the number of times participants submitted information via the online check-in page to the e-coach about weight, calorie intake or physical activity, but did not look within intervention groups to test whether adherence was associated with weight loss or any other outcomes. In the Webber 2008 trial, participants in the online chat intervention group who attended more online chats had greater weight loss. In Tate 2001, Tate 2003 and Tate 2006, login frequency was significantly correlated with weight change in all intervention groups. In both Tate 2001 and Tate 2003, participants in the feedback intervention groups logged in more frequently than participants in the control group. In Tate 2006, post hoc comparisons showed that the control and e-mail feedback groups logged in significantly more often than the automated feedback group did.

Computer-based intervention as adjunct to an in-person intervention: One study (DeLucia 1988) with a total of 29 participants assessed the effects of an interactive computer-based intervention as an adjunct to an in-person behavioral weight loss intervention.

\section{Primary outcomes}

Weight loss outcomes: There was no statistically significant difference in weight loss between groups immediately after the completion of the 10 -week intervention (MD $-0.4 \mathrm{~kg}$ (95\% CI -4.1 to 3.3 ); $\mathrm{P}=0.83 ; 26$ participants; Analysis 4.1 ) or six months after the completion of the intervention (MD $0.1 \mathrm{~kg}$ (95\% CI -3.6 to 3.7); $\mathrm{P}=0.97 ; 26$ participants; Analysis 4.2).

Waist circumference outcomes and health-related quality of life outcomes: DeLucia 1988 did not collect data on waist circumference or health-related quality of life.

\section{Secondary outcomes}

Diet, physical activity, costs and adverse effects outcomes: DeLucia 1988 did not collect data on dietary intake, physical activity or costs. Assessment of adverse effects was not reported. 


\section{Covariates}

Adherence: Treatment groups had equivalent adherence to the intervention, as measured by completion of homework assignments. There was not any exploration of within-group relationships between adherence and outcomes.

\section{Weight maintenance studies}

\section{Computer-based intervention versus minimal or no treatment control for weight}

maintenance: Three studies (Cussler 2008; Svetkey 2008; Wing 2006) with a combined total of 1032 participants assessed the effects of an interactive computer-based intervention compared to a minimal or no treatment control for maintenance of weight loss.

\section{Primary outcomes}

Weight change outcomes: Two trials (Svetkey 2008; Wing 2006) presented data on weight loss outcomes at six months, three trials (Cussler 2008; Svetkey 2008; Wing 2006) presented data on weight loss at 12 months, and two trials (Svetkey 2008; Wing 2006) contained information on weight loss at 18 months. Compared to participants in the minimal or no treatment conditions, participants in the computer interventions regained less weight at six months (MD $-0.7 \mathrm{~kg}(95 \% \mathrm{CI}-1.2$ to -0.2$) ; \mathrm{P}=0.004 ; 897$ participants; two trials; Analysis 5.1) and 12 months (MD $-0.8 \mathrm{~kg}$ (95\% CI -1.4 to -0.2$) ; \mathrm{P}=0.01 ; 1004$ participants; three trials; Analysis 5.2) (Figure 5). Participants in the computer intervention continued to have regained less weight at 18 months $(-0.7 \mathrm{~kg}$ (95\% CI -1.6 to 0.1$) ; \mathrm{P}=$ $0.10 ; 897$ participants; two trials; Analysis 5.3), although the difference was not statistically significant. One study (Svetkey 2008) followed participants to 24 and 30 months; weight maintenance was statistically significantly better in the computer intervention group at 24 months (MD $-0.9 \mathrm{~kg}$ (95\% CI -1.8 to -0.0$)$; $\mathrm{P}=0.04 ; 688$ participants; Analysis 5.4) but not at 30 months ( $\mathrm{MD}-0.3 \mathrm{~kg}(95 \% \mathrm{CI}-1.3$ to 0.5$) ; \mathrm{P}=0.48 ; 688$ participants; Analysis 5.5). Svetkey 2008 also collected data on percent weight change at 30 months, and found that the percentage weight regained during maintenance was not significantly smaller in the intervention group ( $-0.4 \%$ (95\% CI -1.6 to 0.8$) ; \mathrm{P}=0.50 ; 688$ participants; Analysis 5.6).

One study (Cussler 2008) presented BMI outcome data. At 12 months of follow-up, the difference between intervention groups was small and not statistically significant (MD -0.4 $\mathrm{kg} / \mathrm{m}^{2}$ (95\% CI -0.3 to 1.1$) ; \mathrm{P}=0.26 ; 688$ participants; Analysis 5.7).

Waist circumference outcomes: No study included data on change in waist circumference outcomes.

Health-related quality of life outcomes: No study collected data on health-related quality of life outcomes.

\section{Secondary outcomes}

Dietary outcomes: One study (Cussler 2008) reported data on energy intake at 12 months (MD -48 kcal/day (95\% CI -198 to 102); P = 0.53; 107 participants; Analysis 5.8) and one study (Svetkey 2008) reported data on energy intake at 30 months (MD $-72 \mathrm{kcal} / \mathrm{day}(95 \%$ $\mathrm{CI}-168$ to 24$) ; \mathrm{P}=0.14 ; 688$ participants; Analysis 5.9). In both cases, the computer 
intervention group had a smaller increase in $\mathrm{kcal} /$ day intake but the difference was not statistically significant.

Physical activity outcomes: One study (Cussler 2008) reported data on energy expenditure at 12 months; there was no statistically significant difference between intervention groups (MD -7 kcal/day (95\% CI -117 to 103); $\mathrm{P}=0.90 ; 107$ participants; Analysis 5.10).

Cost-effectiveness outcomes: No study included data on costs.

Adverse effects outcomes: Wing 2006 reported that there were no serious adverse events. No other study reported assessing for adverse effects of the intervention.

\section{Covariates}

Adherence: Cussler 2008 used several measures of engagement with the computer-based intervention (e.g. submission of diet and weight logs, number of e-mail contacts, number of articles posted) and found a wide range in adherence to intervention activities. For example, almost one-third of the computer-based group accessed the Internet only once per week during maintenance. Among participants who completed the study, there was a significant correlation between submission of diet logs and change in weight. No other measures of adherence were correlated with weight maintenance. Svetkey 2008 tracked website contacts, and found that participants in the computer-based intervention logged in at least once per month for $77 \%$ of the months of the maintenance intervention. There was no examination in this study of relationships between Inter-net use and weight outcomes. Wing 2006 measured attendance at the chat-room sessions and the percentage of participants who reported their weight each week, and both measures decreased significantly over time $(\mathrm{P}<0.001)$. There was no assessment of relationships between either measure and weight maintenance.

\section{Computer-based intervention versus minimal in-person control treatment for weight} maintenance: Three studies (Harvey-Berino 2002; Svetkey 2008; Wing 2006) with a combined total of 955 participants assessed the effects of an interactive computer-based intervention compared to a minimal in-person treatment control, defined as in-person contact no more than once per month, for maintenance of weight loss.

\section{Primary outcomes}

Weight change outcomes: Two trials (Svetkey 2008; Wing 2006) presented data on weight loss outcomes at six months, three trials (Harvey-Berino 2002; Svetkey 2008; Wing 2006) presented data on weight loss at 12 months, and two trials (Svetkey 2008; Wing 2006) contained information on weight loss at 18 months. At six months, the computer intervention group regained slightly more weight than the face-to-face group, although the difference was not statistically significant (MD $0.5 \mathrm{~kg}$ (95\% CI -0.5 to 1.6 ); $\mathrm{P}=0.32 ; 897$ participants; two trials; Analysis 6.1). At 12 months, the computer group regained more weight than the face-to-face group, and the difference was near to statistical significance (MD $1.6 \mathrm{~kg}$ (95\% -0.1 to 3.2); $\mathrm{P}=0.07$; 955 participants; three trials; Analysis 6.2) (Figure 6). This difference was also seen at 18 months (MD $1.1 \mathrm{~kg}$ (95\% CI -0.2 to 2.5); $\mathrm{P}=0.10$; 897 participants; two trials; Analysis 6.3). Each of these meta-analyses displayed moderate 
to high heterogeneity $\left(\mathrm{I}^{2}=42 \%\right.$ to $\mathrm{I}^{2}=66 \%$ ) due to differing interventions, controls and populations. However, the effects in individual trials, while small and varying in size and statistical significance, were consistently in favor of the face-to-face intervention. One study (Svetkey 2008) followed participants to 24 and 30 months and observed that participants in the computer-based intervention group had gained approximately one $\mathrm{kg}$ more than participants in the in-person intervention group at both time points, and this difference was statistically significant (at 24 months, MD $1.1 \mathrm{~kg}(95 \%$ CI 0.3 to 1.9 ); $\mathrm{P}=0.01 ; 688$ participants; Analysis 6.4) (at 30 months, MD $1.2 \mathrm{~kg}$ (95\% CI 0.3 to 2.1); $\mathrm{P}=0.009 ; 688$ participants; Analysis 6.5). The same study reported data on percent weight change at 30 months, and found that the percentage weight gain during maintenance was $1.5 \%$ greater in the computer-based intervention ( $95 \%$ CI 0.5 to $2.5 ; \mathrm{P}=0.003 ; 688$ participants; Analysis 6.6).

Waist circumference outcomes: No study included data on change in waist circumference.

Health-related quality of life outcomes: No study included data on health-related quality of life.

\section{Secondary outcomes}

Dietary outcomes: One study (Svetkey 2008) reported data on energy intake at 30 months. At 30 months, the computer intervention group took in slightly more calories than the inperson intervention group but this was not statistically significant (MD $39 \mathrm{kcal} / \mathrm{day}$ (95\% CI -45 to 123$) ; \mathrm{P}=0.36 ; 688$ participants; Analysis 6.7).

Physical activity outcomes: No study included data on change in physical activity outcomes.

Cost-effectiveness outcomes: Although the costs of the intervention in one trial (Svetkey 2008) were detailed in related publications (Meenan 2009; Meenan 2010) no data on costeffectiveness or relative costs of interventions and controls were presented.

Adverse effects outcomes: Wing 2006 reported that there were no serious adverse events. No other study reported assessing for adverse effects of the intervention.

\section{Covariates}

Adherence: Harvey-Berino 2002 reported that, compared to participants in the computerbased treatment group, participants in the infrequent in-person treatment group attended a greater percentage of group sessions during the first six months of weight maintenance. However, the infrequent in-person treatment group did not receive any study contacts at all during the second six months of weight maintenance. Svetkey 2008 stated that participants in the personal-contact group completed an average of $91 \%$ of monthly intervention contacts, while participants in the computer-based intervention logged onto the Internet at least once per month for $77 \%$ of the months of the maintenance intervention. Wing 2006 reported that while attendance at both the in-person and the Internet chat-room sessions decreased over time, the percentage of sessions attended was significantly higher in the in- 
person group throughout the trial. Weekly reporting of weight also decreased over time, and was consistently higher among participants in the in-person intervention, but the difference between the in-person and computer-based groups was not statistically significant. None of the three studies explored within-group relationships between adherence or dose of the intervention, and weight outcomes.

\section{Computer-based intervention versus intensive in-person control treatment for weight} maintenance: Only one included study (Harvey-Berino 2002) presented data on the effects of a computer-based intervention versus an intensive in-person intervention, defined as contact that is more frequent than once per month, for maintenance of weight loss. The inperson contact in this study was once every two weeks throughout one year of follow-up.

\section{Primary outcomes}

Weight change outcomes: Compared to participants in the in-person group, participants in the Internet group regained more weight during the first six months of weight maintenance (MD $2.2 \mathrm{~kg}$ (95\% CI 0.3 to 4.1); $\mathrm{P}=0.03 ; 62$ participants; Analysis 7.1). Overall, from the time of entry into the weight loss component of the trial to the end of the 12 months of weight maintenance, participants in the in-person group lost more weight than did participants in the Internet group (MD $4.7 \mathrm{~kg}$ (95\% CI 1.7 to 7.7); $\mathrm{P}=0.002 ; 62$ participants; Analysis 7.2).

Waist circumference and health-related quality of life outcomes: Harvey-Berino 2002 did not present data on change in waist circumference or health-related quality of life outcomes.

\section{Secondary outcomes}

Dietary, physical activity, cost-effectiveness and adverse effects outcomes: HarveyBerino 2002 did not present data on dietary or physical activity outcomes. Information on costs was not collected. No assessment of adverse effects of the intervention was reported.

\section{Covariates}

Adherence: The authors reported that attendance at treatment sessions was greater for the intensive in-person condition than the computer condition, and participants in the in-person condition also reported more peer-support contacts. However, there was no between-group difference in the number of weeks for which self monitoring data were submitted. The authors did not investigate whether there were any within-group relationships between dose of intervention and amount of weight lost.

Subgroup analyses-The number of trials available for analysis was small for all outcomes, and subgroup analyses by age group and overweight versus obesity could not be performed. When the two weight-loss trials that included only men (Morgan 2009; Morgan 2011) were analyzed together, the mean weight loss was larger than that of trials conducted in mixed-gender populations ( $3 \mathrm{~kg}$ versus $2 \mathrm{~kg}$; Analysis 1.1; subgroup analyses 1.1.4 and 1.1.5) but there was substantial heterogeneity in the analysis of men only $\left(\mathrm{I}^{2}=60 \%\right)$, as the mean difference between intervention groups in Morgan 2009 was less than half that 
observed in Morgan 2011. While the computer intervention group in Morgan 2009 lost more weight than the computer intervention group in Morgan 2011, the control group in Morgan 2009 also lost a substantial amount of weight, while the control group in Morgan 2011 did not lose any weight. In the case of these two trials, differences in response to the computer intervention may be related to differences in contextual factors. For example, the earlier trial was conducted at a university and the later trial was conducted in factory shift workers, raising issues such as possible differences in ease and comfort of computer use in the two populations. However, we were unable to explore this explanation further given the available data.

Sensitivity analyses-When we conducted sensitivity analyses omitting the sole quasirandomized trial (Schroder 2010) or the oldest randomized and the sole non-published trial (Threlfall 1984), or both, heterogeneity decreased but the results were consistent with the original analyses. Likewise, omitting the one very large trial (Wing 2006) from weight maintenance analyses did not make large differences to the estimate of effect or the statistical significance of those analyses. When we omitted the cluster-randomized studies (Cussler 2008; Morgan 2011) from analyses, there were not large differences in the estimate of effect or the statistical significance of those analyses, with two exceptions. In the analysis of change in waist circumference at six months, the omission of Morgan 2011 from the analysis (Analysis 1.9: sensitivity analysis 1.9.2) reduced the pooled effect size although the difference between intervention groups remained near statistical significance $(P=0.08$ versus $P=0.07$ ). This change in effect size was likely due to the extremely large change in waist circumference seen in Morgan 2011, which we cannot explain. In the analysis of change in weight maintenance at 12 months (Analysis 5.2), the omission of Cussler 2008 from the analysis did not change the pooled effect estimate of $0.8 \mathrm{~kg}$, but altered the statistical significance from $P=0.01$ to $P=0.08$. Since the estimate of effect in Cussler 2008 was intermediate between that in the other two trials in the analysis, it is likely that the omission of the trial reduced the statistical significance of the effect estimate due to less information being present in the analysis. Because there were few trials available for all outcomes, we could not further examine the effects of components of risk of bias (e.g. allocation concealment) on outcomes. Also, while we had hoped to conduct sensitivity analyses on additional factors (e.g. language of publication), included studies possessed insufficient variability in those factors to allow performance of sensitivity analyses.

We would also have liked to conduct analyses based on adherence to interventions or associations between the intensity of the intervention and effects of interventions. Most studies collected some data on adherence, and the majority of these examined relationships between adherence or intervention dose and weight change outcomes (Bennett 2010; Cussler 2008; Hunter 2008; Morgan 2009; Morgan 2011; Tate 2001; Tate 2003; Tate 2006; Webber 2008; Wylie-Rosett 2001). However, the different measures of adherence, and different analyses of relationships between adherence and outcomes, made combining data across studies impossible.

Publication and small study bias-Because there were five or fewer studies in all meta-analyses, we did not construct funnel plots to examine for publication and small study 
bias. When there are fewer than 10 studies in a comparison, it is difficult to assess asymmetry by visual examination, and the power of the funnel plot test is too low to distinguish chance from real asymmetry (Higgins 2009, Chapter 10).

\section{ADDITIONAL SUMMARY OF FINDINGS [Explanation]}

\begin{tabular}{|c|c|c|c|c|c|}
\hline \multicolumn{6}{|c|}{$\begin{array}{l}\text { Patient or population: adults with overweight or obesity } \\
\text { Settings: community } \\
\text { Intervention: interactive computer intervention } \\
\text { Comparison: in-person intervention }\end{array}$} \\
\hline \multirow[t]{3}{*}{ Outcomes } & \multicolumn{2}{|c|}{ Illustrative comparative risks* $(95 \% \mathrm{CI})$} & \multirow{3}{*}{$\begin{array}{l}\text { Relative } \\
\text { effect }(95 \% \\
\text { CI) }\end{array}$} & \multirow{3}{*}{$\begin{array}{l}\text { No of } \\
\text { participants } \\
\text { (studies) }\end{array}$} & \multirow{3}{*}{$\begin{array}{l}\text { Quality } \\
\text { the evide } \\
\text { (GRADE }\end{array}$} \\
\hline & Assumed risk & Corresponding risk & & & \\
\hline & In-person intervention & Interactive computer intervention & & & \\
\hline Health-related quality of life & See comment & See comment & Not estimable & See comment & See comm \\
\hline Adverse effects & See comment & See comment & Not estimable & See comment & See comm \\
\hline $\begin{array}{l}\text { Weight loss (change in kg weight) } \\
\text { Follow-up: } 6 \text { months }\end{array}$ & $\begin{array}{l}\text { The mean weight loss } \\
\text { in the control group } \\
\text { was } 7.6 \mathrm{~kg}\end{array}$ & $\begin{array}{l}\text { The mean weight loss in the } \\
\text { intervention group was } 2.1 \mathrm{~kg}(0.8 \\
\text { to } 3.4) \text { smaller }\end{array}$ & & 319 (1 study) & $\begin{array}{l}\oplus \oplus \oplus \bigcirc \\
\text { moderate }\end{array}$ \\
\hline $\begin{array}{l}\text { Weight regain (change in kg } \\
\text { weight) } \\
\text { Follow-up: } 12 \text { months }\end{array}$ & $\begin{array}{l}\text { The mean weight } \\
\text { regain in the control } \\
\text { groups ranged from } 4.0 \\
\mathrm{~kg} \text { to } 0.6 \mathrm{~kg}\end{array}$ & $\begin{array}{l}\text { The mean weight regain in the } \\
\text { intervention groups was } 1.6 \mathrm{~kg}(0.1 \\
\text { lower to } 3.2 \text { higher) higher }\end{array}$ & & 955 (3 studies) & $\begin{array}{l}\oplus \oplus \oplus \bigcirc \\
\text { moderate }\end{array}$ \\
\hline $\begin{array}{l}\text { Weight regain (change in kg } \\
\text { weight) Follow-up: } 12 \text { months }\end{array}$ & $\begin{array}{l}\text { The mean weight loss } \\
\text { from start of weight } \\
\text { loss to end of weight } \\
\text { maintenance in the } \\
\text { control group was } 10.4 \\
\mathrm{~kg}\end{array}$ & $\begin{array}{l}\text { The mean weight loss from start of } \\
\text { weight loss to end of weight } \\
\text { maintenance in the intervention } \\
\text { group was } 4.7 \mathrm{~kg}(1.7 \text { to } 7.7) \text { lower }\end{array}$ & & 62 (1 study) & $\begin{array}{l}\oplus \oplus \bigcirc \bigcirc \\
\text { low }^{3}\end{array}$ \\
\hline Physical-activity related outcomes & See comment & See comment & Not estimable & See comment & See comm \\
\hline
\end{tabular}




\begin{tabular}{|c|c|c|c|c|c|}
\hline \multicolumn{6}{|c|}{ Interactive computer intervention compared to in-person intervention (monthly or less) for weight loss or maintenance of weight loss in adults } \\
\hline \multicolumn{6}{|c|}{$\begin{array}{l}\text { Patient or population: adults with overweight or obesity } \\
\text { Settings: community } \\
\text { Intervention: interactive computer intervention } \\
\text { Comparison: in-person intervention }\end{array}$} \\
\hline \multirow[t]{3}{*}{ Outcomes } & \multicolumn{2}{|c|}{ Illustrative comparative risks ${ }^{*}(95 \% \mathrm{CI})$} & \multirow{3}{*}{$\begin{array}{l}\text { Relative } \\
\text { effect }(95 \% \\
\text { CI) }\end{array}$} & \multirow{3}{*}{$\begin{array}{l}\text { No of } \\
\text { participants } \\
\text { (studies) }\end{array}$} & \multirow{3}{*}{$\begin{array}{l}\text { Quality } \\
\text { the evide } \\
\text { (GRADE }\end{array}$} \\
\hline & Assumed risk & Corresponding risk & & & \\
\hline & In-person intervention & Interactive computer intervention & & & \\
\hline Cost-effectiveness & See comment & See comment & Not estimable & 62 (1 study) & See col \\
\hline
\end{tabular}

* The basis for the assumed risk (e.g. the median control group risk across studies) is provided in footnotes. The corresponding risk (and its 95\% confidence interval) is based on the assumed risk in the comparison group and the relative effect of the intervention (and its $95 \% \mathrm{CI}$ ).

CI: confidence interval

GRADE Working Group grades of evidence

High quality: Further research is very unlikely to change our confidence in the estimate of effect.

Moderate quality: Further research is likely to have an important impact on our confidence in the estimate of effect and may change the estimate.

Low quality: Further research is very likely to have an important impact on our confidence in the estimate of effect and is likely to change the estimate.

Very low quality: We are very uncertain about the estimate.

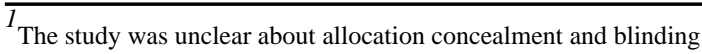

2 Two studies were unclear about details of randomization, unclear about allocation concealment and unclear about blinding.

3 The s

The study was unclear about allocation concealment and blinding, and the total sample size for the comparison was very low.

\section{DISCUSSION}

\section{Summary of main results}

The findings of this review demonstrate that computer-based interventions have a positive effect on short-term weight loss and short-term weight loss maintenance. The strongest conclusion, based on the greatest number of studies, supports the observation that a variety 
of interactive computer-based interventions led to short-term weight loss when compared to a minimal or no treatment condition. Computer-based feedback also appeared to be effective as an adjunct to Internet interventions in promoting weight loss. Fewer trials tested computer-based interventions for maintenance of weight loss, however computer-based interventions consistently led to lower levels of weight regain when compared to a minimal or no treatment condition. Few interventions led to changes in caloric intake, physical activity or waist circumference, though these outcomes were not reported in all studies. Greater amounts of intervention use, particularly self monitoring, were typically associated with greater amounts of weight loss, though it was not clear what intervention elements would best encourage greater use or whether encouraging greater use would lead to larger effects. These results are similar to those of other recent reviews (Neve 2010; Reed 2012).

While interactive computer-based interventions appear to be more effective than a minimal or no treatment control, they do not appear to be more effective than in-person treatments, even in cases where the in-person contacts are infrequent. This was true in the one study comparing in-person and computer-based interventions for weight loss, as well as the three studies comparing in-person and computer-based interventions for maintenance of weight loss. For maintenance of weight loss, both minimal (once per month or less) and intensive (more often than once per month) in-person interventions outperformed computer-based interventions. The amount of additional weight loss, however, is relatively small and of brief duration, making the clinical significance of these differences unclear.

Few studies included cost information, making conclusions about cost-effectiveness difficult. This is similar to the observations of Tate and colleagues in a 2009 review of eight studies examining cost-effectiveness of Internet interventions (Tate 2009). In the present review, however, the studies that examined cost-effectiveness observed relatively high levels of cost effectiveness, and the single study comparing the cost-effectiveness of an inperson and a computer-based intervention found that the computer-based intervention was more cost-effective.

\section{Overall completeness and applicability of evidence}

A challenge in interpreting these findings is the heterogeneity of the intervention goal (loss versus maintenance), timing of measures (three months, six months, 12 months, or longer) and control group (minimal, adjunct to Internet intervention, adjunct to minimal in-person treatment). Given the small number of studies (18 total) and the many permutations of intervention goal, intervention components, control condition and timing, firm conclusions were hard to make and were typically based on a relatively small number of studies. The interventions, however, tended to be similar in that they typically included computer-based education, self monitoring (of weight, intake and activity) using a computer interface, and some form of feedback based upon the self monitoring. With the exception of one study examining a computer-based group chat intervention, and a non-directive counseling arm in a second study, interactive computer-based interventions were consistently more effective than minimal interventions and less effective than in-person contacts for weight loss and weight maintenance. 
A major advantage of computer-based interventions is their ability to reach large numbers of people at a relatively low cost. However, the issue of costs and cost-effectiveness in the area of computer-based interventions is complex. Though cost-analyses can be important tools to assist organizations in making decisions, it is increasingly complicated to understand their significance. Over the past decade, end-users are being provided more and more services for free online and in mobile applications, their costs being offset by revenue from advertising (Miller 2008). In addition, while these analyses are often done from the perspective of the employer or the managed care organization, who pay for a large percentage of care in the U.S., such organizations pay very little for the direct care of overweight and obesity, other than for surgery (Wylie-Rosett 2001). Comparisons with surgery, however, should optimally include a longer time-horizon than is typically included in behavioral interventions. As overweight and obesity are increasingly considered chronic illnesses, interventions will need to examine the cost-effectiveness over time, as the comparator will increasingly be surgery. Sjöström and colleagues, for example, have conducted a 15-year follow-up study of obese patients treated with different surgical approaches (Sjöström 2007). These durations of follow-up are very challenging for behavioral interventions, given the difficulties in assuring long-term fidelity. Furthermore, in 2011, the U.S. Food and Drug Administration (FDA) lowered the body mass index (BMI) threshold for use of laparoscopic band procedures for those with obesity-related conditions, from a previous BMI of $35 \mathrm{~kg} / \mathrm{m}^{2}$ to $30 \mathrm{~kg} / \mathrm{m}^{2}$ (Corbett Dooren 2011), so the rates of surgical treatment of obesity can be expected to increase. Due to these complexities, conclusions from cost-effectiveness studies in obesity treatment, even well-done ones, can be challenging to make in the ever-shifting landscape of the epidemiology and treatment options for obesity.

Finally, interactive technologies change quickly, so it is quite likely that what is reviewed here will be quite different from the trials reviewed 10 years from now. The increased use of smartphones and sophisticated mobile computing means that a growing number of individuals have a global positioning chip and accelerometer with them at all times. This means that applications such as location-based coupons for healthy foods and real-time step counter feedback are technically possible today and will certainly be incorporated into future interventions. The concurrent rise of social networking and the more than 500 million Facebook users worldwide will, for example, likely herald the rise of peer-based weight control interventions (Madden 2006; Pew 2009). We would anticipate future reviews to include smartphone applications, given the rich interactive features of these devices which now often exceed (e.g. accelerometer) those of personal computers.

\section{Quality of the evidence}

We included one quasi-randomized trial and 17 randomized trials. Most randomized trials did not give details about the methods of randomization, and we were uncertain about the concealment of allocation to treatment and the blinding of outcome assessors in many of the included trials. Incomplete outcome reporting was only considered to be a risk in one trial, and selective reporting and other sources of potential bias were not observed. However, only two trials were rated to have no perceived risk of bias. 
Our inclusion criterion of $80 \%$ or greater follow-up was intended to ensure that included trials were of good quality. We instituted this inclusion criterion because loss to follow-up is a serious threat to the validity of a randomized trial (Guyatt 2001).

Due to the methodological quality of some trials and the heterogeneity of some analyses, the overall quality of the evidence on weight loss and weight maintenance according to the GRADE approach ranged between 'moderate' and 'low'.

\section{Potential biases in the review process}

We excluded several studies from this review because they did not meet the inclusion criterion of at least $80 \%$ follow-up. As mentioned above, this was intended to ensure that the included trials were of high quality. The criterion of $80 \%$ follow-up has been used as a quality criterion by some organizations assessing evidence from randomized controlled trials. The McMaster University Mc-Master Online Rating of Evidence (Health Information Research Unit) uses $80 \%$ follow-up of a randomized controlled trial as a criterion for scientific merit (CITE) and the DynaMed Level of Evidence scheme uses 80\% follow-up of trial participants as a criterion for Level 1 (likely reliable) evidence (DynaMed). However, because it is common for behavioral intervention trials to experience large losses to followup, the effect of this exclusion was to lower the number of trials in this review, reduce the total amount of information available for review outcomes, and decrease the power of reported meta-analyses.

\section{Agreements and disagreements with other studies or reviews}

To date, two systematic reviews have been published that examine the impact of web-based weight control programs among adults (Arem 2010; Neve 2010). In 2010 Arem and Irwin published a systematic review that included nine studies (Arem 2010). The authors observed a wide range of weight losses and made few conclusions, in part because the interventions differed so greatly and treatment adherence rates were low (Arem 2010). In 2010, Neve and colleagues published a review that included 20 studies (Neve 2010). Although this review compared a greater number of studies, the heterogeneity of the research questions posed and study designs, coupled with the small number of studies made conclusions difficult (Neve 2010). Neve and colleagues observed that login frequency was associated with impact, consistent with what has been observed in a number of the individual trials in this review (Cussler 2008; Harvey-Berino 2004; Tate 2001; Tate 2003; Womble 2004).

\section{AUTHORS' CONCLUSIONS}

\section{Implications for practice}

This review indicates that interactive computer-based programs are effective weight loss interventions, and that e-mailed or automated counseling increase the effectiveness of computer-based interventions, although the value of online group chats is unclear. These computer-based programs, however, do not result in weight losses that are equivalent to face-to-face treatments, which typically led to a loss of $7 \%$ to $10 \%$ of body weight over 26 weeks (Foster 2005). Providers, however, have few options to offer to their patients, so programs of less impact are still potentially important to consider as treatment options. In 
addition, a recent large study by Jebb and colleagues of 772 adults observed that those who were referred to and provided free access to Weight Watchers lost an additional $2.3 \mathrm{~kg}(95 \%$ confidence interval (CI) -3.0 to -1.6 ), which is quite similar to the losses of interactive computer-based programs in this review (Jebb 2011). Similarly, while there is less available evidence on the effects of interactive computer-based interventions for weight maintenance, this review suggests that here too, computer-based interventions are more effective than no treatment but less effective than face-to-face interventions. The impact of computer-based interventions appears relatively small when compared to standard of care face-to-face interventions published elsewhere. In-person treatments tend to lead to a loss of $7 \%$ to $10 \%$ of body weight in the first six months (Foster 2005; Franz 2007). This is substantially more than the amount of weight lost at six months in the computer-based intervention groups included in this review, which raises the question of what role these interventions may play in addressing the epidemic of overweight and obesity. Weight losses at this level are below the five percent threshold that the U.S. National Heart, Lung and Blood Institute guidelines suggest will lead to clinical improvement, though a meta-analysis of 25 studies and 4874 participants observed blood pressure reductions of $1.1 \mathrm{~mm} \mathrm{Hg}$ (95\% CI 1.4 to 0.7 ) systolic and $0.9 \mathrm{~mm} \mathrm{Hg}$ (95\% CI 1.3 to 0.6) diastolic for each kilogram of weight lost (National Institutes of Health 2000; Neter 2003). It is likely, therefore, that the weight loss observed in the analyses comparing computer-based interventions to minimal or no treatment controls is clinically significant on an individual and public health level, though weight regain will limit the impact of this benefit. All studies reviewed, however, are efficacy studies and not effectiveness studies, so it is not clear whether these interventions would have the same level of impact if integrated into routine primary care settings. Those studies would first need to be done before the interventions would be ready to be used routinely in clinical settings. In the studies examined, adherence decreased dramatically in the first few months. In Tate 2006 , for example, the average number of logins decreased by approximately $50 \%$ over the first three months in the automated feedback treatment group. Without understanding what level of adherence was clinically significant over the long term, it will be difficult for clinicians to recommend and monitor the use of these interventions. Also, using a web-based intervention is more complicated than taking a pill, so physicians would need to understand what compliance means to these interventions to be able to use them routinely. This question will become more relevant should interventions be shown, in the future, to lead to greater effect sizes or clinical improvements.

\section{Implications for research}

There was not a sufficient number of studies to examine the longer-term impacts of computer-based interventions for weight loss. Only one study (Wylie-Rosett 2001) examined 12-month outcomes versus minimal treatment and only one study (Tate 2003) examined 12-month outcomes as an adjunct to an Internet intervention. Both of these studies, however, showed positive results. All studies that examined utilization of interventions over time showed a drop-off in use. For example, Tate and colleagues observed an average monthly login of greater than 20 in months one to three and fewer than 10 in months 10 to 12 (Tate 2003). This is similar to patterns observed in a later study by this group (Tate 2006). Finally, Wing and colleagues observed that $65.7 \%$ of web sessions attended were attended in months zero to six and 34.2\% in months 13 to 18 (Wing 2006). As 
weight management is an ongoing health issue, both longer-term weight-loss studies and additional studies on weight maintenance are needed, as is additional research on adherence to interventions.

We observed heterogeneity across studies in how adherence to the intervention is expressed, allowing us to make general observations about patterns but making specific conclusions about intervention usage over time difficult. Cussler and colleagues expressed adherence as "percent using a feature at least once per week" (Cussler 2008), Svetkey and colleagues expressed adherence as "percent logging in at least once per month" (Stevens 2008) and Wing and colleagues expressed adherence as the overall "percentage of sessions attended" (Wing 2006). Other studies expressed adherence as mean logins per period of time (Bennett 2010), median logins per period of time (Tate 2006) or simply examined the relationship between quartiles of use and outcomes (Hunter 2008), making comparisons difficult. While beyond the scope of our results, the challenges in comparing adherence data lead to the conclusion that the field would move forward more quickly if standards could be created for expressing adherence rates, both in overall use and in the use of specific features. This is particularly important as all studies that reported the relationship between adherence to the intervention and weight control outcomes observed positive associations. Over time, standards have emerged for reporting weight loss in clinical trials, such as kilograms lost, percent of weight lost and percentage of participants losing five percent and 10 percent of body weight. Similar standards for measuring and reporting adherence may be helpful for advancing the field of computer-based weight interventions, and behavioral interventions more generally.

\section{CHARACTERISTICS OF STUDIES}

\section{Characteristics of included studies [ordered by study ID]}

\begin{tabular}{l|l}
\hline Bennett 2010 & PARALLEL RANDOMIZED CONTROLLED CLINICAL TRIAL \\
\hline Participants & $\begin{array}{l}\text { INCLUSION CRITERIA: weight loss intervention trial. Age } 25 \text { to } 65 \text { years, diagnosed } \\
\text { hypertension and use of hypertension medication, non-smoker for at least } 6 \text { months prior to } \\
\text { recruitment, fluency in English, and home or work access to a computer with Internet access } \\
\text { EXCLUSION CRITERIA: current pregnancy, history of a medical illness that would } \\
\text { prohibit exercise, such as known dementia, cancer or stroke } \\
\text { DIAGNOSTIC CRITERIA: BMI } 30.0 \text { to } 40.0 \mathrm{~kg} / \mathrm{m}^{2} \\
\text { CO-MORBIDITIES: all participants had been diagnosed with hypertension and were taking } \\
\text { hypertension medication } \\
\text { CONCOMITANT TREATMENTS: none }\end{array}$ \\
\hline Interventions & $\begin{array}{l}\text { NUMBER OF STUDY CENTRES: } 1 \\
\text { COUNTRY/LOCATION: USA } \\
\text { SETTING: outpatient/community } \\
\text { TREATMENT BEFORE STUDY: none }\end{array}$ \\
\hline Outcomes & $\begin{array}{l}\text { OUTCOME(S) (as stated in the protocol/registered trial documents): no protocol/ } \\
\text { registered trial documents }\end{array}$ \\
\hline Study details & $\begin{array}{l}\text { RUN-IN PERIOD: no } \\
\text { STUDY TERMINATED BEFORE REGULAR END: no }\end{array}$ \\
\hline Publication details & $\begin{array}{l}\text { LANGUAGE OF PUBLICATION: English } \\
\text { COMMERCIAL FUNDING: Sanofi Aventis } \\
\text { NON-COMMERCIAL FUNDING: authors supported by NCI grants } \\
\text { PUBLICATION STATUS: peer-reviewed journal }\end{array}$ \\
\hline
\end{tabular}




\begin{tabular}{|c|c|c|}
\hline Stated aim of study & \multicolumn{2}{|c|}{$\begin{array}{l}\text { Quote: "We aimed to create a moderate-intensity weight loss intervention that, in contrast to } \\
\text { traditional approaches } \ldots \text { would have minimal barriers to participant uptake, be well suited for } \\
\text { web-based implementation, and be sustainable in a wide range of practice settings." }\end{array}$} \\
\hline \multicolumn{3}{|l|}{ Notes } \\
\hline \multicolumn{3}{|l|}{ Risk of bias } \\
\hline Bias & Authors' judgement & Support for judgement \\
\hline $\begin{array}{l}\text { Random sequence } \\
\text { generation (selection } \\
\text { bias) }\end{array}$ & Unclear risk & Randomized, but method not stated \\
\hline $\begin{array}{l}\text { Allocation } \\
\text { concealment } \\
\text { (selection bias) }\end{array}$ & Low risk & $\begin{array}{l}\text { Randomization assignments enclosed in } \\
\text { nontransparent envelopes }\end{array}$ \\
\hline $\begin{array}{l}\text { Blinding } \\
\text { (performance bias } \\
\text { and detection bias) } \\
\text { All outcomes } \\
\end{array}$ & Low risk & $\begin{array}{l}\text { All research staff collecting evaluation data } \\
\text { blinded to randomization status }\end{array}$ \\
\hline $\begin{array}{l}\text { Incomplete outcome } \\
\text { data (attrition bias) } \\
\text { All outcomes }\end{array}$ & Low risk & $\begin{array}{l}43 \text { out of } 51 \text { participants randomized to the } \\
\text { Intervention group completed the study } \\
42 \text { out of } 50 \text { participants randomized to the usual } \\
\text { care group completed the study } \\
\text { Reason for loss of follow-up in both groups was } \\
\text { inability to contact or discontinued intervention } \\
\text { For intention-to-treat analysis, authors used a } \\
\text { baseline carried forward imputation approach }\end{array}$ \\
\hline $\begin{array}{l}\text { Selective reporting } \\
\text { (reporting bias) }\end{array}$ & Low risk & $\begin{array}{l}\text { All of the outcomes listed in the methods section } \\
\text { were reported as results }\end{array}$ \\
\hline Other bias & Low risk & \\
\hline \multicolumn{3}{|l|}{ Cussler 2008} \\
\hline Methods & \multicolumn{2}{|c|}{ PARALLEL CLUSTER-RANDOMIZED CONTROLLED CLINICAL TRIAL } \\
\hline Participants & \multicolumn{2}{|c|}{$\begin{array}{l}\text { INCLUSION CRITERIA: weight maintenance component of weight loss intervention trial. } \\
\text { Age } 40 \text { to } 55 \text { years, non-smoker and access to a computer that could run an Internet browser } \\
\text { and Java scripts } \\
\text { EXCLUSION CRITERIA: major medical illnesses, participation in any other weight loss } \\
\text { program } \\
\text { DIAGNOSTIC CRITERIA: BMI } 25.0 \text { to } 38.0 \mathrm{~kg} / \mathrm{m}^{2} \text { at start of weight loss intervention } \\
\text { CO-MORBIDITIES: not mentioned } \\
\text { CONCOMITANT TREATMENTS: both groups attended weekly support group meetings }\end{array}$} \\
\hline Interventions & \multicolumn{2}{|c|}{$\begin{array}{l}\text { NUMBER OF STUDY CENTRES: } 1 \\
\text { COUNTRY/LOCATION: USA } \\
\text { SETTING: community } \\
\text { TREATMENT BEFORE STUDY: weight maintenance was preceded by a 4-month } \\
\text { behavioral weight loss intervention }\end{array}$} \\
\hline Outcomes & \multicolumn{2}{|c|}{$\begin{array}{l}\text { OUTCOME(S) (as stated in the protocol/registered trial documents): no protocol/ } \\
\text { registered trial documents }\end{array}$} \\
\hline Study details & \multicolumn{2}{|c|}{$\begin{array}{l}\text { RUN-IN PERIOD: no } \\
\text { STUDY TERMINATED BEFORE REGULAR END: no }\end{array}$} \\
\hline Publication details & \multicolumn{2}{|c|}{$\begin{array}{l}\text { LANGUAGE OF PUBLICATION: English } \\
\text { NON-COMMERCIAL FUNDING: NIH grant } \\
\text { PUBLICATION STATUS: peer-reviewed journal }\end{array}$} \\
\hline Stated aim of study & \multicolumn{2}{|c|}{$\begin{array}{l}\text { Quote: "We hypothesized that } \ldots \text { women assigned to an Internet weight loss maintenance } \\
\text { program would regain less weight than women assigned to a self-directed, maintenance } \\
\text { program." }\end{array}$} \\
\hline Notes & \multicolumn{2}{|c|}{$\begin{array}{l}\text { This trial was cluster-randomized, however the investigators had calculated an effective } \\
\text { sample size. "Because of group randomization, a weeknight group intra class correlation was } \\
\text { calculated using the between-group variance divided by the sum of the between-group } \\
\text { variance plus the within-group variance. For change in weight from baseline to } 4 \text { months, the } \\
\text { intra class correlation was } 0.02 \text {, producing an effective sample size of } 107 \text { " (P. 1055). We used } \\
\text { the effective sample size to adjust the sample size in the control and intervention groups } \\
\text { proportionally for all analyses }\end{array}$} \\
\hline
\end{tabular}




\begin{tabular}{|c|c|c|}
\hline Bias & Authors' judgement & Support for judgement \\
\hline $\begin{array}{l}\text { Random sequence } \\
\text { generation (selection } \\
\text { bias) }\end{array}$ & Unclear risk & randomized, but method not stated \\
\hline $\begin{array}{l}\text { Allocation } \\
\text { concealment } \\
\text { (selection bias) }\end{array}$ & Unclear risk & Not reported \\
\hline $\begin{array}{l}\text { Blinding } \\
\text { (performance bias } \\
\text { and detection bias) } \\
\text { All outcomes }\end{array}$ & Unclear risk & Not reported \\
\hline $\begin{array}{l}\text { Incomplete outcome } \\
\text { data (attrition bias) } \\
\text { All outcomes }\end{array}$ & Low risk & $\begin{array}{l}52 \text { out of } 66 \text { participants randomized to the } \\
\text { Internet group completed the study } \\
59 \text { out of } 69 \text { participants randomized to the self } \\
\text { directed group completed the study } \\
\text { Reasons for loss to follow-up not stated } \\
\text { Baseline observation carried forward method used } \\
\text { for the final body weight of } 24 \text { participants who } \\
\text { did not complete the weight maintenance period. } \\
\text { Missing values for all other measured variables } \\
\text { handled similarly }\end{array}$ \\
\hline $\begin{array}{l}\text { Selective reporting } \\
\text { (reporting bias) }\end{array}$ & Low risk & $\begin{array}{l}\text { All of the outcomes listed in the methods section } \\
\text { were reported as results }\end{array}$ \\
\hline Other bias & Unclear risk & $\begin{array}{l}\text { Risks of bias specific to cluster-randomized trials } \\
\text { were assessed as follows: } \\
\text { Recruitment bias: report stated that groups were } \\
\text { randomized but details of methods or procedure } \\
\text { were not given, therefore prior knowledge of } \\
\text { cluster assignment cannot be absolutely ruled out } \\
\text { Baseline differences: no statistically significant } \\
\text { differences between randomized groups } \\
\text { Missing clusters: not present } \\
\text { Incorrect statistical analysis: not present; the } \\
\text { analysis took clustering into account } \\
\text { Comparability with individually randomized } \\
\text { trials: similar effects were seen in this trial and in } \\
\text { the trials using individual randomization }\end{array}$ \\
\hline \multicolumn{3}{|l|}{ DeLucia 1988} \\
\hline Methods & \multicolumn{2}{|c|}{ PARALLEL RANDOMIZED CONTROLLED CLINICAL TRIAL } \\
\hline Participants & \multicolumn{2}{|c|}{$\begin{array}{l}\text { INCLUSION CRITERIA: weight loss intervention trial. Willing to place USD } 50 \text { deposit } \\
\text { refundable upon completing behavioral program } \\
\text { EXCLUSION CRITERIA: student status, participating in another weight-loss program, } \\
\text { taking medication which might affect weight loss } \\
\text { DIAGNOSTIC CRITERIA: at least } 10 \text { lb overweight } \\
\text { CO-MORBIDITIES: not mentioned } \\
\text { CONCOMITANT TREATMENTS: both treatment groups received Ferguson's (Ferguson } \\
\text { 1975) behavioral intervention for weight loss, composed of stimulus control, environmental } \\
\text { support and homework assignments including keeping of food diaries }\end{array}$} \\
\hline Interventions & \multicolumn{2}{|c|}{$\begin{array}{l}\text { NUMBER OF STUDY CENTRES: } 1 \\
\text { COUNTRY/LOCATION: USA } \\
\text { SETTING: university/community } \\
\text { TREATMENT BEFORE STUDY: none }\end{array}$} \\
\hline Outcomes & \multicolumn{2}{|c|}{$\begin{array}{l}\text { OUTCOME(S) (as stated in the protocol/registered trial documents): no protocol/ } \\
\text { registered trial documents }\end{array}$} \\
\hline Study details & \multicolumn{2}{|c|}{$\begin{array}{l}\text { RUN-IN PERIOD: no } \\
\text { STUDY TERMINATED BEFORE REGULAR END: no }\end{array}$} \\
\hline Publication details & \multicolumn{2}{|c|}{$\begin{array}{l}\text { LANGUAGE OF PUBLICATION: English } \\
\text { COMMERCIAL/NON-COMMERCIAL FUNDING: funding not stated } \\
\text { PUBLICATION STATUS: peer-reviewed journal }\end{array}$} \\
\hline Stated aim of study & \multicolumn{2}{|c|}{$\begin{array}{l}\text { Quote: "The present study was designed to provide a "consumer product evaluation" of two } \\
\text { computer-based nutrition programs as adjuncts to the behavioral treatment of obesity..... }\end{array}$} \\
\hline
\end{tabular}


Should the computer programs prove to be incrementally effective on indices of nutritional knowledge, eating behavior, and/or weight loss, behavioral health specialists might rely on them to provide the necessary nutritional aspects of treatment."

\begin{tabular}{l|l} 
Notes & We contacted the author to obtain the sample size for each intervention group and received a
\end{tabular}
reply with this information on 2 April 2010

For weight outcomes, we calculated the change from baseline following procedures in Chapter 16 of the Cochrane Handbook for Systematic Reviews of Interventions (Higgins 2009). We calculated the correlation coefficient from a weight loss study in this review (Hunter 2008) reporting standard deviations for baseline, endpoint and change values of weight, and used the calculated correlation coefficient to impute the missing standard deviation for the change from baseline

\begin{tabular}{|c|c|}
\hline \multicolumn{2}{|l|}{ Risk of bias } \\
\hline Bias & Authors' judgement \\
\hline $\begin{array}{l}\text { Random sequence } \\
\text { generation (selection } \\
\text { bias) }\end{array}$ & Unclear risk \\
\hline $\begin{array}{l}\text { Allocation } \\
\text { concealment } \\
\text { (selection bias) }\end{array}$ & Unclear risk \\
\hline $\begin{array}{l}\text { Blinding } \\
\text { (performance bias } \\
\text { and detection bias) } \\
\text { All outcomes }\end{array}$ & Unclear risk \\
\hline $\begin{array}{l}\text { Incomplete outcome } \\
\text { data (attrition bias) } \\
\text { All outcomes }\end{array}$ & Low risk \\
\hline $\begin{array}{l}\text { Selective reporting } \\
\text { (reporting bias) }\end{array}$ & Low risk \\
\hline Other bias & Low risk \\
\hline \multicolumn{2}{|l|}{ Gabriele 2011} \\
\hline Methods & PARALLEL RANDOMIZED CONTROLLED CLINICAL TRIAL \\
\hline Participants & $\begin{array}{l}\text { INCLUSION CRITERIA: weight loss intervention trial for adults. Inclusion criteria were: } \\
\text { age } 30 \text { to } 60 \text { years, access to e-mail and BMI of } 25 \text { to } 40 \mathrm{~kg} / \mathrm{m}^{2} \\
\text { EXCLUSION CRITERIA: BMI greater than } 40 \mathrm{~kg} / \mathrm{m}^{2} \text {. History of myocardial infarction, } \\
\text { stroke or cancer in the last } 5 \text { years; joint problems that would prohibit exercise, pregnancy, } \\
\text { psychiatric hospitalization in the previous year, weight loss of more than } 10 \text { pounds during the } \\
\text { previous } 6 \text { months, use of weight loss medications during the previous } 6 \text { months, current use } \\
\text { of medication for which substantial weight gain is a potential side effect, and inability to read } \\
\text { and write English fluently } \\
\text { DIAGNOSTIC CRITERIA: participants had to have a BMI between } 25 \text { and } 40 \mathrm{~kg} / \mathrm{m}^{2} \\
\text { CO-MORBIDITIES: not stated } \\
\text { CONCOMITANT TREATMENTS: no }\end{array}$ \\
\hline Interventions & $\begin{array}{l}\text { NUMBER OF STUDY CENTRES: } 1 \\
\text { COUNTRY/LOCATION: USA } \\
\text { SETTING: academic setting } \\
\text { TREATMENT BEFORE STUDY: none }\end{array}$ \\
\hline Outcomes & $\begin{array}{l}\text { OUTCOME(S) (as stated in the protocol/registered trial documents): no protocol/ } \\
\text { registered trial documents }\end{array}$ \\
\hline Study details & $\begin{array}{l}\text { RUN-IN PERIOD: no } \\
\text { STUDY TERMINATED BEFORE REGULAR END: no }\end{array}$ \\
\hline Publication details & $\begin{array}{l}\text { LANGUAGE OF PUBLICATION: English } \\
\text { NON-COMMERCIAL FUNDING: National Heart, Lung, Blood Institute and Washington } \\
\text { University Dissertation Fellowship } \\
\text { PUBLICATION STATUS: peer-reviewed journal }\end{array}$ \\
\hline Stated aim of study & $\begin{array}{l}\text { Quote: "We hypothesized that participants in the nondirective and directive support conditions } \\
\text { would have greater weight loss, improvements in dietary behavior and physical activity, and } \\
\text { engagement than participants in the minimal support condition. In addition ... we expected } \\
\text { that participants in the nondirective support condition would show greater changes in these } \\
\text { outcomes relative to participants in the directive support condition." }\end{array}$ \\
\hline
\end{tabular}




\begin{tabular}{|c|c|c|}
\hline Notes & & \\
\hline \multicolumn{3}{|l|}{ Risk of bias } \\
\hline Bias & Authors' judgement & Support for judgement \\
\hline $\begin{array}{l}\text { Random sequence } \\
\text { generation (selection } \\
\text { bias) }\end{array}$ & Low risk & $\begin{array}{l}\text { Participants were randomly assigned by drawing a } \\
\text { number. For every } 9 \text { patients enrolled, } 3 \text { were } \\
\text { randomized to each condition }\end{array}$ \\
\hline $\begin{array}{l}\text { Allocation } \\
\text { concealment } \\
\text { (selection bias) }\end{array}$ & Unclear risk & Not reported \\
\hline $\begin{array}{l}\text { Blinding } \\
\text { (performance bias } \\
\text { and detection bias) } \\
\text { All outcomes }\end{array}$ & High risk & $\begin{array}{l}\text { Participants were blinded to treatment condition, } \\
\text { but it is not stated that assessors were also blinded }\end{array}$ \\
\hline $\begin{array}{l}\text { Incomplete outcome } \\
\text { data (attrition bias) } \\
\text { All outcomes }\end{array}$ & Low risk & $\begin{array}{l}31 \text { out of } 34 \text { participants randomized to the } \\
\text { Minimal Support Group completed the study at } 12 \\
\text { weeks } \\
33 \text { out of } 35 \text { randomized to the Non-directive } \\
\text { Support Group completed the study at } 12 \text { weeks } \\
32 \text { out of } 35 \text { randomized to the Directive Support } \\
\text { Group completed the study at } 12 \text { weeks } \\
\text { Intention-to-treat analysis performed }\end{array}$ \\
\hline $\begin{array}{l}\text { Selective reporting } \\
\text { (reporting bias) }\end{array}$ & Low risk & $\begin{array}{l}\text { All of the outcomes listed in the methods section } \\
\text { were reported as results }\end{array}$ \\
\hline Other bias & Low risk & \\
\hline \multicolumn{3}{|l|}{ Harvey-Berino 2002} \\
\hline Methods & \multicolumn{2}{|c|}{ PARALLEL RANDOMIZED CONTROLLED CLINICAL TRIAL } \\
\hline Participants & \multicolumn{2}{|c|}{$\begin{array}{l}\text { INCLUSION CRITERIA: weight maintenance intervention trial. At least } 18 \text { years old, } \\
\text { possess a computer with at least } 16 \text { megabytes of RAM and Windows } 95 \text { or } 98 \text { as a computer } \\
\text { operating system, and access to a } 28.8 \text { kbps Internet connection } \\
\text { EXCLUSION CRITERIA: history of major medical or psychiatric problems, a plan to } \\
\text { become pregnant within the next } 18 \text { months, or inability to participate in an exercise program } \\
\text { DIAGNOSTIC CRITERIA: BMI } \geq 25 \mathrm{~kg} / \mathrm{m}^{2} \text { at start of weight loss intervention } \\
\text { CO-MORBIDITIES: not mentioned } \\
\text { CONCOMITANT TREATMENTS: no }\end{array}$} \\
\hline Interventions & \multicolumn{2}{|c|}{$\begin{array}{l}\text { NUMBER OF STUDY CENTRES: } 1 \\
\text { COUNTRY/LOCATION: USA } \\
\text { SETTING: community } \\
\text { TREATMENT BEFORE STUDY: all participants participated in a 24-week behavioral } \\
\text { weight control program before they were told what weight maintenance condition they had } \\
\text { been randomized to }\end{array}$} \\
\hline Outcomes & \multicolumn{2}{|c|}{$\begin{array}{l}\text { OUTCOME(S) (as stated in the protocol/registered trial documents): no protocol/ } \\
\text { registered trial documents }\end{array}$} \\
\hline Study details & \multicolumn{2}{|c|}{$\begin{array}{l}\text { RUN-IN PERIOD: no } \\
\text { STUDY TERMINATED BEFORE REGULAR END: no }\end{array}$} \\
\hline Publication details & \multicolumn{2}{|c|}{$\begin{array}{l}\text { LANGUAGE OF PUBLICATION: English } \\
\text { NON-COMMERCIAL FUNDING: USDA Hatch Act Funds (HA 593) } \\
\text { PUBLICATION STATUS: peer-reviewed journal }\end{array}$} \\
\hline Stated aim of study & \multicolumn{2}{|c|}{$\begin{array}{l}\text { Quote: "[T]he purpose of this study was to test a novel approach to sustaining long-term } \\
\text { contact with individuals following participation in a structured behavioral weight loss } \\
\text { program. We hypothesized that individuals in the Internet condition would maintain more } \\
\text { weight loss than those in the comparable in-person condition." }\end{array}$} \\
\hline Notes & \multicolumn{2}{|c|}{$\begin{array}{l}\text { In August } 2010 \text { we e-mailed the author for information on weight maintenance outcomes at } 12 \\
\text { months of maintenance. We were unable to obtain any response and therefore extracted data } \\
\text { for overall change between the start of the } 6 \text {-month weight loss segment of the trial and the } \\
\text { end of the } 12 \text {-month weight loss segment of the trial }\end{array}$} \\
\hline \multicolumn{3}{|l|}{ Risk of bias } \\
\hline Bias & Authors' judgement & Support for judgement \\
\hline
\end{tabular}




\begin{tabular}{|c|c|c|}
\hline $\begin{array}{l}\text { Random sequence } \\
\text { generation (selection } \\
\text { bias) }\end{array}$ & Unclear risk & randomized, but method not stated \\
\hline $\begin{array}{l}\text { Allocation } \\
\text { concealment } \\
\text { (selection bias) }\end{array}$ & Unclear risk & Not reported \\
\hline $\begin{array}{l}\text { Blinding } \\
\text { (performance bias } \\
\text { and detection bias) } \\
\text { All outcomes }\end{array}$ & Unclear risk & Not reported \\
\hline $\begin{array}{l}\text { Incomplete outcome } \\
\text { data (attrition bias) } \\
\text { All outcomes }\end{array}$ & Low risk & $\begin{array}{l}100 \text { out of } 122 \text { participants completed the study at } \\
6 \text { months } \\
92 \text { out of } 122 \text { participants completed the study at } \\
18 \text { months } \\
90 \text { out of } 122 \text { participants had complete data for } \\
\text { all measures } \\
\text { Data were examined using both an intention- to- } \\
\text { treat analysis and with those having complete data } \\
\text { for all measures (90) }\end{array}$ \\
\hline $\begin{array}{l}\text { Selective reporting } \\
\text { (reporting bias) }\end{array}$ & Low risk & $\begin{array}{l}\text { All of the outcomes listed in the methods section } \\
\text { were reported as results }\end{array}$ \\
\hline Other bias & Low risk & \\
\hline \multicolumn{3}{|l|}{ Harvey-Berino 2010} \\
\hline Methods & \multicolumn{2}{|c|}{ PARALLEL RANDOMIZED CONTROLLED CLINICAL TRIAL } \\
\hline Participants & \multicolumn{2}{|c|}{$\begin{array}{l}\text { INCLUSION CRITERIA: weight loss intervention trial. Adults with a BMI between } 25 \text { and } \\
50 \mathrm{~kg} / \mathrm{m}^{2} \text { and access to a computer with an Internet connection. } \\
\text { EXCLUSION CRITERIA: history of major medical or psychiatric problems, a planned or } \\
\text { recent pregnancy, medical conditions that would prohibit exercise, or a schedule that would } \\
\text { prohibit or restrict attendance at a designated time for weekly group meetings } \\
\text { DIAGNOSTIC CRITERIA: BMI between } 25 \text { and } 50 \mathrm{~kg} / \mathrm{m}^{2} \\
\text { CO-MORBIDITIES: not mentioned } \\
\text { CONCOMITANT TREATMENTS: no }\end{array}$} \\
\hline Interventions & \multicolumn{2}{|c|}{$\begin{array}{l}\text { NUMBER OF STUDY CENTRES: } 2 \\
\text { COUNTRY/LOCATION: USA } \\
\text { SETTING: outpatient clinical centres } \\
\text { TREATMENT BEFORE STUDY: none }\end{array}$} \\
\hline Outcomes & \multicolumn{2}{|c|}{$\begin{array}{l}\text { OUTCOME(S) (as stated in the protocol/registered trial documents): "Primary Outcome } \\
\text { Measures: Body Mass Index or body weight change." } \\
\text { (ClinicalTrials.gov Identifier NCT00265954) }\end{array}$} \\
\hline Study details & \multicolumn{2}{|c|}{$\begin{array}{l}\text { RUN-IN PERIOD: no } \\
\text { STUDY TERMINATED BEFORE REGULAR END: no }\end{array}$} \\
\hline Publication details & \multicolumn{2}{|c|}{$\begin{array}{l}\text { LANGUAGE OF PUBLICATION: English } \\
\text { NON-COMMERCIAL FUNDING: National Institute of Diabetes and Digestive and Kidney } \\
\text { Diseases (NIDDK) } \\
\text { PUBLICATION STATUS: peer-reviewed journal }\end{array}$} \\
\hline Stated aim of study & \multicolumn{2}{|c|}{$\begin{array}{l}\text { Quote: "[T]he purpose of this study was to directly evaluate the comparative efficacy of a } \\
\text { comprehensive behavioral weight loss treatment program delivered online with the same } \\
\text { program delivered in-person and with an innovative combined in-person and online approach." }\end{array}$} \\
\hline \multicolumn{3}{|l|}{ Notes } \\
\hline \multicolumn{3}{|l|}{ Risk of bias } \\
\hline Bias & Authors' judgement & Support for judgement \\
\hline $\begin{array}{l}\text { Random sequence } \\
\text { generation (selection } \\
\text { bias) }\end{array}$ & Low risk & $\begin{array}{l}\text { Participants were randomized using a biased coin } \\
\text { approach }\end{array}$ \\
\hline $\begin{array}{l}\text { Allocation } \\
\text { concealment } \\
\text { (selection bias) }\end{array}$ & Unclear risk & Not reported \\
\hline
\end{tabular}




\begin{tabular}{|c|c|c|}
\hline $\begin{array}{l}\text { Blinding } \\
\text { (performance bias } \\
\text { and detection bias) } \\
\text { All outcomes }\end{array}$ & Unclear risk & Not reported \\
\hline $\begin{array}{l}\text { Incomplete outcome } \\
\text { data (attrition bias) } \\
\text { All outcomes }\end{array}$ & Low risk & $\begin{array}{l}150 \text { out of } 158 \text { participants randomized to the In- } \\
\text { Person group completed the study at } 6 \text { months } \\
153 \text { out of } 162 \text { participants randomized to the } \\
\text { Hybrid group completed the study at } 6 \text { months } \\
159 \text { out of } 161 \text { participants randomized to the } \\
\text { Internet group completed the study at } 6 \text { months }\end{array}$ \\
\hline $\begin{array}{l}\text { Selective reporting } \\
\text { (reporting bias) }\end{array}$ & Low risk & $\begin{array}{l}\text { All outcomes mentioned in the methods section } \\
\text { were reported as results }\end{array}$ \\
\hline Other bias & Low risk & \\
\hline \multicolumn{3}{|l|}{ Hunter 2008} \\
\hline Methods & \multicolumn{2}{|c|}{ PARALLEL RANDOMIZED CONTROLLED CLINICAL TRIAL } \\
\hline Participants & \multicolumn{2}{|c|}{$\begin{array}{l}\text { INCLUSION CRITERIA: weight loss intervention trial. Age between } 18 \text { and } 65 \text {, availability } \\
\text { of a personal computer with Internet access, and plans to remain in the local area for } 1 \text { year } \\
\text { EXCLUSION CRITERIA: loss of more than } 10 \text { pounds in the previous } 3 \text { months, use of } \\
\text { prescription or over-the-counter weight-loss medications in the previous } 6 \text { months, any } \\
\text { physical activity restrictions, history of myocardial infarction, stroke or cancer in the last year, } \\
\text { reported diabetes, angina or thyroid difficulties, or had orthopedic or joint problems that would } \\
\text { prohibit exercise. Women were excluded if they were pregnant or breast-feeding, or planned to } \\
\text { become pregnant within the next year } \\
\text { DIAGNOSTIC CRITERIA: weight } 5 \text { pounds or more above the maximum allowable weight } \\
\text { for the US Air Force. Maximum allowable weight corresponds to BMI = } 25 \text { in women and } \\
\text { BMI = } 27.5 \text { in men for most heights } \\
\text { CO-MORBIDITIES: not mentioned } \\
\text { CONCOMITANT TREATMENTS: no }\end{array}$} \\
\hline Interventions & \multicolumn{2}{|c|}{$\begin{array}{l}\text { NUMBER OF STUDY CENTRES: } 1 \\
\text { COUNTRY/LOCATION: USA } \\
\text { SETTING: military medical research centre } \\
\text { TREATMENT BEFORE STUDY: none }\end{array}$} \\
\hline Outcomes & \multicolumn{2}{|c|}{$\begin{array}{l}\text { OUTCOME(S) (as stated in the protocol/registered trial documents): no protocol/ } \\
\text { registered trial documents }\end{array}$} \\
\hline Study details & \multicolumn{2}{|c|}{$\begin{array}{l}\text { RUN-IN PERIOD: no } \\
\text { STUDY TERMINATED BEFORE REGULAR END: no }\end{array}$} \\
\hline Publication details & \multicolumn{2}{|c|}{$\begin{array}{l}\text { LANGUAGE OF PUBLICATION: English } \\
\text { NON-COMMERCIAL FUNDING: US Department of Defense } \\
\text { PUBLICATION STATUS: peer-reviewed journal }\end{array}$} \\
\hline Stated aim of study & \multicolumn{2}{|c|}{$\begin{array}{l}\text { Quote: "It was hypothesized that those in the Internet-based program would, as a group, } \\
\text { demonstrate the prevention of weight gain or small-to-moderate weight losses. It was further } \\
\text { hypothesized that participants in the usual-care condition would not show any weight loss and } \\
\text { would, in fact, gain weight over the 6-month period from baseline to reassessment." }\end{array}$} \\
\hline \multicolumn{3}{|l|}{ Notes } \\
\hline \multicolumn{3}{|l|}{ Risk of bias } \\
\hline Bias & Authors' judgement & Support for judgement \\
\hline $\begin{array}{l}\text { Random sequence } \\
\text { generation (selection } \\
\text { bias) }\end{array}$ & Low risk & $\begin{array}{l}\text { Randomization was conducted using a random- } \\
\text { numbers table }\end{array}$ \\
\hline $\begin{array}{l}\text { Allocation } \\
\text { concealment } \\
\text { (selection bias) }\end{array}$ & Unclear risk & Not reported \\
\hline $\begin{array}{l}\text { Blinding } \\
\text { (performance bias } \\
\text { and detection bias) } \\
\text { All outcomes }\end{array}$ & High risk & States study could not be blinded \\
\hline $\begin{array}{l}\text { Incomplete outcome } \\
\text { data (attrition bias) } \\
\text { All outcomes }\end{array}$ & Low risk & $\begin{array}{l}206 \text { of the } 224 \text { participants randomized to usual } \\
\text { care completed the study }\end{array}$ \\
\hline
\end{tabular}




\begin{tabular}{|c|c|c|}
\hline & & $\begin{array}{l}193 \text { of the } 227 \text { participants randomized to the } \\
\text { behavioral Internet-based program completed the } \\
\text { study } \\
\text { In both cases reasons given were: leaving the } \\
\text { local area, medical reasons and the wish to } \\
\text { withdraw } \\
\text { Intention-to-treat analysis used using the baseline } \\
\text { observation carried forward approach }\end{array}$ \\
\hline $\begin{array}{l}\text { Selective reporting } \\
\text { (reporting bias) }\end{array}$ & Low risk & $\begin{array}{l}\text { All outcomes mentioned in the methods section } \\
\text { were reported as results }\end{array}$ \\
\hline Other bias & Low risk & \\
\hline \multicolumn{3}{|l|}{ Morgan 2009} \\
\hline Methods & \multicolumn{2}{|c|}{ PARALLEL RANDOMIZED CONTROLLED CLINICAL TRIAL } \\
\hline Participants & \multicolumn{2}{|c|}{$\begin{array}{l}\text { INCLUSION CRITERIA: weight loss intervention trial. Adult men who are overweight or } \\
\text { obese and have access to a computer with e-mail and Internet facilities } \\
\text { EXCLUSION CRITERIA: history of major medical problems such as heart disease in the } \\
\text { past } 5 \text { years, diabetes, orthopedic or joint problems that would be a barrier to physical activity; } \\
\text { recent weight loss of } 4.5 \mathrm{~kg} \text { or more; or taking medications that might affect body weight } \\
\text { DIAGNOSTIC CRITERIA: BMI between } 25 \text { and } 37 \mathrm{~kg} / \mathrm{m}^{2} \\
\text { CO-MORBIDITIES: not mentioned } \\
\text { CONCOMITANT TREATMENTS: no }\end{array}$} \\
\hline Interventions & \multicolumn{2}{|c|}{$\begin{array}{l}\text { NUMBER OF STUDY CENTRES: } 1 \\
\text { COUNTRY/LOCATION: Australia } \\
\text { SETTING: community/university } \\
\text { TREATMENT BEFORE STUDY: none }\end{array}$} \\
\hline Outcomes & \multicolumn{2}{|c|}{$\begin{array}{l}\text { OUTCOME(S) (as stated in the protocol/registered trial documents): change in body } \\
\text { weight }(\mathrm{kg}) \\
\text { (Australian New Zealand Clinical Trials Registry No: ANZCTRN12607000481471) }\end{array}$} \\
\hline Study details & \multicolumn{2}{|c|}{$\begin{array}{l}\text { RUN-IN PERIOD: no } \\
\text { STUDY TERMINATED BEFORE REGULAR END: no }\end{array}$} \\
\hline Publication details & \multicolumn{2}{|c|}{$\begin{array}{l}\text { LANGUAGE OF PUBLICATION: English } \\
\text { NON-COMMERCIAL FUNDING: University of Newcastle strategic pilot grant } \\
\text { PUBLICATION STATUS: peer-reviewed journal }\end{array}$} \\
\hline Stated aim of study & \multicolumn{2}{|c|}{$\begin{array}{l}\text { Quote: "The primary aim of our assessor-blinded randomized controlled trial was to evaluate } \\
\text { the feasibility and efficacy of an Internet-based weight-loss program for over-weight men." }\end{array}$} \\
\hline \multicolumn{3}{|l|}{ Notes } \\
\hline \multicolumn{3}{|l|}{ Risk of bias } \\
\hline Bias & Authors' judgement & Support for judgement \\
\hline $\begin{array}{l}\text { Random sequence } \\
\text { generation (selection } \\
\text { bias) }\end{array}$ & Low risk & $\begin{array}{l}\text { Randomization was generated by computer-based } \\
\text { random number-producing algorithm }\end{array}$ \\
\hline $\begin{array}{l}\text { Allocation } \\
\text { concealment } \\
\text { (selection bias) }\end{array}$ & Low risk & Reported that allocation sequence was concealed \\
\hline $\begin{array}{l}\text { Blinding } \\
\text { (performance bias } \\
\text { and detection bias) } \\
\text { All outcomes }\end{array}$ & Low risk & $\begin{array}{l}\text { Participants blind to group allocation at baseline } \\
\text { assessment } \\
\text { Assessors blinded to treatment allocation at all } \\
\text { time points }\end{array}$ \\
\hline $\begin{array}{l}\text { Incomplete outcome } \\
\text { data (attrition bias) } \\
\text { All outcomes }\end{array}$ & Low risk & $\begin{array}{l}28 \text { out of the } 34 \text { participants assigned to Internet } \\
\text { group completed the study } \\
26 \text { out of the } 31 \text { participants assigned to } \\
\text { Information and Self Help group completed the } \\
\text { study } \\
\text { Reasons for loss to follow-up were: personal } \\
\text { reasons, no contact, unavailable, death and moved } \\
\text { interstate } \\
\text { Intention-to-treat analysis included all } \\
\text { randomized participants. Authors used linear } \\
\text { mixed models to assess analysis of effects of } \\
\text { losses to follow-up }\end{array}$ \\
\hline
\end{tabular}




\begin{tabular}{|c|c|c|}
\hline $\begin{array}{l}\text { Selective reporting } \\
\text { (reporting bias) }\end{array}$ & Low risk & $\begin{array}{l}\text { All outcomes mentioned in the methods section } \\
\text { were reported as results }\end{array}$ \\
\hline Other bias & Low risk & \\
\hline \multicolumn{3}{|l|}{ Morgan 2011} \\
\hline Methods & \multicolumn{2}{|c|}{ PARALLEL CLUSTER-RANDOMIZED CONTROLLED CLINICAL TRIAL } \\
\hline Participants & \multicolumn{2}{|c|}{$\begin{array}{l}\text { INCLUSION CRITERIA: weight loss intervention trial. Adult men aged } 18 \text { to } 65 \text { years with } \\
\text { a BMI between } 25 \text { and } 40 \mathrm{~kg} / \mathrm{m}^{2} \text {. Completion of a pre-exercise risk assessment screening } \\
\text { questionnaire was required } \\
\text { EXCLUSION CRITERIA: history of major medical problems such as heart disease in the } \\
\text { last } 5 \text { years, diabetes, orthopedic or joint problems that would be a barrier to physical activity, } \\
\text { recent weight loss of >=4.5 } \mathrm{kg} \text {, or taking medications that might affect body weight } \\
\text { DIAGNOSTIC CRITERIA: BMI between } 25 \text { and } 40 \mathrm{~kg} / \mathrm{m}^{2} \\
\text { CO-MORBIDITIES: none specified } \\
\text { CONCOMITANT TREATMENTS: no }\end{array}$} \\
\hline Interventions & \multicolumn{2}{|c|}{$\begin{array}{l}\text { NUMBER OF STUDY CENTRES: } 1 \\
\text { COUNTRY/LOCATION: Australia } \\
\text { SETTING: workplace (Tomago Aluminium) } \\
\text { TREATMENT BEFORE STUDY: none }\end{array}$} \\
\hline Outcomes & \multicolumn{2}{|c|}{$\begin{array}{l}\text { OUTCOME(S) (as stated in the protocol/registered trial documents): change in body } \\
\text { weight }(\mathrm{kg}) \\
\text { (Australian New Zealand Clinical Trials Registry No: ANZCTRN12609001003268) }\end{array}$} \\
\hline Study details & \multicolumn{2}{|c|}{$\begin{array}{l}\text { RUN-IN PERIOD: no } \\
\text { STUDY TERMINATED BEFORE REGULAR END: no }\end{array}$} \\
\hline Publication details & \multicolumn{2}{|c|}{$\begin{array}{l}\text { LANGUAGE OF PUBLICATION: English } \\
\text { COMMERCIAL FUNDING: Tomago Aluminium and Hunter Medical Research Institute } \\
\text { PUBLICATION STATUS: peer-reviewed journal }\end{array}$} \\
\hline Stated aim of study & \multicolumn{2}{|c|}{$\begin{array}{l}\text { Quote: "The primary aim of this study was to evaluate the feasibility and efficacy of a } \\
\text { workplace-based weight loss program that targeted overweight and obese male shift workers. } \\
\text { We hypothesized that weight and health-related outcomes and behaviors of men would } \\
\text { improve in the intervention group when compared to a wait-list control group." }\end{array}$} \\
\hline Notes & \multicolumn{2}{|c|}{$\begin{array}{l}\text { We e-mailed the author for information about the confidence interval for weight loss in the } \\
\text { control group of the trial, and received a reply with the requested information (95\% CI-1.017 } \\
\text { to 1.7) on } 25 \text { August } 2011 \\
\text { This trial is cluster-randomized. We contacted the author to confirm that data presented in the } \\
\text { publication were adjusted for clustering. On } 4 \text { September } 2011 \text { we received an e-mail stating } \\
\text { that "[T]he means in Table } 5 \text { are adjusted for clustering." We therefore used the statistics and } \\
\text { sample sizes in Table } 5 \text { for our analyses without further adjustment }\end{array}$} \\
\hline \multicolumn{3}{|l|}{ Risk of bias } \\
\hline Bias & Authors' judgement & Support for judgement \\
\hline $\begin{array}{l}\text { Random sequence } \\
\text { generation (selection } \\
\text { bias) }\end{array}$ & Low risk & $\begin{array}{l}\text { Participants were cluster-randomized based on } \\
\text { timing and rotation of work shifts. Random } \\
\text { allocation sequence generated by a computer- } \\
\text { based random number-producing algorithm }\end{array}$ \\
\hline $\begin{array}{l}\text { Allocation } \\
\text { concealment } \\
\text { (selection bias) }\end{array}$ & Low risk & $\begin{array}{l}\text { Randomization and participant study arm } \\
\text { assignment completed by a researcher not } \\
\text { involved in participant assessment, and allocation } \\
\text { sequence concealed when enrolling participants }\end{array}$ \\
\hline $\begin{array}{l}\text { Blinding } \\
\text { (performance bias } \\
\text { and detection bias) } \\
\text { All outcomes }\end{array}$ & High risk & $\begin{array}{l}\text { States that participants and assessors were blind to } \\
\text { group allocation at baseline assessment, but it is } \\
\text { not stated that assessors were still blind at 14- } \\
\text { week follow-up }\end{array}$ \\
\hline $\begin{array}{l}\text { Incomplete outcome } \\
\text { data (attrition bias) } \\
\text { All outcomes }\end{array}$ & Low risk & $\begin{array}{l}54 \text { out of } 65 \text { participants randomized to the } \\
\text { intervention group completed the study at } 14 \\
\text { weeks } \\
36 \text { out of } 45 \text { participants randomized to the } \\
\text { control group completed the study at } 14 \text { weeks } \\
\text { Intention-to-treat analysis used }\end{array}$ \\
\hline $\begin{array}{l}\text { Selective reporting } \\
\text { (reporting bias) }\end{array}$ & Low risk & $\begin{array}{l}\text { All outcomes mentioned in the methods section } \\
\text { were reported as results }\end{array}$ \\
\hline
\end{tabular}




\begin{tabular}{|c|c|c|}
\hline Other bias & Unclear risk & $\begin{array}{l}\text { Risks of bias specific to cluster-randomized trials } \\
\text { were assessed as follows: } \\
\text { Recruitment bias: report did not provide details of } \\
\text { the cluster-randomization procedure, therefore } \\
\text { prior knowledge of cluster assignment cannot be } \\
\text { absolutely ruled out } \\
\text { Baseline differences: no statistically significant } \\
\text { differences between randomized groups } \\
\text { Missing clusters: not present } \\
\text { Incorrect statistical analysis: not present; the } \\
\text { analysis took clustering into account } \\
\text { Comparability with individually randomized } \\
\text { trials: similar effects were seen in this trial and in } \\
\text { the trials using individual randomization, with the } \\
\text { exception of a larger effect size for decrease in } \\
\text { waist measurement. Since all other effects of the } \\
\text { intervention were comparable to the individually } \\
\text { randomized trials, it is not likely that the } \\
\text { difference in waist measurement is due to cluster- } \\
\text { randomization }\end{array}$ \\
\hline \multicolumn{3}{|l|}{ Schroder 2010} \\
\hline Methods & \multicolumn{2}{|c|}{ PARALLEL QUASI-RANDOMIZED CONTROLLED CLINICAL TRIAL } \\
\hline Participants & \multicolumn{2}{|c|}{$\begin{array}{l}\text { INCLUSION CRITERIA: weight loss intervention trial. Age } 25 \text { to } 65 \text { years, a BMI of } 27 \\
\mathrm{~kg} / \mathrm{m}^{2} \text { or more, fluency in English and daily access to a computer with a Windows operating } \\
\text { system, Internet access and a valid e-mail account } \\
\text { EXCLUSION CRITERIA: diagnosis of diabetes, hypercholesterolemia or a mental disorder, } \\
\text { enrolment in an alternative weight loss program, or having a friend or relative already enrolled } \\
\text { in the study } \\
\text { DIAGNOSTIC CRITERIA: BMI } 27.0 \mathrm{~kg} / \mathrm{m}^{2} \text { or greater } \\
\text { CO-MORBIDITIES: not mentioned } \\
\text { CONCOMITANT TREATMENTS: none }\end{array}$} \\
\hline Interventions & \multicolumn{2}{|c|}{$\begin{array}{l}\text { NUMBER OF STUDY CENTRES: } 1 \\
\text { COUNTRY/LOCATION: USA } \\
\text { SETTING: outpatient/community } \\
\text { TREATMENT BEFORE STUDY: None }\end{array}$} \\
\hline Outcomes & \multicolumn{2}{|c|}{$\begin{array}{l}\text { OUTCOME(S) (as stated in the protocol/registered trial documents): no protocol/ } \\
\text { registered trial documents }\end{array}$} \\
\hline Study details & \multicolumn{2}{|c|}{$\begin{array}{l}\text { RUN-IN PERIOD: no } \\
\text { STUDY TERMINATED BEFORE REGULAR END: no }\end{array}$} \\
\hline Publication details & \multicolumn{2}{|c|}{$\begin{array}{l}\text { LANGUAGE OF PUBLICATION: English } \\
\text { NON-COMMERCIAL FUNDING: grant from Utah State University } \\
\text { PUBLICATION STATUS: peer-reviewed journal }\end{array}$} \\
\hline Stated aim of study & \multicolumn{2}{|c|}{$\begin{array}{l}\text { Quote: "The following hypotheses were tested: (1) A brief CAD intervention will support } \\
\text { initial weight loss relative to a no-treatment wait list control condition. (2) Compared to a } \\
\text { CAD-only condition, CAD augmented with a self-management group (CAD+G) intervention } \\
\text { will further enhance its effectiveness and improve the maintenance of weight loss over a } \\
\text { longer period of time." }\end{array}$} \\
\hline Notes & \multicolumn{2}{|c|}{$\begin{array}{l}\text { We calculated the change from baseline following procedures in Chapter } 16 \text { of the Cochrane } \\
\text { Handbook for Systematic Reviews of Interventions (Higgins 2009). We calculated the } \\
\text { correlation coefficient from a weight loss study in this review (Hunter 2008) reporting } \\
\text { standard deviations for baseline, endpoint and change values of weight, and used the } \\
\text { calculated correlation coefficient to impute the missing standard deviation for the change from } \\
\text { baseline }\end{array}$} \\
\hline \multicolumn{3}{|l|}{ Risk of bias } \\
\hline Bias & Authors' judgement & Support for judgement \\
\hline $\begin{array}{l}\text { Random sequence } \\
\text { generation (selection } \\
\text { bias) }\end{array}$ & High risk & $\begin{array}{l}\text { First author randomly assigned participants, } \\
\text { separately by gender, in the order of their entry } \\
\text { into the study, with every third participant being } \\
\text { assigned to CAD, CAD+G and control groups }\end{array}$ \\
\hline $\begin{array}{l}\text { Allocation } \\
\text { concealment } \\
\text { (selection bias) }\end{array}$ & High risk & No randomization sequence generated to conceal \\
\hline
\end{tabular}




\begin{tabular}{|c|c|c|}
\hline $\begin{array}{l}\text { Blinding } \\
\text { (performance bias } \\
\text { and detection bias) } \\
\text { All outcomes }\end{array}$ & High risk & $\begin{array}{l}\text { First author was aware of assignations, } \\
\text { participants were informed about their group } \\
\text { assignment, but research team members were } \\
\text { blind to the type of intervention assignments }\end{array}$ \\
\hline $\begin{array}{l}\text { Incomplete outcome } \\
\text { data (attrition bias) } \\
\text { All outcomes }\end{array}$ & Low risk & $\begin{array}{l}24 \text { out of } 30 \text { assigned to the CAD group } \\
\text { completed the } 3 \text {-month follow-up } \\
26 \text { out of } 31 \text { assigned to the CAD+G group } \\
\text { completed } 3 \text {-month follow-up } \\
26 \text { out of } 30 \text { assigned to the wait list control group } \\
\text { completed } 3 \text { month-follow-up } \\
\text { No details given for patient dropout } \\
\text { Intention-to-treat analysis used. Missing data } \\
\text { points replaced with pre-intervention scores }\end{array}$ \\
\hline $\begin{array}{l}\text { Selective reporting } \\
\text { (reporting bias) }\end{array}$ & Low risk & $\begin{array}{l}\text { All outcomes mentioned in the methods section } \\
\text { were reported as results }\end{array}$ \\
\hline Other bias & Low risk & \\
\hline \multicolumn{3}{|l|}{ Svetkey 2008} \\
\hline Methods & \multicolumn{2}{|c|}{ PARALLEL RANDOMIZED CONTROLLED CLINICAL TRIAL } \\
\hline Participants & \multicolumn{2}{|c|}{$\begin{array}{l}\text { INCLUSION CRITERIA: weight maintenance intervention trial for adults who had } \\
\text { completed a 6-month weight loss program. Inclusion criteria for the weight loss program were: } \\
\text { taking medication for hypertension, dyslipidemia, or both; having access to a telephone and } \\
\text { the Internet; and keeping a food diary for } 5 \text { days during the screening period } \\
\text { EXCLUSION CRITERIA: exclusion criteria for the weight loss program were: active } \\
\text { cardiovascular disease or a recent cardiovascular event; medication-treated diabetes mellitus, } \\
\text { or any other medical or psychiatric condition that would preclude full participation in the } \\
\text { study; weight loss of more than } 9 \text { kg in the previous } 3 \text { months; recent use of weight loss } \\
\text { medications; and prior weight loss surgery } \\
\text { DIAGNOSTIC CRITERIA: at the beginning of the weight loss intervention, participants had } \\
\text { to have a BMI between } 25 \text { and } 45 \text {. In order to be randomized to the weight maintenance trial, } \\
\text { participants had to have lost at least } 4 \text { kg during the weight loss program } \\
\text { CO-MORBIDITIES: all participants were taking medication for hypertension or } \\
\text { dyslipidemia } \\
\text { CONCOMITANT TREATMENTS: no }\end{array}$} \\
\hline Interventions & \multicolumn{2}{|c|}{$\begin{array}{l}\text { NUMBER OF STUDY CENTRES: } 4 \\
\text { COUNTRY/LOCATION: USA } \\
\text { SETTING: academic medical centres } \\
\text { TREATMENT BEFORE STUDY: all participants had participated in a 6-month behavioral } \\
\text { weight control program before randomization to weight maintenance conditions }\end{array}$} \\
\hline Outcomes & \multicolumn{2}{|c|}{$\begin{array}{l}\text { OUTCOME(S) (as stated in the protocol/registered trial documents): "The primary } \\
\text { outcome will be weight change from the end of the initial weight loss program to the end of } \\
\text { the } 30 \text {-month weight maintenance intervention period." } \\
\text { (ClinicalTrials.gov Identifier NCT00054925) }\end{array}$} \\
\hline Study details & \multicolumn{2}{|c|}{$\begin{array}{l}\text { RUN-IN PERIOD: no } \\
\text { STUDY TERMINATED BEFORE REGULAR END: no }\end{array}$} \\
\hline Publication details & \multicolumn{2}{|c|}{$\begin{array}{l}\text { LANGUAGE OF PUBLICATION: English } \\
\text { NON-COMMERCIAL FUNDING: National Heart, Lung, Blood Institute of the NIH } \\
\text { PUBLICATION STATUS: peer-reviewed journal }\end{array}$} \\
\hline Stated aim of study & \multicolumn{2}{|c|}{$\begin{array}{l}\text { Quote: "To compare two weight loss maintenance interventions [monthly personal contact or } \\
\text { unlimited access to an interactive technology-based intervention] with a self-directed control } \\
\text { group." }\end{array}$} \\
\hline \multicolumn{3}{|l|}{ Notes } \\
\hline \multicolumn{3}{|l|}{ Risk of bias } \\
\hline Bias & Authors' judgement & Support for judgement \\
\hline $\begin{array}{l}\text { Random sequence } \\
\text { generation (selection } \\
\text { bias) }\end{array}$ & Low risk & $\begin{array}{l}\text { Randomization assignments were stratified by } \\
\text { clinic, race and amount of weight loss during } \\
\text { phase } 1 \text { and were allocated in blocks. Allocation } \\
\text { was generated using a password-restricted, web- } \\
\text { based application }\end{array}$ \\
\hline $\begin{array}{l}\text { Allocation } \\
\text { concealment } \\
\text { (selection bias) }\end{array}$ & Low risk & $\begin{array}{l}\text { The allocation assignments were accessible only } \\
\text { to authorized unblinded personnel }\end{array}$ \\
\hline
\end{tabular}




\begin{tabular}{|c|c|c|}
\hline $\begin{array}{l}\text { Blinding } \\
\text { (performance bias } \\
\text { and detection bias) } \\
\text { All outcomes }\end{array}$ & Low risk & $\begin{array}{l}\text { States that measurements were taken by staff } \\
\text { members masked to treatment assignment }\end{array}$ \\
\hline $\begin{array}{l}\text { Incomplete outcome } \\
\text { data (attrition bias) } \\
\text { All outcomes }\end{array}$ & Low risk & $\begin{array}{l}320 \text { out of } 342 \text { randomized to the self directed } \\
\text { weight loss maintenance arm completed the study } \\
\text { at } 30 \text {-month follow-up } \\
323 \text { out of } 348 \text { randomized to the interactive } \\
\text { technology arm completed the study at } 30 \text {-month } \\
\text { follow-up } \\
321 \text { out of } 342 \text { randomized to the personal-contact } \\
\text { arm completed the study at } 30 \text {-month follow-up } \\
\text { Reasons given for loss to follow-up were missed } \\
\text { visits or death in all cases } \\
\text { Multiple imputation used to replace missing end- } \\
\text { of-study weights, missing interim weights and } \\
\text { other measures (apart from weights missing due } \\
\text { to participant death). All randomized surviving } \\
\text { participants included in primary outcome analysis }\end{array}$ \\
\hline $\begin{array}{l}\text { Selective reporting } \\
\text { (reporting bias) }\end{array}$ & Low risk & $\begin{array}{l}\text { All outcomes mentioned in the methods section } \\
\text { were reported as results }\end{array}$ \\
\hline Other bias & Low risk & \\
\hline \multicolumn{3}{|l|}{ Tate 2001} \\
\hline Methods & \multicolumn{2}{|c|}{ PARALLEL RANDOMIZED CONTROLLED CLINICAL TRIAL } \\
\hline Participants & \multicolumn{2}{|c|}{$\begin{array}{l}\text { INCLUSION CRITERIA: weight loss intervention trial for adults. Inclusion criteria were: } \\
\text { age } 18 \text { to } 60 \text { years and BMI of } 25 \text { to } 36 \\
\text { EXCLUSION CRITERIA: history of myocardial infarction, stroke or cancer in the last } 5 \\
\text { years; diabetes, angina, or orthopedic or joint problems that would prohibit exercise; major } \\
\text { psychiatric disease; or current, planned or previous pregnancy within } 6 \text { months. If prospective } \\
\text { participants endorsed any item on the Physical Activity Readiness Questionnaire, physician } \\
\text { consent was required before the individual could be included } \\
\text { DIAGNOSTIC CRITERIA: participants had to have a BMI between } 25 \text { and } 36 \\
\text { CO-MORBIDITIES: not stated } \\
\text { CONCOMITANT TREATMENTS: no }\end{array}$} \\
\hline Interventions & \multicolumn{2}{|c|}{$\begin{array}{l}\text { NUMBER OF STUDY CENTRES: } 1 \\
\text { COUNTRY/LOCATION: USA } \\
\text { SETTING: academic medical centre } \\
\text { TREATMENT BEFORE STUDY: none }\end{array}$} \\
\hline Outcomes & \multicolumn{2}{|c|}{$\begin{array}{l}\text { OUTCOME(S) (as stated in the protocol/registered trial documents): no protocol/ } \\
\text { registered trial documents }\end{array}$} \\
\hline Study details & \multicolumn{2}{|c|}{$\begin{array}{l}\text { RUN-IN PERIOD: no } \\
\text { STUDY TERMINATED BEFORE REGULAR END: no }\end{array}$} \\
\hline Publication details & \multicolumn{2}{|c|}{$\begin{array}{l}\text { LANGUAGE OF PUBLICATION: English } \\
\text { COMMERCIAL FUNDING: Weight Risk Investigators Study Council, a research division } \\
\text { of Knoll Pharmaceutical } \\
\text { PUBLICATION STATUS: peer-reviewed journal }\end{array}$} \\
\hline Stated aim of study & \multicolumn{2}{|c|}{$\begin{array}{l}\text { Quote: "We hypothesized that better weight loss might be produced by using the Internet to } \\
\text { deliver a structured behavioral weight loss program.... To test this hypothesis we conducted a } \\
\text { randomized controlled trial to test the feasibility and initial efficacy of a structured Internet } \\
\text { behavioral weight loss program compared with an educational Web site that was } \\
\text { representative of weight loss resources widely available on the Internet." }\end{array}$} \\
\hline \multicolumn{3}{|l|}{ Notes } \\
\hline \multicolumn{3}{|l|}{ Risk of bias } \\
\hline Bias & Authors' judgement & Support for judgement \\
\hline $\begin{array}{l}\text { Random sequence } \\
\text { generation (selection } \\
\text { bias) }\end{array}$ & Unclear risk & randomized, but method not stated \\
\hline $\begin{array}{l}\text { Allocation } \\
\text { concealment } \\
\text { (selection bias) }\end{array}$ & Unclear risk & Not reported \\
\hline
\end{tabular}




\begin{tabular}{|c|c|c|}
\hline $\begin{array}{l}\text { Blinding } \\
\text { (performance bias } \\
\text { and detection bias) } \\
\text { All outcomes }\end{array}$ & Unclear risk & Not reported \\
\hline $\begin{array}{l}\text { Incomplete outcome } \\
\text { data (attrition bias) } \\
\text { All outcomes }\end{array}$ & Low risk & $\begin{array}{l}32 \text { out of } 45 \text { participants randomized to the } \\
\text { Internet Education group completed baseline, } 3 \\
\text { and } 6 \text {-month follow-up } \\
35 \text { out of } 45 \text { participants randomized to the } \\
\text { Internet Education group completed baseline and } \\
6 \text {-month follow-up } \\
33 \text { out of } 46 \text { participants randomized to the } \\
\text { Internet Behavior Therapy group completed } \\
\text { baseline, } 3 \text { and } 6 \text {-month follow-up } \\
36 \text { out of } 46 \text { participants randomized to the } \\
\text { Internet Behavior Therapy group completed } \\
\text { baseline and 6-month follow-up } \\
\text { An intention-to-treat analysis was performed }\end{array}$ \\
\hline $\begin{array}{l}\text { Selective reporting } \\
\text { (reporting bias) }\end{array}$ & Low risk & $\begin{array}{l}\text { All outcomes mentioned in the methods section } \\
\text { were reported as results }\end{array}$ \\
\hline Other bias & Low risk & \\
\hline \multicolumn{3}{|l|}{ Tate 2003} \\
\hline Methods & \multicolumn{2}{|c|}{ PARALLEL RANDOMIZED CONTROLLED CLINICAL TRIAL } \\
\hline Participants & \multicolumn{2}{|c|}{$\begin{array}{l}\text { INCLUSION CRITERIA: weight loss intervention trial for adults at risk for type } 2 \text { diabetes. } \\
\text { Inclusion criteria were: BMI of } 27 \text { to } 40 \text { and one or more other risk factor for type } 2 \text { diabetes } \\
\text { EXCLUSION CRITERIA: major health or psychiatric disease, pregnancy or recent weight } \\
\text { loss of } 4.5 \mathrm{~kg} \text { or more. If prospective participants endorsed any item on the Physical Activity } \\
\text { Readiness Questionnaire or were taking medication that might be affected by weight loss, } \\
\text { physician consent was required before the individual could be included } \\
\text { DIAGNOSTIC CRITERIA: participants had to have a BMI between } 27 \text { and } 40 \\
\text { CO-MORBIDITIES: all participants had at least one risk factor for type } 2 \text { diabetes (age > }>45 \text {, } \\
\text { family history of diabetes, high cholesterol or blood pressure, impaired glucose tolerance, } \\
\text { history of gestational diabetes, being delivered of a neonate weighing } 4 \mathrm{~kg} \text { or more, or } \\
\text { belonging to a minority group) in addition to overweight. } 69 \% \text { of participants had } 3 \text { or more } \\
\text { risk factors } \\
\text { CONCOMITANT TREATMENTS: no }\end{array}$} \\
\hline Interventions & \multicolumn{2}{|c|}{$\begin{array}{l}\text { NUMBER OF STUDY CENTRES: } 1 \\
\text { COUNTRY/LOCATION: USA } \\
\text { SETTING: academic medical centre } \\
\text { TREATMENT BEFORE STUDY: none }\end{array}$} \\
\hline Outcomes & \multicolumn{2}{|c|}{$\begin{array}{l}\text { OUTCOME(S) (as stated in the protocol/registered trial documents): no protocol/ } \\
\text { registered trial documents }\end{array}$} \\
\hline Study details & \multicolumn{2}{|c|}{$\begin{array}{l}\text { RUN-IN PERIOD: no } \\
\text { STUDY TERMINATED BEFORE REGULAR END: no }\end{array}$} \\
\hline Publication details & \multicolumn{2}{|c|}{$\begin{array}{l}\text { LANGUAGE OF PUBLICATION: English } \\
\text { NON-COMMERCIAL FUNDING: Clinical Research Award, American Diabetes } \\
\text { Association } \\
\text { PUBLICATION STATUS: peer-reviewed journal }\end{array}$} \\
\hline Stated aim of study & \multicolumn{2}{|c|}{$\begin{array}{l}\text { Quote: "[T]he efficacy of Internet-based weight loss programs and specifically e-mail } \\
\text { counseling has not been used in a population at risk of diabetes nor evaluated for a year-long } \\
\text { weight loss intervention." }\end{array}$} \\
\hline Notes & \multicolumn{2}{|c|}{$\begin{array}{l}\text { We e-mailed the author in August } 2010 \text { and October } 2010 \text { to enquire whether it would be } \\
\text { possible to obtain outcome data for } 3 \text { and } 6 \text { months of follow-up. We received a reply but no } \\
\text { additional data, therefore we used only the } 12 \text { months data that were included in the } \\
\text { publication }\end{array}$} \\
\hline \multicolumn{3}{|l|}{ Risk of bias } \\
\hline Bias & Authors' judgement & Support for judgement \\
\hline $\begin{array}{l}\text { Random sequence } \\
\text { generation (selection } \\
\text { bias) }\end{array}$ & Low risk & $\begin{array}{l}\text { Participants were randomized using a } \\
\text { computerized random numbers sequence }\end{array}$ \\
\hline
\end{tabular}




\begin{tabular}{|c|c|c|}
\hline $\begin{array}{l}\text { Allocation } \\
\text { concealment } \\
\text { (selection bias) }\end{array}$ & Unclear risk & Not reported \\
\hline $\begin{array}{l}\text { Blinding } \\
\text { (performance bias } \\
\text { and detection bias) } \\
\text { All outcomes }\end{array}$ & Unclear risk & Not reported \\
\hline $\begin{array}{l}\text { Incomplete outcome } \\
\text { data (attrition bias) } \\
\text { All outcomes }\end{array}$ & Low risk & $\begin{array}{l}39 \text { out of } 46 \text { randomized to the Basic Internet } \\
\text { group completed the study } \\
38 \text { out of } 46 \text { randomized to the Basic Internet Plus } \\
\text { Counselling group completed the study } \\
\text { Reasons for loss of follow-up were medical } \\
\text { reasons, unknown or lack of interest } \\
\text { Intention-to-treat analysis used including all } \\
\text { randomized participants and assuming no change } \\
\text { from baseline for those with missing data }\end{array}$ \\
\hline $\begin{array}{l}\text { Selective reporting } \\
\text { (reporting bias) }\end{array}$ & Low risk & $\begin{array}{l}\text { All outcomes mentioned in the methods section } \\
\text { were reported as results }\end{array}$ \\
\hline Other bias & Low risk & \\
\hline \multicolumn{3}{|l|}{ Tate 2006} \\
\hline Methods & \multicolumn{2}{|c|}{ PARALLEL RANDOMIZED CONTROLLED CLINICAL TRIAL. } \\
\hline Participants & \multicolumn{2}{|c|}{$\begin{array}{l}\text { INCLUSION CRITERIA: weight loss intervention trial. Inclusion criteria were: age } 20 \text { to } 65 \\
\text { years, BMI of } 27 \text { to 40, willingness to use meal replacements as part of the dietary regimen, } \\
\text { and availability of a computer with Internet access } \\
\text { EXCLUSION CRITERIA: history of heart attack, stroke or cancer in the past } 5 \text { years; } \\
\text { diabetes, angina or orthopedic or joint problems that would prohibit exercise; a major } \\
\text { psychiatric disorder involving hospitalization during the past year; current or planned } \\
\text { pregnancy or less than } 6 \text { months postpartum } \\
\text { DIAGNOSTIC CRITERIA: participants had to have a BMI between } 27 \text { and } 40 \\
\text { CO-MORBIDITIES: not mentioned } \\
\text { CONCOMITANT TREATMENTS: all participants were recommended to consume } 2 \text { liquid } \\
\text { meal replacements per day (Slim-Fast) }\end{array}$} \\
\hline Interventions & \multicolumn{2}{|c|}{$\begin{array}{l}\text { NUMBER OF STUDY CENTRES: } 1 \\
\text { COUNTRY/LOCATION: USA } \\
\text { SETTING: Academic medical centre } \\
\text { TREATMENT BEFORE STUDY: none }\end{array}$} \\
\hline Outcomes & \multicolumn{2}{|c|}{$\begin{array}{l}\text { OUTCOME(S) (as stated in the protocol/registered trial documents): weight loss at } 6 \\
\text { months } \\
\text { (ClinicalTrials.gov Identifier NCT00200304) }\end{array}$} \\
\hline Study details & \multicolumn{2}{|c|}{$\begin{array}{l}\text { RUN-IN PERIOD: no } \\
\text { STUDY TERMINATED BEFORE REGULAR END: no }\end{array}$} \\
\hline Publication details & \multicolumn{2}{|c|}{$\begin{array}{l}\text { LANGUAGE OF PUBLICATION: English } \\
\text { COMMERCIAL FUNDING: Slim-Fast Nutrition Institute } \\
\text { PUBLICATION STATUS: peer-reviewed journal }\end{array}$} \\
\hline Stated aim of study & \multicolumn{2}{|c|}{$\begin{array}{l}\text { Quote: "The goal of this study was to determine the short-term efficacy of a self-directed } \\
\text { Internet weight loss program compared with the same program supplemented with behavioral } \\
\text { counseling from either a computer-automated tailored system or from a human counselor." }\end{array}$} \\
\hline \multicolumn{3}{|l|}{ Notes } \\
\hline \multicolumn{3}{|l|}{ Risk of bias } \\
\hline Bias & Authors' judgement & Support for judgement \\
\hline $\begin{array}{l}\text { Random sequence } \\
\text { generation (selection } \\
\text { bias) }\end{array}$ & Low risk & $\begin{array}{l}\text { Computerized random numbers were used to } \\
\text { assign participants to } 1 \text { of } 3 \text { groups }\end{array}$ \\
\hline $\begin{array}{l}\text { Allocation } \\
\text { concealment } \\
\text { (selection bias) }\end{array}$ & Unclear risk & Not reported \\
\hline $\begin{array}{l}\text { Blinding } \\
\text { (performance bias } \\
\text { and detection bias) }\end{array}$ & Unclear risk & $\begin{array}{l}\text { Non-intervention staff weighed participants at } \\
\text { baseline and at } 3 \text { and } 6 \text { months, but no statement } \\
\text { of whether or not they were blinded. Participants }\end{array}$ \\
\hline
\end{tabular}




\begin{tabular}{|c|c|c|}
\hline All outcomes & & $\begin{array}{l}\text { were aware of randomization assignment, but } \\
\text { knowledge of other interventions is unclear. } \\
\text { Stated that human e-counselors blinded to } \\
\text { algorithms used to program automated feedback } \\
\text { counselor, but unclear whether they were aware of } \\
\text { assignment of participants across all } 3 \text { groups }\end{array}$ \\
\hline $\begin{array}{l}\text { Incomplete outcome } \\
\text { data (attrition bias) } \\
\text { All outcomes }\end{array}$ & Low risk & $\begin{array}{l}55 \text { out of } 67 \text { randomized to the Website }+ \text { No } \\
\text { Counselling group completed the study at } 3 \\
\text { months and } 59 \text { completed at } 6 \text { months } \\
47 \text { out of } 61 \text { randomized to the Website }+ \\
\text { Automated Feedback group completed the study } \\
\text { at } 3 \text { months and } 44 \text { completed at } 6 \text { months } \\
56 \text { out of } 64 \text { randomized to the Website }+ \text { Human } \\
\text { Counselling group completed the study at } 3 \\
\text { months and } 52 \text { completed at } 6 \text { months } \\
\text { All participants were included in the intention-to- } \\
\text { treat analysis }\end{array}$ \\
\hline $\begin{array}{l}\text { Selective reporting } \\
\text { (reporting bias) }\end{array}$ & Low risk & $\begin{array}{l}\text { All outcomes mentioned in the methods section } \\
\text { were reported as results }\end{array}$ \\
\hline Other bias & Low risk & \\
\hline \multicolumn{3}{|l|}{ Threlfall 1984} \\
\hline Methods & \multicolumn{2}{|c|}{ PARALLEL RANDOMIZED CONTROLLED CLINICAL TRIAL } \\
\hline Participants & \multicolumn{2}{|c|}{$\begin{array}{l}\text { INCLUSION CRITERIA: weight loss intervention trial for adults. Inclusion criteria were } \\
\text { body weight at least 10\% over the desirable midpoint on the Metropolitan Life Insurance } \\
\text { Company tables but less than } 70 \% \text { overweight by this same criterion } \\
\text { EXCLUSION CRITERIA: planning pregnancy during the course of the intervention } \\
\text { DIAGNOSTIC CRITERIA: participants had to have a body weight at least } 10 \% \text { over the } \\
\text { desirable midpoint on the Metropolitan Life Insurance Company tables but less than } 70 \% \\
\text { overweight by this same criterion } \\
\text { CO-MORBIDITIES: no } \\
\text { CONCOMITANT TREATMENTS: no }\end{array}$} \\
\hline Interventions & \multicolumn{2}{|c|}{$\begin{array}{l}\text { NUMBER OF STUDY CENTRES: } 1 \\
\text { COUNTRY/LOCATION: USA } \\
\text { SETTING: University course } \\
\text { TREATMENT BEFORE STUDY: none }\end{array}$} \\
\hline Outcomes & \multicolumn{2}{|c|}{$\begin{array}{l}\text { OUTCOME(S) (as stated in the protocol/registered trial documents): no protocol/ } \\
\text { registered trial documents }\end{array}$} \\
\hline Study details & \multicolumn{2}{|c|}{$\begin{array}{l}\text { RUN-IN PERIOD: no } \\
\text { STUDY TERMINATED BEFORE REGULAR END: no }\end{array}$} \\
\hline Publication details & \multicolumn{2}{|c|}{$\begin{array}{l}\text { LANGUAGE OF PUBLICATION: English } \\
\text { COMMERCIAL/NON-COMMERCIAL FUNDING: funding source, if any, not stated } \\
\text { PUBLICATION STATUS: dissertation }\end{array}$} \\
\hline Stated aim of study & \multicolumn{2}{|c|}{$\begin{array}{l}\text { Quote: "The current study was designed to test the following hypotheses: During } 10 \text { weeks of } \\
\text { treatment, participants randomly assigned to a computer-administered treatment supplement to } \\
\text { the Jeffrey and Katz (1977) weight control manual will show a greater mean loss of pounds } \\
\text { than will participants assigned to use the manual only." }\end{array}$} \\
\hline \multicolumn{3}{|l|}{ Notes } \\
\hline \multicolumn{3}{|l|}{ Risk of bias } \\
\hline Bias & Authors' judgement & Support for judgement \\
\hline $\begin{array}{l}\text { Random sequence } \\
\text { generation (selection } \\
\text { bias) }\end{array}$ & Unclear risk & randomized, but method not stated \\
\hline $\begin{array}{l}\text { Allocation } \\
\text { concealment } \\
\text { (selection bias) }\end{array}$ & Unclear risk & Not reported \\
\hline $\begin{array}{l}\text { Blinding } \\
\text { (performance bias } \\
\text { and detection bias) } \\
\text { All outcomes }\end{array}$ & High risk & $\begin{array}{l}\text { At baseline participants were measured by a } \\
\text { student nurse, but there is no report of whether the } \\
\text { nurse was blinded to the treatment assignment } \\
\text { The investigator had no contact with either group } \\
\text { but offered counseling during the trial to the }\end{array}$ \\
\hline
\end{tabular}




\begin{tabular}{|c|c|c|}
\hline & & $\begin{array}{l}\text { intervention group. The investigator carried out } \\
\text { the analyses }\end{array}$ \\
\hline $\begin{array}{l}\text { Incomplete outcome } \\
\text { data (attrition bias) } \\
\text { All outcomes }\end{array}$ & Unclear risk & $\begin{array}{l}\text { Reasons for attrition were not explored, with } \\
\text { exception of one participant who became } \\
\text { pregnant. It is unclear whether the reasons for } \\
\text { attrition could be related to outcome }\end{array}$ \\
\hline $\begin{array}{l}\text { Selective reporting } \\
\text { (reporting bias) }\end{array}$ & Low risk & $\begin{array}{l}\text { All outcomes specified in the research hypotheses } \\
\text { were reported }\end{array}$ \\
\hline Other bias & Low risk & \\
\hline \multicolumn{3}{|l|}{ Webber 2008} \\
\hline Methods & \multicolumn{2}{|c|}{ PARALLEL RANDOMIZED CONTROLLED CLINICAL TRIAL } \\
\hline Participants & \multicolumn{2}{|c|}{$\begin{array}{l}\text { INCLUSION CRITERIA: weight loss intervention trial. Adult women ages } 25 \text { to } 40 \text { with a } \\
\text { BMI of } 25 \text { to } 40 \text { and home access to a computer with Internet service } \\
\text { EXCLUSION CRITERIA: diagnosis with a major psychiatric disorder or hospitalization for } \\
\text { a psychiatric disorder within the last year, cancer diagnosis within } 5 \text { years with the exception } \\
\text { of skin cancer, medical diagnosis of HIV, being pregnant, nursing or being less than } 9 \text { months } \\
\text { post-partum, planning to become pregnant within the study period, history of anorexia or } \\
\text { bulimia nervosa, or recent weight loss of } 10 \text { pounds or more. A medical diagnosis of } \\
\text { orthopedic or joint problems that might prohibit regular exercise. Endorsement of any of the } \\
\text { first } 3 \text { items on the Physical Activity Readiness Questionnaire (PAR-Q), or endorsement of } \\
\text { any of the other items on the PAR-AQ without a physician's consent to participate in the trial. } \\
\text { Participants were also excluded if they admitted to knowing another potential study participant } \\
\text { DIAGNOSTIC CRITERIA: participants had to have a BMI between } 25 \text { and } 40 \\
\text { CO-MORBIDITIES: none specified } \\
\text { CONCOMITANT TREATMENTS: no }\end{array}$} \\
\hline Interventions & \multicolumn{2}{|c|}{$\begin{array}{l}\text { NUMBER OF STUDY CENTRES: } 1 \\
\text { COUNTRY/LOCATION: USA } \\
\text { SETTING: academic medical centre } \\
\text { TREATMENT BEFORE STUDY: none }\end{array}$} \\
\hline Outcomes & \multicolumn{2}{|c|}{$\begin{array}{l}\text { OUTCOME(S) (as stated in the protocol/registered trial documents): no protocol/ } \\
\text { registered trial documents }\end{array}$} \\
\hline Study details & \multicolumn{2}{|c|}{$\begin{array}{l}\text { RUN-IN PERIOD: no } \\
\text { STUDY TERMINATED BEFORE REGULAR END: no }\end{array}$} \\
\hline Publication details & \multicolumn{2}{|c|}{$\begin{array}{l}\text { LANGUAGE OF PUBLICATION: English } \\
\text { COMMERCIAL/NON-COMMERCIAL FUNDING: no funding statement } \\
\text { PUBLICATION STATUS: peer-reviewed journal }\end{array}$} \\
\hline Stated aim of study & \multicolumn{2}{|c|}{$\begin{array}{l}\text { Quote: "The goal of the current study was to investigate the efficacy of the addition of weekly } \\
\text { motivationally enhanced chats to a standard behavioral Internet weight loss program. We } \\
\text { hypothesized that an intervention which incorporated a motivationally enhanced face-to-face } \\
\text { session, an Internet behavioral weight loss program, and weekly online chats led using } \\
\text { motivational techniques would produce greater weight loss than a similar intervention which } \\
\text { did not include weekly online chats." }\end{array}$} \\
\hline \multicolumn{3}{|l|}{ Notes } \\
\hline \multicolumn{3}{|l|}{ Risk of bias } \\
\hline Bias & Authors' judgement & Support for judgement \\
\hline $\begin{array}{l}\text { Random sequence } \\
\text { generation (selection } \\
\text { bias) }\end{array}$ & Unclear risk & Not reported \\
\hline $\begin{array}{l}\text { Allocation } \\
\text { concealment } \\
\text { (selection bias) }\end{array}$ & Unclear risk & Not reported \\
\hline $\begin{array}{l}\text { Blinding } \\
\text { (performance bias } \\
\text { and detection bias) } \\
\text { All outcomes }\end{array}$ & Low risk & $\begin{array}{l}\text { Trained research assistants who were blinded to } \\
\text { group assignment took participant measurements }\end{array}$ \\
\hline $\begin{array}{l}\text { Incomplete outcome } \\
\text { data (attrition bias) } \\
\text { All outcomes }\end{array}$ & Low risk & $\begin{array}{l}\text { All } 33 \text { participants randomized to the Enhanced } \\
\text { Intervention group completed the final weight } \\
\text { measurement and questionnaires }\end{array}$ \\
\hline
\end{tabular}




\begin{tabular}{|c|c|c|}
\hline & & $\begin{array}{l}32 \text { of the } 33 \text { participants randomized to the } \\
\text { Minimal Intervention completed the final } \\
\text { measurement and questionnaires }\end{array}$ \\
\hline $\begin{array}{l}\text { Selective reporting } \\
\text { (reporting bias) }\end{array}$ & Low risk & $\begin{array}{l}\text { All outcomes mentioned in the methods section } \\
\text { were reported as results }\end{array}$ \\
\hline Other bias & Low risk & \\
\hline \multicolumn{3}{|l|}{ Wing 2006} \\
\hline Methods & \multicolumn{2}{|c|}{ PARALLEL RANDOMIZED CONTROLLED CLINICAL TRIAL } \\
\hline Participants & \multicolumn{2}{|c|}{$\begin{array}{l}\text { INCLUSION CRITERIA: weight maintenance intervention trial. Adults who had lost at least } \\
10 \% \text { of their body weight during the previous } 2 \text { years. All participants had to have a friend, } \\
\text { physician or weight loss counselor complete and sign a form verifying the amount and timing } \\
\text { of their weight loss } \\
\text { EXCLUSION CRITERIA: serious physical or psychological disorders, pregnancy or a } \\
\text { planned move. Persons with medical conditions that might affect their ability to safely } \\
\text { complete the intervention or their ability to exercise were required to obtain written permission } \\
\text { to participate from a physician } \\
\text { DIAGNOSTIC CRITERIA: participants had to have lost at least } 10 \% \text { of their body weight } \\
\text { during the previous } 2 \text { years } \\
\text { CO-MORBIDITIES: none specified } \\
\text { CONCOMITANT TREATMENTS: no }\end{array}$} \\
\hline Interventions & \multicolumn{2}{|c|}{$\begin{array}{l}\text { NUMBER OF STUDY CENTRES: } 1 \\
\text { COUNTRY/LOCATION: USA } \\
\text { SETTING: academic medical centre/community } \\
\text { TREATMENT BEFORE STUDY: none }\end{array}$} \\
\hline Outcomes & \multicolumn{2}{|c|}{$\begin{array}{l}\text { OUTCOME(S) (as stated in the protocol/registered trial documents): "The primary } \\
\text { outcome measure is weight regain from baseline to } 18 \text { months." (ClinicalTrials.gov Identifier } \\
\text { NCT00067145) }\end{array}$} \\
\hline Study details & \multicolumn{2}{|c|}{$\begin{array}{l}\text { RUN-IN PERIOD: no } \\
\text { STUDY TERMINATED BEFORE REGULAR END: no }\end{array}$} \\
\hline Publication details & \multicolumn{2}{|c|}{$\begin{array}{l}\text { LANGUAGE OF PUBLICATION: English } \\
\text { COMMERCIAL FUNDING: no } \\
\text { NON-COMMERCIAL FUNDING: National Institute of Diabetes and Digestive and Kidney } \\
\text { Diseases } \\
\text { PUBLICATION STATUS: peer-reviewed journal }\end{array}$} \\
\hline Stated aim of study & \multicolumn{2}{|c|}{$\begin{array}{l}\text { Quote: "We hypothesized that the interventions, delivered face to face or over the Internet, } \\
\text { would decrease average weight regain and reduce the proportion of participants who regained } \\
2.3 \mathrm{~kg} \text { or more during a period of } 18 \text { months." }\end{array}$} \\
\hline \multicolumn{3}{|l|}{ Notes } \\
\hline \multicolumn{3}{|l|}{ Risk of bias } \\
\hline Bias & Authors' judgement & Support for judgement \\
\hline $\begin{array}{l}\text { Random sequence } \\
\text { generation (selection } \\
\text { bias) }\end{array}$ & Unclear risk & randomized, but method not stated \\
\hline $\begin{array}{l}\text { Allocation } \\
\text { concealment } \\
\text { (selection bias) }\end{array}$ & Unclear risk & Not reported \\
\hline $\begin{array}{l}\text { Blinding } \\
\text { (performance bias } \\
\text { and detection bias) } \\
\text { All outcomes }\end{array}$ & Unclear risk & Not reported \\
\hline
\end{tabular}




\begin{tabular}{|c|c|c|}
\hline $\begin{array}{l}\text { Incomplete outcome } \\
\text { data (attrition bias) } \\
\text { All outcomes }\end{array}$ & Low risk & $\begin{array}{l}98 \text { out of the } 105 \text { participants randomized to the } \\
\text { Control group completed } 18 \text {-month follow-up } \\
101 \text { out of the } 104 \text { participants randomized to the } \\
\text { Internet group completed } 18 \text {-month follow-up } \\
92 \text { out of the } 105 \text { participants randomized to the } \\
\text { Face-to-face group completed } 18 \text {-month follow- } \\
\text { up } \\
\text { Reasons for loss to follow-up were death, } \\
\text { declined and had cancer } \\
\text { Authors assumed all dropouts regained } 2.3 \mathrm{~kg} \text { or } \\
\text { more }\end{array}$ \\
\hline $\begin{array}{l}\text { Selective reporting } \\
\text { (reporting bias) }\end{array}$ & Low risk & $\begin{array}{l}\text { All outcomes mentioned in the methods section } \\
\text { were reported as results }\end{array}$ \\
\hline Other bias & Low risk & \\
\hline \multicolumn{3}{|l|}{ Wylie-Rosett 2001} \\
\hline Methods & \multicolumn{2}{|c|}{$\begin{array}{l}\text { PARALLEL RANDOMIZED CONTROLLED CLINICAL TRIAL RANDOMIZATION } \\
\text { RATIO: } 1: 2: 2\end{array}$} \\
\hline Participants & \multicolumn{2}{|c|}{$\begin{array}{l}\text { INCLUSION CRITERIA: weight loss intervention trial. Adults who had a BMI greater than } \\
\text { 25, or a BMI of at least } 24 \text { plus at least one cardiovascular risk factor. Participants had to be } \\
\text { willing to follow the study protocol and pay a refundable USD } 100 \text { deposit } \\
\text { EXCLUSION CRITERIA: intention to move beyond commuting distance within the next } 12 \\
\text { months, medical conditions that would interfere with study participation, and unwillingness to } \\
\text { follow the study protocol } \\
\text { DIAGNOSTIC CRITERIA: participants had to have a BMI greater than 25, or a BMI of at } \\
\text { least } 24 \text { plus at least one cardiovascular risk factor } \\
\text { CO-MORBIDITIES: none specified } \\
\text { CONCOMITANT TREATMENTS: no }\end{array}$} \\
\hline Interventions & \multicolumn{2}{|c|}{$\begin{array}{l}\text { NUMBER OF STUDY CENTRES: } 1 \\
\text { COUNTRY/LOCATION: USA } \\
\text { SETTING: Health Maintenance Organisation (HMO) } \\
\text { TREATMENT BEFORE STUDY: none }\end{array}$} \\
\hline Outcomes & \multicolumn{2}{|c|}{$\begin{array}{l}\text { OUTCOME(S) (as stated in the protocol/registered trial documents): no protocol/ } \\
\text { registered trial documents }\end{array}$} \\
\hline Study details & \multicolumn{2}{|c|}{$\begin{array}{l}\text { RUN-IN PERIOD: no } \\
\text { STUDY TERMINATED BEFORE REGULAR END: no }\end{array}$} \\
\hline Publication details & \multicolumn{2}{|c|}{$\begin{array}{l}\text { LANGUAGE OF PUBLICATION: English } \\
\text { NON-COMMERCIAL FUNDING: National Heart, Lung and Blood Institute and the } \\
\text { Diabetes Research and Training Center } \\
\text { PUBLICATION STATUS: peer-reviewed journal }\end{array}$} \\
\hline Stated aim of study & \multicolumn{2}{|c|}{$\begin{array}{l}\text { Quote: "The goals of our study were to evaluate weight-loss outcomes and the effect on CVD } \\
\text { risk factors, and the resources required (from the perspective of a managed care organization) } \\
\text { of the self-help, non clinical, and clinical approaches to weight control." }\end{array}$} \\
\hline \multicolumn{3}{|l|}{ Notes } \\
\hline \multicolumn{3}{|l|}{ Risk of bias } \\
\hline Bias & Authors' judgement & Support for judgement \\
\hline $\begin{array}{l}\text { Random sequence } \\
\text { generation (selection } \\
\text { bias) }\end{array}$ & Unclear risk & randomized, but method not stated \\
\hline $\begin{array}{l}\text { Allocation } \\
\text { concealment } \\
\text { (selection bias) }\end{array}$ & Unclear risk & Not reported \\
\hline $\begin{array}{l}\text { Blinding } \\
\text { (performance bias } \\
\text { and detection bias) } \\
\text { All outcomes }\end{array}$ & Unclear risk & Not reported \\
\hline $\begin{array}{l}\text { Incomplete outcome } \\
\text { data (attrition bias) } \\
\text { All outcomes }\end{array}$ & Low risk & $\begin{array}{l}97 \text { out of the } 116 \text { participants randomized to the } \\
\text { Workbook only intervention group completed the } \\
\text { study }\end{array}$ \\
\hline
\end{tabular}




\begin{tabular}{l|l|l} 
& & $\begin{array}{l}\text { 183 out of the 236 participants randomized to the } \\
\text { Workbook + computer intervention group } \\
\text { completed the study } \\
\text { 194 out of the 236 participants randomized to the } \\
\text { Workbook + computer + staff intervention group } \\
\text { completed the study Reasons for loss to follow-up } \\
\text { were not stated. It was reported that the study } \\
\text { completers did not differ significantly from the } \\
\text { dropouts with respect to baseline characteristics, } \\
\text { but method of handling missing data not stated }\end{array}$ \\
\hline $\begin{array}{l}\text { Selective reporting } \\
\text { (reporting bias) }\end{array}$ & Low risk & $\begin{array}{l}\text { All outcomes mentioned in the methods section } \\
\text { were reported as results }\end{array}$ \\
\hline Other bias & Low risk & \\
\hline
\end{tabular}

Abbreviations:

BMI: body mass index; CAD: computer-assisted dieting; CAD + G: computer-assisted dieting plus group intervention; CI: confidence interval; NCI National Cancer Institute:

\section{Characteristics of excluded studies [ordered by study ID]}

\begin{tabular}{|c|c|}
\hline Study & Reason for exclusion \\
\hline Adachi 2007 & $\begin{array}{l}\text { Computer messages were generated from participant data but participants did not interact } \\
\text { with computer program }\end{array}$ \\
\hline Agras 1990 & Intervention - handheld device \\
\hline Anderson-Bill 2011 & Patients - not all obese \\
\hline Bischoff 2010 & Intervention - physical activity intervention rather than specifically aimed at weight loss \\
\hline Booth 2008 & Patients - dropout rate \\
\hline Brantley 2008 & Patients - dropout rate \\
\hline Burke 2011 & Intervention - handheld device \\
\hline Burnett 1984 & Study design - not RCT or quasi-RCT \\
\hline Burnett 1992 & Patients - dropout rate \\
\hline Campbell 2002 & $\begin{array}{l}\text { Intervention - not interactive; computer messages were generated from survey data but } \\
\text { participants did not interact with computer program }\end{array}$ \\
\hline Cange 2008 & Study design - not RCT or quasi-RCT \\
\hline Carr 2008 & Patients - dropout rate \\
\hline Carr 2009 & $\begin{array}{l}\text { Patients - not all obese } \\
\text { Intervention - physical activity intervention rather than specifically aimed at weight loss }\end{array}$ \\
\hline Carrard 2011 & Patients - aimed specifically at people with eating disorders \\
\hline Castelnuovo 2011 & Patients - dropout rate \\
\hline Christian 2011 & Intervention - not interactive \\
\hline Collinson 2011 & Study design - not RCT or quasi-RCT \\
\hline Cook 2007 & $\begin{array}{l}\text { Patients - not obese } \\
\text { Intervention - not interactive; intervention was a multi-media program but participants did } \\
\text { not interact with it }\end{array}$ \\
\hline Cousineau 2008 & Study design - not RCT or quasi-RCT \\
\hline De Bourdeaudhuij 2007 & Patients - not all obese \\
\hline Dekkers 2011 & Patients - dropout rate \\
\hline Faghri 2008 & Study design - not RCT or quasi-RCT \\
\hline Fitzgibbon 1995 & Intervention - not computer-based \\
\hline
\end{tabular}




\begin{tabular}{|c|c|}
\hline Study & Reason for exclusion \\
\hline Foree-Gavert 1980 & $\begin{array}{l}\text { Intervention - not interactive; computer-generated feedback was given, but participants did } \\
\text { not interact with computer program }\end{array}$ \\
\hline Gold 2007 & Patients - dropout rate \\
\hline Gow 2010 & Patients - not all obese \\
\hline Harvey-Berino 1998 & Intervention - not computer or web-based \\
\hline Harvey-Berino 2002a & Unable to extract data or contact author \\
\hline Harvey-Berino 2004 & $\begin{array}{l}\text { Follow-up in weight maintenance trial was } 84 \% \text { at } 6 \text { months and } 76 \% \text { at } 12 \text { months. Six } \\
\text { months data were not presented in the study report and we were unable to contact the author } \\
\text { for information. Twelve months data were excluded due to follow-up less than } 80 \%\end{array}$ \\
\hline Haugen 2007 & Study design - not RCT or quasi-RCT \\
\hline Heetderks-Cox 2001 & Patients - dropout rate \\
\hline Herrick 2009 & Patients - not all obese \\
\hline Jacobs 2010 & Intervention - not interactive \\
\hline James 2001 & Study design - not RCT or quasi-RCT \\
\hline Jones 1997 & Patients - dropout rate \\
\hline Joo 2010 & Study design - not RCT or quasi-RCT \\
\hline Kalten 2000 & Patients - diabetic \\
\hline Kerr 2008 & Patients - dropout rate \\
\hline Kremers 2005 & Intervention - not interactive \\
\hline Kristal 2000 & Intervention - not interactive \\
\hline Kroeze 2008 & Patients - not obese \\
\hline Kroeze $2008 \mathrm{a}$ & Patients - not obese \\
\hline Liou 2006 & Study design - not RCT or quasi-RCT \\
\hline Lohof 2007 & $\begin{array}{l}\text { Intervention - not interactive; participants recorded activities on a website but no feedback } \\
\text { was given. } \\
\text { Primary outcome was increase in participants' self efficacy and physical activity levels }\end{array}$ \\
\hline Magnusdottir 2010 & $\begin{array}{l}\text { Insufficient information to determine eligibility; author could not be contacted for further } \\
\text { information }\end{array}$ \\
\hline Marcus 2007 & $\begin{array}{l}\text { Patients - not obese } \\
\text { Outcomes - primary outcome was change in physical activity and secondary outcome was } \\
\text { exercise performance }\end{array}$ \\
\hline McConnon 2007 & Patients - dropout rate \\
\hline McDoniel 2010 & Patients - dropout rate \\
\hline McHugh 2008 & Study design - not RCT or quasi-RCT \\
\hline McTigue 2009 & Study design - not RCT or quasi-RCT \\
\hline Micco 2007 & Patients - dropout rate \\
\hline Mobley 2006 & Patients - dropout rate \\
\hline Nieto 2010 & Study design - not RCT or quasi-RCT \\
\hline Park 2009 & Study design - not RCT or quasi-RCT \\
\hline Patrick 2011 & Patients - dropout rate \\
\hline Petersen 2008 & Study design - not RCT or quasi-RCT \\
\hline Polzien 2007 & Intervention - not interactive \\
\hline Pullen 2008 & Patients - dropout rate \\
\hline
\end{tabular}

Cochrane Database Syst Rev. Author manuscript; available in PMC 2014 April 23. 


\begin{tabular}{|c|c|}
\hline Study & Reason for exclusion \\
\hline Riva 2000 & Study design - not RCT or quasi-RCT \\
\hline Rothert 2006 & Patients - dropout rate \\
\hline Ryan 2010 & Patients - dropout rate \\
\hline Sartor 1991 & Patients - dropout rate \\
\hline Sbrocco 1999 & Intervention - not interactive \\
\hline Sbrocco 2005 & Intervention - handheld device \\
\hline Shay 2009 & Patients - dropout rate \\
\hline Smeets 2007 & Patients - not obese \\
\hline Smith 2009 & Outcome - primary outcome was change in physical activity levels \\
\hline Southard 2003 & Patients - not all obese or overweight \\
\hline Steele 2007 & Intervention - physical activity intervention rather than specifically aimed at weight loss \\
\hline Tanaka 2010 & $\begin{array}{l}\text { Intervention - computer messages were generated from participant data but participants did } \\
\text { not interact with computer program }\end{array}$ \\
\hline Taylor 1991 & Intervention - handheld device \\
\hline Thurston 1991 & Study design - not RCT or quasi-RCT \\
\hline Touger-Decker 2010 & Study design - not RCT or quasi-RCT \\
\hline Turnin 2001 & Patients - dropout rate \\
\hline van der Mark 2009 & Study design - not RCT or quasi-RCT \\
\hline van Wier 2009 & Patients - dropout rate \\
\hline Vandelanotte 2005 & Patients - not obese \\
\hline Vandelanotte 2008 & $\begin{array}{l}\text { Patients - not obese } \\
\text { Intervention - not interactive }\end{array}$ \\
\hline Verheijden 2007 & Study design - not RCT or quasi-RCT \\
\hline Webber 2008a & Patients - dropout rate \\
\hline Webber 2010 & Intervention: motivational interviewing and not specifically computer-based weight loss \\
\hline Weinstock 1998 & Intervention - not computer-based \\
\hline Werkman 2010 & Patient - not all obese \\
\hline Winett 2007 & Patients - not all obese \\
\hline Wing 2009 & Patients - dropout rate \\
\hline Womble 2004 & Patients - dropout rate \\
\hline Yon 2007 & Intervention - handheld device \\
\hline
\end{tabular}

Abbreviations:

RCT: randomized controlled trial

\section{Characteristics of ongoing studies [ordered by study ID]}

\begin{tabular}{l|l}
\multicolumn{2}{l}{ Harvey-Berino NCT01232699 } \\
\hline Trial name or title & Internet obesity treatment enhanced with motivational interviewing \\
\hline Methods & $\begin{array}{l}\text { Trial design: randomized controlled trial } \\
\text { Duration of intervention: 6-month weight loss program followed by 12 months of weight } \\
\text { maintenance } \\
\text { Country: United States of America }\end{array}$ \\
\hline
\end{tabular}




\begin{tabular}{l|l} 
Participants & $\begin{array}{l}\text { Inclusion criteria: 18 years and older; male and female; BMI between 18 and 50; must be able } \\
\text { to walk for exercise }\end{array}$ \\
\hline Interventions & $\begin{array}{l}\text { Internet Obesity Treatment: active comparator } \\
\text { Internet Obesity Treatment with Motivational Interviewing: experimental }\end{array}$ \\
\hline Outcomes & $\begin{array}{l}\text { Primary outcome: change in body weight at } 6 \text { months } \\
\text { Secondary outcomes: adherence to treatment components at 6,12 and } 18 \text { months } \\
\text { Motivation measures at 6, 12 and 18 months }\end{array}$ \\
\hline Starting date & December 2010 \\
\hline Contact information & Doris E Ogden, M.S. +1-802-656-1960 doris.ogden@ uvm.edu \\
\hline Notes & $\begin{array}{l}\text { ClinicalTrials.gov Identifier: NCT01232699 } \\
\text { Other Study ID Numbers: 10-124 }\end{array}$ \\
\hline
\end{tabular}

Abbreviations:

BMI: body mass index

\section{Comparison 1. Weight loss: computer vs minimal interventions}

\begin{tabular}{|c|c|c|c|c|}
\hline Outcome or subgroup title & No. of studies & No. of participants & Statistical method & Effect size \\
\hline 1 Weight at $3 \mathrm{mo}$ & 5 & & $\begin{array}{l}\text { Mean Difference (IV, } \\
\text { Random, 95\% CI) }\end{array}$ & Subtotals only \\
\hline $\begin{array}{l}1.1 \text { Computer group } \\
\text { includes computer plus in- } \\
\text { person intervention }\end{array}$ & 5 & 430 & $\begin{array}{l}\text { Mean Difference (IV, } \\
\text { Random, 95\% CI) }\end{array}$ & $-2.48[-3.41,-1.55]$ \\
\hline $\begin{array}{l}\text { 1.2 Comparison excludes } \\
\text { quasi-randomized trial } \\
\text { (Schroder 2010) }\end{array}$ & 4 & 339 & $\begin{array}{l}\text { Mean Difference (IV, } \\
\text { Random, 95\% CI) }\end{array}$ & $-2.76[-3.67,-1.85]$ \\
\hline $\begin{array}{l}1.3 \text { Computer group } \\
\text { excludes computer plus in- } \\
\text { person intervention }\end{array}$ & 5 & 399 & $\begin{array}{l}\text { Mean Difference (IV, } \\
\text { Random, 95\% CI) }\end{array}$ & $-2.52[-3.44,-1.60]$ \\
\hline $\begin{array}{l}\text { 1.4 Comparison excludes } \\
\text { workplace setting trial }\end{array}$ & 4 & 320 & $\begin{array}{l}\text { Mean Difference (IV, } \\
\text { Random, 95\% CI) }\end{array}$ & $-2.18[-2.90,-1.46]$ \\
\hline $\begin{array}{l}1.5 \text { Trials including only } \\
\text { men }\end{array}$ & 2 & 175 & $\begin{array}{l}\text { Mean Difference (IV, } \\
\text { Random, 95\% CI) }\end{array}$ & $-3.13[-5.58,-0.69]$ \\
\hline $\begin{array}{l}1.6 \text { Trials including both } \\
\text { men and women }\end{array}$ & 3 & 255 & $\begin{array}{l}\text { Mean Difference (IV, } \\
\text { Random, 95\% CI) }\end{array}$ & $-1.97[-2.93,-1.01]$ \\
\hline 2 Weight at $6 \mathrm{mo}$ & 2 & 511 & $\begin{array}{l}\text { Mean Difference (IV, } \\
\text { Random, 95\% CI) }\end{array}$ & $-1.52[-2.13,-0.90]$ \\
\hline 3 Weight at $12 \mathrm{mo}$ & 1 & & $\begin{array}{l}\text { Mean Difference (IV, } \\
\text { Random, 95\% CI) }\end{array}$ & Totals not selected \\
\hline $\begin{array}{l}3.1 \text { Computer group } \\
\text { includes computer plus in- } \\
\text { person intervention }\end{array}$ & 1 & & $\begin{array}{l}\text { Mean Difference (IV, } \\
\text { Random, 95\% CI) }\end{array}$ & $0.0[0.0,0.0]$ \\
\hline $\begin{array}{l}3.2 \text { Computer group } \\
\text { excludes computer plus in- } \\
\text { person intervention }\end{array}$ & 1 & & $\begin{array}{l}\text { Mean Difference (IV, } \\
\text { Random, 95\% CI) }\end{array}$ & $0.0[0.0,0.0]$ \\
\hline 4 Change in weight at $3 \mathrm{mo}$ & 1 & 101 & $\begin{array}{l}\text { Mean Difference (IV, } \\
\text { Random, 95\% CI) }\end{array}$ & $-2.99[-4.08,-1.90]$ \\
\hline $\begin{array}{l}5 \text { Change in weight at } 12 \\
\text { mo }\end{array}$ & 1 & & $\begin{array}{l}\text { Mean Difference (IV, } \\
\text { Random, 95\% CI) }\end{array}$ & Totals not selected \\
\hline $\begin{array}{l}5.1 \text { Computer group } \\
\text { includes computer plus in- } \\
\text { person intervention }\end{array}$ & 1 & & $\begin{array}{l}\text { Mean Difference (IV, } \\
\text { Random, 95\% CI) }\end{array}$ & $0.0[0.0,0.0]$ \\
\hline $\begin{array}{l}5.2 \text { Computer group } \\
\text { excludes computer plus in- } \\
\text { person intervention }\end{array}$ & 1 & & $\begin{array}{l}\text { Mean Difference (IV, } \\
\text { Random, 95\% CI) }\end{array}$ & $0.0[0.0,0.0]$ \\
\hline
\end{tabular}




\begin{tabular}{|c|c|c|c|c|}
\hline Outcome or subgroup title & No. of studies & No. of participants & Statistical method & Effect size \\
\hline $6 \mathrm{BMI}$ at 3 to $4 \mathrm{mo}$ & 4 & & $\begin{array}{l}\text { Mean Difference (IV, } \\
\text { Random, 95\% CI) }\end{array}$ & Subtotals only \\
\hline $\begin{array}{l}\text { 6.1 Computer group } \\
\text { includes computer plus in- } \\
\text { person intervention }\end{array}$ & 4 & 367 & $\begin{array}{l}\text { Mean Difference (IV, } \\
\text { Random, 95\% CI) }\end{array}$ & $-0.96[-1.35,-0.57]$ \\
\hline $\begin{array}{l}6.2 \text { Computer group } \\
\text { excludes computer plus in- } \\
\text { person intervention }\end{array}$ & 4 & 336 & $\begin{array}{l}\text { Mean Difference (IV, } \\
\text { Random, 95\% CI) }\end{array}$ & $-0.99[-1.36,-0.61]$ \\
\hline $7 \mathrm{BMI}$ at 6 to $7 \mathrm{mo}$ & 2 & 464 & $\begin{array}{l}\text { Mean Difference (IV, } \\
\text { Random, 95\% CI) }\end{array}$ & $-0.68[-0.92,-0.45]$ \\
\hline $8 \mathrm{BMI}$ at $12 \mathrm{mo}$ & 1 & & $\begin{array}{l}\text { Mean Difference (IV, } \\
\text { Random, 95\% CI) }\end{array}$ & Totals not selected \\
\hline $\begin{array}{l}\text { 8.1 Computer group } \\
\text { includes computer plus in- } \\
\text { person intervention }\end{array}$ & 1 & & $\begin{array}{l}\text { Mean Difference (IV, } \\
\text { Random, 95\% CI) }\end{array}$ & $0.0[0.0,0.0]$ \\
\hline $\begin{array}{l}8.2 \text { Computer group } \\
\text { excludes computer plus in- } \\
\text { person intervention }\end{array}$ & 1 & & $\begin{array}{l}\text { Mean Difference (IV, } \\
\text { Random, 95\% CI) }\end{array}$ & $0.0[0.0,0.0]$ \\
\hline $\begin{array}{l}9 \text { Waist circumference at } 3 \\
\text { mo }[\mathrm{cm}]\end{array}$ & 3 & & $\begin{array}{l}\text { Mean Difference } \\
\text { (Random, 95\% CI) }\end{array}$ & Subtotals only \\
\hline $\begin{array}{l}9.1 \text { Waist circumference } \\
\text { at } 3 \text { mo }\end{array}$ & 3 & 276 & $\begin{array}{l}\text { Mean Difference } \\
\text { (Random, 95\% CI) }\end{array}$ & $-2.95[-6.17,0.27]$ \\
\hline $\begin{array}{l}9.2 \text { Waist circumference } \\
\text { at } 3 \text { mo (sensitivity analysis } \\
\text { without Morgan 2011) }\end{array}$ & 2 & 166 & $\begin{array}{l}\text { Mean Difference } \\
\text { (Random, 95\% CI) }\end{array}$ & $-1.44[-3.05,0.17]$ \\
\hline $\begin{array}{l}10 \text { Waist circumference at } 6 \\
\text { mo }\end{array}$ & 2 & 464 & $\begin{array}{l}\text { Mean Difference (IV, } \\
\text { Random, 95\% CI) }\end{array}$ & $-1.68[-2.45,-0.91]$ \\
\hline $\begin{array}{l}11 \text { Waist circumference at } \\
12 \text { mo }\end{array}$ & 1 & & $\begin{array}{l}\text { Mean Difference (IV, } \\
\text { Random, 95\% CI) }\end{array}$ & Totals not selected \\
\hline $\begin{array}{l}11.1 \text { Computer group } \\
\text { includes computer plus in- } \\
\text { person intervention }\end{array}$ & 1 & & $\begin{array}{l}\text { Mean Difference (IV, } \\
\text { Random, 95\% CI) }\end{array}$ & $0.0[0.0,0.0]$ \\
\hline $\begin{array}{l}11.2 \text { Computer group } \\
\text { excludes computer plus in- } \\
\text { person intervention }\end{array}$ & 1 & & $\begin{array}{l}\text { Mean Difference (IV, } \\
\text { Random, 95\% CI) }\end{array}$ & $0.0[0.0,0.0]$ \\
\hline $\begin{array}{l}12 \text { Energy intake at } 3 \text { to } 4 \\
\text { mo }\end{array}$ & 1 & & $\begin{array}{l}\text { Mean Difference (IV, } \\
\text { Random, 95\% CI) }\end{array}$ & Totals not selected \\
\hline 13 Energy intake at 6 mo & 1 & & $\begin{array}{l}\text { Mean Difference (IV, } \\
\text { Random, 95\% CI) }\end{array}$ & Totals not selected \\
\hline 14 Energy intake at $12 \mathrm{mo}$ & 1 & & $\begin{array}{l}\text { Mean Difference (IV, } \\
\text { Random, 95\% CI) }\end{array}$ & Totals not selected \\
\hline $\begin{array}{l}14.1 \text { Computer group } \\
\text { includes computer plus in- } \\
\text { person intervention }\end{array}$ & 1 & & $\begin{array}{l}\text { Mean Difference (IV, } \\
\text { Random, 95\% CI) }\end{array}$ & $0.0[0.0,0.0]$ \\
\hline $\begin{array}{l}14.2 \text { Computer group } \\
\text { excludes computer plus in- } \\
\text { person intervention }\end{array}$ & 1 & & $\begin{array}{l}\text { Mean Difference (IV, } \\
\text { Random, 95\% CI) }\end{array}$ & $0.0[0.0,0.0]$ \\
\hline $\begin{array}{l}15 \text { Energy intake from fat at } \\
6 \text { mo }\end{array}$ & 1 & & $\begin{array}{l}\text { Mean Difference (IV, } \\
\text { Random, 95\% CI) }\end{array}$ & Totals not selected \\
\hline $\begin{array}{l}16 \text { Energy intake from fat at } \\
12 \text { mo }\end{array}$ & 1 & & $\begin{array}{l}\text { Mean Difference (IV, } \\
\text { Random, 95\% CI) }\end{array}$ & Totals not selected \\
\hline $\begin{array}{l}\text { 16.1 Computer group } \\
\text { includes computer plus in- } \\
\text { person intervention }\end{array}$ & 1 & & $\begin{array}{l}\text { Mean Difference (IV, } \\
\text { Random, 95\% CI) }\end{array}$ & $0.0[0.0,0.0]$ \\
\hline $\begin{array}{l}\text { 16.2 Computer group } \\
\text { excludes computer plus in- } \\
\text { person intervention }\end{array}$ & 1 & & $\begin{array}{l}\text { Mean Difference (IV, } \\
\text { Random, 95\% CI) }\end{array}$ & $0.0[0.0,0.0]$ \\
\hline
\end{tabular}




\begin{tabular}{|c|c|c|c|c|}
\hline Outcome or subgroup title & No. of studies & No. of participants & Statistical method & Effect size \\
\hline 17 Dietary fibre at $6 \mathrm{mo}$ & 1 & & $\begin{array}{l}\text { Mean Difference (IV, } \\
\text { Random, 95\% CI) }\end{array}$ & Totals not selected \\
\hline 18 Physical activity at $3 \mathrm{mo}$ & 2 & & $\begin{array}{l}\text { Mean Difference } \\
\text { (Random, 95\% CI) }\end{array}$ & Totals not selected \\
\hline $\begin{array}{l}18.1 \text { Total MET minutes } \\
\text { (log transformed) }\end{array}$ & 1 & & $\begin{array}{l}\text { Mean Difference } \\
\text { (Random, 95\% CI) }\end{array}$ & $0.0[0.0,0.0]$ \\
\hline 18.2 Mean steps/day & 1 & & $\begin{array}{l}\text { Mean Difference } \\
\text { (Random, 95\% CI) }\end{array}$ & $0.0[0.0,0.0]$ \\
\hline 19 Physical activity at 6 mo & 2 & 464 & $\begin{array}{l}\text { Std. Mean Difference } \\
\text { (IV, Random, 95\% CI) }\end{array}$ & $-0.04[-0.22,0.14]$ \\
\hline $\begin{array}{l}20 \text { Physical activity at } 12 \\
\text { mo }\end{array}$ & 1 & & $\begin{array}{l}\text { Mean Difference (IV, } \\
\text { Random, 95\% CI) }\end{array}$ & Totals not selected \\
\hline $\begin{array}{l}20.1 \text { Computer group } \\
\text { includes computer plus in- } \\
\text { person intervention }\end{array}$ & 1 & & $\begin{array}{l}\text { Mean Difference (IV, } \\
\text { Random, 95\% CI) }\end{array}$ & $0.0[0.0,0.0]$ \\
\hline $\begin{array}{l}20.2 \text { Computer group } \\
\text { excludes computer plus in- } \\
\text { person intervention }\end{array}$ & 1 & & $\begin{array}{l}\text { Mean Difference (IV, } \\
\text { Random, 95\% CI) }\end{array}$ & $0.0[0.0,0.0]$ \\
\hline
\end{tabular}

\section{Comparison 2. Weight loss: computer vs in-person interventions}

\begin{tabular}{|c|c|c|c|c|}
\hline $\begin{array}{l}\text { Outcome or subgroup } \\
\text { title }\end{array}$ & No. of studies & No. of participants & Statistical method & Effect size \\
\hline 1 Weight at $6 \mathrm{mo}$ & 1 & & $\begin{array}{l}\text { Mean Difference (IV, Fixed, } \\
95 \% \text { CI) }\end{array}$ & Totals not selected \\
\hline $\begin{array}{l}1.1 \text { Computer vs in- } \\
\text { person }\end{array}$ & 1 & & $\begin{array}{l}\text { Mean Difference (IV, Fixed, } \\
95 \% \text { CI) }\end{array}$ & $0.0[0.0,0.0]$ \\
\hline $\begin{array}{l}\quad 1.2 \text { Computer vs } \\
\text { hybrid computer/in- } \\
\text { person }\end{array}$ & 1 & & $\begin{array}{l}\text { Mean Difference (IV, Fixed, } \\
\text { 95\% CI) }\end{array}$ & $0.0[0.0,0.0]$ \\
\hline $\begin{array}{l}2 \text { Change in weight at } \\
6 \text { mo }\end{array}$ & 1 & & $\begin{array}{l}\text { Mean Difference (IV, } \\
\text { Random, 95\% CI) }\end{array}$ & Totals not selected \\
\hline $\begin{array}{l}2.1 \text { Computer vs in- } \\
\text { person }\end{array}$ & 1 & & $\begin{array}{l}\text { Mean Difference (IV, } \\
\text { Random, 95\% CI) }\end{array}$ & $0.0[0.0,0.0]$ \\
\hline $\begin{array}{l}2.2 \text { Computer vs } \\
\text { hybrid computer/in- } \\
\text { person }\end{array}$ & 1 & & $\begin{array}{l}\text { Mean Difference (IV, } \\
\text { Random, 95\% CI) }\end{array}$ & $0.0[0.0,0.0]$ \\
\hline
\end{tabular}

\section{Comparison 3. Weight loss: computer-delivered interaction as adjunct to Internet program}

\begin{tabular}{|c|c|c|c|c|}
\hline $\begin{array}{l}\text { Outcome or } \\
\text { subgroup title }\end{array}$ & No. of studies & No. of participants & Statistical method & Effect size \\
\hline 1 Weight at 3 to 4 mo & 4 & & $\begin{array}{l}\text { Mean Difference (IV, } \\
\text { Random, 95\% CI) }\end{array}$ & Subtotals only \\
\hline $\begin{array}{l}\quad 1.1 \text { Adjunct } \\
\text { interactive computer } \\
\text { group includes both e- } \\
\text { mail and automated } \\
\text { feedback }\end{array}$ & 3 & 352 & $\begin{array}{l}\text { Mean Difference (IV, } \\
\text { Random, 95\% CI) }\end{array}$ & $-2.14[-2.85,-1.43]$ \\
\hline $\begin{array}{l}1.2 \text { Adjunct } \\
\text { interactive computer } \\
\text { group includes only e- } \\
\text { mail feedback }\end{array}$ & 3 & 291 & $\begin{array}{l}\text { Mean Difference (IV, } \\
\text { Random, 95\% CI) }\end{array}$ & $-2.29[-3.14,-1.45]$ \\
\hline
\end{tabular}




\begin{tabular}{|c|c|c|c|c|}
\hline $\begin{array}{l}\text { Outcome or } \\
\text { subgroup title }\end{array}$ & No. of studies & No. of participants & Statistical method & Effect size \\
\hline $\begin{array}{l}1.3 \text { Adjunct } \\
\text { interactive computer } \\
\text { group includes only } \\
\text { automated feedback }\end{array}$ & 1 & 128 & $\begin{array}{l}\text { Mean Difference (IV, } \\
\text { Random, 95\% CI) }\end{array}$ & $-1.80[-3.15,-0.45]$ \\
\hline $\begin{array}{l}1.4 \text { Adjunct } \\
\text { interactive computer } \\
\text { group was non- } \\
\text { directive e-coaching }\end{array}$ & 1 & 69 & $\begin{array}{l}\text { Mean Difference (IV, } \\
\text { Random, 95\% CI) }\end{array}$ & $-0.25[-2.17,1.67]$ \\
\hline $\begin{array}{l}1.5 \text { Adjunct } \\
\text { interactive computer } \\
\text { group participated in } \\
\text { online group chats }\end{array}$ & 1 & 66 & $\begin{array}{l}\text { Mean Difference (IV, } \\
\text { Random, 95\% CI) }\end{array}$ & $1.51[-0.71,3.73]$ \\
\hline 2 Weight at $6 \mathrm{mo}$ & 1 & & $\begin{array}{l}\text { Mean Difference (IV, } \\
\text { Random, } 95 \% \text { CI) }\end{array}$ & Totals not selected \\
\hline $\begin{array}{l}2.1 \text { Adjunct } \\
\text { interactive computer } \\
\text { group includes both e- } \\
\text { mail and automated } \\
\text { feedback }\end{array}$ & 1 & & $\begin{array}{l}\text { Mean Difference (IV, } \\
\text { Random, 95\% CI) }\end{array}$ & $0.0[0.0,0.0]$ \\
\hline $\begin{array}{l}2.2 \text { Adjunct } \\
\text { interactive computer } \\
\text { group includes only e- } \\
\text { mail feedback }\end{array}$ & 1 & & $\begin{array}{l}\text { Mean Difference (IV, } \\
\text { Random, 95\% CI) }\end{array}$ & $0.0[0.0,0.0]$ \\
\hline $\begin{array}{l}2.3 \text { Adjunct } \\
\text { interactive computer } \\
\text { group includes only } \\
\text { automated feedback }\end{array}$ & 1 & & $\begin{array}{l}\text { Mean Difference (IV, } \\
\text { Random, 95\% CI) }\end{array}$ & $0.0[0.0,0.0]$ \\
\hline 3 Weight at $12 \mathrm{mo}$ & 1 & & $\begin{array}{l}\text { Mean Difference (IV, } \\
\text { Random, 95\% CI) }\end{array}$ & Totals not selected \\
\hline $\begin{array}{l}4 \text { Change in weight at } \\
3 \text { mo }\end{array}$ & 2 & & $\begin{array}{l}\text { Mean Difference (IV, } \\
\text { Random, 95\% CI) }\end{array}$ & Subtotals only \\
\hline $\begin{array}{l}\text { 4.1 Adjunct } \\
\text { interactive computer } \\
\text { group includes both e- } \\
\text { mail and automated } \\
\text { feedback }\end{array}$ & 2 & 227 & $\begin{array}{l}\text { Mean Difference (IV, } \\
\text { Random, 95\% CI) }\end{array}$ & $-2.48[-4.09,-0.87]$ \\
\hline $\begin{array}{l}4.2 \text { Adjunct } \\
\text { interactive computer } \\
\text { group includes only e- } \\
\text { mail feedback }\end{array}$ & 2 & 180 & $\begin{array}{l}\text { Mean Difference (IV, } \\
\text { Random, 95\% CI) }\end{array}$ & $-2.65[-4.73,-0.56]$ \\
\hline $\begin{array}{l}\quad 4.3 \text { Adjunct } \\
\text { interactive computer } \\
\text { group includes only } \\
\text { automated feedback }\end{array}$ & 1 & 102 & $\begin{array}{l}\text { Mean Difference (IV, } \\
\text { Random, 95\% CI) }\end{array}$ & $-2.60[-4.19,-1.01]$ \\
\hline $\begin{array}{l}\quad 4.4 \text { Adjunct } \\
\text { interactive computer } \\
\text { group was non- } \\
\text { directive e-coaching }\end{array}$ & 1 & 69 & $\begin{array}{l}\text { Mean Difference (IV, } \\
\text { Random, 95\% CI) }\end{array}$ & $-0.15[-2.29,1.99]$ \\
\hline $\begin{array}{l}5 \text { Change in weight at } \\
6 \text { mo }\end{array}$ & 1 & & $\begin{array}{l}\text { Mean Difference (IV, } \\
\text { Random, 95\% CI) }\end{array}$ & Totals not selected \\
\hline $\begin{array}{l}5.1 \text { Adjunct } \\
\text { interactive computer } \\
\text { group includes both e- } \\
\text { mail and automated } \\
\text { feedback }\end{array}$ & 1 & & $\begin{array}{l}\text { Mean Difference (IV, } \\
\text { Random, 95\% CI) }\end{array}$ & $0.0[0.0,0.0]$ \\
\hline $\begin{array}{l}5.2 \text { Adjunct } \\
\text { interactive computer } \\
\text { group includes only e- } \\
\text { mail feedback }\end{array}$ & 1 & & $\begin{array}{l}\text { Mean Difference (IV, } \\
\text { Random, } 95 \% \text { CI) }\end{array}$ & $0.0[0.0,0.0]$ \\
\hline $\begin{array}{l}5.3 \text { Adjunct } \\
\text { interactive computer }\end{array}$ & 1 & & $\begin{array}{l}\text { Mean Difference (IV, } \\
\text { Random, } 95 \% \text { CI) }\end{array}$ & $0.0[0.0,0.0]$ \\
\hline
\end{tabular}




\begin{tabular}{|c|c|c|c|c|}
\hline $\begin{array}{l}\text { Outcome or } \\
\text { subgroup title }\end{array}$ & No. of studies & No. of participants & Statistical method & Effect size \\
\hline \multicolumn{5}{|l|}{$\begin{array}{l}\text { group includes only } \\
\text { automated feedback }\end{array}$} \\
\hline $\begin{array}{l}6 \text { Change in weight at } \\
12 \text { oo }\end{array}$ & 1 & & $\begin{array}{l}\text { Mean Difference (IV, } \\
\text { Random, 95\% CI) }\end{array}$ & Totals not selected \\
\hline $7 \mathrm{BMI}$ at $12 \mathrm{mo}$ & 1 & & $\begin{array}{l}\text { Mean Difference (IV, } \\
\text { Random, 95\% CI) }\end{array}$ & Totals not selected \\
\hline $\begin{array}{l}8 \text { Waist circumference } \\
\text { at } 3 \mathrm{mo}\end{array}$ & 2 & & $\begin{array}{l}\text { Mean Difference (IV, } \\
\text { Random, 95\% CI) }\end{array}$ & Subtotals only \\
\hline $\begin{array}{l}\quad 8.1 \text { Adjunct } \\
\text { interactive computer } \\
\text { group was e- } \\
\text { counselling or } \\
\text { feedback }\end{array}$ & 2 & 160 & $\begin{array}{l}\text { Mean Difference (IV, } \\
\text { Random, 95\% CI) }\end{array}$ & $-2.62[-4.04,-1.21]$ \\
\hline $\begin{array}{l}8.2 \text { Adjunct } \\
\text { interactive computer } \\
\text { group was non- } \\
\text { directive e-counselling }\end{array}$ & 1 & 69 & $\begin{array}{l}\text { Mean Difference (IV, } \\
\text { Random, 95\% CI) }\end{array}$ & $-0.33[-2.82,2.16]$ \\
\hline $\begin{array}{l}9 \text { Waist circumference } \\
\text { at } 12 \mathrm{mo}\end{array}$ & 1 & & $\begin{array}{l}\text { Mean Difference (IV, } \\
\text { Random, 95\% CI) }\end{array}$ & Totals not selected \\
\hline $\begin{array}{l}10 \text { Calories at } 3 \text { to } 4 \\
\text { mo }\end{array}$ & 2 & & $\begin{array}{l}\text { Mean Difference (IV, } \\
\text { Random, 95\% CI) }\end{array}$ & Totals not selected \\
\hline $\begin{array}{l}10.1 \text { Adjunct } \\
\text { interactive computer } \\
\text { group includes both e- } \\
\text { mail and automated } \\
\text { feedback }\end{array}$ & 1 & & $\begin{array}{l}\text { Mean Difference (IV, } \\
\text { Random, 95\% CI) }\end{array}$ & $0.0[0.0,0.0]$ \\
\hline $\begin{array}{l}10.2 \text { Adjunct } \\
\text { interactive computer } \\
\text { group includes only e- } \\
\text { mail feedback }\end{array}$ & 1 & & $\begin{array}{l}\text { Mean Difference (IV, } \\
\text { Random, 95\% CI) }\end{array}$ & $0.0[0.0,0.0]$ \\
\hline $\begin{array}{l}10.3 \text { Adjunct } \\
\text { interactive computer } \\
\text { group includes only } \\
\text { automated feedback }\end{array}$ & 1 & & $\begin{array}{l}\text { Mean Difference (IV, } \\
\text { Random, 95\% CI) }\end{array}$ & $0.0[0.0,0.0]$ \\
\hline $\begin{array}{l}10.4 \text { Adjunct } \\
\text { interactive computer } \\
\text { group participated in } \\
\text { online group chats }\end{array}$ & 1 & & $\begin{array}{l}\text { Mean Difference (IV, } \\
\text { Random, 95\% CI) }\end{array}$ & $0.0[0.0,0.0]$ \\
\hline 11 Calories at $6 \mathrm{mo}$ & 1 & & $\begin{array}{l}\text { Mean Difference (IV, } \\
\text { Random, 95\% CI) }\end{array}$ & Totals not selected \\
\hline $\begin{array}{l}11.1 \text { Adjunct } \\
\text { interactive computer } \\
\text { group includes both e- } \\
\text { mail and automated } \\
\text { feedback }\end{array}$ & 1 & & $\begin{array}{l}\text { Mean Difference (IV, } \\
\text { Random, 95\% CI) }\end{array}$ & $0.0[0.0,0.0]$ \\
\hline $\begin{array}{l}11.2 \text { Adjunct } \\
\text { interactive computer } \\
\text { group includes only e- } \\
\text { mail feedback }\end{array}$ & 1 & & $\begin{array}{l}\text { Mean Difference (IV, } \\
\text { Random, 95\% CI) }\end{array}$ & $0.0[0.0,0.0]$ \\
\hline $\begin{array}{l}11.3 \text { Adjunct } \\
\text { interactive computer } \\
\text { group includes only } \\
\text { automated feedback }\end{array}$ & 1 & & $\begin{array}{l}\text { Mean Difference (IV, } \\
\text { Random, 95\% CI) }\end{array}$ & $0.0[0.0,0.0]$ \\
\hline $\begin{array}{l}12 \text { Calories from fat at } \\
3 \text { to } 4 \text { mo }\end{array}$ & 2 & & $\begin{array}{l}\text { Mean Difference (IV, } \\
\text { Random, 95\% CI) }\end{array}$ & Totals not selected \\
\hline $\begin{array}{l}12.1 \text { Adjunct } \\
\text { interactive computer } \\
\text { group includes both e- } \\
\text { mail and automated } \\
\text { feedback }\end{array}$ & 1 & & $\begin{array}{l}\text { Mean Difference (IV, } \\
\text { Random, 95\% CI) }\end{array}$ & $0.0[0.0,0.0]$ \\
\hline
\end{tabular}




\begin{tabular}{|c|c|c|c|c|}
\hline $\begin{array}{l}\text { Outcome or } \\
\text { subgroup title }\end{array}$ & No. of studies & No. of participants & Statistical method & Effect size \\
\hline $\begin{array}{l}12.2 \text { Adjunct } \\
\text { interactive computer } \\
\text { group includes only e- } \\
\text { mail feedback }\end{array}$ & 1 & & $\begin{array}{l}\text { Mean Difference (IV, } \\
\text { Random, 95\% CI) }\end{array}$ & $0.0[0.0,0.0]$ \\
\hline $\begin{array}{l}12.3 \text { Adjunct } \\
\text { interactive computer } \\
\text { group includes only } \\
\text { automated feedback }\end{array}$ & 1 & & $\begin{array}{l}\text { Mean Difference (IV, } \\
\text { Random, 95\% CI) }\end{array}$ & $0.0[0.0,0.0]$ \\
\hline $\begin{array}{l}12.4 \text { Adjunct } \\
\text { interactive computer } \\
\text { group participated in } \\
\text { online group chats }\end{array}$ & 1 & & $\begin{array}{l}\text { Mean Difference (IV, } \\
\text { Random, 95\% CI) }\end{array}$ & $0.0[0.0,0.0]$ \\
\hline $\begin{array}{l}13 \text { Calories from fat at } \\
6 \mathrm{mo}\end{array}$ & 1 & & $\begin{array}{l}\text { Mean Difference (IV, } \\
\text { Random, 95\% CI) }\end{array}$ & Totals not selected \\
\hline $\begin{array}{l}13.1 \text { Adjunct } \\
\text { interactive computer } \\
\text { group includes both e- } \\
\text { mail and automated } \\
\text { feedback }\end{array}$ & 1 & & $\begin{array}{l}\text { Mean Difference (IV, } \\
\text { Random, 95\% CI) }\end{array}$ & $0.0[0.0,0.0]$ \\
\hline $\begin{array}{l}13.2 \text { Adjunct } \\
\text { interactive computer } \\
\text { group includes only e- } \\
\text { mail feedback }\end{array}$ & 1 & & $\begin{array}{l}\text { Mean Difference (IV, } \\
\text { Random, 95\% CI) }\end{array}$ & $0.0[0.0,0.0]$ \\
\hline $\begin{array}{l}13.3 \text { Adjunct } \\
\text { interactive computer } \\
\text { group includes only } \\
\text { automated feedback }\end{array}$ & 1 & & $\begin{array}{l}\text { Mean Difference (IV, } \\
\text { Random, 95\% CI) }\end{array}$ & $0.0[0.0,0.0]$ \\
\hline $\begin{array}{l}14 \text { Calories from fat at } \\
12 \mathrm{mo}\end{array}$ & 1 & & $\begin{array}{l}\text { Mean Difference (IV, } \\
\text { Random, 95\% CI) }\end{array}$ & Totals not selected \\
\hline $\begin{array}{l}15 \text { Physical activity at } \\
\text { to } 4 \text { mo }\end{array}$ & 3 & & $\begin{array}{l}\text { Mean Difference (IV, } \\
\text { Random, 95\% CI) }\end{array}$ & Subtotals only \\
\hline $\begin{array}{l}15.1 \text { Adjunct } \\
\text { interactive computer } \\
\text { group includes both e- } \\
\text { mail and automated } \\
\text { feedback }\end{array}$ & 2 & 250 & $\begin{array}{l}\text { Mean Difference (IV, } \\
\text { Random, 95\% CI) }\end{array}$ & $346.87[93.88,599.86]$ \\
\hline $\begin{array}{l}15.2 \text { Adjunct } \\
\text { interactive computer } \\
\text { group includes only e- } \\
\text { mail feedback }\end{array}$ & 2 & 203 & $\begin{array}{l}\text { Mean Difference (IV, } \\
\text { Random, 95\% CI) }\end{array}$ & $353.45[96.19,610.70]$ \\
\hline $\begin{array}{l}15.3 \text { Adjunct } \\
\text { interactive computer } \\
\text { group includes only } \\
\text { automated feedback }\end{array}$ & 1 & 102 & $\begin{array}{l}\text { Mean Difference (IV, } \\
\text { Random, 95\% CI) }\end{array}$ & $189.30[-375.33,753.93]$ \\
\hline $\begin{array}{l}15.4 \text { Adjunct } \\
\text { interactive computer } \\
\text { group participated in } \\
\text { online chats }\end{array}$ & 1 & 65 & $\begin{array}{l}\text { Mean Difference (IV, } \\
\text { Random, 95\% CI) }\end{array}$ & $498.0[-510.96,1506.96]$ \\
\hline $\begin{array}{l}16 \text { Physical activity at } \\
6 \text { mo }\end{array}$ & 1 & & $\begin{array}{l}\text { Mean Difference (IV, } \\
\text { Random, 95\% CI) }\end{array}$ & Totals not selected \\
\hline $\begin{array}{l}16.1 \text { Interactive } \\
\text { group includes both e- } \\
\text { mail and automated } \\
\text { feedback }\end{array}$ & 1 & & $\begin{array}{l}\text { Mean Difference (IV, } \\
\text { Random, 95\% CI) }\end{array}$ & $0.0[0.0,0.0]$ \\
\hline $\begin{array}{l}16.2 \text { Interactive } \\
\text { group includes only e- } \\
\text { mail feedback }\end{array}$ & 1 & & $\begin{array}{l}\text { Mean Difference (IV, } \\
\text { Random, 95\% CI) }\end{array}$ & $0.0[0.0,0.0]$ \\
\hline $\begin{array}{l}16.3 \text { Interactive } \\
\text { group includes only } \\
\text { automated feedback }\end{array}$ & 1 & & $\begin{array}{l}\text { Mean Difference (IV, } \\
\text { Random, 95\% CI) }\end{array}$ & $0.0[0.0,0.0]$ \\
\hline
\end{tabular}




\begin{tabular}{lccll}
\hline $\begin{array}{l}\text { Outcome or } \\
\text { subgroup title }\end{array}$ & No. of studies & No. of participants & Statistical method & Effect size \\
\hline $\begin{array}{l}17 \text { Physical activity at } \\
12 \text { mo }\end{array}$ & 1 & $\begin{array}{l}\text { Mean Difference (IV, } \\
\text { Random, 95\% CI) }\end{array}$ & Totals not selected \\
\hline
\end{tabular}

\section{Comparison 4. Weight loss: Computer intervention as adjunct to in-person program}

\begin{tabular}{lclll}
\hline $\begin{array}{l}\text { Outcome or subgroup } \\
\text { title }\end{array}$ & No. of studies & No. of participants & Statistical method & Effect size \\
\hline 1 Weight at 10 weeks & 1 & $\begin{array}{l}\text { Mean Difference (IV, } \\
\text { Random, 95\% CI) }\end{array}$ & Totals not selected \\
& \multirow{2}{*}{$\begin{array}{l}\text { Mean Difference (IV, } \\
\text { Random, 95\% CI) }\end{array}$} & Totals not selected \\
$\begin{array}{l}\text { 2 Weight at } 6 \text { mo after } \\
\text { end of treatment }\end{array}$ & 1 & & \\
\hline
\end{tabular}

\section{Comparison 5. Weight maintenance: computer vs minimal intervention}

\begin{tabular}{|c|c|c|c|c|}
\hline $\begin{array}{l}\text { Outcome or } \\
\text { subgroup title }\end{array}$ & No. of studies & No. of participants & Statistical method & Effect size \\
\hline $\begin{array}{l}1 \text { Weight at } 6 \mathrm{mo} \\
{[\mathrm{kg}]}\end{array}$ & 2 & 897 & $\begin{array}{l}\text { Mean Difference (Random, } \\
95 \% \text { CI) }\end{array}$ & $-0.70[-1.17,-0.23]$ \\
\hline $\begin{array}{l}2 \mathrm{Weight} \text { at } 12 \mathrm{mo} \\
{[\mathrm{kg}]}\end{array}$ & 3 & 1004 & $\begin{array}{l}\text { Mean Difference (Random, } \\
95 \% \text { CI) }\end{array}$ & $-0.78[-1.38,-0.17]$ \\
\hline $\begin{array}{l}3 \text { Weight at } 18 \mathrm{mo} \\
{[\mathrm{kg}]}\end{array}$ & 2 & 897 & $\begin{array}{l}\text { Mean Difference (Random, } \\
95 \% \text { CI) }\end{array}$ & $-0.73[-1.60,0.14]$ \\
\hline $\begin{array}{l}4 \text { Weight at } 24 \mathrm{mo} \\
{[\mathrm{kg}]}\end{array}$ & 1 & & $\begin{array}{l}\text { Mean Difference (Random, } \\
95 \% \mathrm{CI} \text { ) }\end{array}$ & Totals not selected \\
\hline 5 Weight at $30 \mathrm{mo}$ & 1 & & $\begin{array}{l}\text { Mean Difference (IV, } \\
\text { Random, 95\% CI) }\end{array}$ & Totals not selected \\
\hline $\begin{array}{l}6 \text { Change in weight at } \\
30 \mathrm{mo}[\%]\end{array}$ & 1 & & $\begin{array}{l}\text { Mean Difference (Random, } \\
95 \% \mathrm{CI} \text { ) }\end{array}$ & Totals not selected \\
\hline $7 \mathrm{BMI}$ at $12 \mathrm{mo}$ & 1 & & $\begin{array}{l}\text { Mean Difference (IV, } \\
\text { Random, 95\% CI) }\end{array}$ & Totals not selected \\
\hline $\begin{array}{l}8 \text { Energy intake at } 12 \\
\text { mo }\end{array}$ & 1 & & $\begin{array}{l}\text { Mean Difference (IV, } \\
\text { Random, 95\% CI) }\end{array}$ & Totals not selected \\
\hline $\begin{array}{l}9 \text { Energy intake at } 30 \\
\mathrm{mo}[\mathrm{kcal} / \mathrm{day}]\end{array}$ & 1 & & $\begin{array}{l}\text { Mean Difference (Random, } \\
\text { 95\% CI) }\end{array}$ & Totals not selected \\
\hline $\begin{array}{l}10 \text { Energy } \\
\text { expenditure at } 12 \mathrm{mo}\end{array}$ & 1 & 107 & $\begin{array}{l}\text { Mean Difference (IV, } \\
\text { Random, 95\% CI) }\end{array}$ & $\begin{array}{l}-7.00[-117.14,103 . \\
14]\end{array}$ \\
\hline
\end{tabular}

\section{Comparison 6. Weight maintenance: computer vs infrequent in-person support}

\begin{tabular}{lccll}
\hline $\begin{array}{l}\text { Outcome or subgroup } \\
\text { title }\end{array}$ & No. of studies & No. of participants & Statistical method & Effect size \\
\hline 1 Weight at $6 \mathrm{mo}[\mathrm{kg}]$ & 2 & 897 & $\begin{array}{l}\text { Mean Difference (Random, } \\
95 \% \mathrm{CI})\end{array}$ & $0.54[-0.53,1.62]$ \\
2 Weight at $12 \mathrm{mo}[\mathrm{kg}]$ & 3 & 955 & $\begin{array}{l}\text { Mean Difference (Random, } \\
95 \% \mathrm{CI})\end{array}$ & $1.56[-0.12,3.23]$ \\
3 Weight at $18 \mathrm{mo}[\mathrm{kg}]$ & 2 & 897 & $\begin{array}{l}\text { Mean Difference (Random, } \\
95 \% \text { CI) }\end{array}$ & $1.12[-0.20,2.45]$ \\
& 1 & & $\begin{array}{l}\text { Mean Difference (Random, } \\
95 \% \mathrm{CI})\end{array}$ & Totals not selected
\end{tabular}




\begin{tabular}{lcclc}
\hline $\begin{array}{l}\text { Outcome or subgroup } \\
\text { title }\end{array}$ & No. of studies & No. of participants & Statistical method & Effect size \\
\hline 5 Weight at 30 mo & 1 & $\begin{array}{l}\text { Mean Difference (IV, } \\
\text { Random, 95\% CI) }\end{array}$ & Totals not selected \\
& 1 & $\begin{array}{l}\text { Mean Difference (Random, } \\
95 \% \text { CI) }\end{array}$ & Totals not selected \\
$\begin{array}{l}\text { 6 Change in weight at } \\
30 \text { mo [\%] }\end{array}$ & 1 & $\begin{array}{l}\text { Mean Difference (Random, } \\
95 \% \text { CI) }\end{array}$ & Totals not selected \\
$\begin{array}{l}7 \text { Energy intake at 30 } \\
\text { mo [kcal/day] }\end{array}$ & & & \\
\hline
\end{tabular}

\section{Comparison 7. Weight maintenance: computer vs frequent in-person support}

\begin{tabular}{lclll}
\hline $\begin{array}{l}\text { Outcome or } \\
\text { subgroup title }\end{array}$ & No. of studies & No. of participants & Statistical method & Effect size \\
\hline 1 Weight at 6 mo & 1 & $\begin{array}{l}\text { Mean Difference (IV, } \\
\text { Random, 95\% CI) }\end{array}$ & Totals not selected \\
& \multirow{2}{*}{$\begin{array}{l}\text { Mean Difference (IV, } \\
\text { Random, 95\% CI) }\end{array}$} & Totals not selected \\
\hline
\end{tabular}

\section{References}

* Indicates the major publication for the study

\section{References to studies included in this review}

Bennett 2010 \{published data only\}. Bennett GG, Herring SJ, Puleo E, Stein EK, Emmons KM, Gillman MW. Web-based weight loss in primary care: a randomized controlled trial. Obesity (Silver Spring, Md). 2010; 18(2):308-13.

Cussler 2008 \{published data only\}. Cussler EC, Teixeira PJ, Going SB, Houtkooper LB, Metcalfe LL, Blew RM, et al. Maintenance of weight loss in overweight middle-aged women through the Internet. Obesity (Silver Spring, Md). 2008; 16(5):1052-60.

DeLucia 1988 \{published and unpublished data\}. DeLucia JL, Kalodner CR, Horan JJ. The effect of two nutritional software programs used as adjuncts to the behavioral treatment of obesity. Journal of Substance Abuse. 1988; 1(2):203-8. [PubMed: 2980870]

Gabriele 2011 \{published data only\}. Gabriele JM, Carpenter BD, Tate DF, Fisher EB. Directive and nondirective e-coach support for weight loss in overweight adults. Annals of Behavioral Medicine. 2011; 41 (2):252-63. [PubMed: 21108032]

Harvey-Berino 2002 \{published data only\}. Harvey-Berino J, Pintauro S, Buzzell P, DiGiulio M, Gold $\mathrm{BC}$, Moldovan C, et al. Does using the Internet facilitate the maintenance of weight loss? International Journal of Obesity and Related Metabolic Disorders. 2002; 26(9):1254-60. [PubMed: 12187404]

Harvey-Berino 2010 \{published data only\}. Harvey-Berino J, West D, Krukowski R, Prewitt E, VanBiervliet A, Ashikaga T, et al. Internet delivered behavioral obesity treatment. Preventive Medicine. 2010; 51 (2):123-8. [PubMed: 20478333] Krukowski RA, Tilford JM, Harvey-Berino J, West DS. Comparative cost-effectiveness for in-person versus online behavioral weight loss programs. Obesity Reviews. 2010; 11(Suppl 1):249.Krukowski RA, Tilford JM, Harvey-Berino J, West DS. Comparing behavioral weight loss modalities: incremental cost-effectiveness of an internet-based versus an in-person condition. Obesity (Silver Spring, Md). 2011; 19(8):1629-35.

Hunter 2008 \{published data only\}. Hunter CM, Peterson AL, Alvarez LM, Poston WC, Brundige AR, Haddock CK, et al. Weight management using the internet a randomized controlled trial. American Journal of Preventive Medicine. 2008; 34(2):119-26. [PubMed: 18201641] Rasu RS, Hunter CM, Peterson AL, Maruska HM, Foreyt JP. Economic evaluation of an Internet-based weight management program. American Journal of Managed Care. 2010; 16(4):e98-104. 
[PubMed: 20370312] Rasu RS, Hunter CM, Peterson AL, Maruska HM, Foreyt JP. Economic evaluation of an Internet-based weight management program. American Journal of Managed Care. 2010; 16(4):e98-e104. [PubMed: 20370312]

Morgan 2009 \{published data only\}. Collins CE, Morgan PJ, Warren JM, Lubans DR, Callister R. Men participating in a weight-loss intervention are able to implement key dietary messages, but not those relating to vegetables or alcohol: the Self-Help, Exercise and Diet using Internet Technology (SHED-IT) study. Public Health Nutrition. 2011; 14(1):168-75. [PubMed: 20602869] Lubans DR, Morgan PJ, Collins CE, Warren JM, Callister R. Exploring the mechanisms of weight loss in the SHED-IT intervention for overweight men: a mediation analysis. International Journal of Behavioral Nutrition and Physical Activity. 2009; 6:76. [PubMed: 19922613] Morgan PJ, Lubans DR, Collins CE, Warren JM, Callister R. 12-month outcomes and process evaluation of the SHED-IT RCT: an internet-based weight loss program targeting men. Obesity (Silver Spring, Md). 2011; 19(1):142-51.Morgan PJ, Lubans DR, Collins CE, Warren JM, Callister R. The SHED-IT randomized controlled trial: evaluation of an Internetbased weight-loss program for men. Obesity (Silver Spring, Md). 2009; 17(11):2025-32.

Morgan 2011 \{published and unpublished data\}. Morgan PJ, Collins CE, Plotnikoff RC, Cook AT, Berthon B, Mitchell S, et al. Efficacy of a workplace-based weight loss program for overweight male shift workers: the Workplace POWER (Preventing Obesity Without Eating like a Rabbit) randomized controlled trial. Preventive Medicine. 2011; 52 (5):317-25. [PubMed: 21300083]

Schroder 2010 \{published data only\}. Schroder KE. Computer-assisted dieting: effects of a randomised controlled intervention. Psychology and Health. 2010; 25(5):519-34. [PubMed: 20204974]

* Svetkey 2008 \{published data only\}. Brantley P, Appel L, Hollis J, Stevens V, Ard J, Champagne C, et al. Design considerations and rationale of a multi-center trial to sustain weight loss: the Weight Loss Maintenance Trial. Clinical Trials (London, England). 2008; 5(5):546-56.Funk KL, Stevens VJ, Appel LJ, Bauck A, Brantley PJ, Champagne CM, et al. Associations of internet website use with weight change in a long-term weight loss maintenance program. Journal of Medical Internet Research. 2010; 12(3):e29. [PubMed: 20663751] Hollis JF, Gullion CM, Stevens VJ, Brantley PJ, Appel LJ, Ard JD, et al. Weight loss during the intensive intervention phase of the weightloss. American Journal of Preventive Medicine. 2008; 35(2):118-26. [PubMed: 18617080] Meenan RT, Stevens VJ, Funk K, Bauck A, Jerome GJ, Lien LF, et al. Development and implementation cost analysis of telephone- and Internet-based interventions for the maintenance of weight loss. International Journal of Technology Assessment in Health Care. 2009; 25(3):40010. [PubMed: 19619360] Meenan RT, Stevens VJ, Funk K, Bauck A, Jerome GJ, Stevens VJ, et al. PS2-34: Implementation cost analysis of telephone and internet-based interventions for the maintenance of weight loss. Clinical Medicine and Research. 2010; 8(1):52-b.Stevens VJ, Funk KL, Brantley PJ, Erlinger TP, Myers VH, Champagne CM, et al. Design and implementation of an interactive website to support long-term maintenance of weight loss. Journal of Medical Internet Research. 2008; 10(1):e1. [PubMed: 18244892] Svetkey LP, Stevens VJ, Brantley PJ, Appel LJ, Hollis JF, Loria CM, et al. Comparison of strategies for sustaining weight loss: the weight loss maintenance randomized controlled trial. JAMA. 2008; 299(10):1139-48. [PubMed: 18334689]

Tate 2001 ppublished data only\}. Tate DF, Wing RR, Winett RA. Using Internet technology to deliver a behavioral weight loss program. JAMA. 2001; 285(9):1172-7. [PubMed: 11231746]

Tate 2003 \{published data only\}. Tate DF, Jackvony EH, Wing RR. Effects of Internet behavioral counseling on weight loss in adults at risk for type 2 diabetes: a randomized trial. JAMA. 2003; 289(14):1833-6. [PubMed: 12684363]

Tate 2006 \{published data only\}. Tate DF, Jackvony EH, Wing RR. A randomized trial comparing human e-mail counseling, computer-automated tailored counseling, and no counseling in an Internet weight loss program. Archives of Internal Medicine. 2006; 166(15):1620-5. [PubMed: 16908795]

Threlfall 1984 \{published data only\}. Threlfall WE. Computer-assisted bibliotherapy for weight control. Dissertation Abstracts International. 1984; 45(6-A):1697-8.

Webber 2008 \{published data only\}. Webber KH, Tate DF, Michael Bowling J. A randomized comparison of two motivationally enhanced Internet behavioral weight loss programs. Behaviour Research and Therapy. 2008; 46(9):1090-5. [PubMed: 18675402] Webber KH, Tate DF, Ward 
DS, Bowling JM. Motivation and its relationship to adherence to self-monitoring and weight loss in a 16-week Internet behavioral weight loss intervention. Journal of Nutrition Education and Behavior. 2010; 42(3):161-7. [PubMed: 20138583]

*Wing 2006 \{published data only\}. Marinilli Pinto A, Gorin AA, Raynor HA, Tate DF, Fava JL, Wing RR. Successful weight-loss maintenance in relation to method of weight loss. Obesity (Silver Spring, Md). 2008; 16(11):2456-61.Wing RR, Tate DF, Gorin AA, Raynor HA, Fava JL. A selfregulation program for maintenance of weight loss. New England Journal of Medicine. 2006; 355(15):1563-71. [PubMed: 17035649] Wing RR, Tate DF, Gorin AA, Raynor HA, Fava JL, Machan J. STOP regain: are there negative effects of daily weighing? [erratum appears in Journal of Consulting \& Clinical Psychology 2007 Oct;75(5):715]. Journal of Consulting \& Clinical Psychology. 2007; 75(4):652-6. [PubMed: 17663619]

Wylie-Rosett 2001 \{published data only\}. Wylie-Rosett J, Swencionis C, Ginsberg M, Cimino C, Wassertheil-Smoller S, Caban A, et al. Computerized weight loss intervention optimizes staff time: the clinical and cost results of a controlled clinical trial conducted in a managed care setting. Journal of the American Dietetic Association. 2001; 101(10):1155-62. quiz 1163-4. [PubMed: 11678486]

\section{References to studies excluded from this review}

Adachi 2007 \{published data only\}. Adachi Y, Sato C, Yamatsu K, Ito S, Adachi K, Yamagami T. A randomized controlled trial on the long-term effects of a 1-month behavioral weight control program assisted by computer tailored advice. Behaviour Research and Therapy. 2007; 45(3): 459-70. [PubMed: 16713991]

Agras 1990 \{published data only\}. Agras WS, Barr TC, Feldman DE, Losch M, Burnett KF. Developing computer-assisted therapy for the treatment of obesity. Behavior Therapy. 1990; 1:99-109.

Anderson-Bill 2011 \{published data only\}. Anderson-Bill ES, Winett RA, Wojcik JR, Winett SG. Web-based guide to health: relationship of theoretical variables to change in physical activity, nutrition and weight at 16-months. Journal of Medical Internet Research. 2011; 13(1):e27. [PubMed: 21447470]

Vol Kinesiology \& Health Bischoff 2010 \{published data only\}. Bischoff, SA. ProQuest Dissertation Dissertations. United States —- Wyoming: Kinesiology \& Health; 2010. The effects of goal setting on increasing physical activity behavior through a 16-week internet-delivered intervention.

Booth 2008 \{published data only\}. Booth AO, Nowson CA, Matters H, Booth AO, Nowson CA, Matters $\mathrm{H}$. Evaluation of an interactive, Internet-based weight loss program: a pilot study. Health Education Research. 2008; 23(3):371-81. [PubMed: 18349032]

Brantley 2008 \{published data only\}. Brantley P, Appel L, Hollis J, Stevens V, Ard J, Champagne C, et al. Design considerations and rationale of a multi-center trial to sustain weight loss: the Weight Loss Maintenance Trial. Clinical Trials. 2008; 5(5):546-56. [PubMed: 18827047]

Burke 2011 \{published data only\}. Burke LE, Conroy MB, Sereika SM, Elci OU, Styn MA, Acharya $\mathrm{SD}$, et al. The effect of electronic self-monitoring on weight loss and dietary intake: a randomized behavioral weight loss trial. Obesity. 2011; 19(2):338-44. [PubMed: 20847736]

Burnett 1984 \{published data only\}. Burnett, KF. Dissertation. Stanford University; 1984. Ambulatory computer-assisted therapy in the behavioral treatment of obesity.

Burnett 1992 \{published data only\}. Burnett KF, Taylor C, Agras W. Ambulatory computer-assisted behavior therapy for obesity: an empirical model for examining behavioral correlates of treatment outcome. Computers in Human Behavior. 1992; 8(2-3):239-48.

Campbell 2002 \{published data only\}. Campbell MK, Tessaro I, DeVellis B, Benedict S, Kelsey K, Belton L, et al. Effects of a tailored health promotion program for female blue-collar workers: Health Works for Women. Preventive Medicine. 2002; 34(3):313-23. [PubMed: 11902848]

Cange 2008 \{published data only\}. Cange A, Bickmore T, Harris K, Neylon D, Kvedar J, Brown J, et al. Improving adherence to an exercise program: a personalized virtual coach. Telemedicine and e-Health. 2008; 14(Suppl 1):39. 
Carr 2008 \{published data only\}. Carr LJ, Bartee RT, Dorozynski C, Broomfield JF, Smith ML, Smith DT, et al. Internet-delivered behavior change program increases physical activity and improves cardiometabolic disease risk factors in sedentary adults: results of a randomized controlled trial. Preventive Medicine. 2008; 46(5):431-8. [PubMed: 18207228]

Carr 2009 \{published data only\}. Carr LJ. Short and long-term efficacy of an internet-delivered physical activity behavior change program on physical activity and cardiometabolic disease risk factors in sedentary, overweight adults. Dissertation Abstracts International: Section B: The Sciences and Engineering. 2009; 69(12-B):7454.

Carrard 2011 \{published data only\}. Carrard I, Crepin C, Rouget P, Lam T, Van der Linden M, Golay A. Acceptance and efficacy of a guided internet self-help treatment program for obese patients with binge eating disorder. Clinical Practice and Epidemiology in Mental Health. 2011; 7:8-18. [PubMed: 21552482]

Castelnuovo 2011 \{published data only\}. Castelnuovo G, Manzoni GM, Cuzziol P, Cesa GL, Corti S, Tuzzi C, et al. TECNOB Study: ad interim results of a randomized controlled trial of a multidisciplinary telecare intervention for obese patients with type-2 diabetes. Clinical Practice and Epidemiology in Mental Health. 2011; 7:44-50. [PubMed: 21559233]

Christian 2011 \{published data only\}. Christian JG, Byers TE, Christian KK, Goldstein MG, Bock BC, Prioreschi B, et al. A computer support program that helps clinicians provide patients with metabolic syndrome tailored counseling to promote weight loss. Journal of the American Dietetic Association. 2011; 111(1):75-83. [PubMed: 21185968]

Collinson 2011 \{published data only\}. Collinson A, Lindley R, Campbell A, Waters I, Lindley T, Wallace A. An evaluation of an internet-based approach to weight loss with low glycaemic load principles. Journal of Human Nutrition and Dietetics. 2011; 24(2):192-5. [PubMed: 21843154]

Cook 2007 \{published data only\}. Cook RF, Billings DW, Hersch RK, Back AS, Hendrickson A, Cook Royer F, et al. A field test of a web-based workplace health promotion program to improve dietary practices, reduce stress, and increase physical activity: randomized controlled trial. Journal of Medical Internet Research. 2007; 9(2):e17. [PubMed: 17581811]

Cousineau 2008 \{published data only\}. Cousineau T, Houle B, Bromberg J, Fernandez KC, Kling WC. A pilot study of an online workplace nutrition program: the value of participant input in program development. Journal of Nutrition Education and Behavior. 2008; 40(3):160-7. [PubMed: 18457784]

De Bourdeaudhuij 2007 \{published data only\}. De Bourdeaudhuij I, Stevens V, Vandelanotte C, Brug $\mathrm{J}$. Evaluation of an interactive computer-tailored nutrition intervention in a real-life setting. Annals of Behavioral Medicine. 2007; 33(1):39-48. [PubMed: 17291169]

Dekkers 2011 \{published data only\}. Dekkers JC, van Wier MF, Ariens GA, Hendriksen IJ, Pronk NP, Smid T, et al. Comparative effectiveness of lifestyle interventions on cardiovascular risk factors among a Dutch overweight working population: a randomized controlled trial. BMC Public Health. 2011; 11(1):49. [PubMed: 21261935]

Faghri 2008 \{published data only\}. Faghri PD, Omokaro C, Parker C, Nichols E, Gustavesen S, Blozie E. E-technology and pedometer walking program to increase physical activity at work. Journal of Primary Prevention. 2008; 29(1):73-91. [PubMed: 18213518]

Fitzgibbon 1995 \{published data only\}. Fitzgibbon ML, Stolley MR, Kirschenbaum DS. An obesity prevention pilot program for African-American mothers and daughters. Journal of Nutrition Education. 1995; 27(2):93-9.

Foree-Gavert 1980 \{published data only\}. Foree-Gavert S, Gavert L. Obesity: behavior therapy with computer-feedback versus traditional starvation treatment. Scandinavian Journal of Behaviour Therapy. 1980; 9(1):1-14.

Gold 2007 \{published data only\}. Gold BC, Burke S, Pintauro S, Buzzell P, Harvey-Berino J, Gold $\mathrm{BC}$, et al. Weight loss on the web: a pilot study comparing a structured behavioral intervention to a commercial program. Obesity. 2007; 15(1):155-64. [PubMed: 17228043]

Gow 2010 \{published data only\}. Gow RW, Trace SE, Mazzeo SE. Preventing weight gain in first year college students: an online intervention to prevent the "freshman fifteen". Eating Behaviors. 2010; 11(1):33-9. [PubMed: 19962118] 
Harvey-Berino 1998 \{published data only\}. Harvey-Berino J. Changing health behavior via telecommunications technology: using interactive television to treat obesity. Behavior Therapy. 1998; (3):505-19.

Harvey-Berino 2002a \{published data only\}. Harvey-Berino J, Pintauro SJ, Gold EC. The feasibility of using Internet support for the maintenance of weight loss. Behavior Modification. 2002; 26(1): 103-16. [PubMed: 11799651]

Harvey-Berino 2004 \{published data only\}. Harvey-Berino J, Pintauro S, Buzzell P, Gold EC. Effect of internet support on the long-term maintenance of weight loss. Obesity Research. 2004; 12(2): 320-9. [PubMed: 14981225]

Haugen 2007 \{published data only\}. Haugen HA, Tran ZV, Wyatt HR, Barry MJ, Hill JO. Using telehealth to increase participation in weight maintenance programs. Obesity (Silver Spring, Md). 2007; 15(12):3067-77.

Heetderks-Cox 2001 \{published data only\}. Heetderks-Cox MJ, Alford BB, Bednar CM, Heiss CJ, Tauai LA, Edgren KK. CD-ROM nutrient analysis database assists self-monitoring behavior of active duty Air Force personnel receiving nutrition counseling for weight loss. Journal of the American Dietetic Association. 2001; (9):1041-6. [PubMed: 11573756]

Herrick 2009 \{published data only\}. Herrick, M. Dissertation. South Dakota: United States: South Dakota State University; 2009. Characterization of time and order of internet lessons in Project WebHealth.

Jacobs 2010 \{published data only\}. Jacobs N, Clays E, De Bacquer D, De Backer G, Dendale P, Thijs $\mathrm{H}$, et al. Effect of a tailored behaviour change programme on a composite lifestyle change score: a randomised controlled trial. European Journal of Cardiovascular Prevention and Rehabilitation. 2010; 17:S106.

James 2001 \{published data only\}. James LC, Folen RA, Earles J. Behavioral telehealth applications in the treatment of obese soldiers: a feasibility project and a report on preliminary findings. Military Psychology. 2001; 13(3):177-86.

Jones 1997 \{published data only\}. Jones, KS. Dissertation. Arizona: United States: Arizona State University; 1997. A comparison of instructional methods for weight loss and curriculum comprehension in women.

Joo 2010 \{published data only\}. Joo NS, Park YW, Park KH, Kim CW, Kim BT. Cost-effectiveness of a community-based obesity control programme (Provisional abstract). Journal of Telemedicine and Telecare. 2010; 16(2):63-7. [PubMed: 20008053]

Kalten 2000 \{published data only\}. Kalten MR, Ardito DA, Cimino C, Wylie-Rosett J. A webaccessible core weight management program. Diabetes Educator. 2000; (6):929-36. [PubMed: 11912805]

Kerr 2008 \{published data only\}. Kerr J, Patrick K, Norman G, Stein MB, Calfas K, Zabinski M, et al. Randomized control trial of a behavioral intervention for overweight women: impact on depressive symptoms. Depression and Anxiety. 2008; 25(7):555-8. [PubMed: 17557319]

Kremers 2005 \{published data only\}. Kremers SPJ, Visscher TLS, Brug J, Chin A, Paw MJM, Schouten EG, et al. Netherlands research programme weight gain prevention (NHF-NRG): rationale, objectives and strategies. European Journal of Clinical Nutrition. 2005; 59 (4):498507. [PubMed: 15714217]

Kristal 2000 \{published data only\}. Kristal AR, Curry SJ, Shattuck AL, Feng Z, Li S. A randomized trial of a tailored, self-help dietary intervention: the Puget Sound Eating Patterns study. Preventive Medicine. 2000; (4):380-9. [PubMed: 11006063]

Kroeze 2008 \{published data only\}. Kroeze W, Oenema A, Campbell M, Brug J. The efficacy of webbased and print-delivered computer-tailored interventions to reduce fat intake: results of a randomized, controlled trial. Journal of Nutrition Education and Behavior. 2008; 40(4):226-36. [PubMed: 18565463]

Kroeze 2008a \{published data only\}. Kroeze W, Oenema A, Dagnelie PC, Brug J. Examining the minimal required elements of a computer-tailored intervention aimed at dietary fat reduction: results of a randomized controlled dismantling study. Health Education Research. 2008; 23(5): 880-91. [PubMed: 18063650] 
Liou 2006 \{published data only\}. Liou T-H, Chen C-H, Hsu C-Y, Chou P, Chiu H-W. A pilot study of videoconferencing for an Internet-based weight loss programme for obese adults in Taiwan. Journal of Telemedicine and Telecare. 2006; 12(7):370-3. [PubMed: 17059655]

Lohof 2007 \{published data only\}. Lohof Christy, H. Dissertation. Wyoming: United States: University of Wyoming; 2007. Self-efficacy and physical activity: the effect of a theory-driven, Internet-based intervention.

Magnusdottir 2010 \{published data only\}. Magnusdottir OK, Ramel A, Thorsdottir I. One year weight reduction in young overweight adults: two months controlled modest energy restriction and/or 12 months program with internet based education and visits to the clinic. Obesity Reviews. 2010; 11:247-8.

Marcus 2007 \{published data only\}. Marcus BH, Napolitano MA, King AC, Lewis BA, Whiteley JA, Albrecht AE, et al. Examination of print and telephone channels for physical activity promotion: rationale, design, and baseline data from Project STRIDE. Contemporary Clinical Trials. 2007; 28(1):90-104. [PubMed: 16839823]

McConnon 2007 \{published data only\}. McConnon A, Kirk SF, Cockroft JE, Harvey EL, Greenwood DC, Thomas JD, et al. The Internet for weight control in an obese sample: results of a randomised controlled trial. BMC Health Services Research. 2007; 7:206. [PubMed: 18093289]

McDoniel 2010 \{published data only\}. McDoniel SO, Wolskee P, Shen J. Treating obesity with a novel hand-held device, computer software program, and Internet technology in primary care: the SMART motivational trial. Patient Education and Counseling. 2010; 79(2):185-91. [PubMed: 19699049]

McHugh 2008 \{published data only\}. McHugh, JE. Dissertation. Florida: United States: Nova Southeastern University; 2008. The effectiveness of web-based tailored messaging on employee health.

McTigue 2009 \{published data only\}. McTigue KM, Conroy MB, Hess R, Bryce CL, Fiorillo AB, Fischer GS, et al. Using the Internet to translate an evidence-based lifestyle intervention into practice. Telemedicine Journal and e-health. 2009; 15(9):851-8. [PubMed: 19919191]

Micco 2007 \{published data only\}. Micco N, Gold B, Buzzell P, Leonard H, Pintauro S, HarveyBerino J, et al. Minimal in-person support as an adjunct to internet obesity treatment. Annals of Behavioral Medicine. 2007; 33(1):49-56. [PubMed: 17291170]

Mobley 2006 \{published data only\}. Mobley, AR. Dissertation. Maryland: United States: University of Maryland, College Park; 2006. Evaluation of behavioral theory and integrated Internet/ telephone technologies to support military obesity and weight management programs.

Nieto 2010 \{published data only\}. Nieto, L. Dissertation. United States: TUI University; 2010. A comparison of weight loss outcome across three distinct weight-loss program delivery venues. Vol. TUI University, California

Park 2009 \{published data only\}. Park M-J, Kim H-S, Kim K-S. Cellular phone and Internet-based individual intervention on blood pressure and obesity in obese patients with hypertension. International Journal of Medical Informatics. 2009; 78(10):704-10. [PubMed: 19643661]

[Epub ahead of print] Patrick 2011 \{published data only\}. Patrick K, Calfas KJ, Norman GJ, Rosenberg D, Zabinski MF, Sallis JF, et al. Outcomes of a 12- month web-based intervention for overweight and obese men. Annals of Behavioral Medicine. 2011 Aug 6.

Petersen 2008 \{published data only\}. Petersen R, Sill S, Lu C, Young J, Edington DW. Effectiveness of employee Internet-based weight management program. Journal of Occupational and Environmental Medicine. 2008; 50(2):163-71. [PubMed: 18301173]

Polzien 2007 \{published data only\}. Polzien KM, Jakicic JM, Tate DF. The efficacy of a technologybased system in a short-term behavioral weight loss intervention. Obesity. 2007; 15(4):825-30. [PubMed: 17426316]

Pullen 2008 \{published data only\}. Pullen CH, Hageman PA, Boeckner L, Walker SN, Oberdorfer MK. Feasibility of internet-delivered weight loss interventions among rural women ages 50-69. Journal of Geriatric Physical Therapy. 2008; 31(3):105-12. [PubMed: 19856616]

Riva 2000 \{published data only\}. Riva G, Bacchetta M, Baruffi M, Rinaldi S, Vincelli F, Molinari E. Virtual reality-based experiential cognitive treatment of obesity and binge-eating disorders. Clinical Psychology and Psychotherapy. 2000; 7(3):209-19. 
Rothert 2006 \{published data only\}. Rothert K, Strecher VJ, Doyle LA, Caplan WM, Joyce JS, Jimison HB, et al. Web-based weight management programs in an integrated health care setting: a randomized, controlled trial. Obesity. 2006; 14(2):266-72. [PubMed: 16571852]

Ryan 2010 \{published data only\}. Ryan DH, Johnson WD, Myers VH, Prather TL, McGlone MM, Rood J, et al. Nonsurgical weight loss for extreme obesity in primary care settings: results of the Louisiana Obese Subjects Study. Archives of Internal Medicine. 2010; 170(2):146-54. [PubMed: 20101009]

Sartor 1991 \{published data only\}. Sartor, MR. Dissertation Abstracts International. Vol. 52. University of Mississippi; US: 1991. The use of computer technology in teaching weight loss; p. 4462-A

Sbrocco 1999 \{published data only\}. Sbrocco T, Nedegaard RC, Stone JM, Lewis EL. Behavioral choice treatment promotes continuing weight loss: preliminary results of a cognitive-behavioral decision-based treatment for obesity. Journal of Consulting and Clinical Psychology. 1999; 67(2):260-6. [PubMed: 10224737]

Sbrocco 2005 \{published data only\}. Sbrocco T, Carter MM, Lewis EL, Vaughn NA, Kalupa KL, King S, et al. Church-based obesity treatment for African-American women improves adherence. Ethnicity and Disease. 2005; 15(2):246-55. [PubMed: 15825971]

Shay 2009 \{published data only\}. Shay LE, Seibert D, Watts D, Sbrocco T, Pagliara C. Adherence and weight loss outcomes associated with food-exercise diary preference in a military weight management program. Eating Behaviors. 2009; 10(4):220-7. [PubMed: 19778751]

Smeets 2007 \{published data only\}. Smeets T, Kremers SP, Brug J, de Vries H, Kremers SPJ. Effects of tailored feedback on multiple health behaviors. [erratum appears in Annals of Behavioral Medicine 2007 Jul-Aug;34(1):104]. Annals of Behavioral Medicine. 2007; 33 (2):117-23. [PubMed: 17447863]

Smith 2009 \{published data only\}. Smith DT, Carr LJ, Dorozynski C, Gomashe C, Smith DT, Carr LJ, et al. Internet-delivered lifestyle physical activity intervention: limited inflammation and antioxidant capacity efficacy in overweight adults. Journal of Applied Physiology. 2009; 106(1): 49-56. [PubMed: 19008491]

Southard 2003 \{published data only\}. Southard BH, Southard DR, Nuckolls J. Clinical trial of an Internet-based case management system for secondary prevention of heart disease. Journal of Cardiopulmonary Rehabilitation. 2003; 23(5):341-8. [PubMed: 14512778]

Steele 2007 \{published data only\}. Steele RM, Mummery WK, Dwyer T. Examination of program exposure across intervention delivery modes: face-to-face versus internet. International Journal of Behavioral Nutrition and Physical Activity. 2007; 4:7. [PubMed: 17352817]

Tanaka 2010 \{published data only\}. Tanaka M, Adachi Y, Adachi K, Sato C. Effects of a non-face-toface behavioral weight-control program among Japanese overweight males: a randomized controlled trial. International Journal of Behavioral Medicine. 2010; 17(1):17-24. [PubMed: 19685190]

Taylor 1991 \{published data only\}. Taylor CB, Agras WS, Losch M, Plante TG, Burnett K. Improving the effectiveness of computer-assisted weight loss. Behavior Therapy. 1991; (2):229-36.

Thurston 1991 \{published data only\}. Thurston, WE. Dissertation. Canada: University of Calgary (Canada); 1991. Development and formative evaluation of a decision-management health promotion program on healthy weights for women.

Touger-Decker 2010 \{published data only\}. Touger-Decker R, Denmark R, Bruno M, O'SullivanMaillet J, Lasser N. Workplace weight loss program; comparing live and internet methods. Journal of Occupational and Environmental Medicine. 2010; 52(11):1112-8. [PubMed: 21063189]

Turnin 2001 ppublished data only\}. Turnin MC, Bourgeois O, Cathelineau G, Leguerrier AM, Halimi $\mathrm{S}$, Sandre-Banon D, et al. Multicenter randomized evaluation of a nutritional education software in obese patients. Diabetes and Metabolism. 2001; 27(2 Pt 1):139-47. [PubMed: 11353880]

van der Mark 2009 \{published data only\}. van der Mark M, Jonasson J, Svensson M, Linne Y, Rossner S, Lagerros YT. Older members perform better in an internet-based behavioral weight loss program compared to younger members. Obesity Facts. 2009; 2(2):74-9. [PubMed: 20054209] 
[DOI: 101186/1471-2458-9-6] van Wier 2009 \{published data only\}. van Wier MF, Ariens GA, Dekkers JC, Hendriksen IJ, Smid T, van Mechelen W. Phone and e-mail counselling are effective for weight management in an overweight working population: a randomized controlled trial. BMC Public Health. 2009; 9(1):6. [PubMed: 19134171]

Vandelanotte 2005 \{published data only\}. Vandelanotte C, De Bourdeaudhuij I, Sallis JF, Spittaels H, Brug J. Efficacy of sequential or simultaneous interactive computer-tailored interventions for increasing physical activity and decreasing fat intake. Annals of Behavioral Medicine. 2005; 29(2):138-46. [PubMed: 15823787]

Vandelanotte 2008 \{published data only\}. Vandelanotte C, Reeves MM, Brug J, De Bourdeaudhuij I, Vandelanotte C, Reeves MM, et al. A randomized trial of sequential and simultaneous multiple behavior change interventions for physical activity and fat intake. Preventive Medicine. 2008; 46(3):232-7. [PubMed: 17707079]

Verheijden 2007 \{published data only\}. Verheijden MW, Jans MP, Hildebrandt VH, Hopman-Rock M. Rates and determinants of repeated participation in web-based behavior change program for healthy body weight and healthy lifestyle. Journal of Medical Internet Research. 2007; 9(1):1-7.

Webber 2008a \{published data only\}. Webber KH, Tate DF, Quintiliani LM, Webber KH, Tate DF, Quintiliani LM. Motivational interviewing in internet groups: a pilot study for weight loss. Journal of the American Dietetic Association. 2008; 108(6):1029-32. [PubMed: 18502239]

Webber 2010 \{published data only\}. Webber KH, Gabriele JM, Tate DF, Dignan MB. The effect of a motivational intervention on weight loss is moderated by level of baseline controlled motivation. International Journal of Behavioral Nutrition and Physical Activity. 2010; 7:4. [PubMed: 20157441]

Weinstock 1998 \{published data only\}. Weinstock RS, Dai H, Wadden TA. Diet and exercise in the treatment of obesity: effects of 3 interventions in insulin resistance. Archives of Internal Medicine. 1998; 158(22):2477-83. [PubMed: 9855386]

Werkman 2010 \{published data only\}. Werkman A, Hulshof PJ, Stafleu A, Kremers SP, Kok FJ, Schouten EG, et al. Effect of an individually tailored one-year energy balance programme on body weight, body composition and lifestyle in recent retirees: a cluster randomised controlled trial. BMC Public Health. 2010; 10:110. [PubMed: 20205704]

Winett 2007 \{published data only\}. Winett RA, Anderson ES, Wojcik JR, Winett SG, Bowden T, Winett Richard A, et al. Guide to health: nutrition and physical activity outcomes of a grouprandomized trial of an Internet-based intervention in churches. Annals of Behavioral Medicine. 2007; 33(3):251-61. [PubMed: 17600452]

Wing 2009 \{published data only\}. Wing RR, Pinto AM, Crane MM, Kumar R, Weinberg BM, Gorin AA. A statewide intervention reduces BMI in adults: Shape Up Rhode Island Results. Obesity. 2009; 17(5):991-5. [PubMed: 19180068]

Womble 2004 \{published data only\}. Womble LG, Wadden TA, McGuckin BG, Sargent SL, Rothman RA, Krauthamer-Ewing ES. A randomized controlled trial of a commercial internet weight loss program. Obesity Research. 2004; 12(6):1011-8. [PubMed: 15229342]

Yon 2007 \{published data only\}. Yon BA, Johnson RK, Harvey-Berino J, Gold BC, Howard AB, Yon $\mathrm{BA}$, et al. Personal digital assistants are comparable to traditional diaries for dietary selfmonitoring during a weight loss program. Journal of Behavioral Medicine. 2007; 30(2):165-75. [PubMed: 17216341]

\section{References to ongoing studies}

Harvey-Berino NCT01232699 \{published data only\}. Harvey-Berino, JR. Internet obesity treatment enhanced with motivational interviewing. Clinicaltrials.gov

\section{Additional references}

Arem 2010. Arem H, Irwin M. A review of web-based weight loss interventions in adults. Obesity Reviews. 2011; 12(5):e236-43. [PubMed: 20804523] 
Block 2000. Block G, Gillespie C, Rosenbaum EH, Jenson C. A rapid food screener to assess fat and fruit and vegetable intake. American Journal of Preventive Medicine. 2000; 18(4):284-8. [PubMed: 10788730]

Brownell 2000. Brownell, KD. The Learn Program for Weight Management 2000. Euless, TX: American Health Pub Co; 2000.

Cohen 1960. Cohen J. A coefficient of agreement for nominal scales. Educational and Psychological Measurement. 1960; 20:37-46.

Corbett Dooren 2011. Corbett Dooren, J. The Wall Street Journal. Washington, DC: Dow Jones \& Company, Inc; 2011 Feb 16. FDA approves wider use of Allergan's lap band for obesity.

DPP Research Group 2002. Diabetes Prevention Program (DPP) Research Group . The Diabetes Prevention Program (DPP): description of lifestyle intervention. Diabetes Care. 2002; 25(12): 2165-71. [PubMed: 12453955]

DynaMed. DynaMed. Levels of evidence. DynaMed; http://dynamed.ebscohost.com/content/LOE [Accessed February 22, 2012]

Ferguson 1975. Ferguson, JM. Learning to Eat: Behavior Modification for Weight Control. Palo Alto, CA: Bull Publishing Co; 1975.

Finkelstein 2003. Finkelstein EA, Fiebelkorn IC, Wang G. National medical spending attributable to overweight and obesity: how much, and who's paying? Health Affairs (Project Hope). 2003; (Suppl Web Exclusives):W3-219-26. [PubMed: 14527256]

Foster 2005. Foster GD, Makris AP, Bailer BA. Behavioral treatment of obesity. American Journal of Clinical Nutrition. 2005; 82(1 Suppl):230S-5S. [PubMed: 16002827]

Franz 2007. Franz MJ, VanWormer JJ, Crain AL, Boucher JL, Histon T, Caplan W, et al. Weight-loss outcomes: a systematic review and meta-analysis of weight-loss clinical trials with a minimum 1year follow-up. Journal of the American Dietetic Association. 2007; 107(10):1755-67. [PubMed: 17904936]

Glasgow 2007. Glasgow RE, Nelson CC, Kearney KA, Reid R, Ritzwoller DP, Strecher VJ, et al. Reach, engagement, and retention in an Internet-based weight loss program in a multi-site randomized controlled trial. Journal of Medical Internet Research. 2007; 9(2):e11. [PubMed: 17513282]

Guyatt 2001. Guyatt, G.; Cook, C.; Devereaux, PJ.; Meade, M.; Straus, S. Users' Guides to the Medical Literature: a Manual for Evidence Based Practice. AMA Press; 2001. Therapy.

Health Information Research Unit. Health Information Research Unit McMaster University. McMaster Online Rating of Evidence (MORE). Hamilton, Ontario: McMaster University; http:// hiru.mcmaster.ca/morenew/ [Accessed February 22, 2012]

Heinen 2009. Heinen L, Darling H. Addressing obesity in the workplace: the role of employers. Milbank Quarterly. 2009; 87(1):101-22. [PubMed: 19298417]

Higgins 2002. Higgins JPT, Thompson SG. Quantifying heterogeneity in a meta-analysis. Statistics in Medicine. 2002; 21:1539-58. [PubMed: 12111919]

Higgins 2003. Higgins JPT, Thompson SG, Deeks JJ, Altman DG. Measuring inconsistency in metaanalysis. BMJ. 2003; 327:557-60. [PubMed: 12958120]

Higgins 2009. Higgins, JPT.; Green, S., editors. Cochrane Handbook for Systematic Reviews of Interventions. The Cochrane Collaboration; 2009. Version 5.0.2 [updated September 2009]Available from www.cochrane-handbook.org

Jebb 2011. Jebb SA, Ahern AL, Olson AD, Aston LM, Holzapfel C, Stoll J, et al. Primary care referral to a commercial provider for weight loss treatment versus standard care: a randomised controlled trial. Lancet. 2011 Sep 7. [Epub ahead of print].

Kroeze 2006. Kroeze W, Werkman A, Brug J. A systematic review of randomized trials on the effectiveness of computer-tailored education on physical activity and dietary behaviors. Annals of Behavioral Medicine. 2006; 31(3):205-23. [PubMed: 16700634]

Krukowski 2010. Krukowski RA, Tilford JM, Harvey-Berino J, West DS. Comparative costeffectiveness for in-person versus online behavioral weight loss programs. Obesity Reviews. 2010; 11(Suppl 1):249.

Lau 2006. Lau J, Ioannidis JPA, Terrin N, Schmid CH, Olkin I. The case of the misleading funnel plot. BMJ. 2006; 333:597-600. [PubMed: 16974018] 
Liberati 2009. Liberati A, Altman DG, Tetzlaff J, Mulrow C, Gøtzsche PC, Ioannidis JPA, et al. The PRISMA statement for reporting systematic and meta-analyses of studies that evaluate interventions: explanation and elaboration. PLoS Medicine. 1999; 6(7):1-28.10.1371/ journal.pmed.1000100

Madden 2006. Madden, M.; Fox, S. Riding the waves of "Web 2.0": more than a buzzword, but still not easily defined. Washington, DC: Pew Research Center for the People \& the Press; 2006. p. 6http://pewresearch.org/pubs/71/riding-the-waves-of-web-20

Meenan 2009. Meenan RT, Stevens VJ, Funk K, Bauck A, Jerome GJ, Lien LF, et al. Development and implementation cost analysis of telephone- and Internet-based interventions for the maintenance of weight loss. International Journal of Technology Assessment in Health Care. 2009; 25(3):400-10. [PubMed: 19619360]

Meenan 2010. Meenan RT, Stevens VJ, Funk K, et al. PS2-34: Implementation cost analysis of telephone and Internet-based interventions for the maintenance of weight loss. Clinical Medicine and Research. 2010; 8(1):52-b.

Miller 2008. Miller Claire Cain. The New York Times. New York: The New York Times; Aug 14. 2008 Woman to Woman, Online; p. 1-C

Mitchell 2008. Mitchell, D. The New York Times. New York: The New York Times; Aug 20. 2008 A small empire built on cuddly and fuzzy branches out from the web; p. 4-C

Murray 2005. Murray E, Burns J, See TS, Lai R, Nazareth I. Interactive health communication applications for people with chronic disease. Cochrane Database of Systematic Reviews. 2005; (4)10.1002/14651858.CD004274.pub4

National Institutes of Health 2000. National Institutes of Health. Clinical Guidelines on the Identification, Evaluation and Treatment of Overweight and Obesity in Adults. Bethesda, Maryland: National Institutes of Health; 2000. p. 94http://www.nhlbi.nih.gov/guidelines/obesity/ obgdlns.htm

Neter 2003. Neter JE, Stam BE, Kok FJ, Grobbee DE, Geleijnse JM. Influence of weight reduction on blood pressure: a meta-analysis of randomized controlled trials. Hypertension. 2003; 42(5):87884. [PubMed: 12975389]

Neve 2010. Neve M, Morgan PJ, Jones PR, Collins CE. Effectiveness of web-based interventions in achieving weight loss and weight loss maintenance in overweight and obese adults: a systematic review with meta-analysis. Obesity Reviews. 2010; 11(4):306-21. [PubMed: 19754633]

Perri 1992. Perri, MG.; Nezu, AM.; Viegener, BJ. Improving the Long-term Management of Obesity: Theory, Research, and Clinical Guidelines. New York, NY: Wiley; 1992.

Perri 2001. Perri MG, Nezu AM, McKelvey WF, Shermer RL, Renjilian DA, Viegener BJ. Relapse prevention training and problem-solving therapy in the long-term management of obesity. Journal of Consulting and Clinical Psychology. 2001; 69(4):722-6. [PubMed: 11550740]

Perri 2008. Perri MG, Limacher MC, Durning PE, Janicke DM, Lutes LD, Bobroff LB, et al. Extended-care programs for weight management in rural communities: the treatment of obesity in underserved rural settings (TOURS) randomized trial. Archives of Internal Medicine. 2008; 168(21):2347-54. [PubMed: 19029500]

Pew 2009. Pew Research Center for the People \& the Press. Internet, Cell Phones Are Changes for the Better. Washington, DC: Pew Research Center for the People \& the Press; 2009. p. 22http:// pewresearch.org/

Pi-Sunyer 2007. Pi-Sunyer FX. How effective are lifestyle changes in the prevention of type 2 diabetes mellitus? Nutrition Reviews. 2007; 65(3):101-10. [PubMed: 17425061]

Rasu 2010. Rasu RS, Hunter CM, Peterson AL, Maruska HM, Foreyt JP. Economic evaluation of an Internet-based weight management program. American Journal of Managed Care. 2010; 16(4):e98-104. [PubMed: 20370312]

Reed 2012. Reed VA, Schifferdecker KE, Rezaee ME, O’Connor S, Larson RJ. The effect of computers for weight loss: a systematic review and meta-analysis of randomized trials. Journal of General Internal Medicine. 2012; 27(1):99-108. [PubMed: 21805218]

Rothman 2000. Rothman AJ. Toward a theory-based analysis of behavioral maintenance. Health Psychology. 2000; 19(1 Suppl):64-9. [PubMed: 10709949] 
Rothman 2009. Rothman AJ, Sheeran P, Wood W. Reflective and automatic processes in the initiation and maintenance of dietary change. Annals of Behavioral Medicine. 2009; 38(Suppl 1):S4-17. [PubMed: 19787308]

Sjöström 2007. Sjöström L, Narbro K, Sjöström CD, Karason K, Larsson B, Wedel H, et al. Effects of bariatric surgery on mortality in Swedish obese subjects. New England Journal of Medicine. 2007; 357(8):741-52. [PubMed: 17715408]

Sterne 2001. Sterne, JAC.; Egger, M.; Davey Smith, G. Investigating and dealing with publication and other biases. In: Egger, M.; Davey Smith, G.; Altman, DG., editors. Systematic Reviews in Health Care; Meta-analysis in Context. London: BMJ Publishing Group; 2001. p. 189-208.

Stevens 2001. Stevens VJ, Obarzanek E, Cook NR, Lee IM, Appel LJ, Smith West D, et al. Long-term weight loss and changes in blood pressure: results of the Trials of Hypertension Prevention, phase II. Annals of Internal Medicine. 2001; 134 (1):1-11. [PubMed: 11187414]

Stevens 2008. Stevens VJ, Funk KL, Brantley PJ, Erlinger TP, Myers VH, Champagne CM, et al. Design and implementation of an interactive website to support long-term maintenance of weight loss. Journal of Medical Internet Research. 2008; 10(1):e1. [PubMed: 18244892]

Tate 2009. Tate DF, Finkelstein EA, Khavjou O, Gustafson A. Cost effectiveness of internet interventions: review and recommendations. Annals of Behavioral Medicine. 2009; 38 (1):40-5. [PubMed: 19834778]

Wantland 2004. Wantland DJ, Portillo CJ, Holzemer WL, Slaughter R, McGhee EM. The effectiveness of web-based vs. non-web-based interventions: a meta-analysis of behavioral change outcomes. Journal of Medical Internet Research. 2004; 6(4):e40. [PubMed: 15631964]

Wing 2005. Wing RR, Phelan S. Long-term weight loss maintenance. American Journal of Clinical Nutrition. 2005; 82(1 Suppl):222S-5S. [PubMed: 16002825]

Withrow 2011. Withrow D, Alter DA. The economic burden of obesity worldwide: a systematic review of the direct costs of obesity. Obesity Reviews. 2011; 12(2):131-41. [PubMed: 20122135]

World Health Organization 2004. World Health Organization. Global Strategy on Diet, Physical Activity and Health. Geneva: World Health Organization; 2004. p. 21http://www.who.int/ dietphysicalactivity/strategy/en/

World Health Organization 2011. World Health Organization. WHO Fact Sheet. Vol. 311. Geneva: World Health Organization; 2011. Obesity and overweight.

\section{APPENDICES}

\section{Appendix 1. Search strategies}

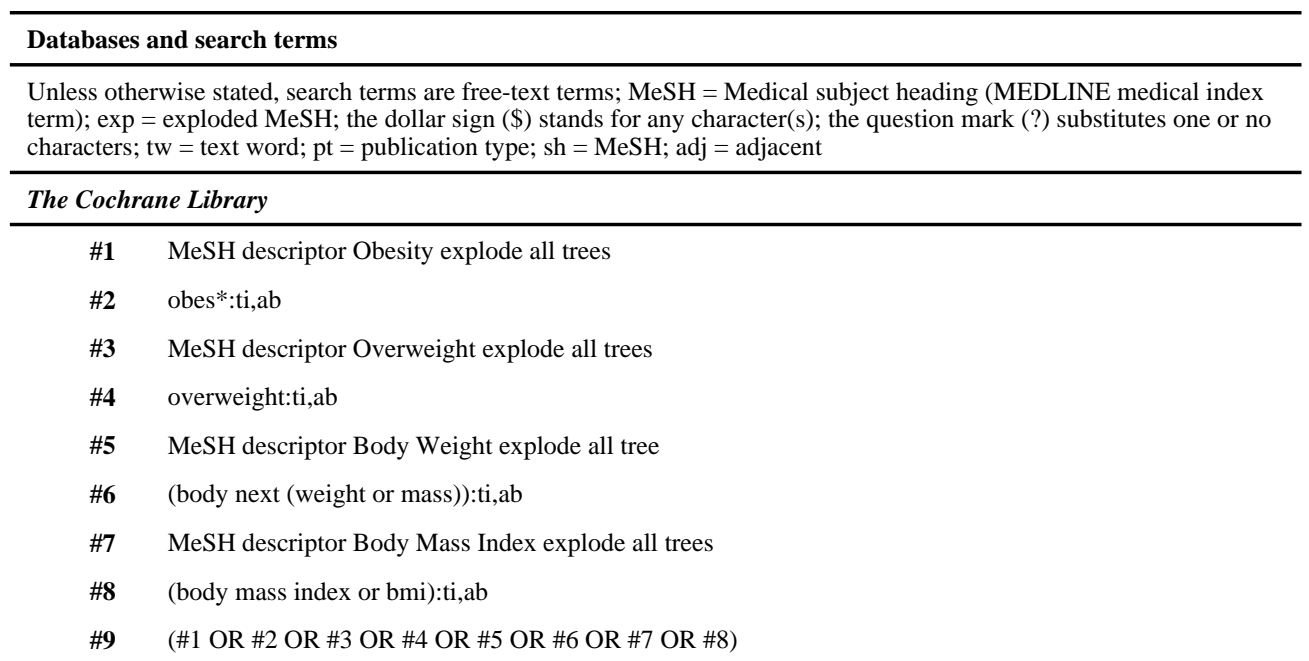




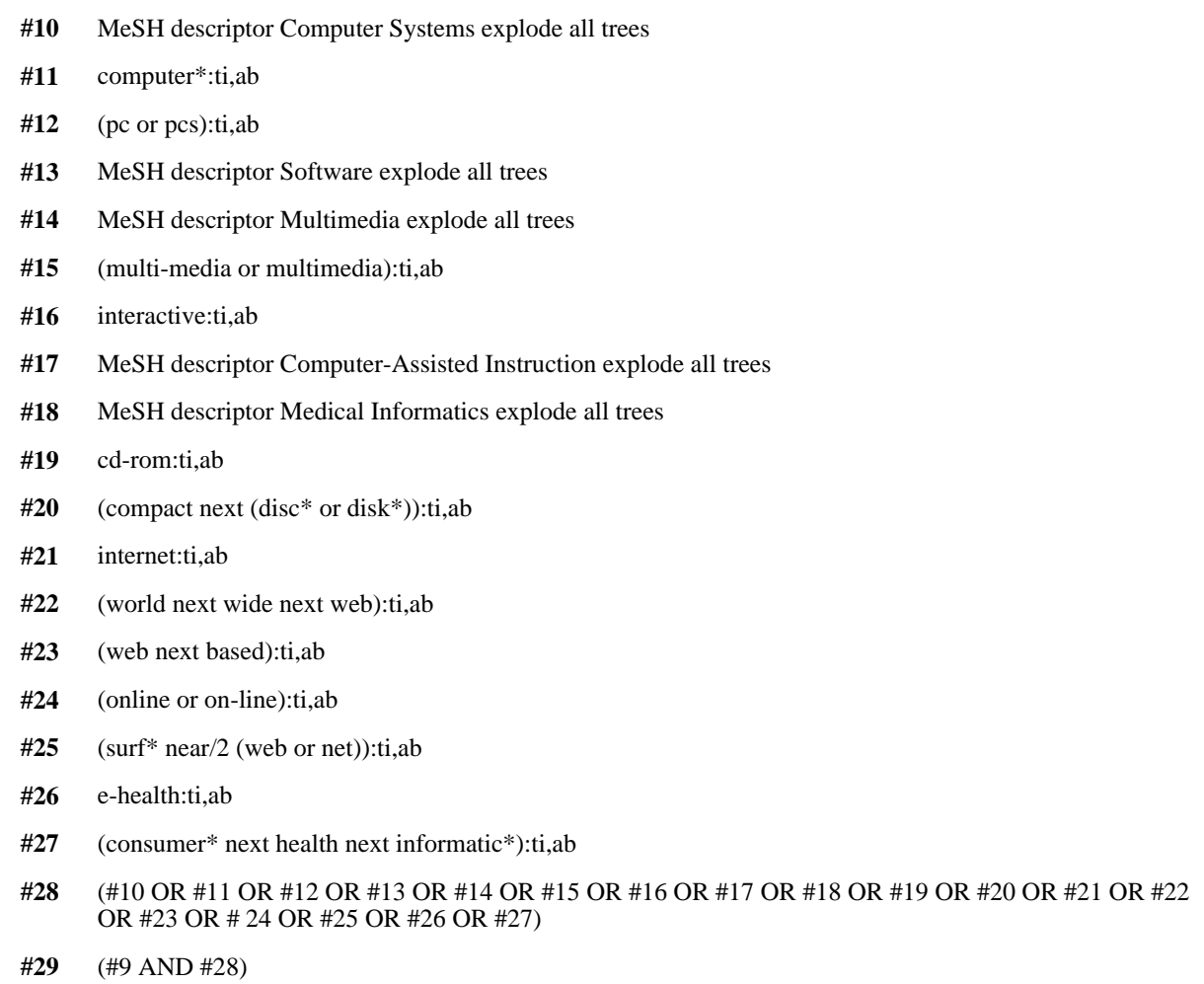

MEDLINE (original search)

1 exp Obesity/

2 obes\$.tw.

3 exp Overweight/

4 overweight.tw.

5 exp Body Weight/

6 (body adj (weight or mass)).tw.

7 exp Body Mass Index/

8 (body mass index or bmi).tw.

9 or $/ 1-8$

10 exp Computer systems/

11 computer\$.tw.

12 (pc or pcs).tw.

13 exp software/

14 exp Multimedia/

15 (multi-media or multimedia).tw.

16 interactive.tw.

17 computer-assisted instruction/

18 exp medical informatics/

19 cd-rom.tw.

20 (compact adj dis?\$).tw.

21 internet.tw. 


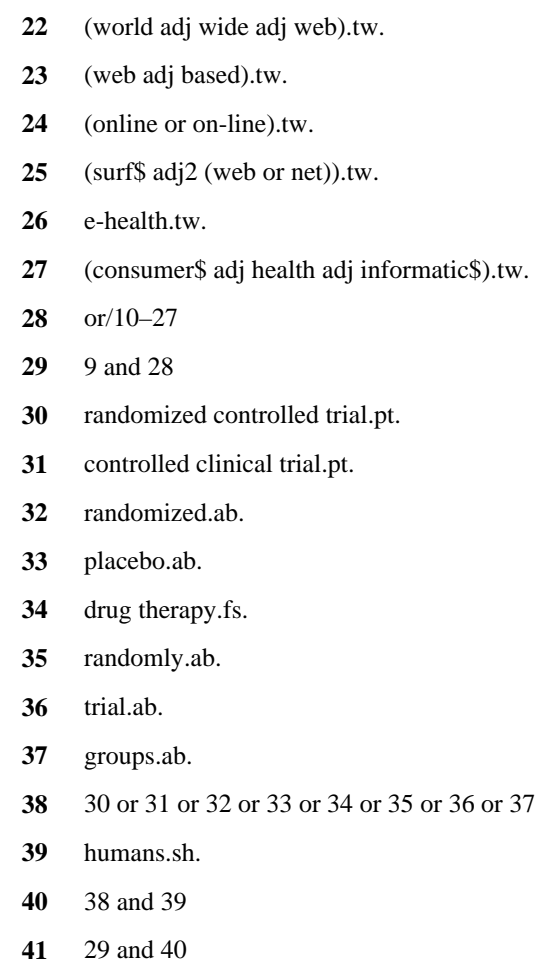

\begin{tabular}{cll}
\hline MEDLINE (updated search) \\
\hline $\mathbf{1}$ & exp Obesity/ \\
$\mathbf{2}$ & obes\$.tw. \\
$\mathbf{3}$ & exp Overweight/ \\
$\mathbf{4}$ & overweight.tw. \\
$\mathbf{5}$ & exp Body Weight/ \\
$\mathbf{6}$ & (body adj (weight or mass)).tw. \\
$\mathbf{7}$ & exp Body Mass Index/ \\
$\mathbf{8}$ & (body mass index or bmi).tw. \\
$\mathbf{9}$ & or/1-8 \\
$\mathbf{1 0}$ & exp Computer systems/ \\
$\mathbf{1 1}$ & computer\$.tw. \\
$\mathbf{1 2}$ & (pc or pcs).tw. \\
$\mathbf{1 3}$ & exp software/ \\
$\mathbf{1 4}$ & exp Multimedia/ \\
$\mathbf{1 5}$ & (multi-media or multimedia).tw. \\
$\mathbf{1 6}$ & interactive.tw. \\
$\mathbf{1 7}$ & computer-assisted instruction/ \\
$\mathbf{1 8}$ & exp medical informatics/ \\
$\mathbf{1 9}$ & cd-rom.tw. \\
$\mathbf{2 0}$ & (compact adj dis?\$).tw. \\
$\mathbf{2 1}$ & internet.tw. \\
$\mathbf{2 2}$ & (world adj wide adj web).tw.
\end{tabular}


23 (web adj based).tw.

24 (online or on-line).tw.

25 (surf\$ adj2 (web or net)).tw.

26 e-health.tw.

27 (consumer\$ adj health adj informatic\$).tw.

28 or $/ 10-27$

$29 \quad 9$ and 28

30 randomized controlled trial.pt.

31 controlled clinical trial.pt.

32 randomized.ab.

33 placebo.ab.

34 drug therapy.fs.

35 randomly.ab.

36 trial.ab.

37 groups.ab.

38 or $/ 30-37$

39 (animals not (humans and animals)).sh.

$40 \quad 38$ not 39

4129 and 40

\section{EMBASE}

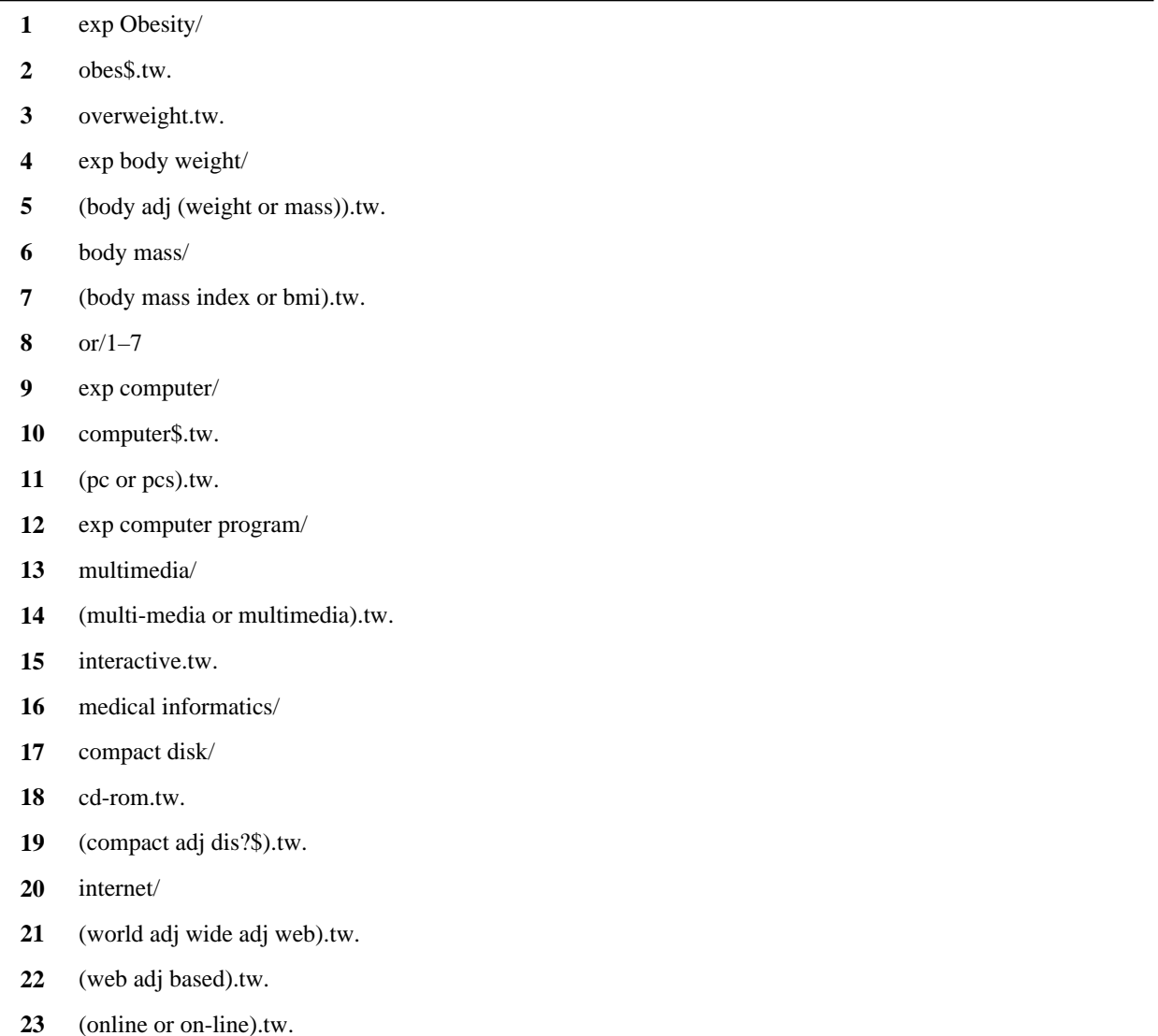




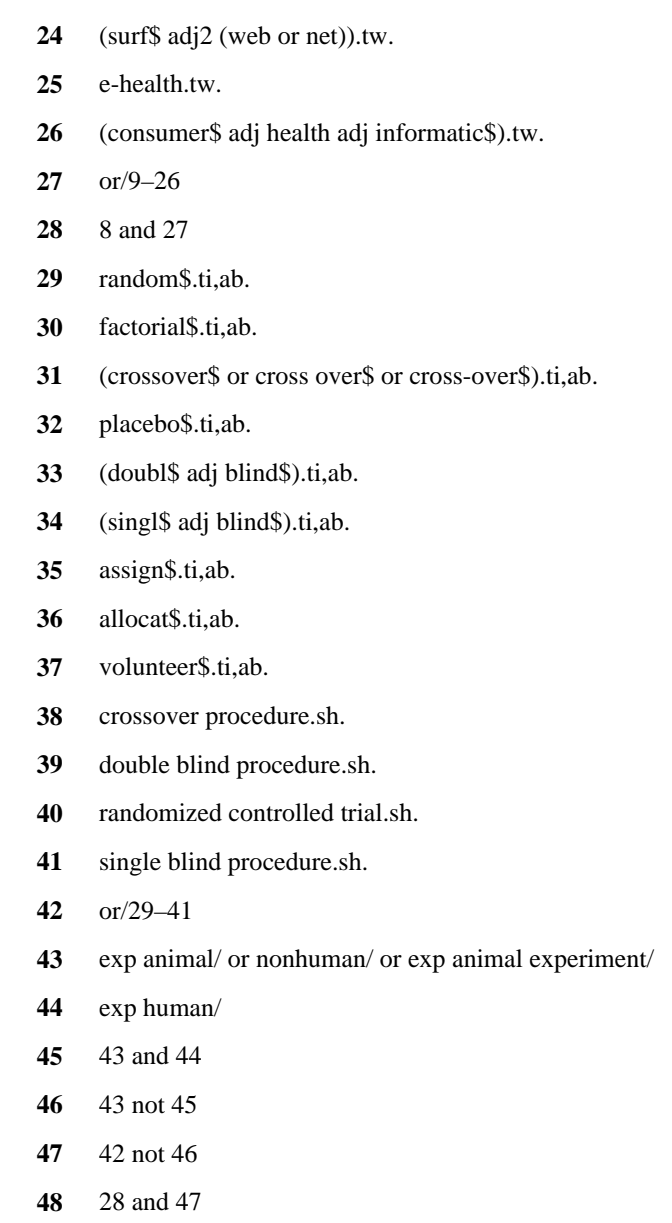

\begin{tabular}{ll}
\hline LILACS & \\
\hline (Obes* OR Overweight) AND (Computer* OR internet OR Web) (All indexes) \\
\hline CINAHL & \\
\hline $\mathbf{1}$ & exp Obesity/ \\
$\mathbf{2}$ & obes\$.tw. \\
$\mathbf{3}$ & exp Overweight/ \\
$\mathbf{4}$ & overweight.tw. \\
$\mathbf{5}$ & exp Body Weight/ \\
$\mathbf{6}$ & (body adj (weight or mass)).tw. \\
$\mathbf{7}$ & exp Body Mass Index/ \\
$\mathbf{8}$ & (body mass index or bmi).tw. \\
$\mathbf{9}$ & or/1-8 \\
$\mathbf{1 0}$ & exp Computer systems/ \\
$\mathbf{1 1}$ & computer\$.tw. \\
$\mathbf{1 2}$ & (pc or pcs).tw. \\
$\mathbf{1 3}$ & exp software/ \\
$\mathbf{1 4}$ & exp Multimedia/ \\
$\mathbf{1 5}$ & (multi-media or multimedia).tw.
\end{tabular}




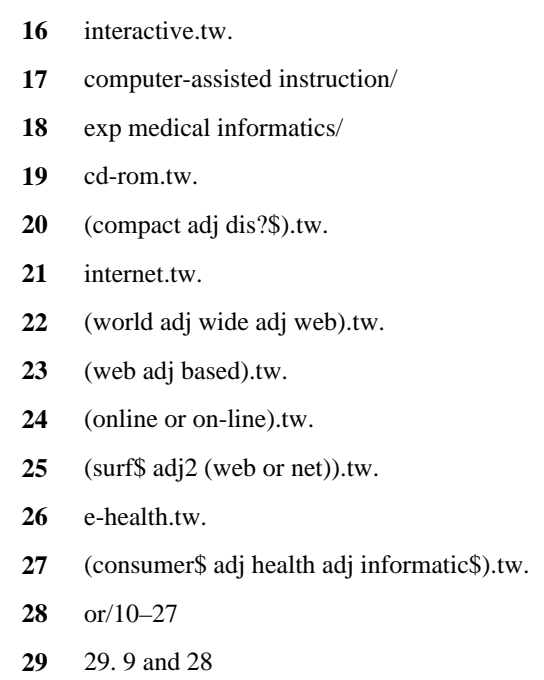

CINAHL (updated search)

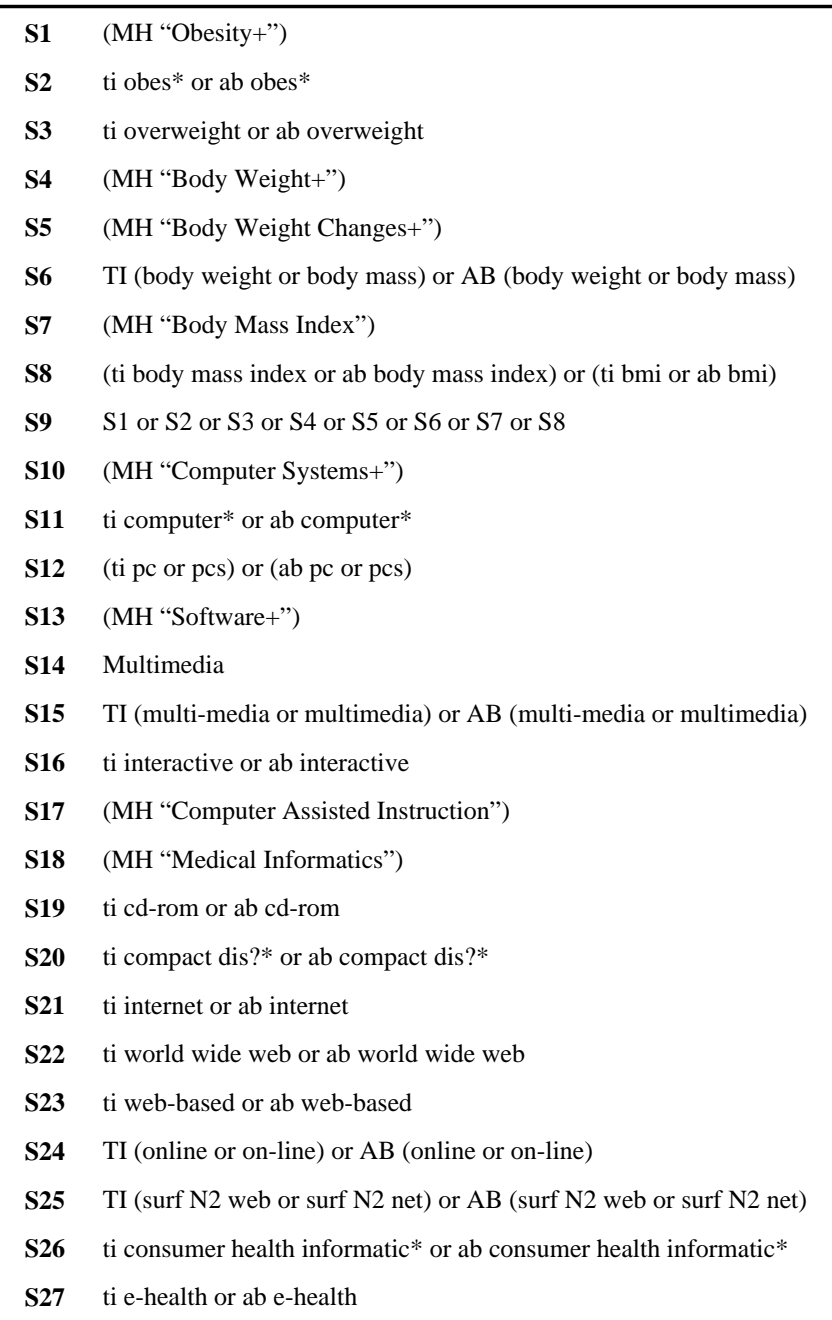


S28 S10 or S11 or S12 or S13 or S14 or S15 or S16 or S17 or S18 or S19 or S20 or S21 or S22 or S23 or S24 or S25 or S26 or S27

S29 S9 and $\mathrm{S} 28$

S30 (MH "Clinical Trials+")

S31 PT clinical trial

S32 TI clinical* trial* or AB clinical* trial*

S33 TI singl* blind* or TI singl* mask* or TI doub* blind* or TI doubl* mask* or TI trebl* blind* or TI trebl* mask* or TI tripl* blind* or TI tripl* mask*

S34 AB singl* blind* or AB singl* mask* or AB doub* blind* or AB doubl* mask* or AB trebl* blind* or $\mathrm{AB}$ trebl* mask* or AB tripl* blind* or AB tripl* mask*

S35 TI Randomi?ed control* trial* or AB Randomi?ed control* trial*

S36 (MH "Random Assignment")

S37 TI Random* allocat* or AB Random* allocat*

S38 TI Placebo* or AB Placebo*

S39 (MH "Placebos")

S40 (MH "Quantitative Studies")

S41 TI Allocat* random* or AB Allocat* random*

S42 S30 or S31 or S32 or S33 or S34 or S35 or S36 or S37 or S38 or S39 or S40 or S41

$\mathbf{S 4 3} \quad \mathrm{S} 29$ and $\mathrm{S} 42$

\section{Web of Science}

\#1 (obes* or overwieght or body weight or body mass index or bmi) in Title

\#2 (computer* or pc or pcs or software or mutimedia or multi-media or interactive or cd-rom* or compact disk*or compact disc* or internet or web-based or world wide web or online or on-line or e-health or consumer* health informatic*) in Topic

\#3 ((trial* or random* or placebo* or control* or double or treble or triple or blind* or mask* or allocat* or prospective* or volunteer*or comparative or evaluation or follow-up or follow up)) in Topic

\#4 \#1 and \#2 and \#3

Dissertation Abstracts

obes* OR overwieght OR body weight OR body mass index OR bmi in Citation and Abstract

AND

computer* OR pc OR pcs OR software OR mutimedia OR multi-media OR interactive OR cd-rom* OR compact disk*OR compact disc* OR internet OR web-based or world wide web OR online OR on-line OR e-health OR consumer* health informatic*) in Citation and Abstract

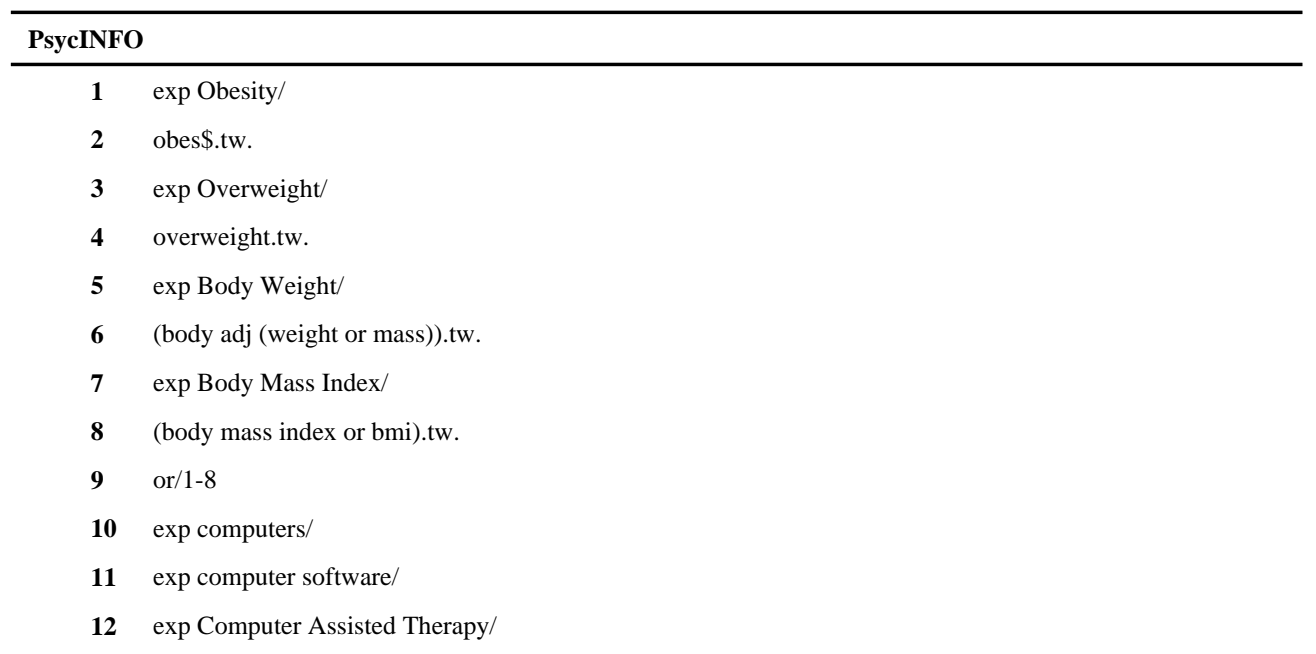


computer\$.tw.

14

(pc or pcs).tw.

(multi-media or multimedia).tw.

16 interactive.tw.

17 exp Computer Assisted Instruction/

18 exp Information Technology/

19 cd-rom.tw.

20 (compact adj dis?\$).tw.

21 internet.tw.

22 (world adj wide adj web).tw.

23 (web adj based).tw.

24 (online or on-line).tw.

25 (surf\$ adj2 (web or net)).tw.

26 e-health.tw.

27 (consumer\$ adj health adj informatic\$).tw.

28 or $/ 10-27$

299 and 28

Cochrane Medicine Field Specialized Register

Obesity in Health Condition

Computer-based intervention OR web-based intervention in Intervention

\section{CRISP}

Search 1:

Obesity and computer
Obesity and software

Obesity and multimedia

Obesity and internet

Obesity and online

Obesity and web

Search 2:

Overweight and computer

Overweight and software

Overweight and multimedia

Overweight and internet

Overweight and online

Overweight and web

\section{Appendix 2. Descriptions of interventions}

\begin{tabular}{l|l|l|l}
\hline Characteristic Study ID & Design & Intervention(s) & Control(s) \\
\hline Bennett 2010 & Parallel RCT & $\begin{array}{l}\text { Internet-based interactive weight loss } \\
\text { approach. Participants collaborated } \\
\text { with health coach to select series of } \\
\text { behavior change goals, and were } \\
\text { encouraged to use website for regular } \\
\text { self monitoring. Behavioral skills } \\
\text { training and regular health coach } \\
\text { support also provided }\end{array}$ & $\begin{array}{l}\text { Current standard of } \\
\text { outpatient care plus a copy } \\
\text { of the 'Aim for a Healthy } \\
\text { Weight' written materials } \\
\text { published by the National } \\
\text { Heart, Lung and Blood } \\
\text { Institute }\end{array}$ \\
\hline Cussler 2008 & Cluster-RCT & $\begin{array}{l}\text { Internet-based program with private } \\
\text { mail, group mail, bulletin board, chat } \\
\text { rooms, monitoring tools for weight, } \\
\text { physical activity and diet, curriculum } \\
\text { materials, dietary and physical }\end{array}$ & $\begin{array}{l}\text { Continue to practice } \\
\text { principles learned during } \\
\text { weight loss intervention. } \\
\text { No contact with study } \\
\text { staff except for testing }\end{array}$ \\
& &
\end{tabular}




\begin{tabular}{|c|c|c|c|}
\hline \multirow[t]{2}{*}{ Characteristic Study ID } & \multirow[t]{2}{*}{ Design } & Intervention(s) & Control(s) \\
\hline & & $\begin{array}{l}\text { activity information, and links to } \\
\text { websites of interest }\end{array}$ & \\
\hline DeLucia 1988 & Parallel RCT & $1 \begin{array}{l}\text { Ferguson behavioral } \\
\text { program plus The Eating } \\
\text { Machine (Thorne 1982), } \\
\text { a nutritional software } \\
\text { intervention administered } \\
\text { in weekly 90-minute } \\
\text { Applie IIe computer } \\
\text { sessions. Computerized } \\
\text { feedback of user dietary } \\
\text { patterns. } \\
2 \quad \text { Ferguson behavioral } \\
\text { program plus EATS } \\
\text { (Byrd-Bredbenner 1981), } \\
\text { a nutritional software } \\
\text { intervention administered } \\
\text { in weekly 90-minute } \\
\text { Apple Ile computer } \\
\text { sessions. Computerized } \\
\text { feedback of user dietary } \\
\text { patterns }\end{array}$ & $\begin{array}{l}\text { Ferguson program only. } \\
\text { No computerized } \\
\text { intervention. }\end{array}$ \\
\hline Gabriele 2011 & Parallel RCT & 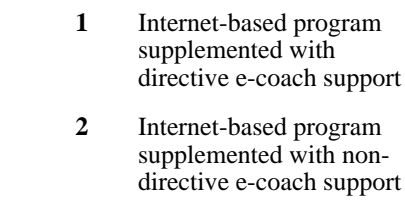 & $\begin{array}{l}\text { Internet-based program } \\
\text { with minimal support }\end{array}$ \\
\hline Harvey-Berino 2002 & Parallel RCT & $\begin{array}{l}\text { Internet support. } 52 \text { weeks of bi- } \\
\text { weekly Internet chat sessions } \\
\text { facilitated by a group therapist. E- } \\
\text { mail from group therapist in weeks } \\
\text { when meetings not held }\end{array}$ & $1 \begin{array}{l}\text { Frequent in- } \\
\text { person } \\
\text { support. 52 } \\
\text { weeks of bi- } \\
\text { weekly in- } \\
\text { person group } \\
\text { therapist } \\
\text { meetings. } \\
\text { Phone calls } \\
\text { from therapist } \\
\text { in weeks when } \\
\text { meetings not } \\
\text { held. } \\
\text { Minimal in- } \\
\text { person } \\
\text { support. Six } \\
\text { months of } \\
\text { monthly in- } \\
\text { person support } \\
\text { group } \\
\text { meetings. No } \\
\text { contact } \\
\text { between } \\
\text { meetings. No } \\
\text { contact for } \\
\text { months } 7 \text { to } 12\end{array}$ \\
\hline Harvey-Berino 2010 & Parallel RCT & $\begin{array}{l}\text { Weight loss program with online } \\
\text { recording of diet, physical activity } \\
\text { and weight, and weekly online chat } \\
\text { sessions }\end{array}$ & $\begin{array}{l}\text { Weight loss } \\
\text { program with } \\
\text { online } \\
\text { recording of } \\
\text { diet, physical } \\
\text { activity and } \\
\text { weight, and } \\
\text { weekly online } \\
\text { chat sessions, } \\
\text { with the } \\
\text { exception that }\end{array}$ \\
\hline
\end{tabular}




\begin{tabular}{|c|c|c|c|c|}
\hline \multirow[t]{2}{*}{ Characteristic Study ID } & \multirow[t]{2}{*}{ Design } & \multicolumn{2}{|c|}{ Intervention(s) } & Control(s) \\
\hline & & & & $\begin{array}{ll} & \text { once per } \\
\text { month the } \\
\text { meetings were } \\
\text { in-person } \\
2 \quad \text { Weight loss } \\
\text { program with } \\
\text { paper } \\
\text { recording of } \\
\text { diet, physical } \\
\text { activity and } \\
\text { weight, and } \\
\text { weekly in- } \\
\text { person chat } \\
\text { sessions }\end{array}$ \\
\hline Hunter 2008 & Parallel RCT & $\begin{array}{l}\text { Behavio } \\
\text { Submiss } \\
\text { exercise } \\
\text { week, w } \\
\text { and weel } \\
\text { quizzes }\end{array}$ & $\begin{array}{l}1 \text { Internet treatment. } \\
n \text { of electronic food and } \\
\text { iaries at least } 5 \text { times a } \\
\text { kly counselor feedback } \\
\text { y website lessons and }\end{array}$ & Usual care \\
\hline Morgan 2009 & Parallel RCT & $\begin{array}{l}\text { Internet } \\
\text { monitori } \\
\text { regular } f \\
\text { online er } \\
\text { and prog }\end{array}$ & $\begin{array}{l}\text { eight loss program. Self } \\
\text { of diet and activity with } \\
\text { dback based on participant } \\
\text { ies. Information session } \\
\text { im booklet }\end{array}$ & $\begin{array}{l}\text { Information session } \\
\text { (modified) and program } \\
\text { booklet }\end{array}$ \\
\hline Morgan 2011 & Cluster RCT & $\begin{array}{l}\text { Internet } \\
\text { online e: } \\
\text { monitori } \\
\text { mail feec } \\
\text { program } \\
\text { financial }\end{array}$ & $\begin{array}{l}\text { eight loss program with } \\
\text { ng, exercise and weight } \\
\text {, and individualized e- } \\
\text { ack. Information session, } \\
\text { ooklet and group-based } \\
\text { ncentives }\end{array}$ & Wait list control \\
\hline Schroder 2010 & Parallel quasi-RCT & $\begin{array}{l}1 \\
2\end{array}$ & $\begin{array}{l}\text { Computer-assisted } \\
\text { dieting intervention. } \\
\text { Provision of interactive } \\
\text { diet software. } \\
\text { Computer-assisted } \\
\text { dieting intervention plus } \\
\text { in-person intervention. } \\
\text { Provision of interactive } \\
\text { diet software plus } 4 \\
\text { sessions of in-person self } \\
\text { management group } \\
\text { training }\end{array}$ & Wait list control \\
\hline Svetkey 2008 & Parallel RCT & $\begin{array}{l}1 \\
2\end{array}$ & $\begin{array}{l}\text { In-person support. } 30 \\
\text { months of person-to- } \\
\text { person guidance and } \\
\text { support by telephone for } \\
5 \text { to } 15 \text { minutes each } \\
\text { month except for every } \\
\text { fourth month. Every } \\
\text { fourth month included } \\
45-\text { to } 60 \text {-minute face-to- } \\
\text { face contact. Self } \\
\text { reported weight (or } \\
\text { measured weight each } \\
\text { fourth month), review of } \\
\text { progress and action } \\
\text { plans. } \\
\text { Interactive technology- } \\
\text { based intervention. } \\
\text { Unlimited access to } \\
\text { weight loss maintenance } \\
\text { support website, weekly } \\
\text { login encouraged. Self } \\
\text { monitoring of physical }\end{array}$ & $\begin{array}{l}\text { Self directed weight } \\
\text { maintenance. Receipt of } \\
\text { printed life-style } \\
\text { guidelines and meeting } \\
\text { with study interventionist } \\
\text { at randomizations and } \\
\text { after 12-month data } \\
\text { collection visit }\end{array}$ \\
\hline
\end{tabular}




\begin{tabular}{|c|c|c|c|c|}
\hline \multirow[t]{2}{*}{ Characteristic Study ID } & \multirow[t]{2}{*}{ Design } & \multicolumn{2}{|c|}{ Intervention(s) } & \multirow[t]{2}{*}{ Control(s) } \\
\hline & & & $\begin{array}{l}\text { activity and calorie } \\
\text { intake, and reporting of } \\
\text { current weight. E-mail } \\
\text { prompts and automated } \\
\text { telephone calls if failure } \\
\text { to make self scheduled } \\
\text { logins }\end{array}$ & \\
\hline Tate 2001 & Parallel RCT & \multicolumn{2}{|c|}{$\begin{array}{l}\text { Internet behavioral therapy. Internet } \\
\text { education, plus weekly submission of } \\
\text { electronic self monitoring diaries, } \\
\text { together with any questions or } \\
\text { comments, to a behavioral therapist. } \\
\text { Weekly e-mail received from } \\
\text { therapist with behavioral weight loss } \\
\text { lesson and individualized feedback as } \\
\text { well as answers to questions. Access } \\
\text { to electronic bulletin board for social } \\
\text { support from other participants }\end{array}$} & $\begin{array}{l}\text { Internet educational } \\
\text { intervention. Given access } \\
\text { to study website with } \\
\text { basic information related } \\
\text { to weight loss and an } \\
\text { organized directory of } \\
\text { selected Internet } \\
\text { resources. One-hour } \\
\text { lesson on behavioral } \\
\text { weight control. } \\
\text { Encouraged to use the self } \\
\text { monitoring web resources } \\
\text { to track diet and exercise }\end{array}$ \\
\hline Tate 2003 & Parallel RCT & \multicolumn{2}{|c|}{$\begin{array}{l}\text { Internet weight loss program plus } \\
\text { weekly e-mail behavioral counselling }\end{array}$} & $\begin{array}{l}\text { Internet weight loss } \\
\text { program only }\end{array}$ \\
\hline Tate 2006 & Parallel RCT & 1 & $\begin{array}{l}\text { Internet weight loss } \\
\text { program plus weekly e- } \\
\text { mail behavioral } \\
\text { counselling } \\
\text { Internet weight loss } \\
\text { program plus weekly } \\
\text { automated computer } \\
\text { feedback }\end{array}$ & $\begin{array}{l}\text { Internet weight loss } \\
\text { program only }\end{array}$ \\
\hline Threlfall 1984 & Parallel RCT & \multicolumn{2}{|c|}{$\begin{array}{l}\text { Jeffrey and Katz weight loss manual } \\
\text { plus computer-based lessons written } \\
\text { by the study author that included self } \\
\text { regulatory activities and management } \\
\text { and additional practice of Jeffrey and } \\
\text { Katz learning }\end{array}$} & $\begin{array}{l}\text { Jeffrey and Katz weight } \\
\text { loss manual only }\end{array}$ \\
\hline Webber 2008 & Parallel RCT & \multicolumn{2}{|c|}{$\begin{array}{l}\text { Internet weight loss program with } \\
\text { study website, online self monitoring, } \\
\text { and message boards, with addition of } \\
\text { moderated online chat group sessions }\end{array}$} & $\begin{array}{l}\text { Internet weight loss } \\
\text { program with study } \\
\text { website, online self } \\
\text { monitoring and message } \\
\text { boards }\end{array}$ \\
\hline Wing 2006 & Parallel RCT & 2 & $\begin{array}{l}\text { Internet weight } \\
\text { maintenance program } \\
\text { incorporating self } \\
\text { monitoring and feedback } \\
\text { In-person weight } \\
\text { maintenance program } \\
\text { incorporating self } \\
\text { monitoring and feedback }\end{array}$ & Quarterly newsletters \\
\hline Wylie-Rosett 2001 & Parallel RCT & 1 & $\begin{array}{l}\text { Computerized weight } \\
\text { loss intervention. } \\
\text { Workbook plus } \\
\text { interactive computerized } \\
\text { tailored behavioral goals } \\
\text { based upon participant } \\
\text { input } \\
\text { Computerized weight } \\
\text { loss intervention. } \\
\text { Workbook plus } \\
\text { interactive computerized } \\
\text { tailored behavioral goals } \\
\text { based upon participant }\end{array}$ & Workbook \\
\hline
\end{tabular}




\begin{tabular}{l|l|l|l}
\hline Characteristic Study ID & Design & Intervention(s) & Control(s) \\
\hline & & $\begin{array}{l}\text { input and staff } \\
\text { consultation }\end{array}$ & \\
& & & \\
\hline
\end{tabular}

\section{Appendix 3. Baseline characteristics (I)}

\begin{tabular}{|c|c|c|c|c|c|c|}
\hline Characteristic Study ID & Intervention(s) and control(s) & Participating population $a$ & Country & Setting & Sex [female \%] & $\begin{array}{l}\text { Age } \\
\text { [mean } \\
\text { years } \\
\text { (SD)] }\end{array}$ \\
\hline Bennett 2010 & $\begin{array}{l}\text { I: Internet-based interactive } \\
\text { weight loss approach; health } \\
\text { coach support } \\
\text { C: current standard of } \\
\text { outpatient care and written } \\
\text { materials }\end{array}$ & $\begin{array}{l}\text { Obese and hypertensive } \\
\text { patients who visited the } \\
\text { internal medicine } \\
\text { department of a large } \\
\text { outpatient practice }\end{array}$ & USA & outpatient community & $\begin{array}{l}\text { T: } 47.5 \\
\text { I: } 41.2 \\
\text { C: } 54.0\end{array}$ & $\begin{array}{l}\text { T: } 54.4 \\
(8.1) \\
\text { I: } 54.4 \\
\text { (7.4) } \\
\text { C: } \\
54.5 \\
(8.9)\end{array}$ \\
\hline Cussler 2008 & $\begin{array}{l}\text { I: Internet-based program } \\
\text { C: continue to practice } \\
\text { principles during weight loss } \\
\text { intervention }\end{array}$ & $\begin{array}{l}\text { Women who had } \\
\text { completed participation in } \\
\text { a 4-month behavioral } \\
\text { weight-loss program }\end{array}$ & USA & community & $\begin{array}{l}\text { T: } 100 \\
\text { I: } 100 \\
\text { C: } 100\end{array}$ & $\begin{array}{l}\text { T: } 48.0 \\
\text { (4.4) } \\
\text { I: } 48.0 \\
(4.6) \\
\text { C: } 48 . \\
4(4.3)\end{array}$ \\
\hline DeLucia 1988 & $\begin{array}{l}\text { I1: Ferguson behavioral } \\
\text { program and nutritional } \\
\text { software 'The Eating Machine' } \\
\text { I2: Ferguson behavioral } \\
\text { program and nutritional } \\
\text { software "EATS' } \\
\text { C: Ferguson program }\end{array}$ & $\begin{array}{l}\text { Participants recruited } \\
\text { through a university } \\
\text { faculty-staff newsletter }\end{array}$ & USA & university community & $\begin{array}{l}\text { T: } 90 \\
\text { I1: } 90 \\
\text { I2: }: 90 \\
\text { C: } 89\end{array}$ & $\begin{array}{l}\text { T: } 40.6 \\
\text { II:- } \\
\text { I2:- } \\
\text { C: }-\end{array}$ \\
\hline Gabriele 2011 & $\begin{array}{l}\text { I1: Internet-based program and } \\
\text { directive e-coach support } \\
\text { I2: Internet-based program and } \\
\text { non-directive e-cocach support } \\
\text { C: Internet-based program with } \\
\text { minimal support }\end{array}$ & $\begin{array}{l}\text { C: Internet-based program } \\
\text { with minimal support }\end{array}$ & USA & academic & $\begin{array}{l}\text { T: } 84 \\
\text { I1: } 80 \\
\text { I2: } 86 \\
\text { C: } 85\end{array}$ & $\begin{array}{l}\text { T: } 45.4 \\
\text { (8.7. } \\
\mathrm{I1}: \\
42.9 \\
(7.5) \\
12: \\
46.6 \\
(8.5) \\
\mathrm{C}: \\
46.8 \\
(9.6)\end{array}$ \\
\hline Harvey-Berino 2002 & $\begin{array}{l}\text { I: Internet support } \\
\text { C1: frequent in-person support } \\
\text { C2: minimal in-person support }\end{array}$ & $\begin{array}{l}\text { Participants, recruited from } \\
\text { newspaper advertisements, } \\
\text { who completed a 24-week } \\
\text { weight loss program }\end{array}$ & USA & community & $\begin{array}{l}85 \\
\text { I: } 90 \\
\text { C1: } 86 \\
\text { C2: } 81\end{array}$ & $\begin{array}{l}48.4 \\
(9.6) \\
\text { I. } 46.3 \\
(11.1) \\
\text { C1: } \\
49.8 \\
(8.4) \\
\text { C2: } \\
49.1 \\
(9.1)\end{array}$ \\
\hline Harvey-Berino 2010 & $\begin{array}{l}\text { I: online recording and chat } \\
\text { sessions } \\
\text { C1: online recording and chat } \\
\text { sessions and in-person } \\
\text { meetings } \\
\text { C2: paper recording and in- } \\
\text { person chat sessions }\end{array}$ & $\begin{array}{l}\text { Participants recruited from } \\
2 \text { clinical centres }\end{array}$ & USA & outpatient clinical centres & $\begin{array}{l}\text { T: } 93 \\
\text { I: } 92 \\
\text { C1: } 94 \\
\text { C2: } 94\end{array}$ & $\begin{array}{l}\text { T: } 46.6 \\
(9.9) \\
\text { I. } 46.2 \\
(9.8) \\
\text { C1: } \\
46.7 \\
(9.6) \\
\text { C2: } \\
46.7 \\
(10.2)\end{array}$ \\
\hline Hunter 2008 & $\begin{array}{l}\text { I: behavioral Internet treatment } \\
\text { C: usual care }\end{array}$ & $\begin{array}{l}\text { Active duty militiary } \\
\text { personnel recruited through } \\
\text { e-mial advertisements and } \\
\text { flyers }\end{array}$ & USA & $\begin{array}{l}\text { military medical research } \\
\text { center }\end{array}$ & $\begin{array}{l}\text { T: } 50 \\
\text { I: } 50 \\
\text { C: } 50\end{array}$ & $\begin{array}{l}\text { T: } 33.9 \\
\text { (7.3) } \\
\text { I: } 33.5 \\
(7.4) \\
\text { C: } \\
34.4 \\
(7.2)\end{array}$ \\
\hline Morgan 2009 & $\begin{array}{l}\text { I: Internet weight loss } \\
\text { program; information session } \\
\text { and program booklet } \\
\text { C: information session } \\
\text { (modified) and program } \\
\text { booklet }\end{array}$ & $\begin{array}{l}\text { Male university staff and } \\
\text { students recruited from } \\
\text { university notice boards } \\
\text { and website }\end{array}$ & Australia & community university & $\begin{array}{l}\text { T: } 0 \\
\text { I: } 0 \\
\text { C: } 0\end{array}$ & $\begin{array}{l}\text { T: } 35.9 \\
(11.1) \\
\text { I } 37.5 \\
(10.4) \\
\text { C: } \\
34.0 \\
(11.6)\end{array}$ \\
\hline Morgan 2011 & $\begin{array}{l}\text { I: Internet weight loss } \\
\text { program; information session } \\
\text { and program booklet; group- } \\
\text { based financial incentives } \\
\text { C: wait list }\end{array}$ & $\begin{array}{l}\text { Male shift workers } \\
\text { recruited from the } \\
\text { workplace }\end{array}$ & Australia & workplace & $\begin{array}{l}\text { T: } 0 \\
\text { I: } 0 \\
\text { C: } 0\end{array}$ & $\begin{array}{l}\text { T: } 44.4 \\
(8.6) \\
\text { I } 44.8 \\
(8.3) \\
\text { C: } \\
43.7 \\
(9.1)\end{array}$ \\
\hline Schroder 2010 & $\begin{array}{l}\text { Il: computer-assisted } \\
\text { intervention and interactive } \\
\text { soffware }\end{array}$ & $\begin{array}{l}\text { Participants recruited } \\
\text { through announcements in }\end{array}$ & USA & outpatient community & $\begin{array}{l}\text { T: } 85 \\
\text { I1: } 87 \\
\text { I2: } 84\end{array}$ & $\begin{array}{l}\text { T: } 42.6 \\
\text { (10.7) } \\
\text { I1: - }\end{array}$ \\
\hline
\end{tabular}




\begin{tabular}{|c|c|c|c|c|c|c|}
\hline Characteristic Study ID & Intervention(s) and control(s) & Participating population $a$ & Country & Setting & Sex [female \%] & $\begin{array}{l}\text { Age } \\
\text { [mean } \\
\text { years } \\
\text { (SD)] }\end{array}$ \\
\hline & $\begin{array}{l}\text { I2: computer-assisted } \\
\text { intervention and interactive } \\
\text { software; in-person self } \\
\text { management group training } \\
\text { C: wait list }\end{array}$ & $\begin{array}{l}\text { local newspapers and radio } \\
\text { stations }\end{array}$ & & & C: 83 & $\begin{array}{l}\text { I2:- } \\
\text { C:- }\end{array}$ \\
\hline Svetkey 2008 & $\begin{array}{l}\text { I1: in-person support } \\
\text { I2: interactive technology- } \\
\text { based intervention; weight loss } \\
\text { maintenance support website } \\
\text { C: printed life-style guidelines; } \\
\text { meeting with study } \\
\text { interventionist }\end{array}$ & $\begin{array}{l}\text { Participants taking } \\
\text { hypertension or } \\
\text { dyslipidemia medications, } \\
\text { who completed a 6-month } \\
\text { weight loss program and } \\
\text { lost at least } 4 \mathrm{~kg}\end{array}$ & USA & academic medical centres & $\begin{array}{l}\text { 63 } \\
\text { I1: } 62 \\
\text { I2: } 63 \\
\text { C: } 65\end{array}$ & $\begin{array}{l}55.6 \\
(8.7) \\
\mathrm{I1}: \\
55.4 \\
(9.1) \\
12: \\
55.7 \\
(8.5) \\
\mathrm{C} \\
55.8 \\
(8.5)\end{array}$ \\
\hline Tate 2001 & $\begin{array}{l}\text { I: Internet behavioral therapy } \\
\text { C: Internet educational } \\
\text { intervention }\end{array}$ & $\begin{array}{l}\text { Participants, employed by a } \\
\text { large network of hospitals } \\
\text { with access to e-mail and } \\
\text { the Internet, recruited } \\
\text { through a series of } 2 \text { e-mail } \\
\text { messages and an } \\
\text { advertisement posted to the } \\
\text { work site's Intranet website }\end{array}$ & USA & academic medical center & $\begin{array}{l}\text { T: } 89 \\
\text { I: } 89 \\
\text { C: } 89\end{array}$ & $\begin{array}{l}\text { T: } 40.9 \\
\text { (10.6) } \\
\text { I: } 41.1 \\
(11.6) \\
\text { C: } \\
40.6 \\
(9.7)\end{array}$ \\
\hline Tate 2003 & $\begin{array}{l}\text { I: Internet weight loss program } \\
\text { and weekly e-mail behavioral } \\
\text { counseling } \\
\text { C: Internet weight loss } \\
\text { program }\end{array}$ & $\begin{array}{l}\text { Participants, recruited from } \\
\text { newspaper advertisements, } \\
\text { who were overweight or } \\
\text { obese, and had at least one } \\
\text { additional risk factor for } \\
\text { type } 2 \text { diabetes }\end{array}$ & USA & academic medical center & $\begin{array}{l}\text { T: } 89 \\
\text { I: } 91 \\
\text { C: } 89\end{array}$ & $\begin{array}{l}\text { T: }: 48.5 \\
(9.4) \\
\text { I: } 49.8 \\
(9.3) \\
\text { C: } \\
47.3 \\
(9.5)\end{array}$ \\
\hline Tate 2006 & $\begin{array}{l}\text { I1: Internet Weight loss } \\
\text { program and weekly e-mail } \\
\text { behavioral counselling } \\
\text { I2: Internet weight loss } \\
\text { program and weekly } \\
\text { automated computer feedback } \\
\text { C: Internet weight loss } \\
\text { program }\end{array}$ & $\begin{array}{l}\text { Participants, recruited from } \\
\text { newspaper advertisements, } \\
\text { who were over-weight or } \\
\text { obese, and were willing to } \\
\text { use meal replacements as } \\
\text { part of the dietary regimen }\end{array}$ & USA & academic medical center & $\begin{array}{l}84 \\
\text { I1: } 84 \\
\text { I2: } 87 \\
\text { C: } 82\end{array}$ & $\begin{array}{l}49.2 \\
(9.9) \\
\mathrm{I} 1: \\
47.9 \\
(9.8) \\
12: \\
49.7 \\
(11.4) \\
\text { C: } \\
49.9 \\
(8.3)\end{array}$ \\
\hline Threlfall 1984 & $\begin{array}{l}\text { I: weight loss manual plus } \\
\text { computer-based lessons } \\
\text { C: weight loss manual }\end{array}$ & $\begin{array}{l}\text { Participants recruited from } \\
\text { posters, hand-outs and } \\
\text { counselor contacts. The } \\
\text { study was an independent- } \\
\text { study college course }\end{array}$ & USA & university course & $\begin{array}{l}\text { T: } 91 \\
\text { I:- } \\
\text { C: }\end{array}$ & - \\
\hline Webber 2008 & $\begin{array}{l}\text { I: Internet weight loss program } \\
\text { and online chat group sessions } \\
\text { C: Internet weight loss me }\end{array}$ & $\begin{array}{l}\text { Female participants } \\
\text { recruited through } \\
\text { newspaper advertisements }\end{array}$ & USA & academic center medical & $\begin{array}{l}\text { T: } 100 \\
\text { I: } 100 \\
\text { C: } 100\end{array}$ & $\begin{array}{l}\text { T: } 50.0 \\
(9.9) \\
\text { I: } 49.3 \\
(10.6) \\
\text { C: } \\
50.8 \\
(9.3)\end{array}$ \\
\hline Wing 2006 & $\begin{array}{l}\text { I1: Internet weight } \\
\text { maintenance program } \\
\text { I2: in-person Weight } \\
\text { maintenance program } \\
\text { C: quarterly newsletters }\end{array}$ & $\begin{array}{l}\text { Adults, recruited through } \\
\text { newspaper advertisements, } \\
\text { brochures, and contacts } \\
\text { with commercial and } \\
\text { research weight-control } \\
\text { programs, who had lost at } \\
\text { least } 10 \% \text { of their body } \\
\text { weight during the previous } \\
2 \text { years }\end{array}$ & USA & $\begin{array}{l}\text { Academic medical centre } \\
\text { community }\end{array}$ & $\begin{array}{l}\text { T: } 81 \\
\text { I1 } 81 \\
\text { I2: } 80 \\
\text { C: } 83\end{array}$ & $\begin{array}{l}\text { T: } 51.3 \\
\text { (10.1) } \\
\text { I1: } \\
50.9 \\
(9.3) \\
\text { I2: } \\
51.0 \\
(10.3) \\
\text { C: } \\
52.0 \\
(10.8)\end{array}$ \\
\hline Wylie-Rosett 2006 & $\begin{array}{l}\text { I1: computerized weight loss } \\
\text { intervention and workbook } \\
\text { I2: computerized weight loss } \\
\text { intervention, workbook and } \\
\text { staff consultation } \\
\text { C: workbook }\end{array}$ & $\begin{array}{l}\text { Participants recruited from } \\
\text { HMO and surrounding } \\
\text { community ysing a variety } \\
\text { of techniques, who had a } \\
\text { BMI greater than } 25 \text { or a } \\
\text { BMI of } 24 \text { plus at least one } \\
\text { cardiovascular risk factor }\end{array}$ & USA & $\begin{array}{l}\text { health maintenance } \\
\text { organization (HMO) }\end{array}$ & $\begin{array}{l}\text { T: } 81.5 \\
\text { I1: }: 83 \\
\text { I2: } 82 \\
\text { C: } 86\end{array}$ & $\begin{array}{l}\text { T: } 52.6 \\
\text { (11.3) } \\
\text { I1: } \\
52.7 \\
(11.27) \\
\text { I2: } \\
51.6 \\
(12.14) \\
\text { C: } \\
52.5 \\
(11.5)\end{array}$ \\
\hline
\end{tabular}

"-" denotes not reported

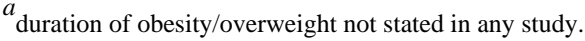

Abbreviations:

BMI: body mass index; C: control; HMO: health maintenance organization; I: intervention; T: total 


\section{Appendix 4. Baseline characteristics (II)}

\begin{tabular}{|c|c|c|c|c|c|}
\hline Characteristic Study ID & Intervention(s) and control(s) & BMI [mean kg/m2(SD)] & $\begin{array}{l}\text { Weight } \\
{[\text { [mean }} \\
\text { (SD) lb or } \\
\text { kg] } a\end{array}$ & Ethnic groups $[\%]$ & Duration of intervention/follow-up \\
\hline Bennett 2010 & $\begin{array}{l}\text { I: Internet-based interactive } \\
\text { weight loss approach; health } \\
\text { coach support } \\
\text { C: current standard of } \\
\text { outpatient care and written } \\
\text { materials }\end{array}$ & $\begin{array}{l}\text { T: } 34.6(3.2) \\
\text { I: } 35.0(3.5) \\
\text { C: } 34.6(3.2)\end{array}$ & $\begin{array}{l}\text { T: } 97.3 \\
(10.9) \mathrm{kg} \\
\text { I: } 101.10 \\
(15.4) \\
\text { C: } 97.3 \\
(10.9)\end{array}$ & $\begin{array}{l}\text { T: } 50 \text { White, } 31 \\
\text { Black, } 5 \text { Hispanic, } \\
15 \text { other } \\
\text { I: } 45 \text { White, } 37 \\
\text { Black, } 6 \text { Hispanic, } \\
12 \text { other } \\
\text { C: } 54 \text { White, } 24 \\
\text { Black, } 4 \text { Hispanic, } \\
18 \text { other }\end{array}$ & 12 weeks \\
\hline Cussler 2008 & $\begin{array}{l}\text { I: Internet-based program } \\
\text { C: continue to practice } \\
\text { principles during weight loss } \\
\text { intervention }\end{array}$ & $\begin{array}{l}\text { T: } 30.7(3.6) \\
\text { I: } 31.09(3.9) \\
\text { C: } 30.4(3.3)\end{array}$ & $\begin{array}{l}\text { T: } 83.7 \\
(11.8) \mathrm{kg} \\
\text { I: } 84.6 \\
(12.9) \mathrm{kg} \\
\text { C: } 82.8 \\
(10.7) \mathrm{kg}\end{array}$ & $\begin{array}{l}\text { Primarily white, } \\
\text { numbers not stated }\end{array}$ & 12 months \\
\hline DeLucia 1988 & $\begin{array}{l}\text { I1: Ferguson behavioral } \\
\text { program and nutritional } \\
\text { softuare 'The Eating Machine' } \\
\text { I2: Ferguson behavioral } \\
\text { program and nutritional } \\
\text { software 'EAT' } \\
\text { C: Ferguson program }\end{array}$ & - & $\begin{array}{l}\text { T: } 174.2 \\
(39.17 \mathrm{lb} \\
\text { I1: 1173.3 } \\
(43.36) \mathrm{lb} \\
\text { I2: 12:.72 } \\
(40.52) \mathrm{lb} \\
\text { C: } 172.32 \\
(36.92) \mathrm{lb}\end{array}$ & & 10 weeks \\
\hline Gabriele 2011 & $\begin{array}{l}\text { I1: Internet-based program and } \\
\text { directive e-coach support } \\
\text { I2: Internet-based program and } \\
\text { non-directive e-coach support } \\
\text { C: Internet-based program with } \\
\text { minimal support }\end{array}$ & $\begin{array}{l}\text { T: } 32.07(4.3) \\
\text { II: } 32.60(4.58) \\
\text { I2: } 31.56(4.61) \\
\text { C: } 32.04(3.81)\end{array}$ & $\begin{array}{l}\mathrm{T}: 87.9 \\
(13.8 \mathrm{~kg} \\
\mathrm{I1}: 90.88 \\
(15.14 \mathrm{~kg} \\
\mathrm{I2}: 85.67 \\
(13.33 \mathrm{~kg} \\
\mathrm{C}: 87.27 \\
(12.52) \mathrm{kg}\end{array}$ & $\begin{array}{l}\text { T: } 71 \text { Caucasian } \\
\text { I1: } 77 \text { Cuacasian } \\
\text { I2: 60 Caucasian } \\
\text { C: } 76 \text { Caucasian }\end{array}$ & 12 weeks \\
\hline Harvey-Berino 2002 & $\begin{array}{l}\text { I: Internet support } \\
\text { C: frequent in-person support } \\
\text { C2: minimal in-person support }\end{array}$ & $\begin{array}{l}\text { T: } 32.2(4.5) b \\
\text { I: } 32.2(4.0) \\
\text { C1: } 31.5(4.8) \\
\text { C2: } 32.8(4.6)\end{array}$ & $\begin{array}{l}\text { T: } 88.7 \\
(13.3) \mathrm{kg} b \\
\text { I: } 89.3 \\
(15.3) \\
\text { C1: } 86.5 \\
(10.1) \\
\text { C2: } 9.2 \\
(13.9)\end{array}$ & $\begin{array}{l}\text { T: } 98 \text { White } \\
\text { I: } 97 \text { White } \\
\text { C1: } 100 \text { White } \\
\text { C2: } 97 \text { White }\end{array}$ & 52 weeks \\
\hline Harvey-Berino 2010 & $\begin{array}{l}\text { I: online recording and chat } \\
\text { sessions re recording and chat } \\
\text { C1: : online recon } \\
\text { sessions and in-person } \\
\text { meetings } \\
\text { C2: paper recording and in- } \\
\text { person chat sessions }\end{array}$ & $\begin{array}{l}\text { T: } 35.7(5.6) \\
\text { I: } 35.6(5.7) \\
\text { C1: } 35.6(5.5) \\
\text { C2: } 36.0(5.7)\end{array}$ & $\begin{array}{l}\text { T: } 97.0 \\
(17.7) \mathrm{kg} \\
\text { I: } 97.2 \\
(18.7) \\
\text { C1: } 96.5 \\
(16) \\
\text { C2: } 97.4 \\
(18.5)\end{array}$ & $\begin{array}{l}\text { T: } 28 \text { African- } \\
\text { American } \\
\text { I: } 30 \text { African- } \\
\text { American } \\
\text { C1: } 26 \text { African- } \\
\text { American } \\
\text { C2: } 29 \text { African- } \\
\text { American }\end{array}$ & 6 months \\
\hline Hunter 2008 & $\begin{array}{l}\text { I: behavioral Internet treatment } \\
\text { C: usual care }\end{array}$ & $\begin{array}{l}\text { T: } 29.3(3.0) \\
\text { I: } 29.4(3.0) \\
\text { C: } 29.3(3.0)\end{array}$ & $\begin{array}{l}\text { T: } 87.0 \\
(15.1) \mathrm{kg} \\
\text { I: } 87.4 \\
(15.6) \mathrm{kg} \\
\text { C: } 86.6 \\
(14.7) \mathrm{kg}\end{array}$ & $\begin{array}{l}\text { T: } 56 \text { White } \\
\text { I: } 58 \text { White } \\
\text { C: } 53 \text { White }\end{array}$ & 6 months \\
\hline Morgan 2009 & $\begin{array}{l}\text { I: Internet weight loss } \\
\text { program; information session } \\
\text { and program booklet } \\
\text { C: information session } \\
\text { (modified) and program } \\
\text { booklet }\end{array}$ & $\begin{array}{l}\text { T: } 30.6(2.8) \\
\text { I: } 30.6(2.7) \\
\text { C: } 30.5(3.0)\end{array}$ & $\begin{array}{l}\text { T: } 99.1 \\
(12.8) \mathrm{kg} \\
\text { I: } 99.1 \\
(12.2) \\
\text { C: } 99.2 \\
(13.7)\end{array}$ & - & 3 months \\
\hline Morgan 2011 & $\begin{array}{l}\text { I: Internet weight loss } \\
\text { program, information session } \\
\text { and program booklet; group- } \\
\text { based financial incentives } \\
\text { C: wait list }\end{array}$ & $\begin{array}{l}\text { T: } 30.5(3.6) \\
\text { II } 30.7(3.6) \\
\text { C: } 30.2(3.5)\end{array}$ & $\begin{array}{l}\text { T: } 94.9 \\
(13.4) \mathrm{kg} \\
\text { I: } 96.3 \\
(12.9) \mathrm{kg} \\
\text { C: } 92.9 \\
\text { (14.1) } \mathrm{kg}\end{array}$ & - & 3 months \\
\hline Schroder 2010 & $\begin{array}{l}\text { I1: computer-assisted } \\
\text { intervention and interactive } \\
\text { software } \\
\text { I2: computer-assisted } \\
\text { intervention and interactive } \\
\text { software; in-person self } \\
\text { management group training } \\
\text { C: wait list }\end{array}$ & $\begin{array}{l}\text { T: } 34.6(5.4) \\
\text { II: } 34.8(5.96) \\
\text { I2: } 34.48(5.03) \\
\text { C: } 34.54(5.28)\end{array}$ & $\begin{array}{l}\text { T: } 217.4 \\
(36.21 \mathrm{lb} \\
11: 215.22 \\
(35.74) \mathrm{lb} \\
\mathrm{I} 2: 219.75 \\
(38.35) \mathrm{lb} \\
\mathrm{C}: 217.28 \\
(35.43) \mathrm{lb}\end{array}$ & $\begin{array}{l}\text { T: } 95 \text { Caucasian } \\
\text { II:- } \\
\text { I2:- } \\
\text { C: - }\end{array}$ & 3 months $c$ \\
\hline Svetkey 2008 & $\begin{array}{l}\text { I1: in-person support } \\
\text { I2: interactive technology- } \\
\text { based intervention; weight loss } \\
\text { maintenance support website } \\
\text { C: printed life-style guidelines; } \\
\text { meeting with study } \\
\text { interventionist }\end{array}$ & $\begin{array}{l}\text { T: } 34.1(4.8) b \\
\text { II: } 14.2(4.8) \\
\text { I2: }: 24.2(4.9) \\
\text { C: } 34.0(4.8)\end{array}$ & $\begin{array}{l}\text { T: } 88.2 \\
(15.8) \mathrm{kg} \\
\text { I1: } 88.7 \\
(16.9) \mathrm{kg} \\
\text { I2: } 88.6 \\
(15.4) \mathrm{kg} \\
\text { C: } 87.4 \\
(15.3) \mathrm{kg}\end{array}$ & $\begin{array}{l}\text { T: } 38 \text { African- } \\
\text { American, } 62 \text { non- } \\
\text { African American } \\
\text { II: } 39 \text { African- } \\
\text { American, } 61 \text { non- } \\
\text { African American } \\
\text { I2: } 38 \text { African- } \\
\text { American, } 62 \text { non- } \\
\text { African American } \\
\text { C: } 37 \text { African- } \\
\text { American, } 63 \text { non- } \\
\text { African American }\end{array}$ & 30 months \\
\hline
\end{tabular}




\begin{tabular}{|c|c|c|c|c|c|}
\hline Characteristic Study ID & Intervention(s) and control(s) & BMI [mean kg/m2(SD)] & $\begin{array}{l}\text { Weight } \\
\text { [mean } \\
(\mathrm{SD}) \text { lb or } \\
\mathrm{kg}]^{a}\end{array}$ & Ethnic groups [\%] & Duration of intervention/follow-up \\
\hline Tate 2001 & $\begin{array}{l}\text { I: Internet behavioral therapy } \\
\text { C: Internet educational } \\
\text { intervention }\end{array}$ & $\begin{array}{l}\text { T: } 29.0(3.0) \\
\text { I: } 29.1(3.0) \\
\text { C: } 28.9(3.1)\end{array}$ & $\begin{array}{l}\text { T: } 78.1 \\
\text { (10.5) kg } \\
\text { I: } 77.4 \\
(9.4) \mathrm{kg} \\
\text { C: } 7.8 \\
\text { (11.6) } \mathrm{kg}\end{array}$ & $\begin{array}{l}\text { T: } 84 \text { White } \\
\text { I: } 89 \text { White } \\
\text { C: } 78 \text { White }\end{array}$ & 6 months \\
\hline Tate 2003 & $\begin{array}{l}\text { I: Internet weight loss program } \\
\text { and weekly e-mail behavioral } \\
\text { counselling } \\
\text { C: Internet weight loss } \\
\text { program }\end{array}$ & $\begin{array}{l}\text { T: } 33.1(3.8) \\
\text { I: } 32.5(3.8) \\
\text { C: } 33.7(3.7)\end{array}$ & $\begin{array}{l}\text { T: } 87.8 \\
\text { (13.5) } \mathrm{kg} \\
\text { I: } 86.2 \\
(14.3) \mathrm{kg} \\
\text { C: } 89.4 \\
\text { (12.6) } \mathrm{kg}\end{array}$ & $\begin{array}{l}\text { T: } 89 \text { White } \\
\text { I: } 89 \text { White } \\
\text { C: } 89 \text { White }\end{array}$ & 12 months \\
\hline Tate 2006 & $\begin{array}{l}\text { I1: Internet weight loss } \\
\text { program and weekly e-mail } \\
\text { behavioral counselling } \\
\text { I2: Internet weight loss } \\
\text { program and weekly } \\
\text { automated computer feedback } \\
\text { C: Internet weight loss } \\
\text { program }\end{array}$ & $\begin{array}{l}32.6(3.5) \\
\text { I1: } 32.8(3.4) \\
\text { I2: } 32.7(3.5) \\
\text { C: } 32.3(3.7)\end{array}$ & $\begin{array}{l}\text { T: } 88.8 \\
(13.3) \mathrm{kg} \\
\mathrm{I} 1: 89.0 \\
(13.0) \mathrm{kg} \\
\mathrm{I} 2: 89.0 \\
(13.2) \mathrm{kg} \\
\text { C: } 8.3 \\
(13.9) \mathrm{kg}\end{array}$ & $\begin{array}{l}\text { T: } 10 \text { minority } \\
\text { ethnicity } \\
\text { I1: } 13 \text { minority } \\
\text { ethnicity } \\
\text { I2: } 10 \text { minority } \\
\text { ethnicity } \\
\text { C: } 9 \text { minority } \\
\text { ethnicity }\end{array}$ & 6 months \\
\hline Threlfall 1984 & $\begin{array}{l}\text { I: weight loss manual plus } \\
\text { computer-based lessons } \\
\text { C: weight loss manual }\end{array}$ & - & $\begin{array}{l}\text { T: } 176.3 \\
(26.4) \mathrm{lb} \\
\mathrm{I}: \\
181.5(31.3) \\
\mathrm{lb} \\
\mathrm{C}: \\
171.4(21.9) \\
\mathrm{lb}\end{array}$ & - & 10 weeks \\
\hline Webber 2008 & $\begin{array}{l}\text { I: Internet weight loss program } \\
\text { and online chat group sessions } \\
\text { C: Internet weight loss } \\
\text { program }\end{array}$ & $\begin{array}{l}\text { T: } 31.1(3.7) \\
\text { I: } 30.8(4.0) \\
\text { C: } 31.4(3.3)\end{array}$ & $\begin{array}{l}\text { T: } 82.3 \\
(11.21) \mathrm{kg} \\
\mathrm{I}: 82.1 \\
(13.6) \mathrm{kg} \\
\text { C: } 82.5 \\
(8.4) \mathrm{kg}\end{array}$ & $\begin{array}{l}\text { T: } 86 \text { White } \\
\text { I: } 88 \text { White } \\
\text { C: } 85 \text { White }\end{array}$ & 16 weeks \\
\hline Wing 2006 & $\begin{array}{l}\text { I1: Internet weight } \\
\text { maintenance program } \\
\text { I2: in-person weight } \\
\text { maintenance program } \\
\text { C: quarterly newsletters }\end{array}$ & $\begin{array}{l}\text { T: } 28.6(4.8) \\
\text { I1: } 28.1(4.6) \\
\text { I2: } 28.7(4.7) \\
\text { C: } 29.1(5.0)\end{array}$ & $\begin{array}{l}\text { T: } 77.8 \\
(16.1) \mathrm{kg} \\
\text { II: } 76.0 \\
(16.4) \mathrm{kg} \\
\text { I2: } 78.6 \\
(17.1) \mathrm{kg} \\
\text { C: } 78.8 \\
\text { (14.8) } \mathrm{kg}\end{array}$ & - & 18 months \\
\hline Wylie-Rosett 2006 & $\begin{array}{l}\text { I1: computerized weight loss } \\
\text { intervention and work-book } \\
\text { I2: computerized weight loss } \\
\text { intervention, work-book and } \\
\text { staff consultation } \\
\text { C: workbook }\end{array}$ & $\begin{array}{l}\text { T: } 36(6.5) \\
\text { I1: } 35.7(6.7) \\
\text { I2:35.16(6.5) } \\
\text { C: } 36.5(6.0)\end{array}$ & $\begin{array}{l}\text { T: } 214.2 \\
(44.1) \mathrm{lb} \\
\mathrm{I}(1: 213.3 \\
(44.0) \mathrm{lb} \\
\mathrm{I} 2: 211.8 \\
(43.4) \mathrm{lb} \\
\text { C: } 220.8 \\
(45.6) \mathrm{lb}\end{array}$ & $\begin{array}{l}\text { T: } 84 \text { White } \\
\text { I1: } 83 \text { White } \\
\text { I2: } 82 \text { White } \\
\text { C: } 86 \text { White }\end{array}$ & 12 months \\
\hline
\end{tabular}

“-” denotes not reported

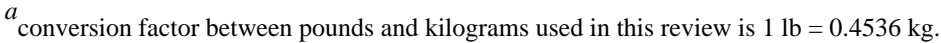

$b$ at start of weight-loss intervention.

${ }^{c}$ control group patients were distributed between intervention groups, and intervention continued for additional three months

Abbreviations:

BMI: body mass index; C: control; I: intervention; T: total

\section{Appendix 5. Matrix of study endpoints}

\begin{tabular}{|c|c|c|c|}
\hline Characteristic Study ID & Primary endpoint(s) & Secondary endpoint(s) & Other endpoint(s) \\
\hline Bennett 2010 & $\begin{array}{l}\text { Change in body weight } \\
\text { (absolute weight change in } \\
\mathrm{kg} \text { - at least } 5 \mathrm{~kg} \text { ) }\end{array}$ & $\begin{array}{l}\text { Change in BMI, blood } \\
\text { pressure control and waist } \\
\text { circumference }\end{array}$ & \\
\hline Cussler 2008 & $\begin{array}{l}\text { Change in body weight } \\
\text { (absolute weight change in } \\
\text { kg and percentage total } \\
\text { weight) }\end{array}$ & - & $\begin{array}{l}\text { Change in BMI, change in } \\
\text { body composition } \\
\text { (percent fat, total body fat } \\
\text { and fat-free mass), and } \\
\text { change in calorie intake }\end{array}$ \\
\hline
\end{tabular}




\begin{tabular}{|c|c|c|c|}
\hline Characteristic Study ID & Primary endpoint(s) & Secondary endpoint(s) & Other endpoint(s) \\
\hline DeLucia 1988 & $\begin{array}{l}\text { Change in body weight } \\
\text { (absolute weight change in } \\
\text { lb) }\end{array}$ & $\begin{array}{l}\text { Percentage excess weight } \\
\text { lost (lb lost/lb overweight) }\end{array}$ & \\
\hline Gabriele 2011 & $\begin{array}{l}\text { Change in body weight and } \\
\text { waist circumference }\end{array}$ & $\begin{array}{l}\text { Change in physical activity, } \\
\text { dietary behavior, and } \\
\text { program engagement with } \\
\text { the intervention }\end{array}$ & \\
\hline Harvey-Berino 2002 & Change in body weight & $\begin{array}{l}\text { Energy intake and energy } \\
\text { expended in physical } \\
\text { activity }\end{array}$ & \\
\hline Harvey-Berino 2010 & Change in body weight & - & $\begin{array}{l}\text { Change in BMI, change in } \\
\text { dietary energy intake and } \\
\text { percent fat intake, energy } \\
\text { expended in physical } \\
\text { activity }\end{array}$ \\
\hline Hunter 2008 & $\begin{array}{l}\text { Change in body weight } \\
\text { (absolute weight change in } \\
\mathrm{kg} \text { and percentage change } \\
\text { from baseline), change in } \\
\text { percent body fat, change in } \\
\text { waist circumference }\end{array}$ & - & $\begin{array}{l}\text { Changes in dietary intake } \\
\text { of fat, fruit, vegetables } \\
\text { and fibre, and changes in } \\
\text { physical activity }\end{array}$ \\
\hline Morgan 2009 & $\begin{array}{l}\text { Change in body weight } \\
\text { (absolute weight change in } \\
\mathrm{kg} \text { and percentage change } \\
\text { from baseline) }\end{array}$ & $\begin{array}{l}\text { BMI, waist circumference, } \\
\text { blood pressure, physical } \\
\text { activity, dietary intake }\end{array}$ & \\
\hline Morgan 2011 & Change in body weight & $\begin{array}{l}\text { Waist circumference, BMI, } \\
\text { blood pressure, resting heart } \\
\text { rate }\end{array}$ & \\
\hline Schroder 2010 & $\begin{array}{l}\text { Change in body weight } \\
\text { (absolute change in lb) and } \\
\text { change in BMI }\end{array}$ & $\begin{array}{l}\text { Lipid panel results, } \\
\text { including total blood } \\
\text { cholesterol, HDL, LDL, } \\
\text { ratio of total cholesterol to } \\
\text { HDS and triglycerides }\end{array}$ & \\
\hline Svetkey 2008 & $\begin{array}{l}\text { Weight change (absolute } \\
\text { weight change in kg) from } \\
\text { the end of the initial weight } \\
\text { loss program to the end of } \\
\text { the 30-month weight } \\
\text { maintenance intervention } \\
\text { period }\end{array}$ & - & $\begin{array}{l}\text { Change in weight from } \\
\text { entry into weight loss } \\
\text { program to end of study, } \\
\text { dichotomous measures of } \\
\text { weight change } \\
\text { (maintenance of } 4 \mathrm{~kg} \\
\text { weight loss or more, no } \\
\text { net weight gain from } \\
\text { entry, 5\% or more weight } \\
\text { loss from entry, } 3 \% \text { or } \\
\text { less weight gain from } \\
\text { randomization). Changes } \\
\text { in total energy intake } \\
\text { (kcal/d) and MVPA (min/ } \\
\text { wk) }\end{array}$ \\
\hline Tate 2001 & $\begin{array}{l}\text { Change in body weight } \\
\text { (absolute change in } \mathrm{kg} \text { ) } \\
\text { measured at } 6 \text { and } 12 \\
\text { months }\end{array}$ & - & $\begin{array}{l}\text { Waist circumference, } \\
\text { Paffenbarger activity } \\
\text { questionnaire, Block Food } \\
\text { Frequency questionnaire, } \\
\text { Centers for } \\
\text { Epidemiological Studies } \\
\text { Depression Scale }\end{array}$ \\
\hline Tate 2003 & Weight change at 12 months & - & $\begin{array}{l}\text { Waist circumference, } \\
\text { venous blood glucose, } \\
\text { Paffenbarger activity } \\
\text { questionnaire, Block Food } \\
\text { Frequency questionnaire, } \\
\text { Centres for } \\
\text { Epidemiological Studies } \\
\text { Depression Scale }\end{array}$ \\
\hline
\end{tabular}




\begin{tabular}{|c|c|c|c|}
\hline Characteristic Study ID & Primary endpoint(s) & Secondary endpoint(s) & Other endpoint(s) \\
\hline Tate 2006 & Weight change at 6 months & $\begin{array}{l}\text { Dietary intake (total calories } \\
\text { and percent calories from } \\
\text { fat), energy expenditure } \\
\text { (kcal/week) }\end{array}$ & \\
\hline Threlfall 1984 & - & - & $\begin{array}{l}\text { Change in weight } \\
\text { (pounds), percent } \\
\text { reduction in excess body } \\
\text { weight and costs }\end{array}$ \\
\hline Webber 2008 & Weight change at 16 weeks & - & $\begin{array}{l}\text { Dietary intake (calories, } \\
\text { percent fat), physical } \\
\text { activity (kcal/week) }\end{array}$ \\
\hline Wing 2006 & Weight change at 18 months & $\begin{array}{l}\text { Percentage of participants } \\
\text { gaining } 2.3 \mathrm{~kg} \text { or more, } \\
\text { changes in diet, changes in } \\
\text { physical activity, use of } \\
\text { behavioral strategies }\end{array}$ & \\
\hline Wylie-Rosett 2001 & $-a$ & - & $\begin{array}{l}\text { Body weight, body } \\
\text { composition, waist and } \\
\text { hip circumference, lipid } \\
\text { measurements, blood } \\
\text { pressure, physical activity } \\
\text { and dietary in-take }\end{array}$ \\
\hline
\end{tabular}

"-" denotes not reported

Primary or secondary endpoint(s) refer to verbatim statements in the publication, other endpoints relate to outcomes which were not specified as 'primary' or 'secondary' outcomes in the publication

$a_{\text {change in body weight was not specified as a primary outcome, but was used to calculate sample size }}$

Abbreviations:

BMI: body mass index; C: control; I: intervention; HDL: high-density lipoprotein; LDL: low-density lipoprotein; MVPA: moderate to vigorous physical activity

\section{Appendix 6. Adverse events}

\begin{tabular}{|c|c|c|c|c|c|c|c|c|}
\hline Characteristic Study ID & Intervention(s) and control(s) & Deaths [n] & $\begin{array}{l}\text { Adverse } \\
\text { events } \\
{[\mathrm{n}] \boldsymbol{a}}\end{array}$ & $\begin{array}{l}\text { Serious } \\
\text { adverse } \\
\text { events } \\
\text { (n) }\end{array}$ & $\begin{array}{l}\text { Dropouts } \\
\text { due to } \\
\text { adverse } \\
\text { events } \\
\text { [n] } \\
\end{array}$ & Hospitalisation [n] & Outpatient treatment [n] & Symptoms [n] \\
\hline Bennett 2010 & $\begin{array}{l}\text { I: Internet-based interactive } \\
\text { weight loss approach; health } \\
\text { coach support } \\
\text { C: current standard of out- } \\
\text { patient care and written } \\
\text { materials }\end{array}$ & T: 0 & T: - & T: 0 & T: 0 & T: 0 & T: 0 & T: 0 \\
\hline Cussler 2008 & $\begin{array}{l}\text { I: Internet-based program } \\
\text { C: continue to practice } \\
\text { principles during weight loss } \\
\text { intervention }\end{array}$ & $\mathrm{T}: 0$ & T: - & $\mathrm{T}: 0$ & T: 0 & T: 0 & T: 0 & T: 0 \\
\hline DeLucia 1988 & $\begin{array}{l}\text { I1: Ferguson behavioral } \\
\text { program and nutritional } \\
\text { software 'The Eating Machine' } \\
\text { I2: Ferguson behavioral } \\
\text { program and nutritional } \\
\text { software 'EATS' } \\
\text { C: Ferguson program }\end{array}$ & T: 0 & T: - & $\mathrm{T:} 0$ & T: 0 & T: 0 & T: 0 & T: 0 \\
\hline Gabriele 2011 & $\begin{array}{l}\text { I1: Internet-based program and } \\
\text { directive e-coach support } \\
\text { I2: Internet-based program and } \\
\text { non-directive e-coach support } \\
\text { C: Internet-based program with } \\
\text { minimal support }\end{array}$ & $\mathrm{T}: 0$ & T: - & T: 0 & T: 0 & T: 0 & T: 0 & T: 0 \\
\hline Harvey-Berino 2002 & $\begin{array}{l}\text { I: Internet support } \\
\text { C: frequent in-person support } \\
\text { C2: minimal in-person support }\end{array}$ & T: 0 & T: - & $\mathrm{T:} 0$ & T: 0 & T: 0 & T: 0 & T: 0 \\
\hline Harvey Berino 2010 & $\begin{array}{l}\text { I: online recording and chat } \\
\text { sessions }\end{array}$ & T: 0 & T: - & $\mathrm{T:} 0$ & $\mathrm{~T}: 0$ & T: 0 & T: 0 & T: 0 \\
\hline
\end{tabular}




\begin{tabular}{|c|c|c|c|c|c|c|c|c|}
\hline Characteristic Study ID & Intervention(s) and control(s) & Deaths $[\mathrm{n}]$ & $\begin{array}{l}\text { Adverse } \\
\text { events } \\
{[\mathrm{n}]}\end{array}$ & $\begin{array}{l}\text { Serious } \\
\text { adverse } \\
\text { events } \\
\text { (n) }\end{array}$ & $\begin{array}{l}\text { Dropouts } \\
\text { due to } \\
\text { adverse } \\
\text { events } \\
\text { [n] }\end{array}$ & Hospitalisation [n] & Outpatient treatment $[\mathrm{n}]$ & Symptoms $[\mathrm{n}]$ \\
\hline & $\begin{array}{l}\text { C1: online recording and chat } \\
\text { sessions and in-person } \\
\text { meetings } \\
\text { C2: paper recording and in- } \\
\text { person chat sessions }\end{array}$ & & & & & & & \\
\hline Hunter 2008 & $\begin{array}{l}\text { I: behavioral Internet treatment } \\
\text { C: usual care }\end{array}$ & T: 0 & T:- & T: 0 & $\mathrm{~T}: 0$ & T: 0 & T: 0 & T: 0 \\
\hline Morgan 2009 & $\begin{array}{l}\text { I: Internet weight loss } \\
\text { program; information session } \\
\text { and program booklet } \\
\text { C: information session } \\
\text { (modified) and program } \\
\text { booklet }\end{array}$ & $\mathrm{T}: 0$ & T:- & T: 0 & $\mathrm{~T}: 0$ & T: 0 & T: 0 & T: 0 \\
\hline Morgan 2011 & $\begin{array}{l}\text { I: Internet weight loss } \\
\text { program; information session } \\
\text { and program booklet; group- } \\
\text { based financial incentives } \\
\text { C: wait list }\end{array}$ & T: 0 & T:- & T: 0 & $\mathrm{~T}: 0$ & T: 0 & T: 0 & T: 0 \\
\hline Schroder 2010 & $\begin{array}{l}\text { I1: computer-assisted } \\
\text { intervention and interactive } \\
\text { software } \\
\text { I2: computer-assisted } \\
\text { intervention and interactive } \\
\text { software; in-person self } \\
\text { management group training } \\
\text { C: wait list }\end{array}$ & T: 0 & T:- & T: 0 & $\mathrm{~T}: 0$ & T: 0 & T: 0 & T: 0 \\
\hline Svetkey 2008 & $\begin{array}{l}\text { I1: in-person support } \\
\text { 12: interactive technology- } \\
\text { based intervention; weight loss } \\
\text { maintenance support website } \\
\text { C: printed life-style guide- } \\
\text { lines, meeting with study } \\
\text { interventionist }\end{array}$ & $\begin{array}{l}\text { I1: } 1 / 342 \\
\text { I2: } 1 / 3438 \\
\text { C1 } 1 / 1 / 142 \\
\text { T: } 3 / 1032\end{array}$ & T:- & T: 0 & $\mathrm{~T}: 0$ & T: 0 & T: 0 & T: 0 \\
\hline Tate 2001 & $\begin{array}{l}\text { I: Internet behavioral therapy } \\
\text { C: Internet educational } \\
\text { intervention }\end{array}$ & $\mathrm{T}: 0$ & T:- & T: 0 & $\mathrm{~T}: 0$ & T: 0 & T: 0 & T: 0 \\
\hline Tate 2003 & $\begin{array}{l}\text { I: Internet weight loss program } \\
\text { and weekly e-mail behavioral } \\
\text { counselling } \\
\text { C: Internet weight loss } \\
\text { program }\end{array}$ & T: 0 & T:- & T: 0 & $\mathrm{~T}: 0$ & T: 0 & T: 0 & T: 0 \\
\hline Tate 2006 & $\begin{array}{l}\text { I1: Internet weight loss } \\
\text { program and weekly --mail } \\
\text { behavioral counselling } \\
\text { I2: Internet weight loss } \\
\text { program and weekly } \\
\text { automated computer feed-back } \\
\text { C: Internet weight loss } \\
\text { program }\end{array}$ & $\mathrm{T}: 0$ & $\mathrm{~T}: 0$ & $\mathrm{~T}: 0$ & $\mathrm{~T}: 0$ & $\mathrm{~T}: 0$ & T: 0 & T: 0 \\
\hline Threlfall 1984 & $\begin{array}{l}\text { I: weight loss manual plus } \\
\text { computer-based lessons } \\
\text { C: weight loss manual }\end{array}$ & T: 0 & T:- & T: 0 & $\mathrm{~T}: 0$ & $\mathrm{~T}: 0$ & T: 0 & T: 0 \\
\hline Webber 2008 & $\begin{array}{l}\text { I: Internet weight loss program } \\
\text { and online chat group sessions } \\
\text { C: Internet weight loss } \\
\text { program }\end{array}$ & T: 0 & T:- & T: 0 & $\mathrm{~T}: 0$ & T: 0 & T: 0 & T: 0 \\
\hline Wing 2006 & $\begin{array}{l}\text { I1: Internet weight } \\
\text { maintenance program } \\
\text { I2: in-person weight } \\
\text { maintenance program } \\
\text { C: quarterly newsletters }\end{array}$ & T: 0 & T: 0 & T: 0 & $\mathrm{~T}: 0$ & $\mathrm{~T}: 0$ & T: 0 & T: 0 \\
\hline Wylie-Rosett 2001 & $\begin{array}{l}\text { I1: computerized weight loss } \\
\text { intervention and workbook } \\
\text { I2: computerized weight loss } \\
\text { intervention, work-book and } \\
\text { staff consultation } \\
\text { C: workbook }\end{array}$ & T: 0 & T:- & T: 0 & $\mathrm{~T}: 0$ & T: 0 & T: 0 & T: 0 \\
\hline
\end{tabular}

"-" denotes not reported

${ }^{a}$ No study made any mention of adverse effects with the exception of Wing 2006, which reported that there were no serious adverse events and Tate 2006, which reported that there were no significant adverse events

Abbreviations:

C: control; I: intervention; T: total 


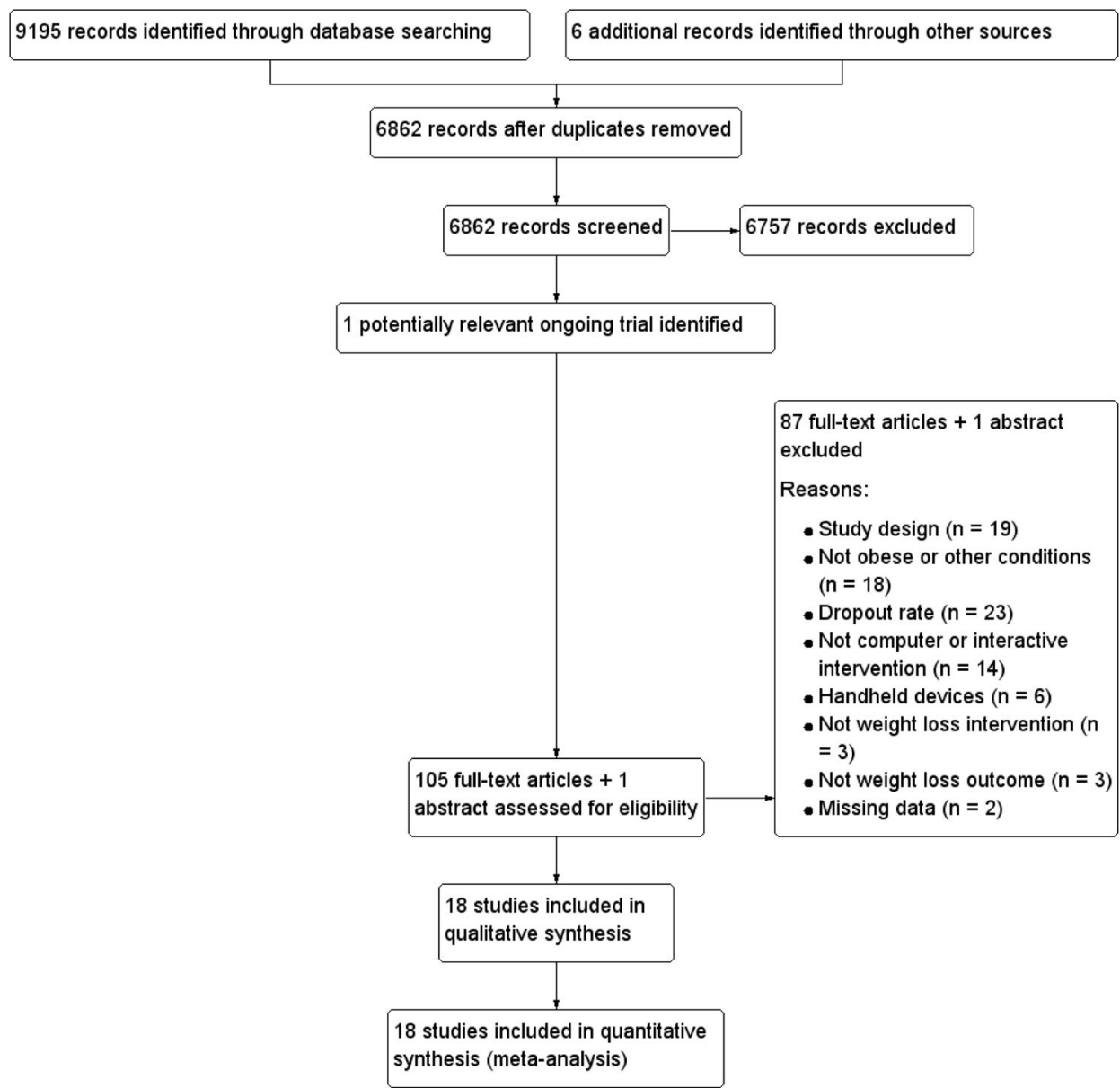

Figure 1.

Study flow diagram. 


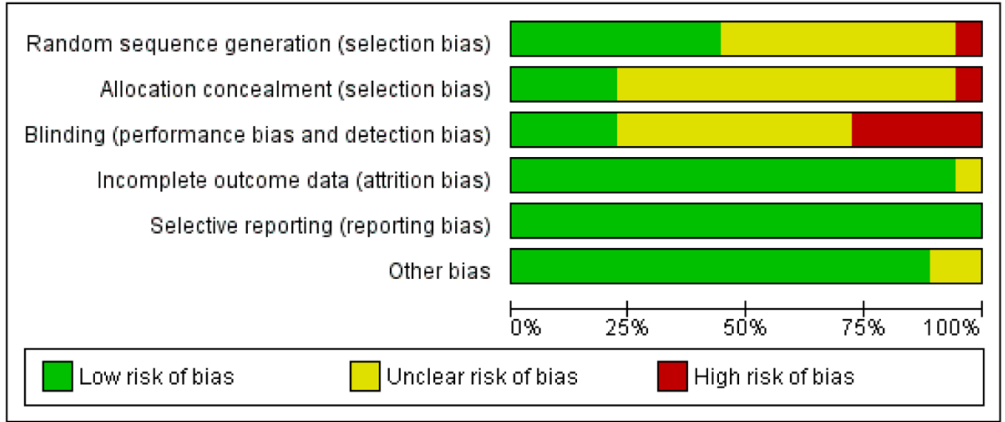

Figure 2.

'Risk of bias' graph: review authors' judgements about each risk of bias item presented as percentages across all included studies. 


\begin{tabular}{|c|c|c|c|c|c|c|}
\hline & 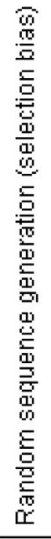 & 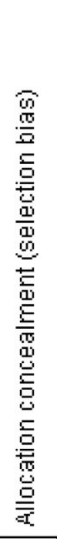 & 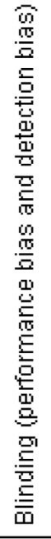 & 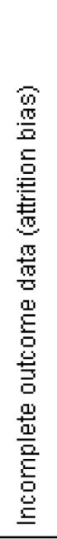 & 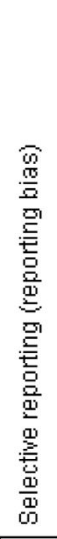 & 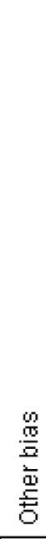 \\
\hline Bennett 2010 & $?$ & + & $\oplus$ & + & + & + \\
\hline Cussler 2008 & $?$ & $?$ & $?$ & + & $\oplus$ & $?$ \\
\hline DeLucia 1988 & $?$ & $?$ & $?$ & + & + & + \\
\hline Gabriele 2011 & $\oplus$ & $?$ & $\odot$ & + & + & + \\
\hline Harvey-Berino 2002 & $?$ & $?$ & $?$ & + & + & + \\
\hline Harvey-Berino 2010 & $\oplus$ & $?$ & $?$ & + & + & + \\
\hline Hunter 2008 & $\oplus$ & $?$ & $\odot$ & + & $\oplus$ & + \\
\hline Morgan 2009 & $\oplus$ & + & + & + & + & + \\
\hline Morgan 2011 & $\odot$ & + & $\odot$ & + & + & $?$ \\
\hline Schroder 2010 & 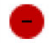 & - & - & + & + & + \\
\hline Swetkey 2008 & $\oplus$ & 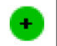 & $\oplus$ & $\oplus$ & + & + \\
\hline Tate 2001 & $?$ & $?$ & $?$ & + & + & + \\
\hline Tate 2003 & $\oplus$ & $?$ & $?$ & + & + & + \\
\hline Tate 2006 & $\oplus$ & $?$ & $?$ & + & + & + \\
\hline Threlfall 1984 & $?$ & $?$ & & $?$ & + & + \\
\hline Webber 2008 & $?$ & $?$ & + & + & + & + \\
\hline Wing 2006 & $?$ & $?$ & $?$ & + & $\oplus$ & + \\
\hline Wylie-Rosett 2001 & $?$ & $?$ & $?$ & + & + & + \\
\hline
\end{tabular}

Figure 3.

'Risk of bias' summary: review authors' judgements about each risk of bias item for each included study. 


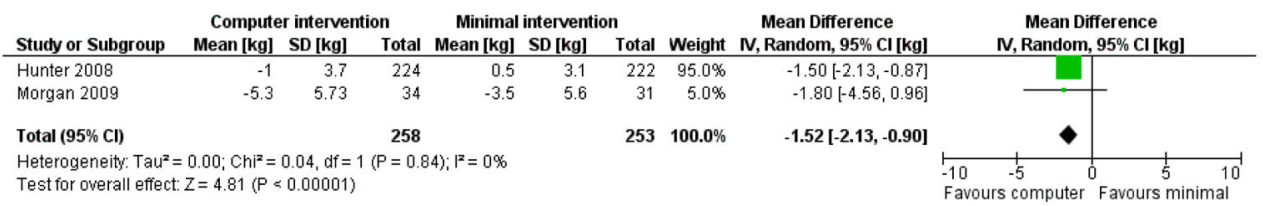

Figure 4.

Forest plot of comparison: 1 Weight loss: computer vs minimal intervention, outcome: 1.2 Weight at $6 \mathrm{mo}$ [kg]. 


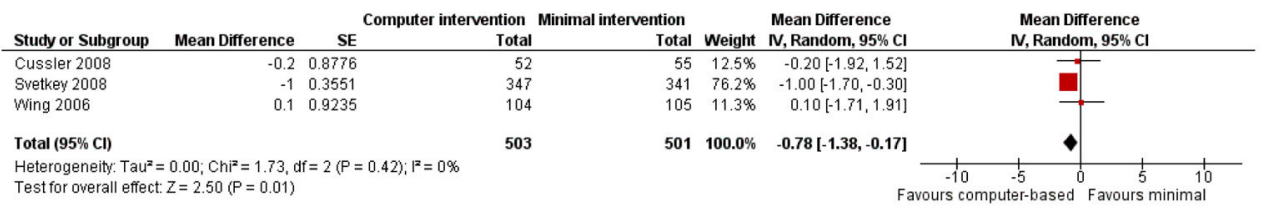

Figure 5.

Forest plot of comparison: 5 Weight maintenance: computer vs minimal intervention, outcome: 5.2 Weight at $12 \mathrm{mo}$ [kg]. 


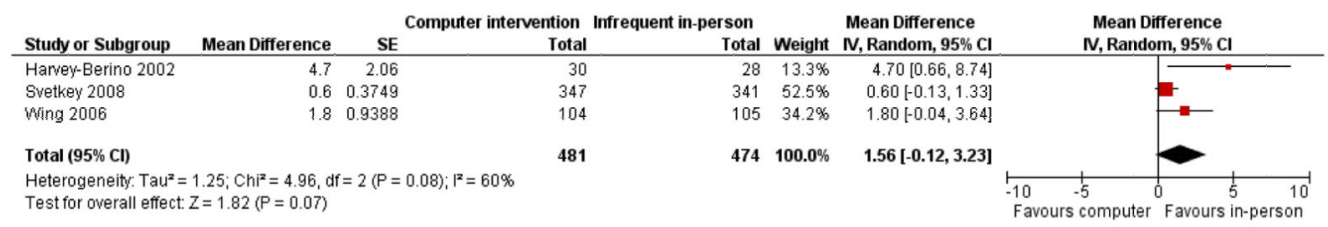

Figure 6.

Forest plot of comparison: 6 Weight maintenance: computer vs infrequent in-person support, outcome: 6.2 Weight at 12 mo $[\mathrm{kg}]$. 


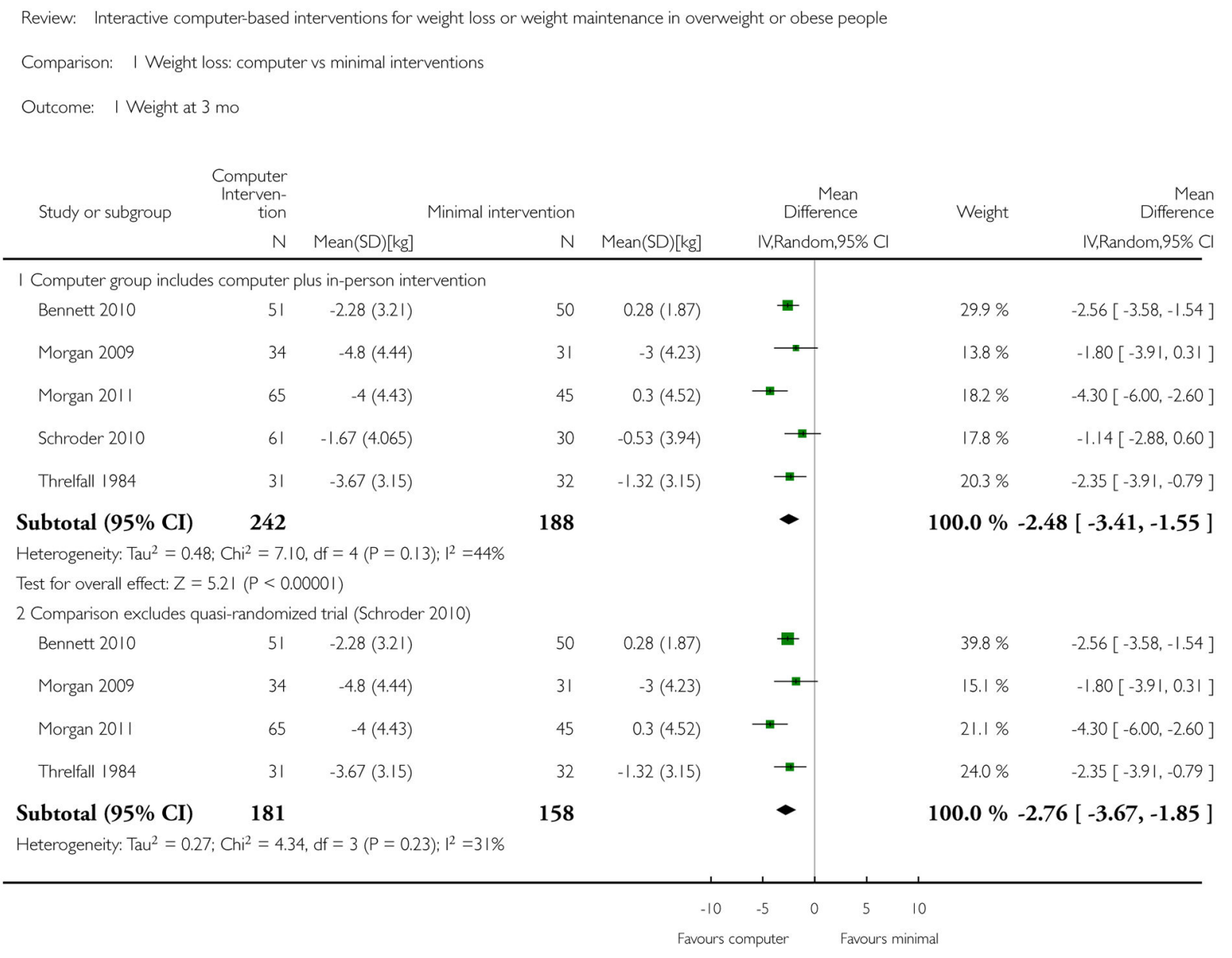




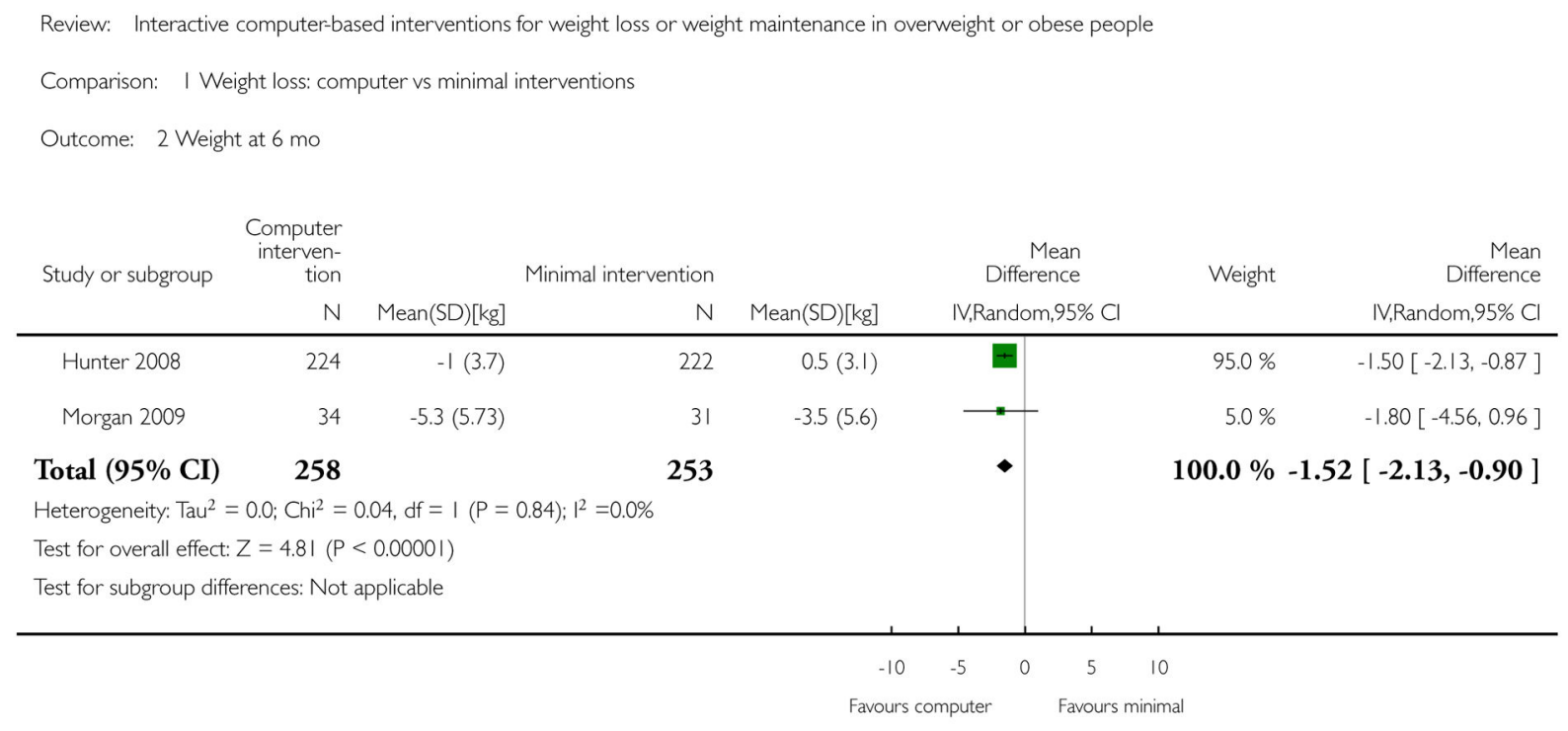

\section{Analysis 1.2.}

Comparison 1 Weight loss: computer vs minimal interventions, Outcome 2 Weight at 6 mo. 


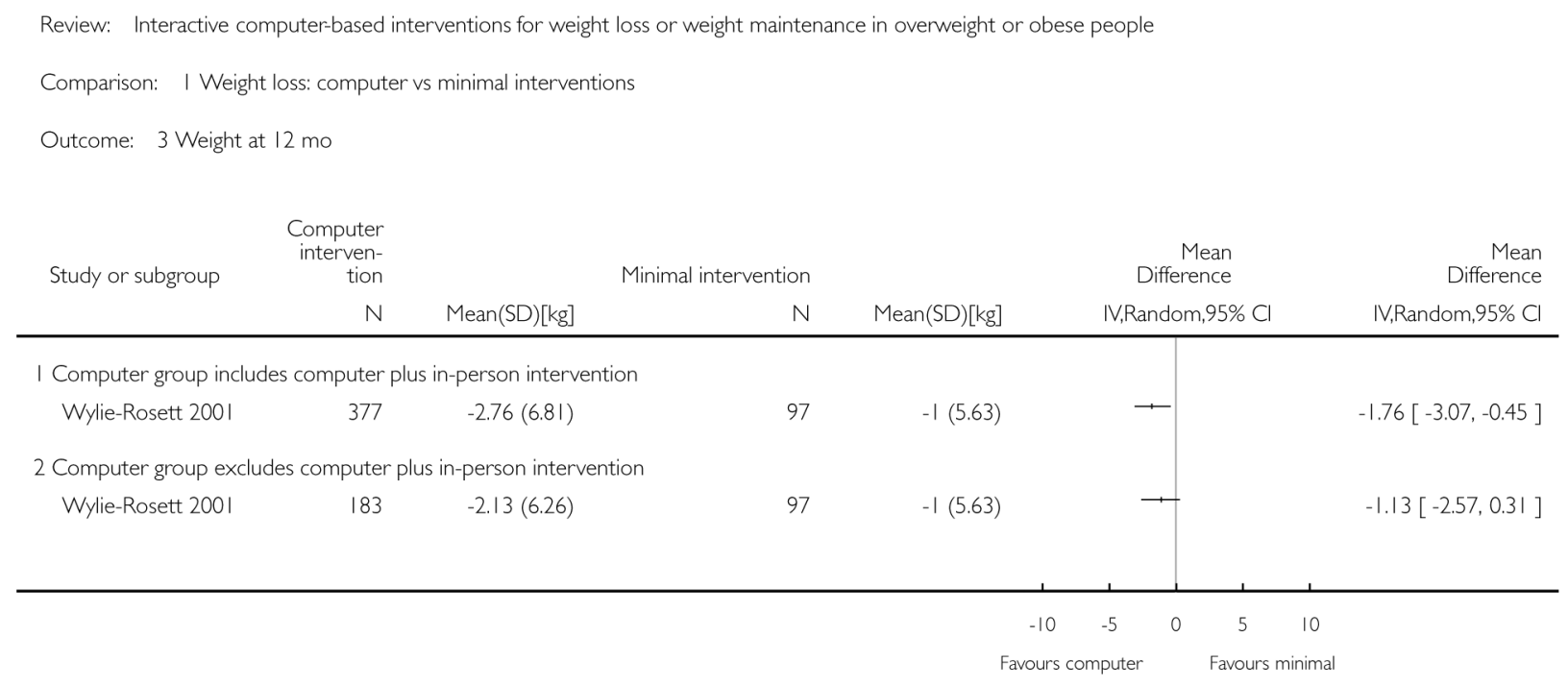

Analysis 1.3.

Comparison 1 Weight loss: computer vs minimal interventions, Outcome 3 Weight at 12 mo. 


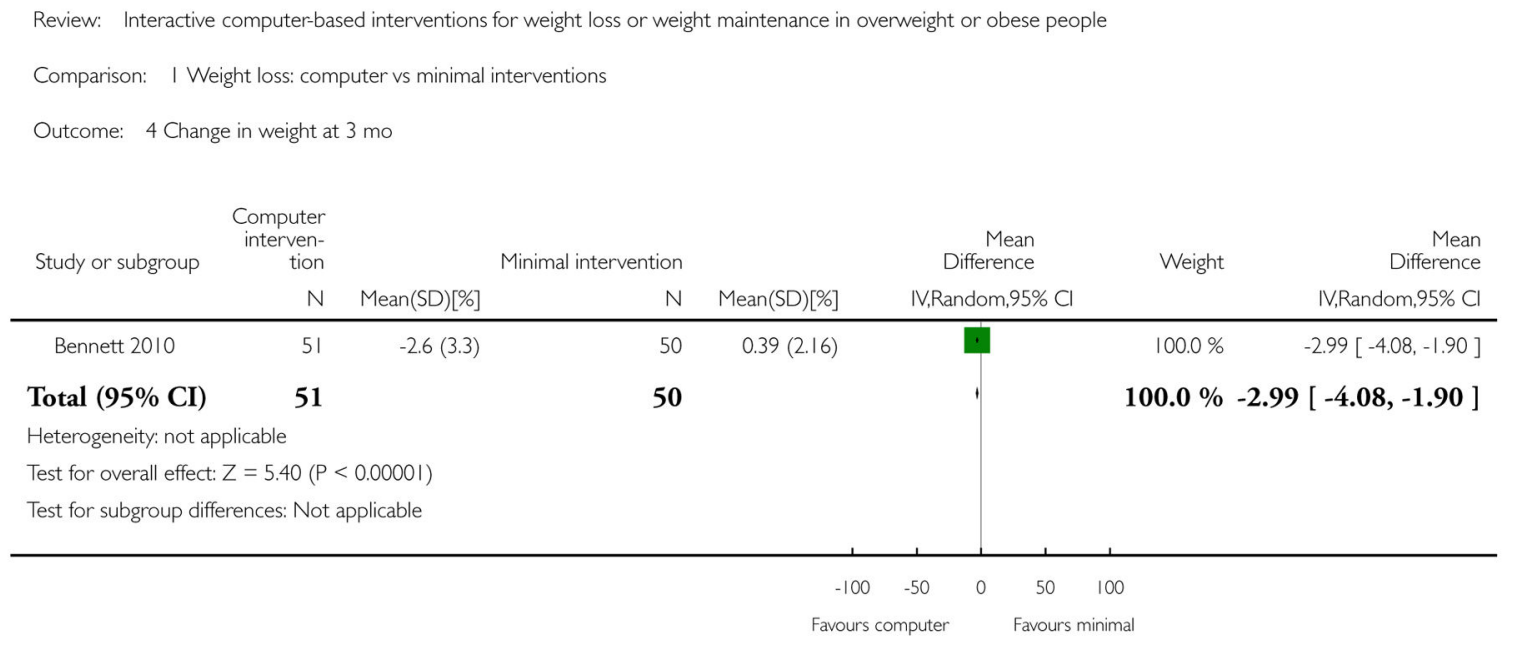

\section{Analysis 1.4.}

Comparison 1 Weight loss: computer vs minimal interventions, Outcome 4 Change in weight at 3 mo. 


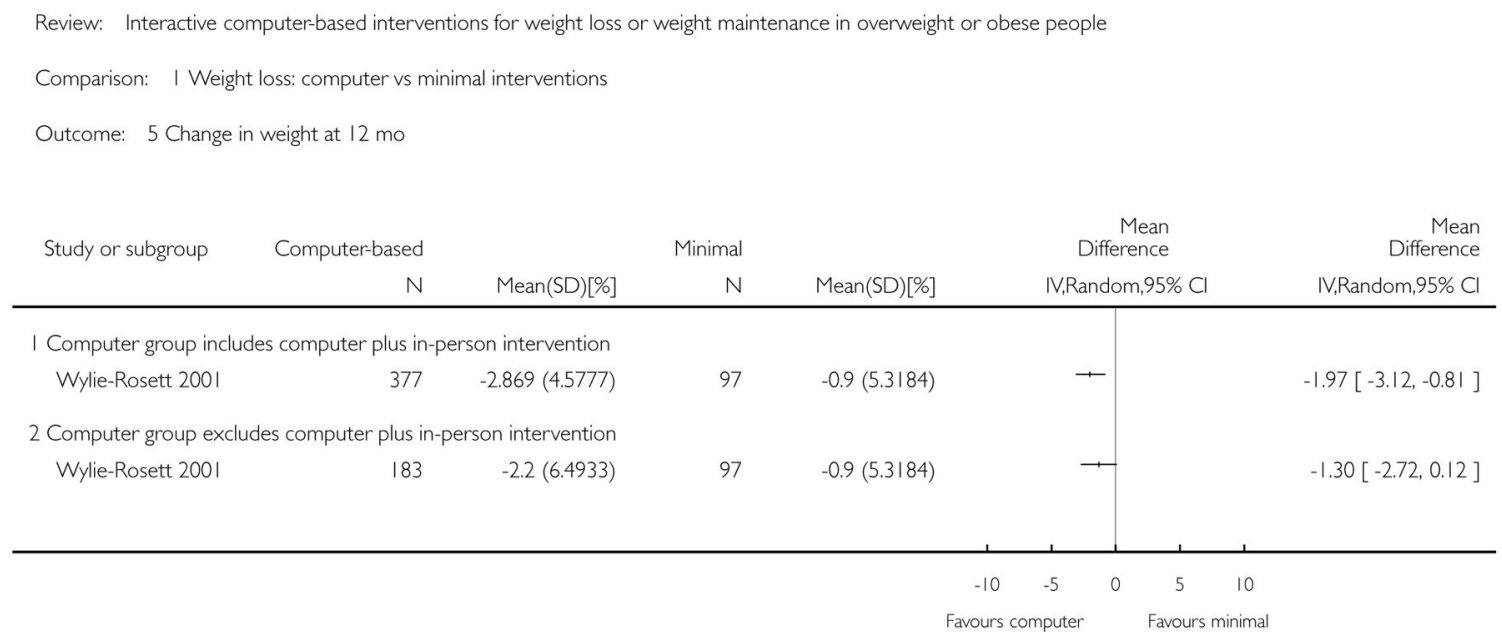

Analysis 1.5.

Comparison 1 Weight loss: computer vs minimal interventions, Outcome 5 Change in weight at $12 \mathrm{mo}$. 


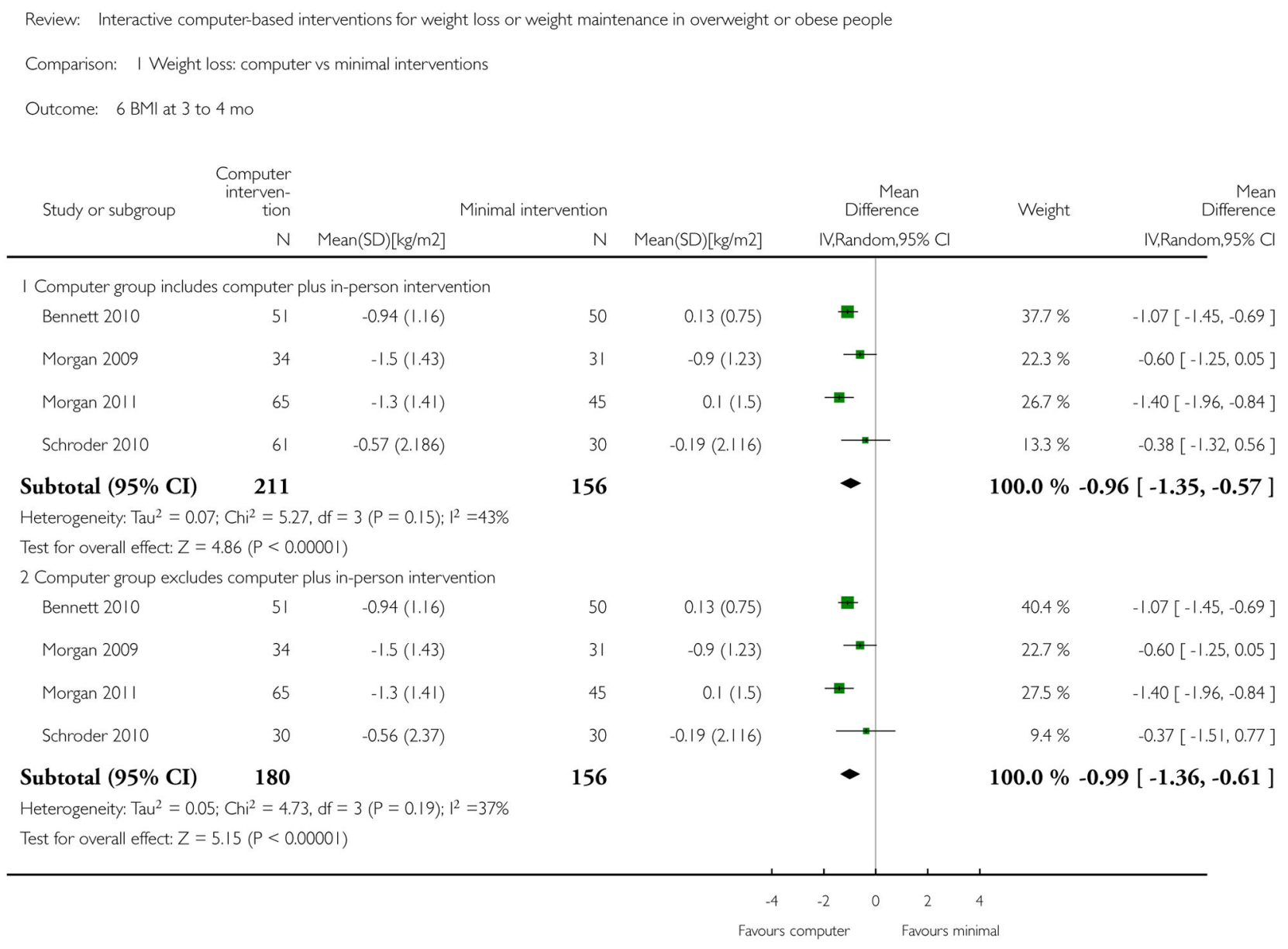

Analysis 1.6.

Comparison 1 Weight loss: computer vs minimal interventions, Outcome 6 BMI at 3 to 4 mo. 
Review: Interactive computer-based interventions for weight loss or weight maintenance in overweight or obese people

Comparison: I Weight loss: computer vs minimal interventions

Outcome: $7 \mathrm{BMl}$ at 6 to $7 \mathrm{mo}$

\begin{tabular}{|c|c|c|c|c|c|c|c|}
\hline \multirow[t]{2}{*}{ Study or subgroup } & $\begin{array}{r}\text { Computer } \\
\text { interven- } \\
\text { tion }\end{array}$ & \multicolumn{3}{|c|}{ Mlnimal intervention } & \multirow{2}{*}{$\begin{array}{c}\text { Mean } \\
\text { Difference } \\
\text { IV,Random,95\% Cl }\end{array}$} & \multirow[t]{2}{*}{ Weight } & \multirow{2}{*}{$\begin{array}{r}\text { Mean } \\
\text { Difference } \\
\text { |V,Random,95\% Cl }\end{array}$} \\
\hline & N & Mean $(S D)[\mathrm{kg} / \mathrm{m} 2]$ & N & $\operatorname{Mean}(\mathrm{SD})[\mathrm{kg} / \mathrm{m} 2]$ & & & \\
\hline Hunter 2008 & 193 & $-0.5(1.4)$ & 206 & $0.2(1.1)$ & $\square$ & $91.6 \%$ & $-0.70[-0.95,-0.45]$ \\
\hline Morgan 2009 & 34 & $-1.6(1.72)$ & 31 & $-1.1(1.64)$ & $\longrightarrow$ & $8.4 \%$ & $-0.50[-1.32,0.32]$ \\
\hline Total $(95 \% \mathrm{CI})$ & 227 & & 237 & & $\bullet$ & $100.0 \%$ & $8[-0.92,-0.45]$ \\
\hline \multicolumn{8}{|c|}{ Heterogeneity: Tau $^{2}=0.0 ; \mathrm{Chi}^{2}=0.21, \mathrm{df}=\mathrm{I}(\mathrm{P}=0.65) ; \mathrm{I}^{2}=0.0 \%$} \\
\hline \multicolumn{8}{|c|}{ Test for overall effect: $Z=5.64(P<0.00001)$} \\
\hline \multicolumn{8}{|c|}{ Test for subgroup differences: Not applicable } \\
\hline
\end{tabular}

Analysis 1.7.

Comparison 1 Weight loss: computer vs minimal interventions, Outcome 7 BMI at 6 to 7 mo. 


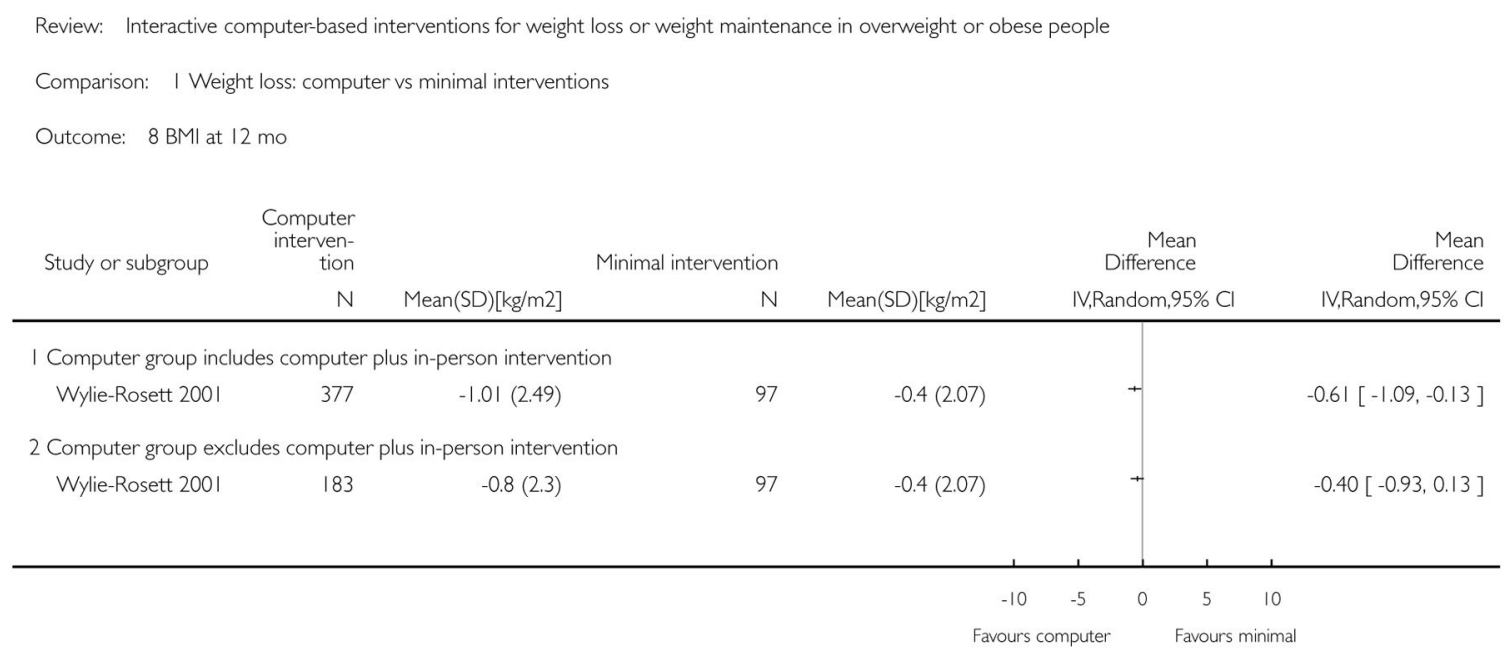

Analysis 1.8.

Comparison 1 Weight loss: computer vs minimal interventions, Outcome 8 BMI at 12 mo. 


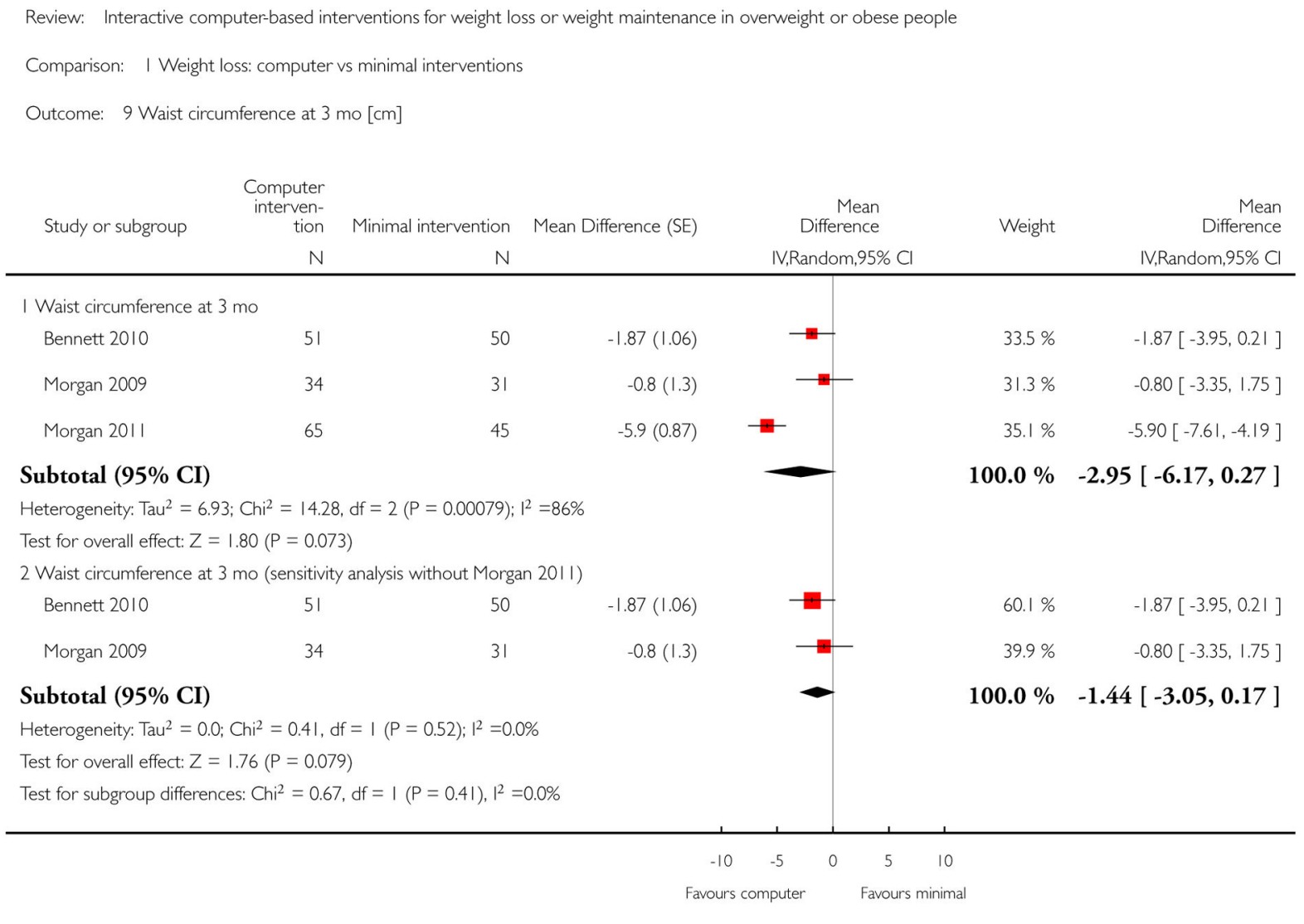

Analysis 1.9.

Comparison 1 Weight loss: computer vs minimal interventions, Outcome 9 Waist circumference at 3 mo [cm]. 


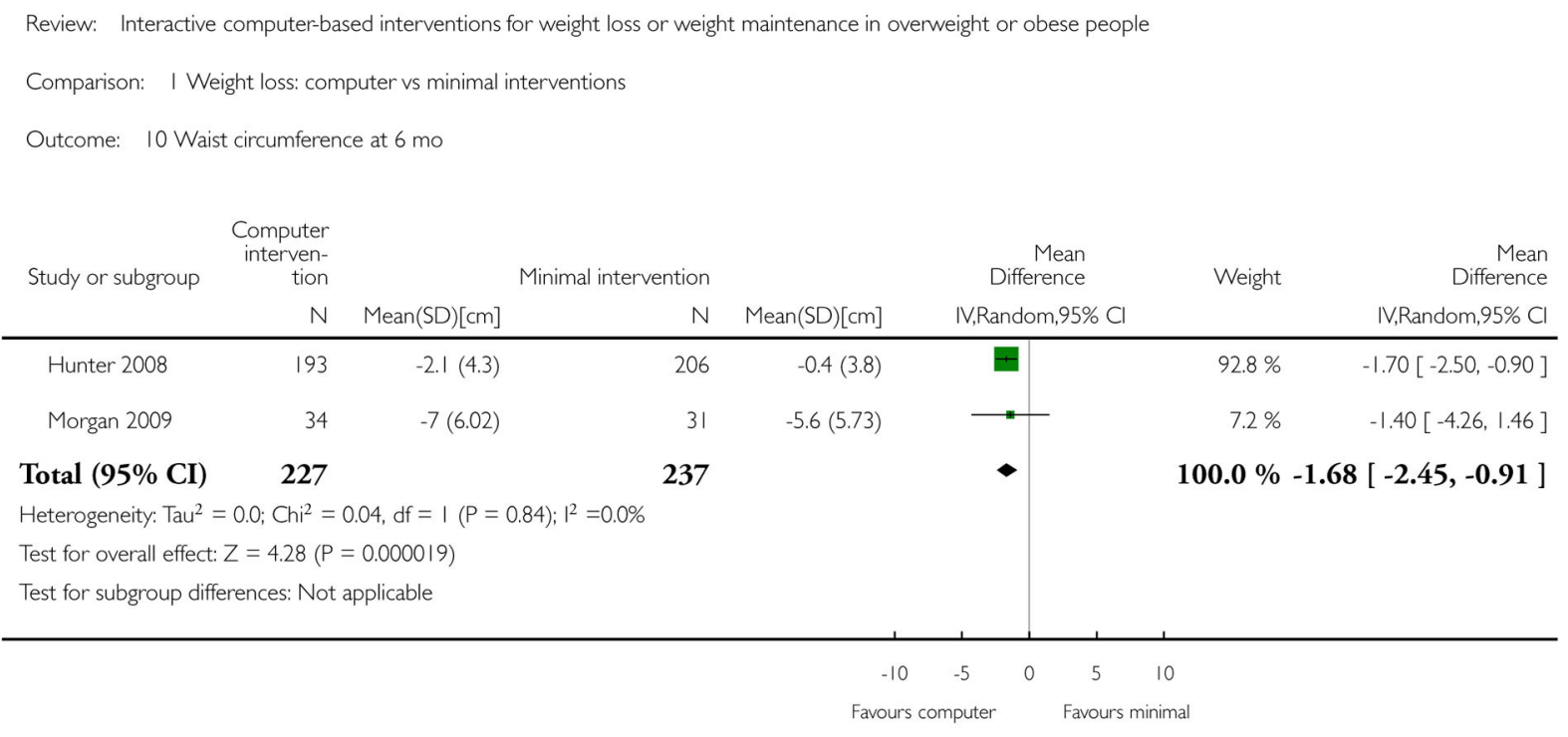

Analysis 1.10.

Comparison 1 Weight loss: computer vs minimal interventions, Outcome 10 Waist circumference at 6 mo. 


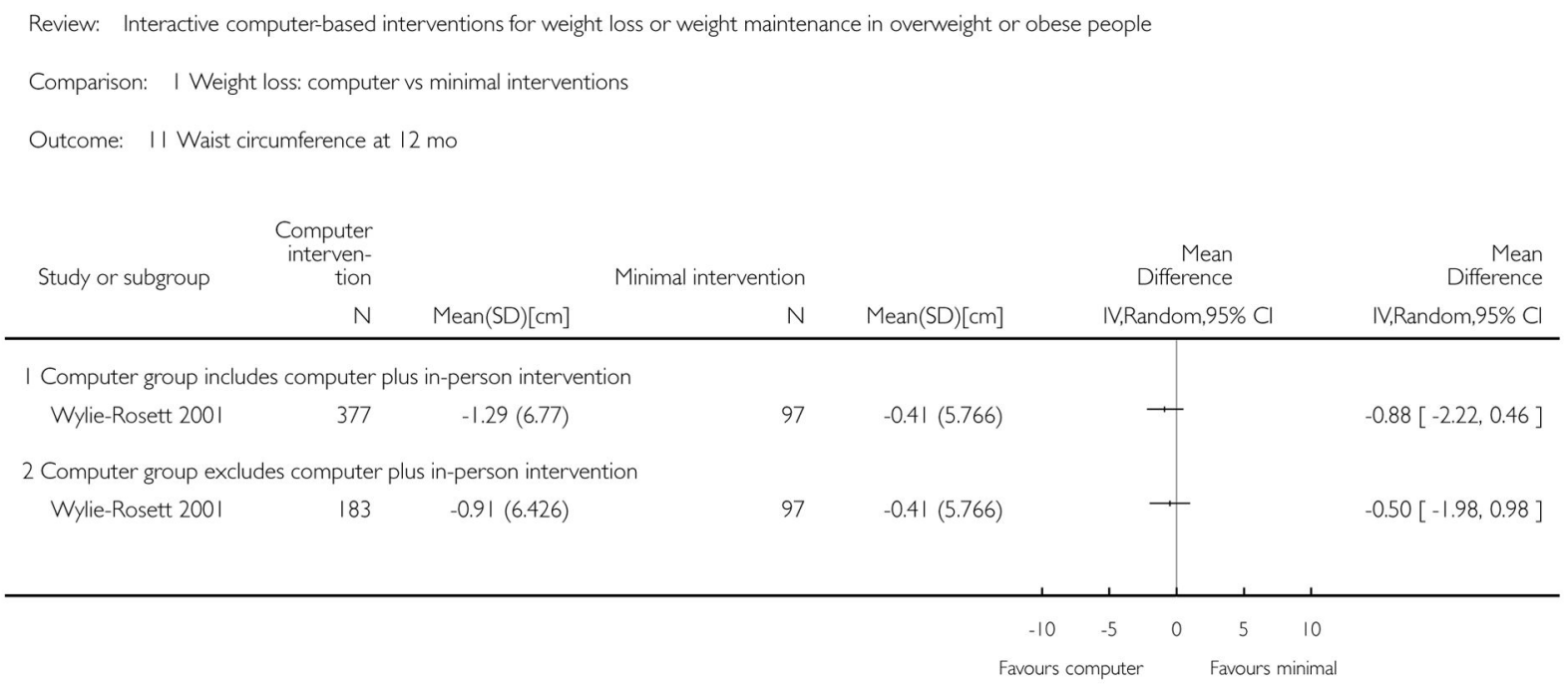

Analysis 1.11.

Comparison 1 Weight loss: computer vs minimal interventions, Outcome 11 Waist circumference at 12 mo. 


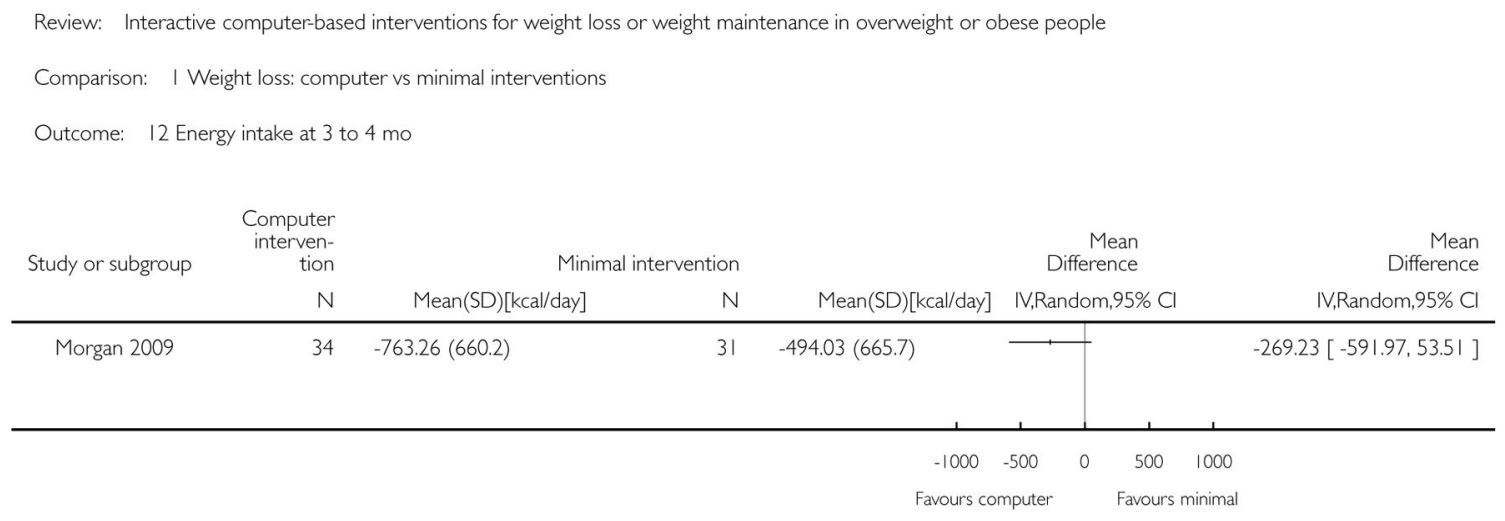

Analysis 1.12.

Comparison 1 Weight loss: computer vs minimal interventions, Outcome 12 Energy intake at 3 to 4 mo. 


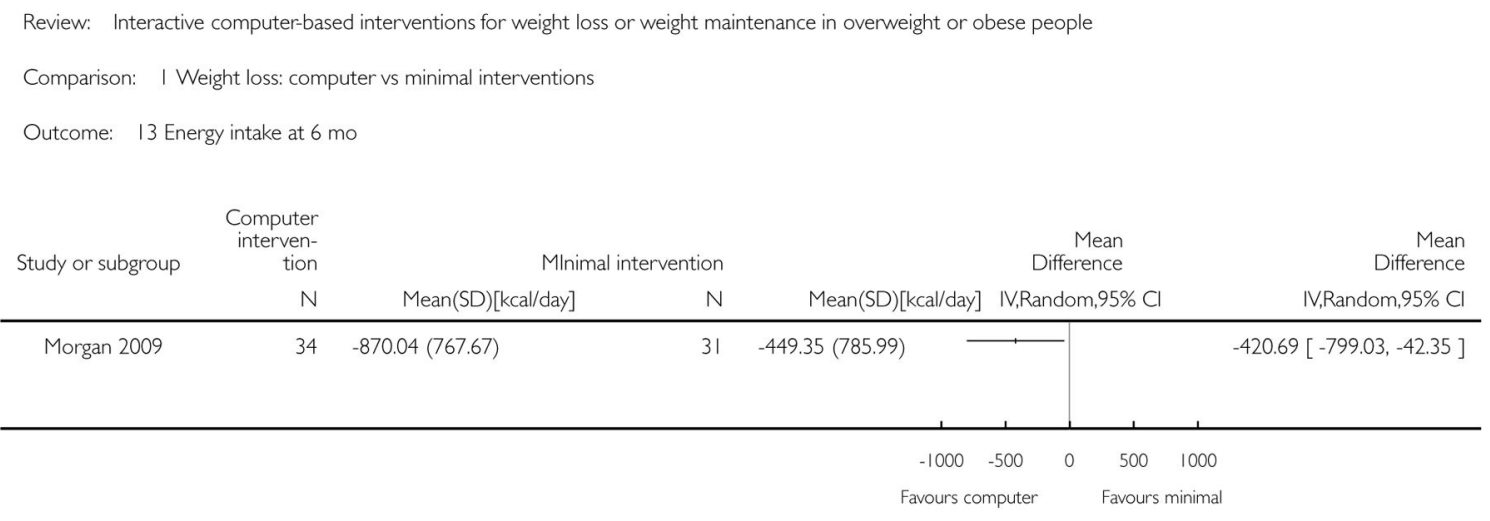

Analysis 1.13.

Comparison 1 Weight loss: computer vs minimal interventions, Outcome 13 Energy intake at 6 mo. 


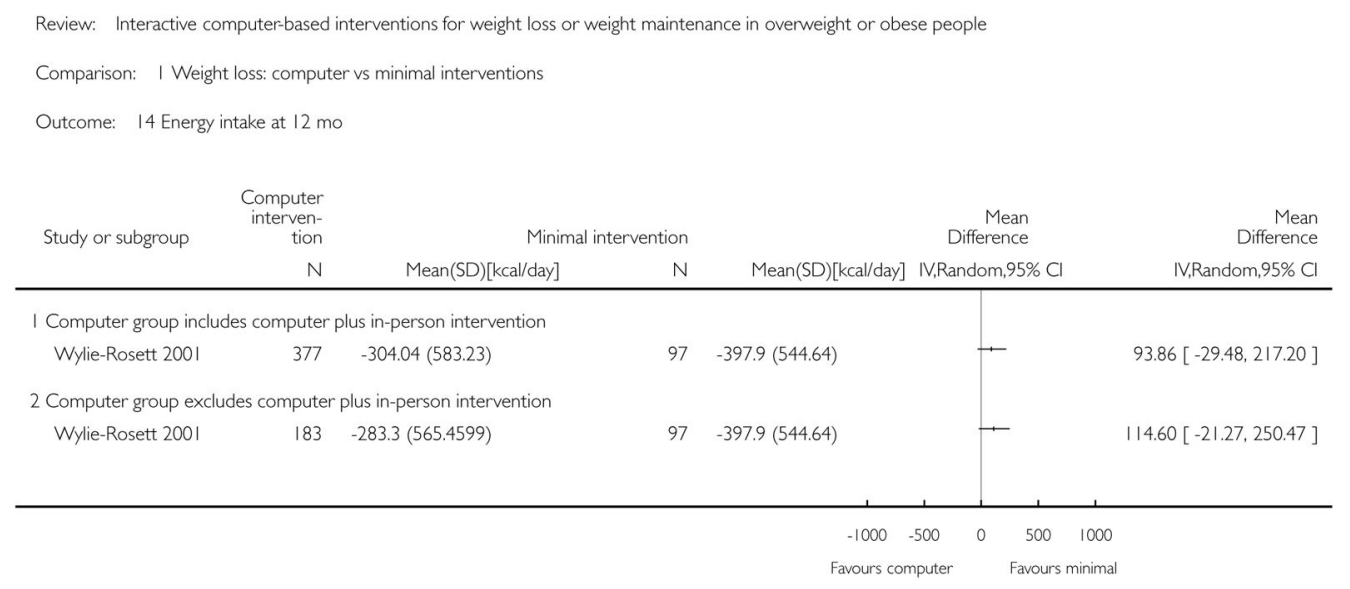

Analysis 1.14.

Comparison 1 Weight loss: computer vs minimal interventions, Outcome 14 Energy intake at 12 mo. 


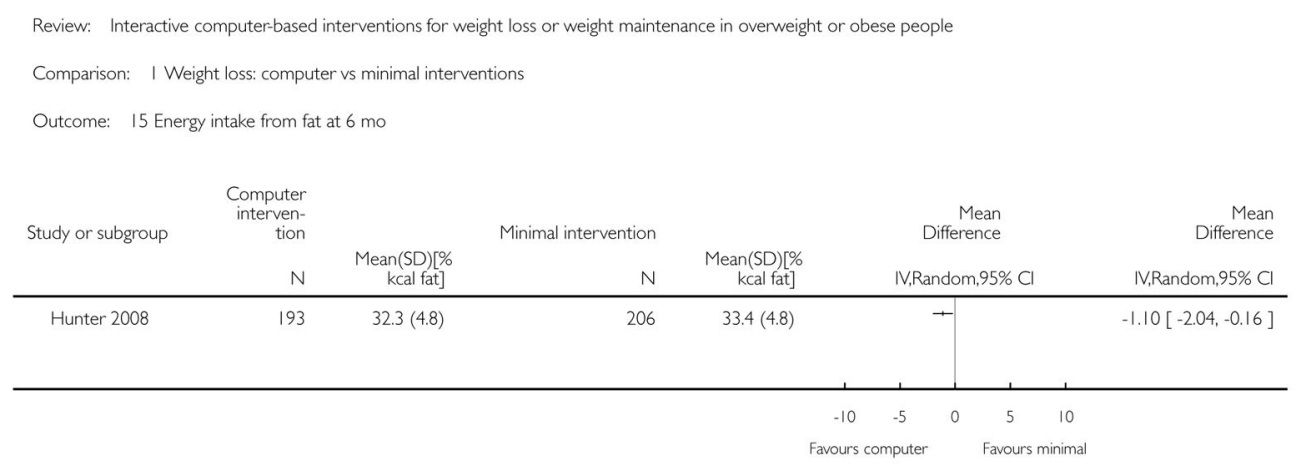

Analysis 1.15.

Comparison 1 Weight loss: computer vs minimal interventions, Outcome 15 Energy intake from fat at 6 mo. 


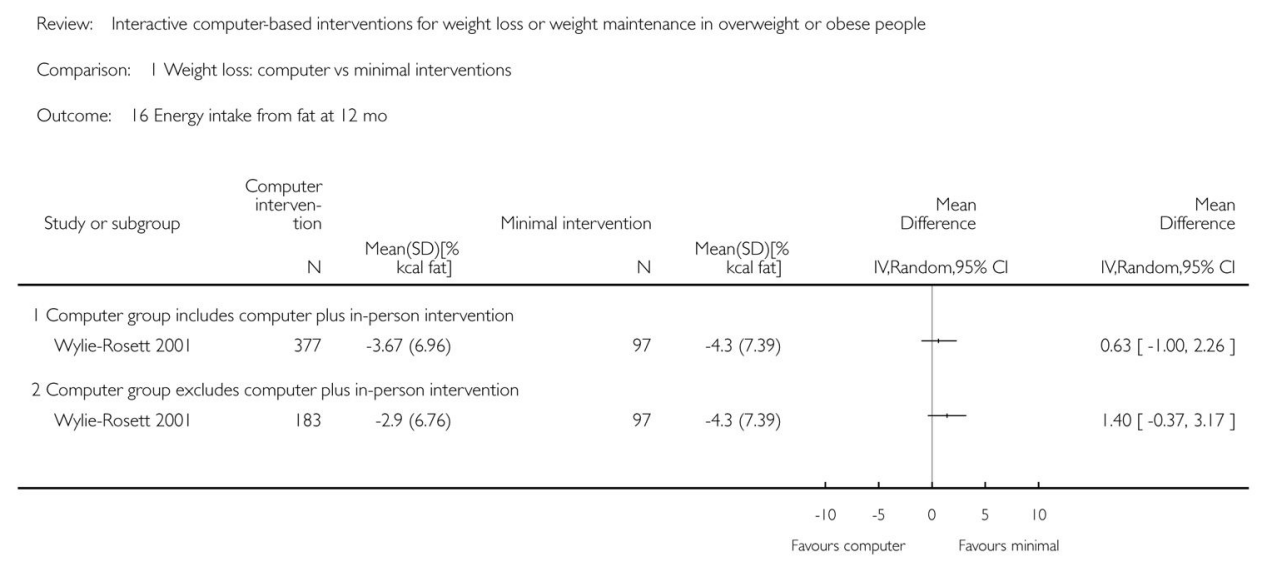

Analysis 1.16.

Comparison 1 Weight loss: computer vs minimal interventions, Outcome 16 Energy intake from fat at 12 mo. 


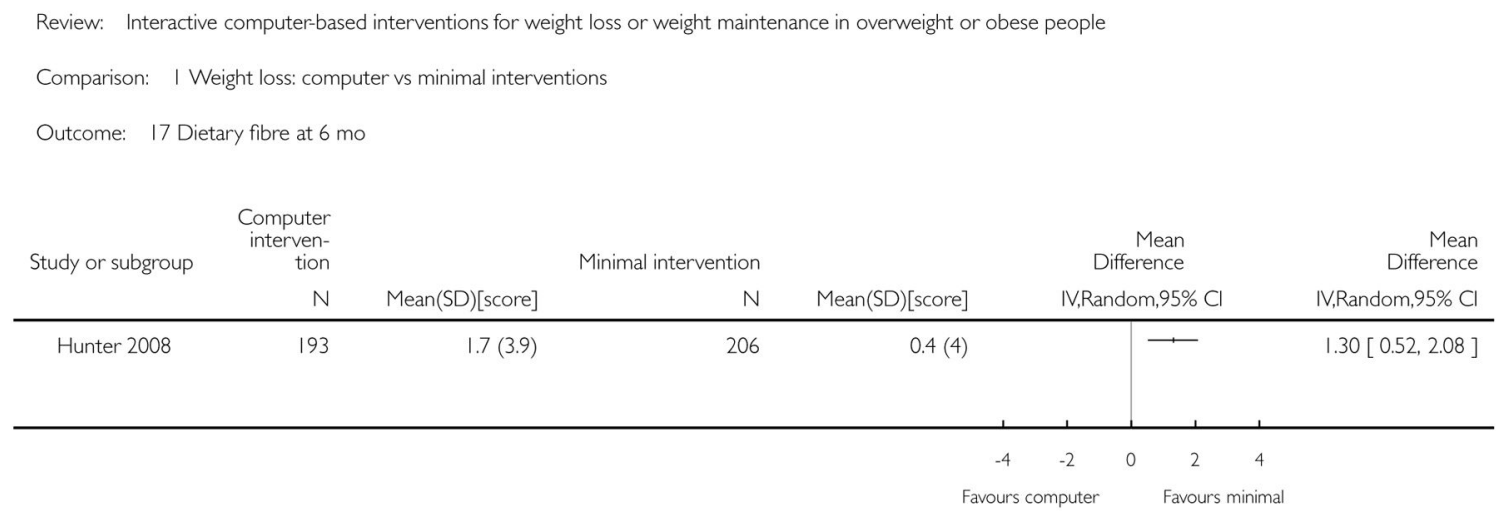

Analysis 1.17.

Comparison 1 Weight loss: computer vs minimal interventions, Outcome 17 Dietary fibre at 6 mo. 


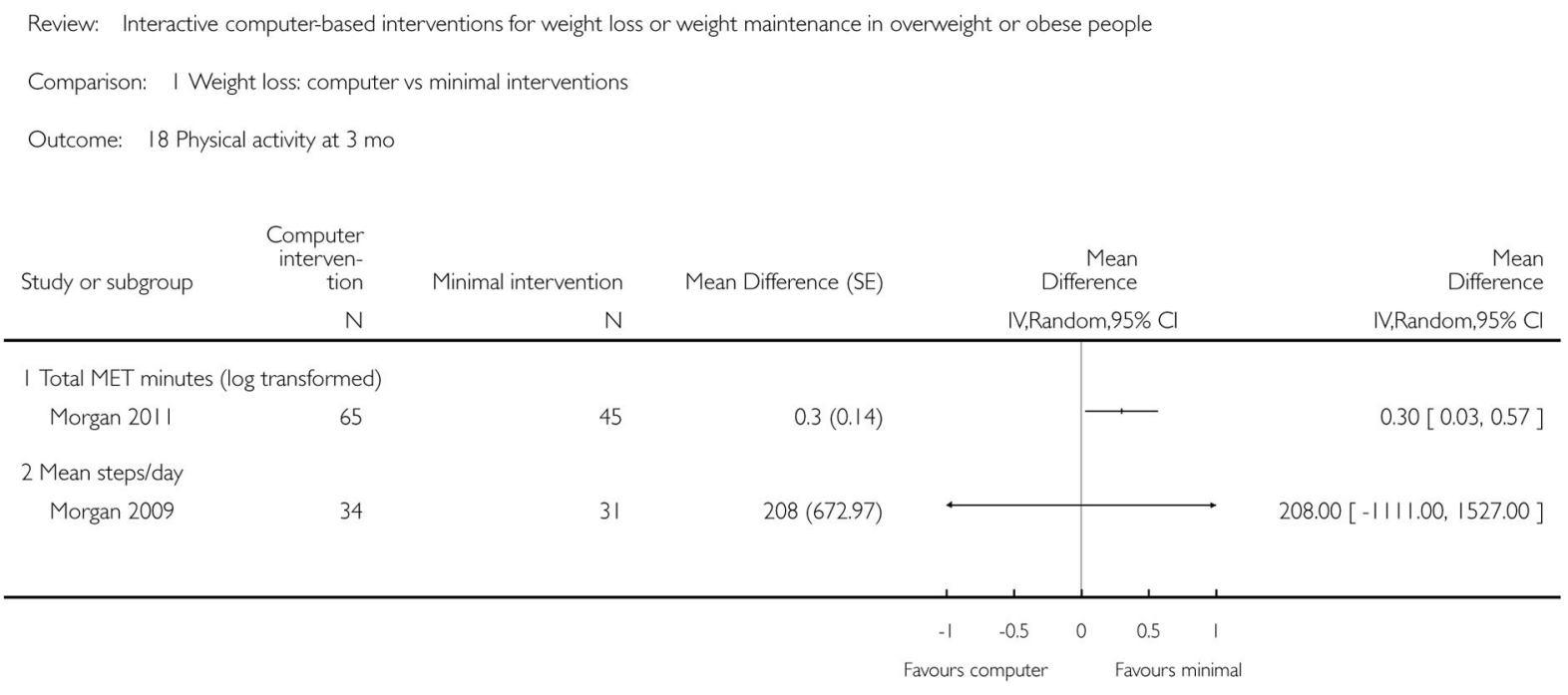

Analysis 1.18.

Comparison 1 Weight loss: computer vs minimal interventions, Outcome 18 Physical activity at 3 mo. 


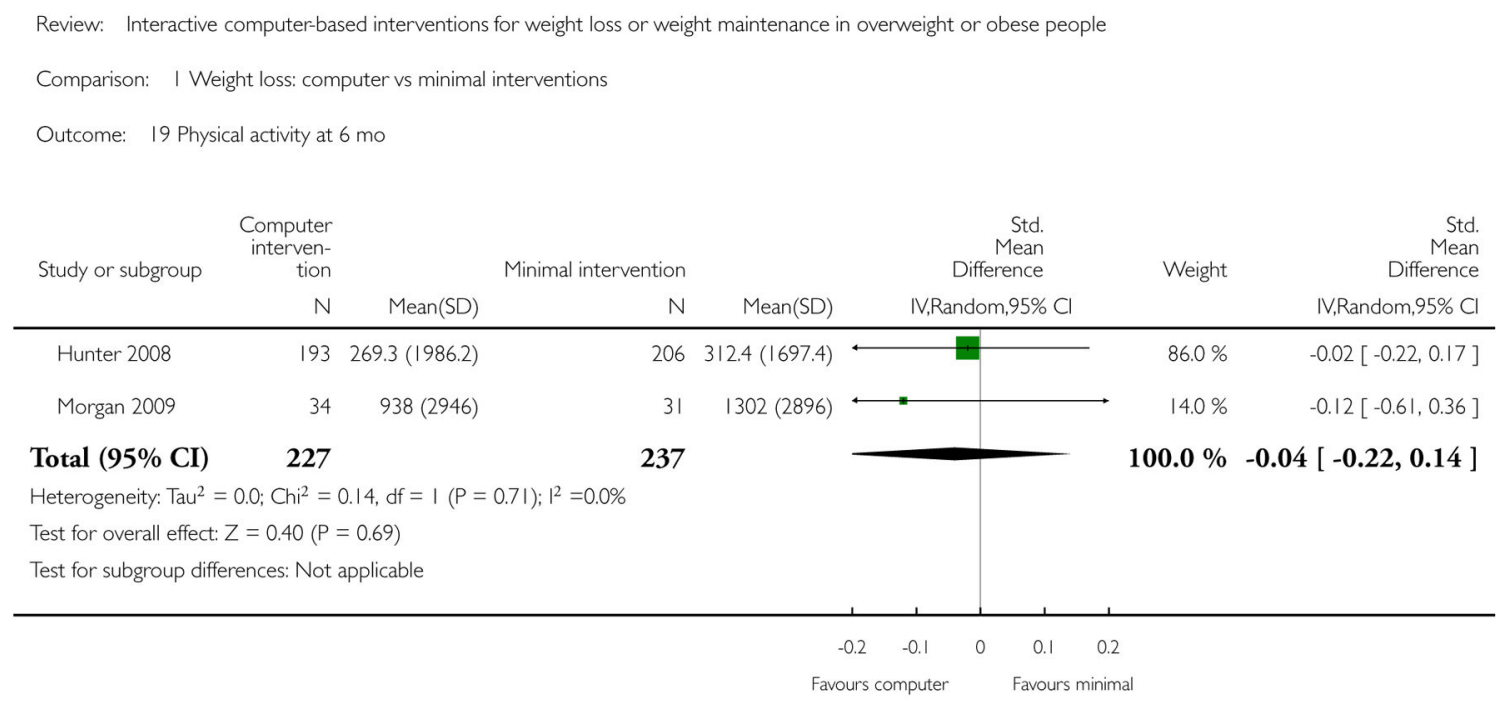

Analysis 1.19.

Comparison 1 Weight loss: computer vs minimal interventions, Outcome 19 Physical activity at 6 mo. 


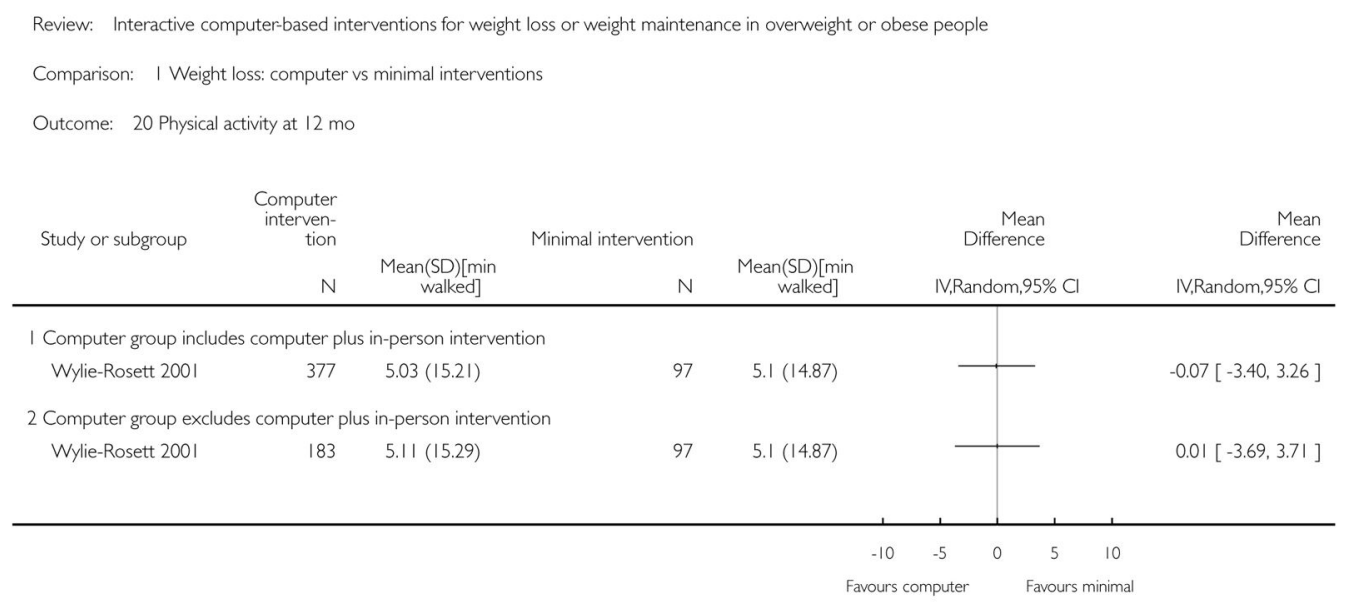

Analysis 1.20.

Comparison 1 Weight loss: computer vs minimal interventions, Outcome 20 Physical activity at 12 mo. 


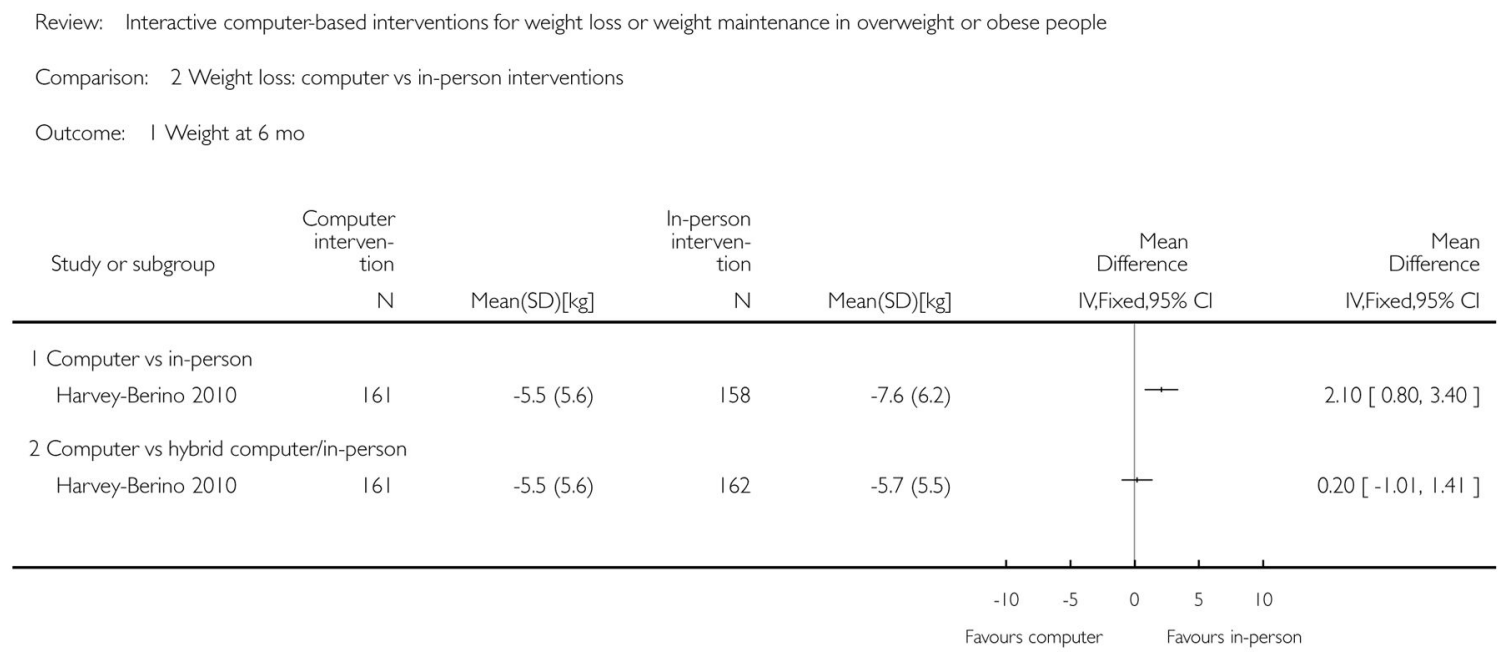

Analysis 2.1.

Comparison 2 Weight loss: computer vs in-person interventions, Outcome 1 Weight at 6 mo. 


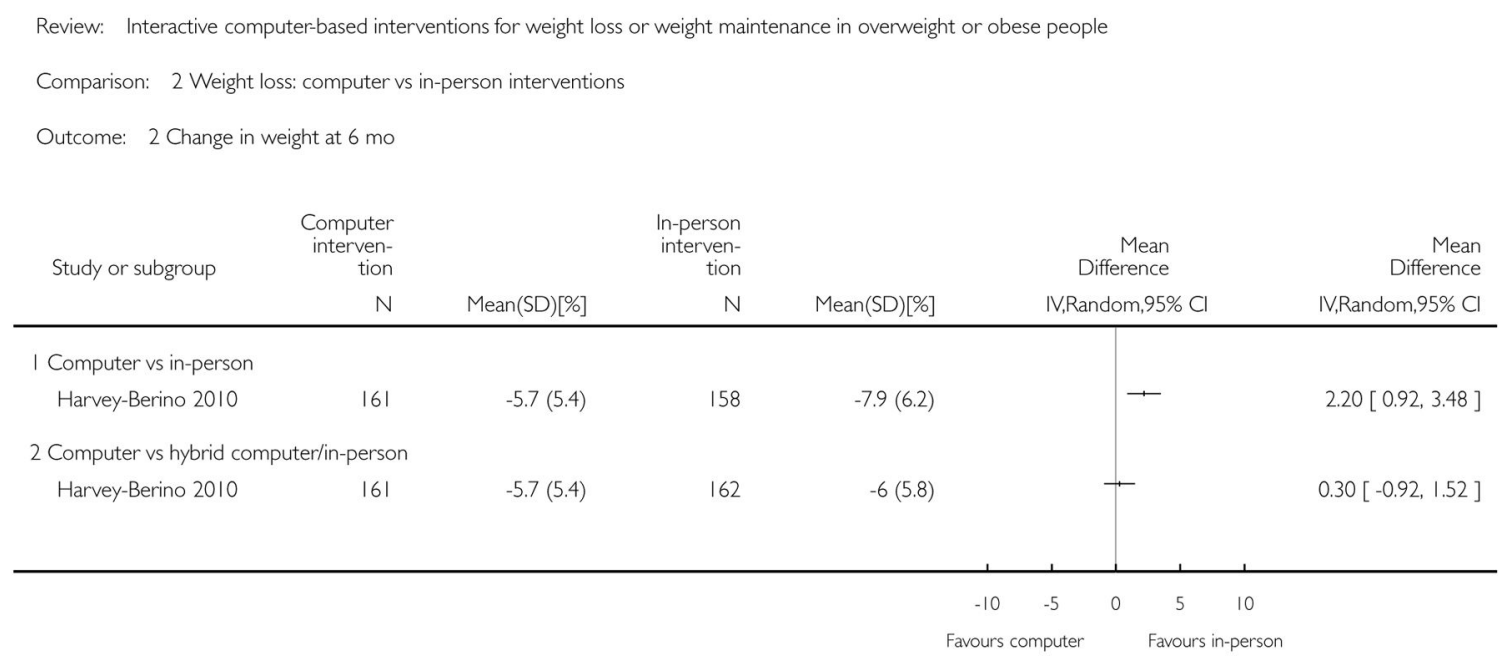

Analysis 2.2.

Comparison 2 Weight loss: computer vs in-person interventions, Outcome 2 Change in weight at 6 mo. 


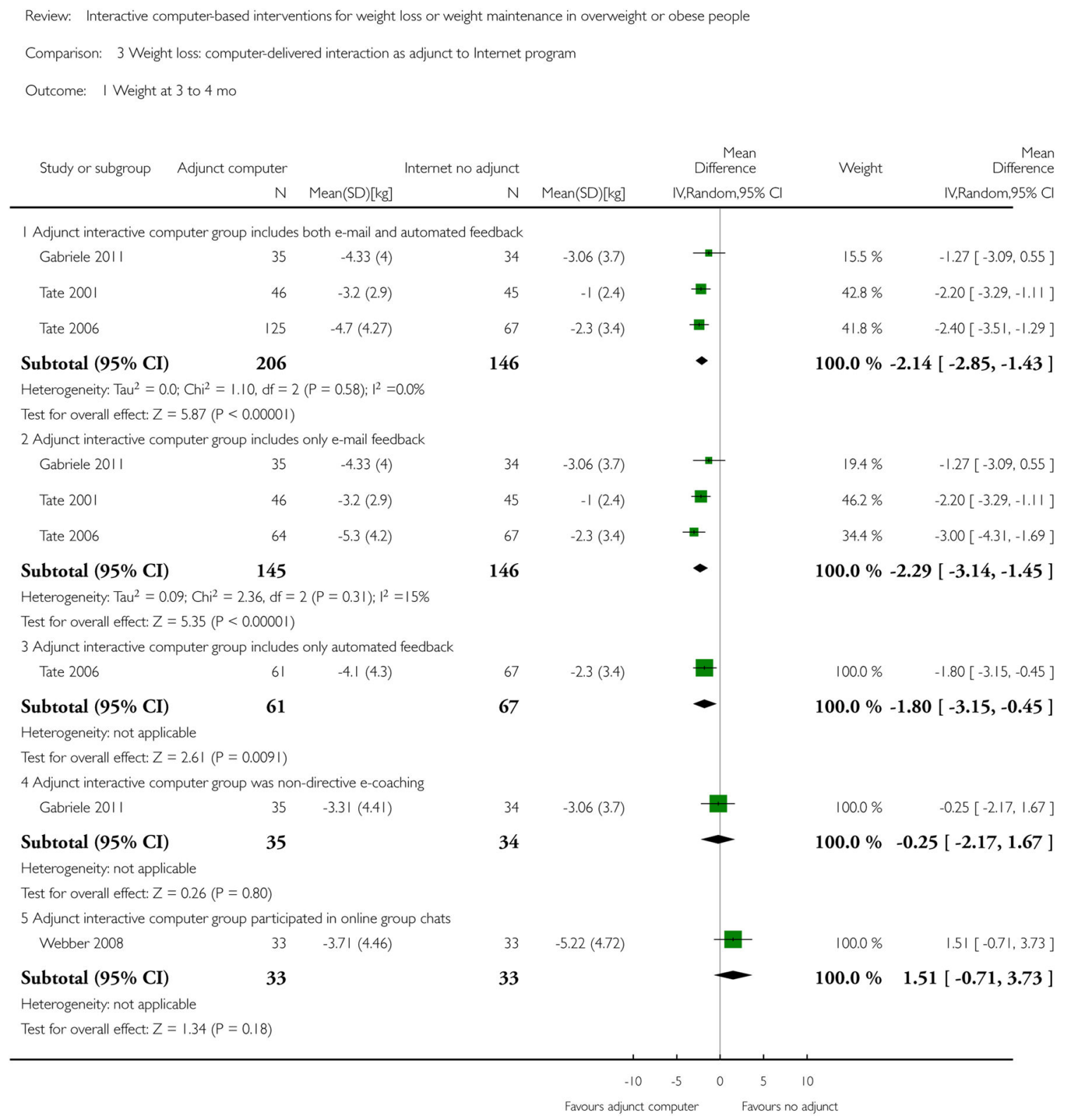

Analysis 3.1.

Comparison 3 Weight loss: computer-delivered interaction as adjunct to Internet program, Outcome 1 Weight at 3 to 4 mo. 


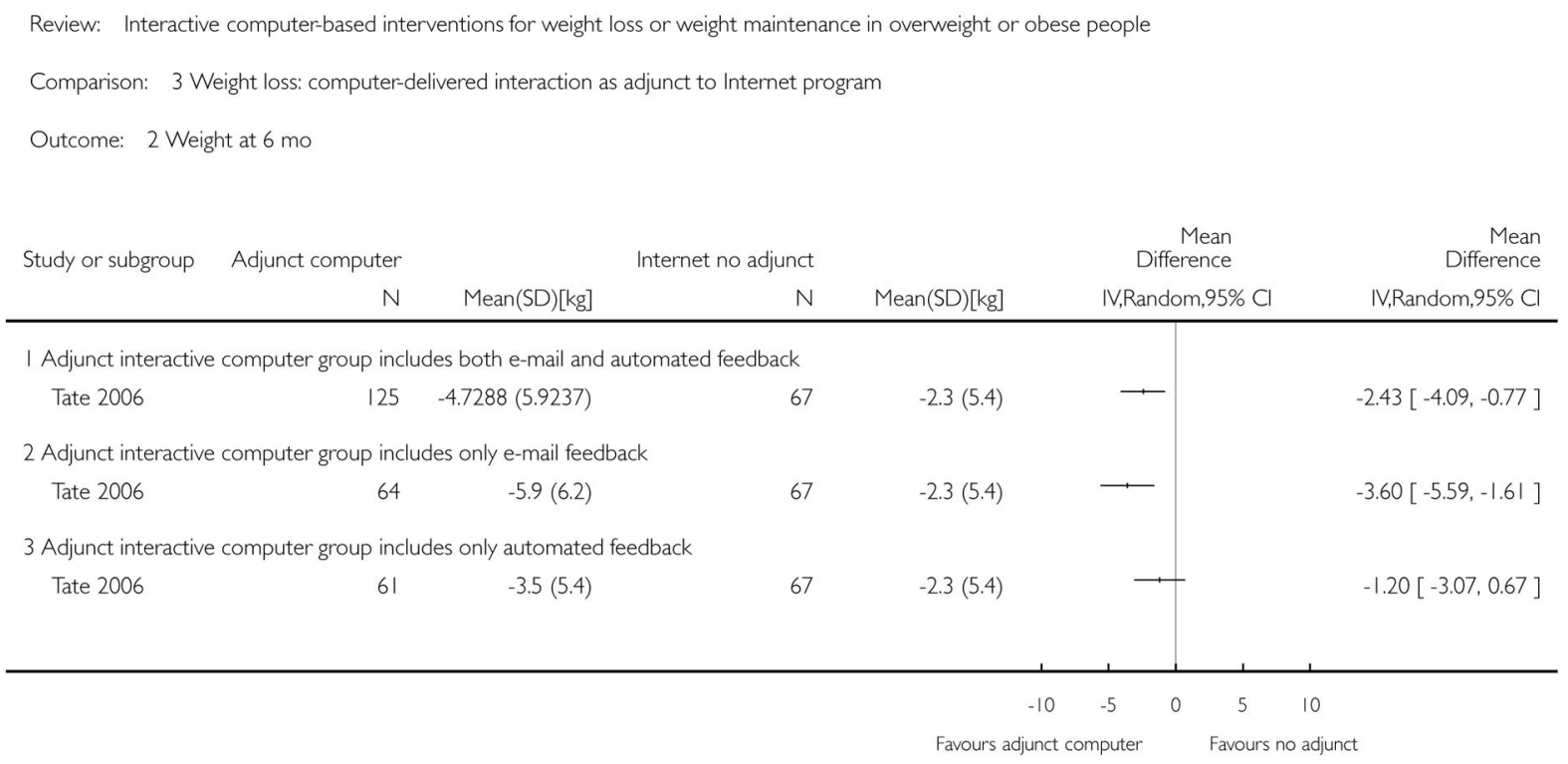

Analysis 3.2.

Comparison 3 Weight loss: computer-delivered interaction as adjunct to Internet program, Outcome 2 Weight at 6 mo. 


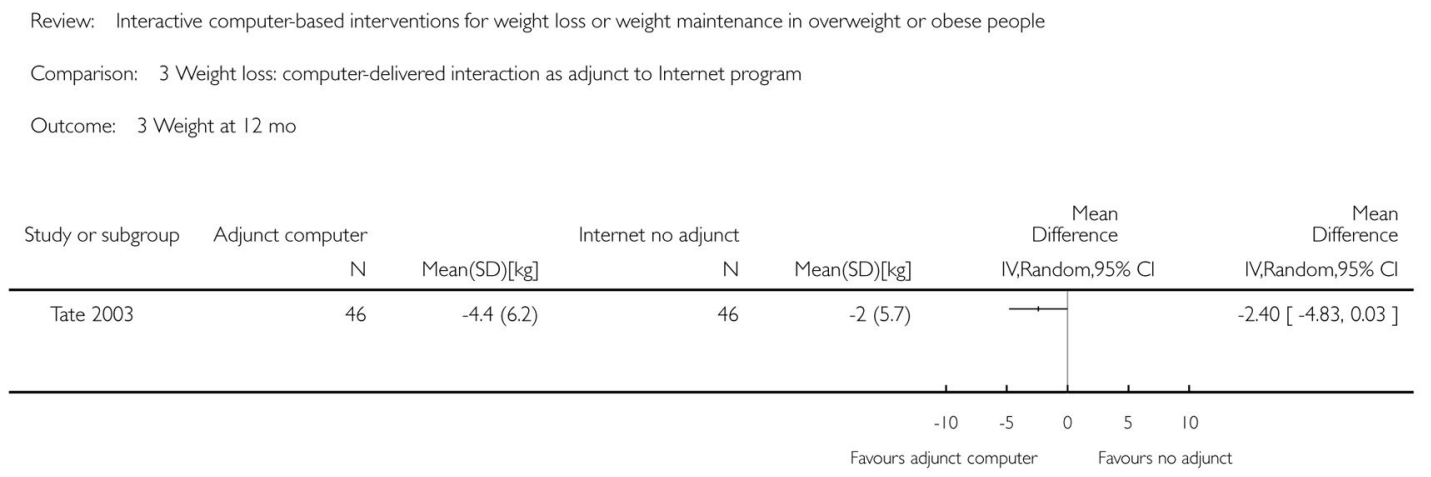

Analysis 3.3.

Comparison 3 Weight loss: computer-delivered interaction as adjunct to Internet program, Outcome 3 Weight at 12 mo. 


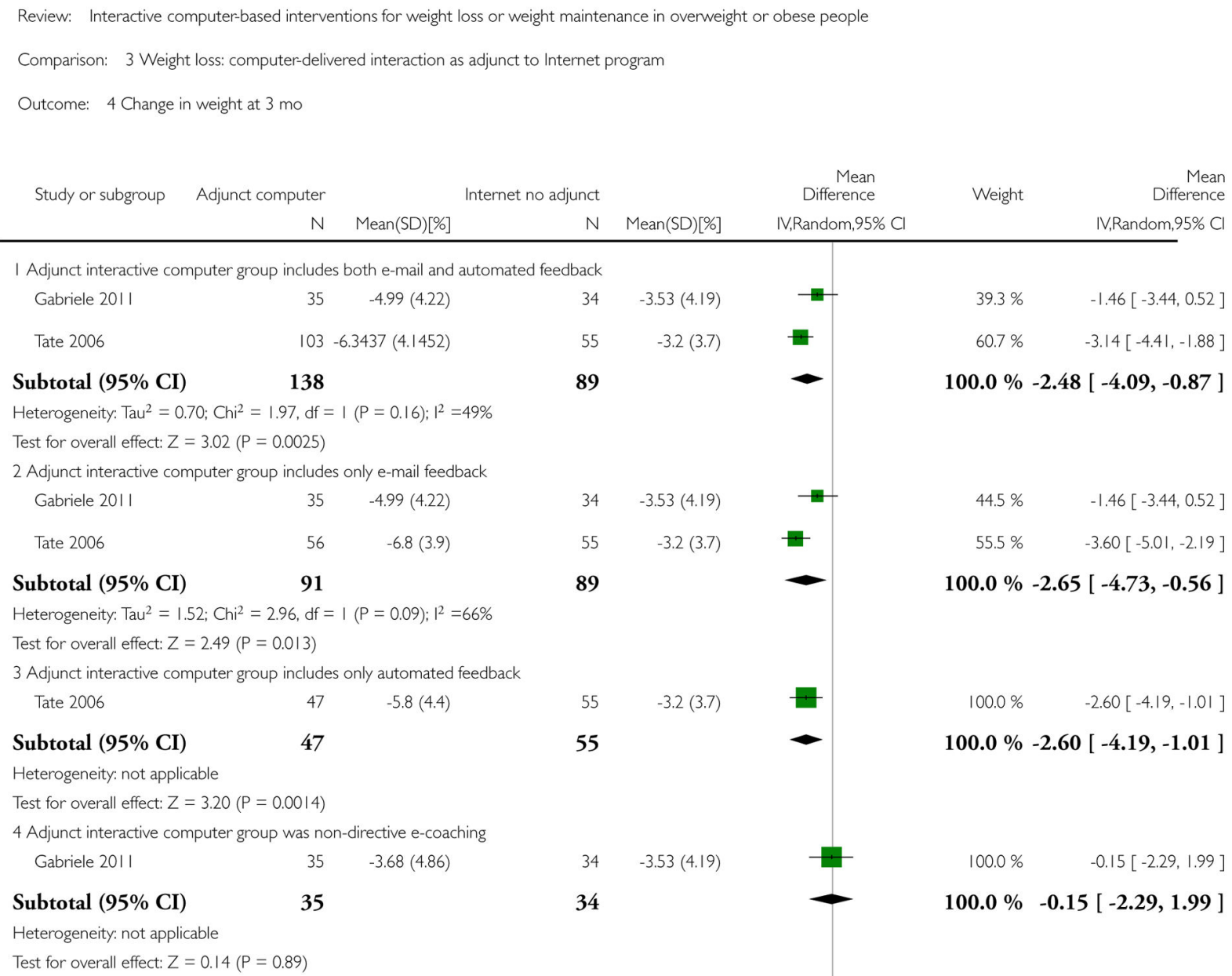

$-3.53(4.19)$

\section{Analysis 3.4.}

Comparison 3 Weight loss: computer-delivered interaction as adjunct to Internet program, Outcome 4 Change in weight at 3 mo. 


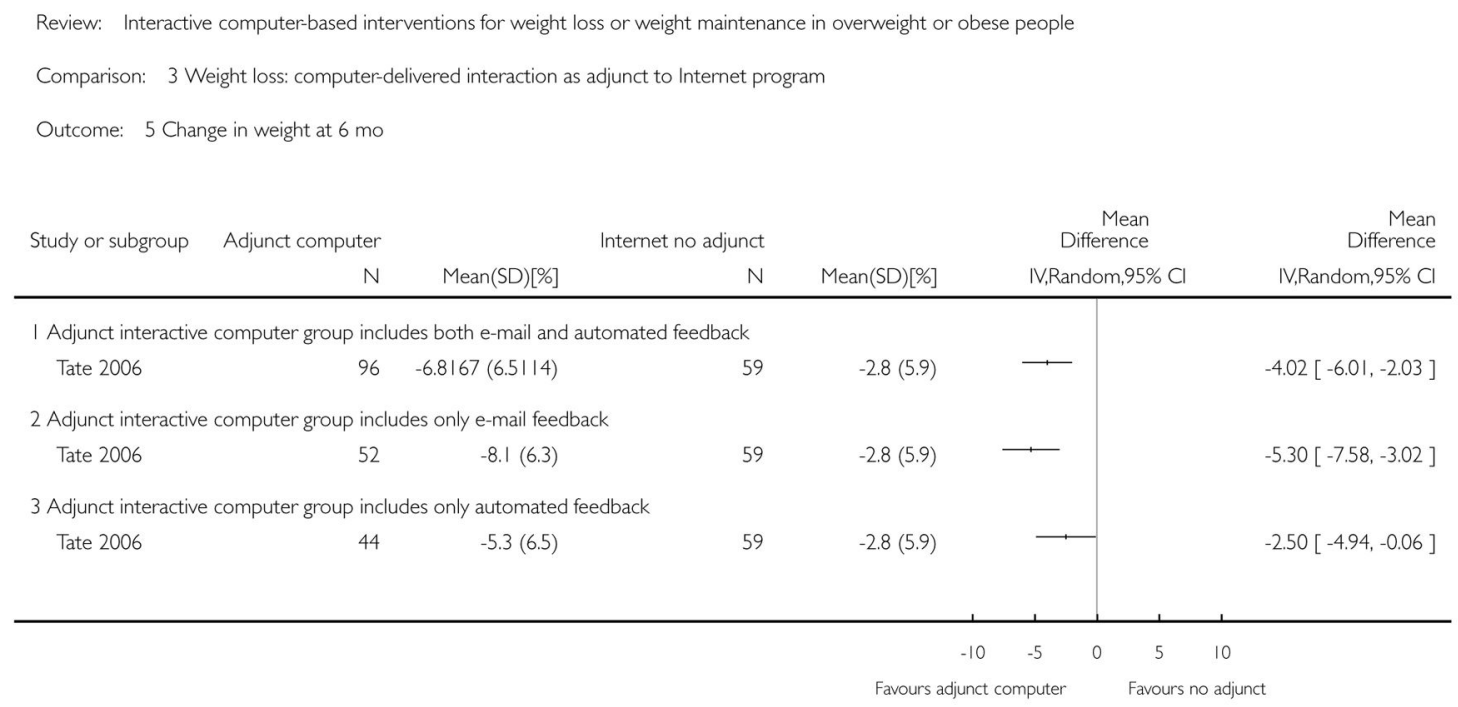

Analysis 3.5.

Comparison 3 Weight loss: computer-delivered interaction as adjunct to Internet program, Outcome 5 Change in weight at 6 mo. 


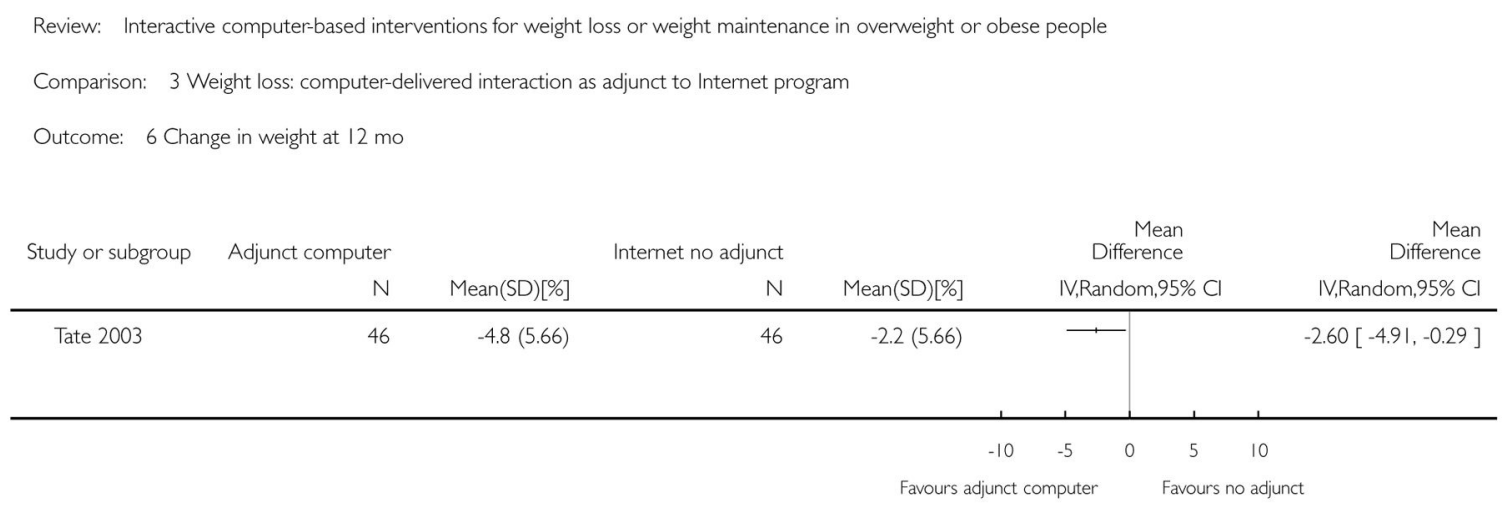

Analysis 3.6.

Comparison 3 Weight loss: computer-delivered interaction as adjunct to Internet program, Outcome 6 Change in weight at 12 mo. 


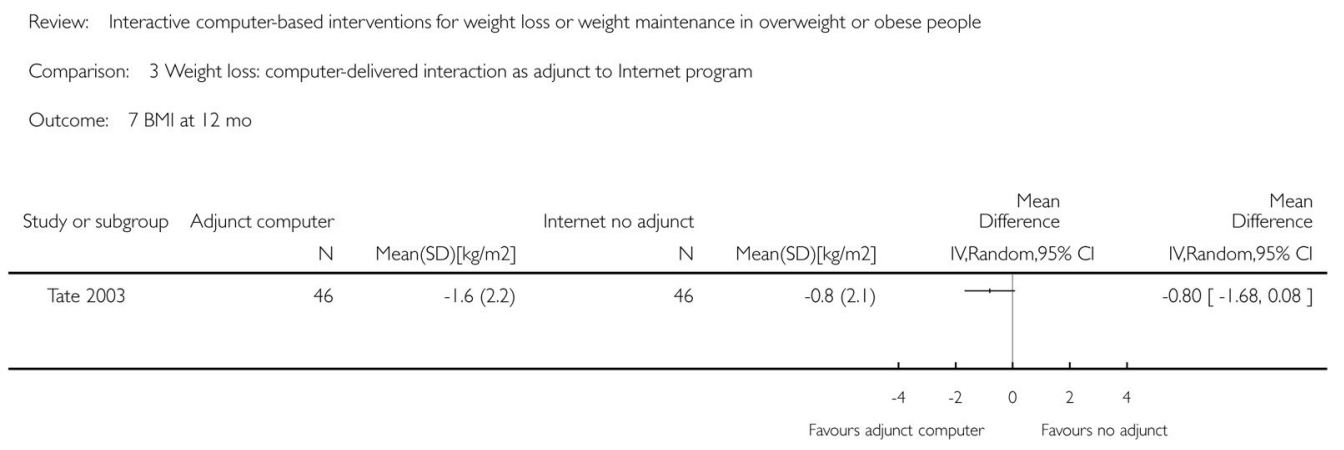

Analysis 3.7.

Comparison 3 Weight loss: computer-delivered interaction as adjunct to Internet program, Outcome 7 BMI at 12 mo. 


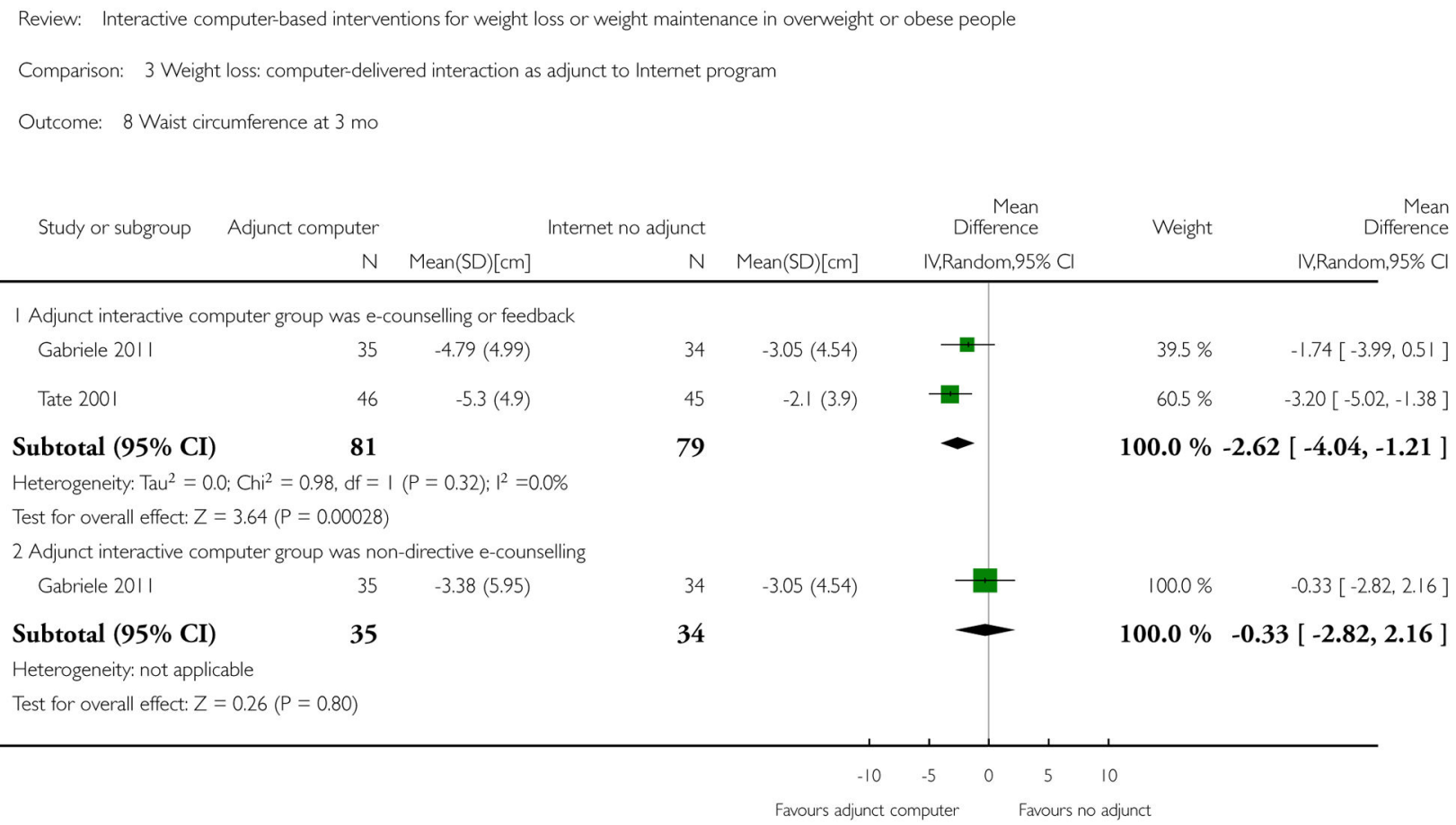

, Rendom,

I Adjunct interactive computer group was e-counselling or feedback Gabriele 2011

Tate 200I

$35-4.79(4.99)$

$46-5.3(4.9)$

$34 \quad-3.05(4.54)$

Subtotal $(95 \% \mathrm{CI})$

81

$45-2.1(3.9)$

79

Heterogeneity: $\mathrm{Tau}^{2}=0.0 ; \mathrm{Chi}^{2}=0.98, \mathrm{df}=\mathrm{I}(\mathrm{P}=0.32) ; \mathrm{I}^{2}=0.0 \%$ Test for overall effect: $Z=3.64(P=0.00028)$

2 Adjunct interactive computer group was non-directive e-counselling Gabriele 201। $35-3.38(5.95)$

\section{Analysis 3.8.}

Comparison 3 Weight loss: computer-delivered interaction as adjunct to Internet program, Outcome 8 Waist circumference at 3 mo. 


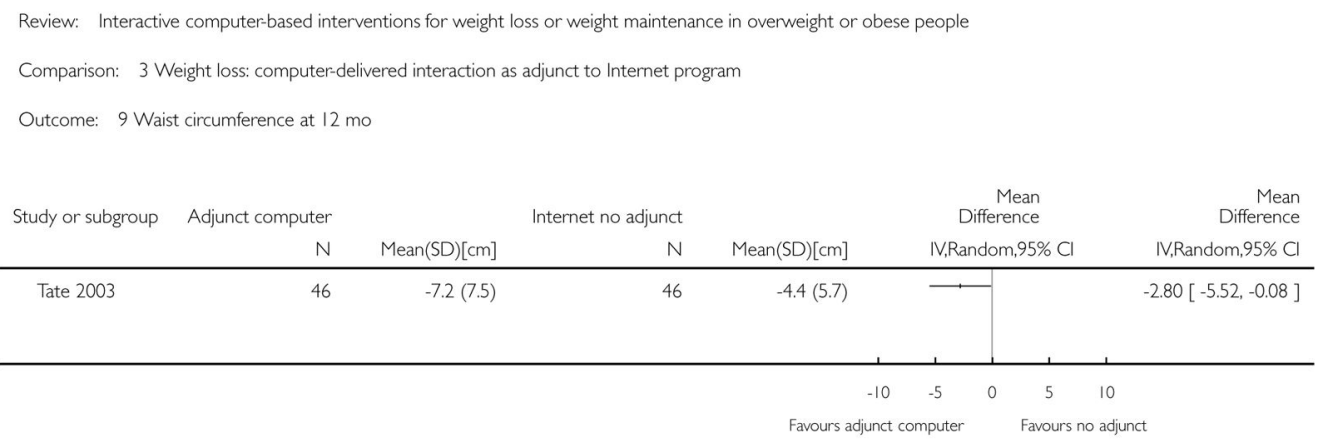

Analysis 3.9.

Comparison 3 Weight loss: computer-delivered interaction as adjunct to Internet program, Outcome 9 Waist circumference at 12 mo. 


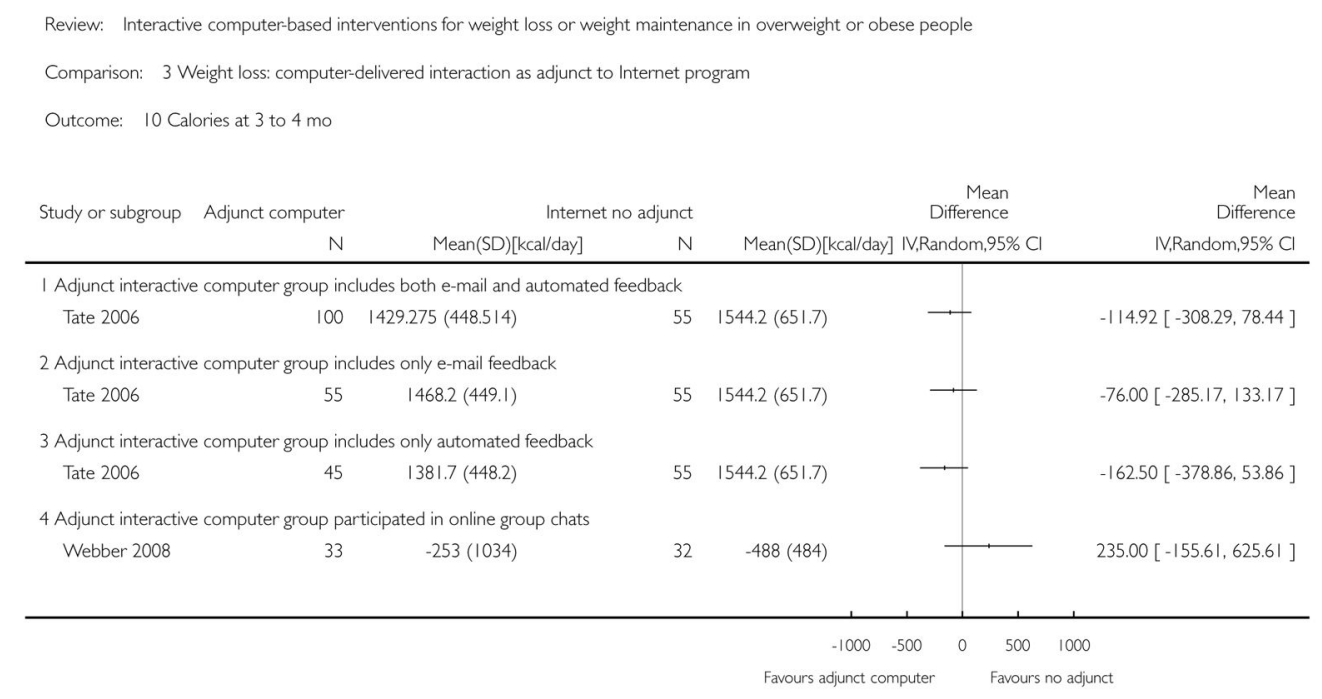

Analysis 3.10.

Comparison 3 Weight loss: computer-delivered interaction as adjunct to Internet program, Outcome 10 Calories at 3 to 4 mo. 


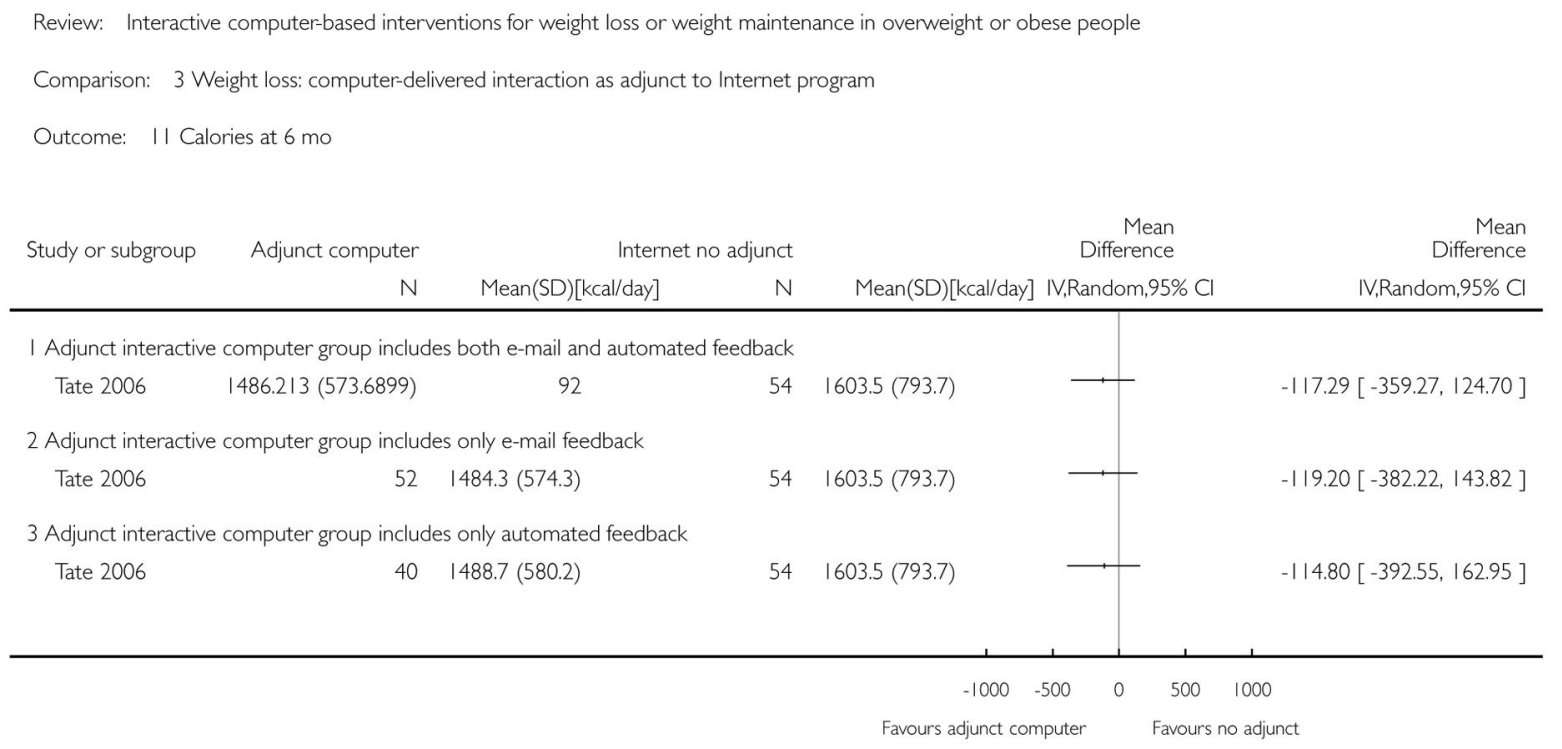

Analysis 3.11.

Comparison 3 Weight loss: computer-delivered interaction as adjunct to Internet program, Outcome 11 Calories at 6 mo. 


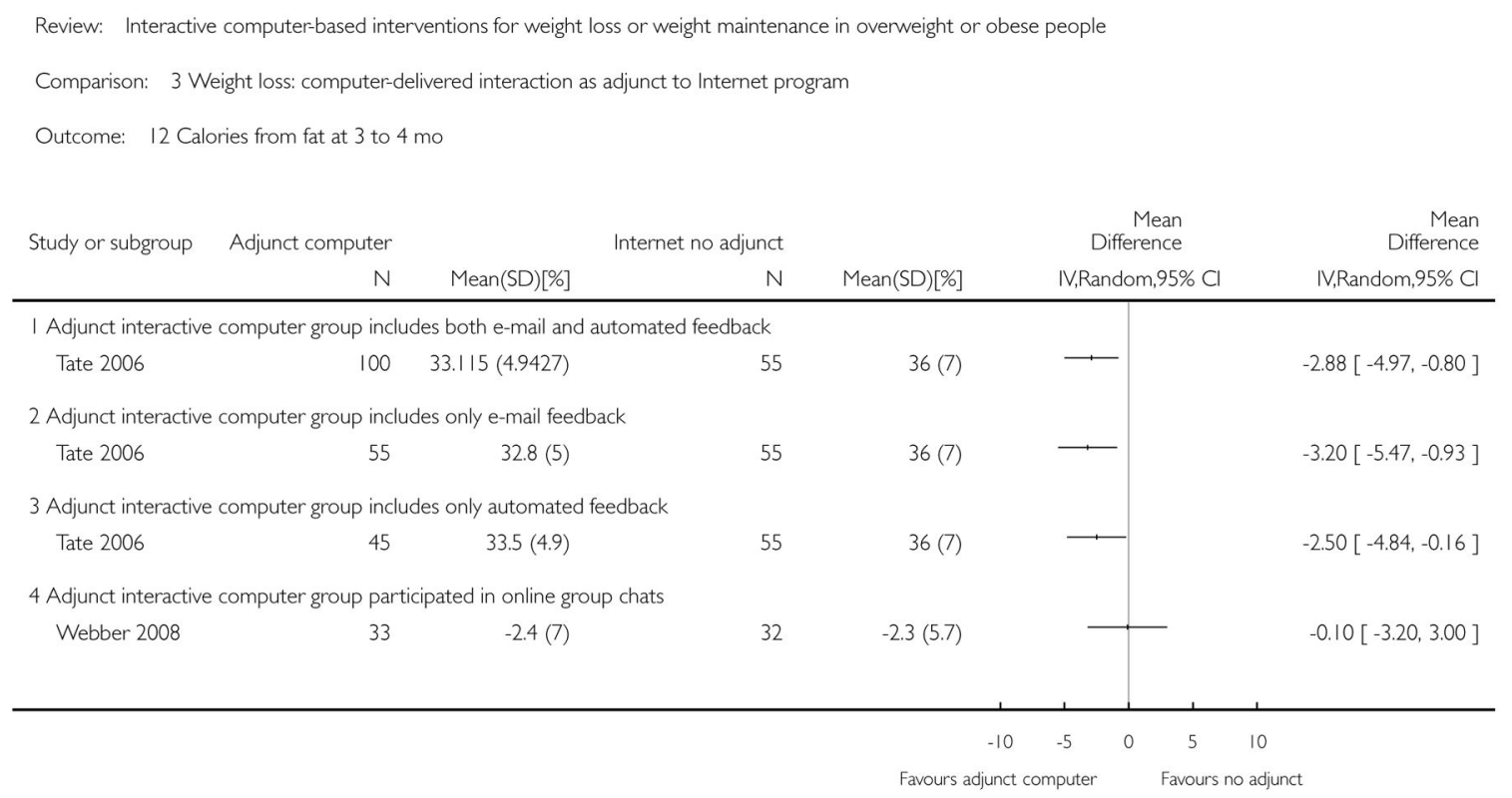

Analysis 3.12.

Comparison 3 Weight loss: computer-delivered interaction as adjunct to Internet program, Outcome 12 Calories from fat at 3 to 4 mo. 


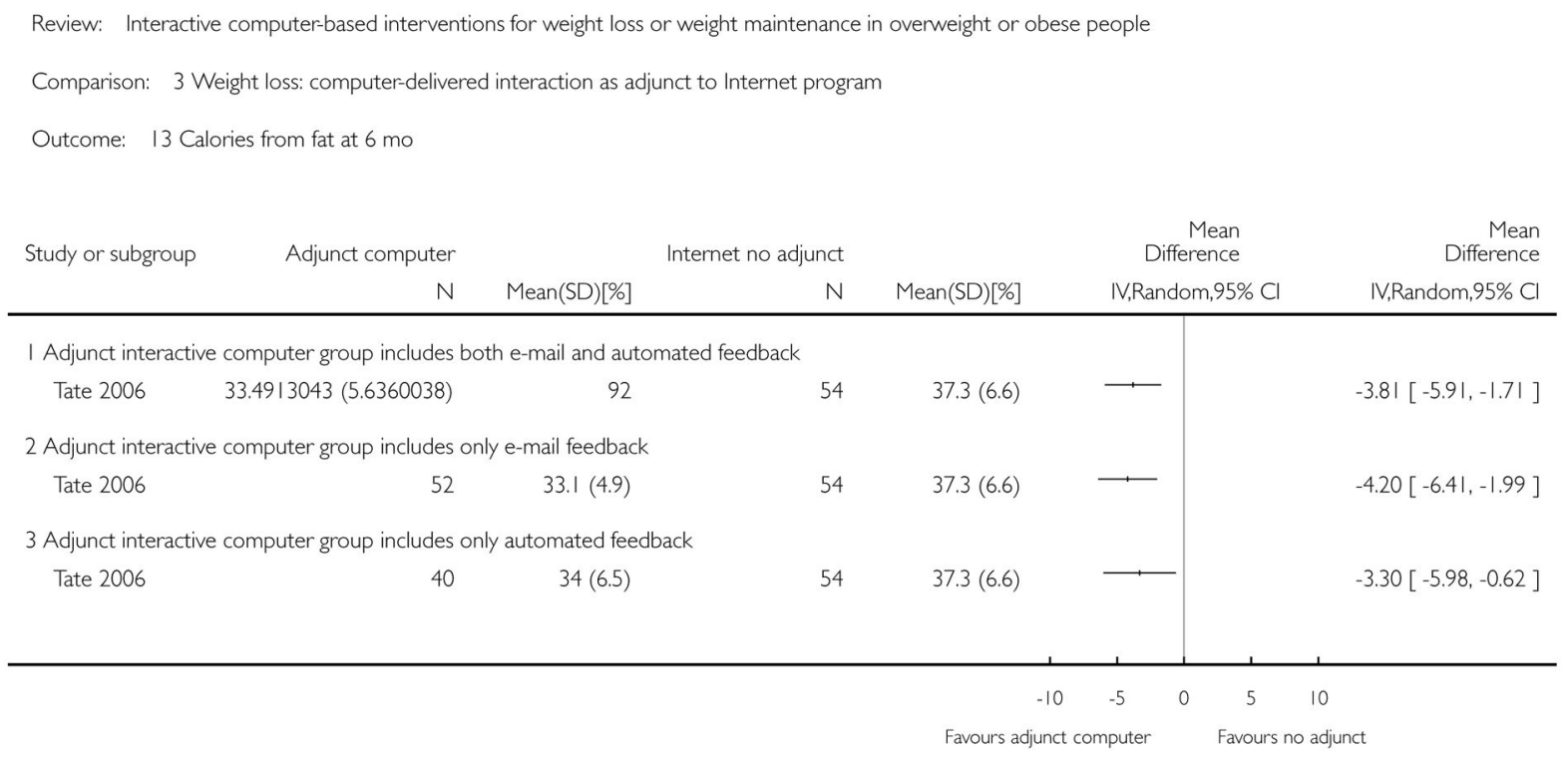

Analysis 3.13.

Comparison 3 Weight loss: computer-delivered interaction as adjunct to Internet program, Outcome 13 Calories from fat at 6 mo. 


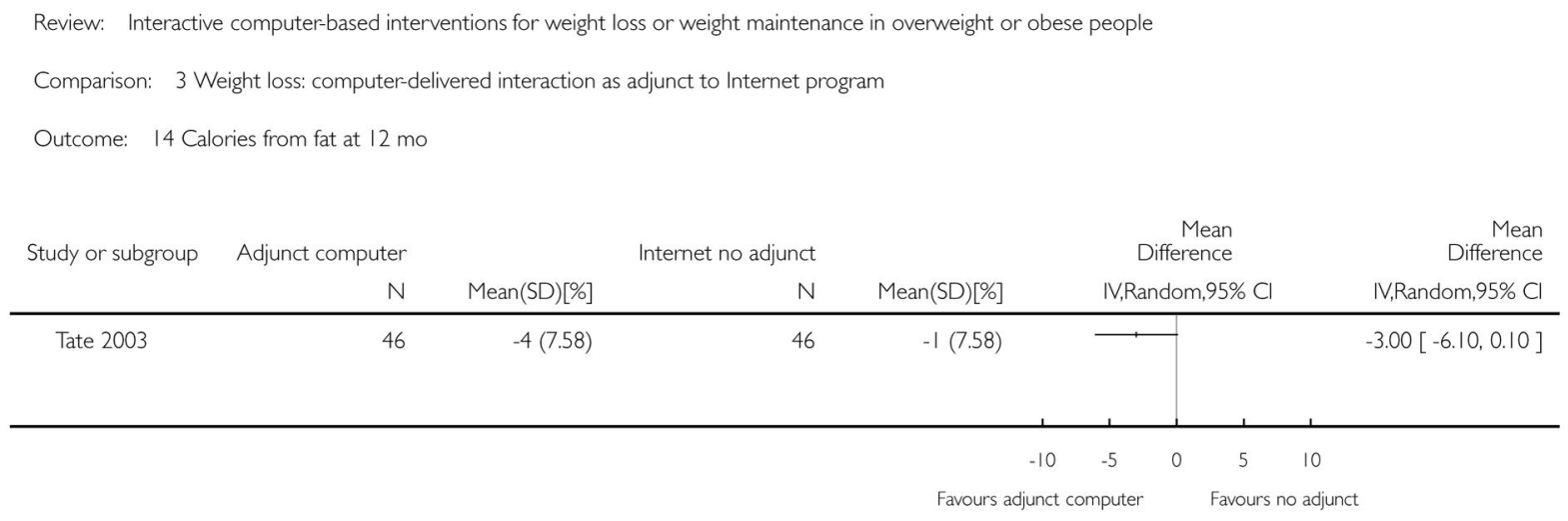

Analysis 3.14.

Comparison 3 Weight loss: computer-delivered interaction as adjunct to Internet program, Outcome 14 Calories from fat at 12 mo. 


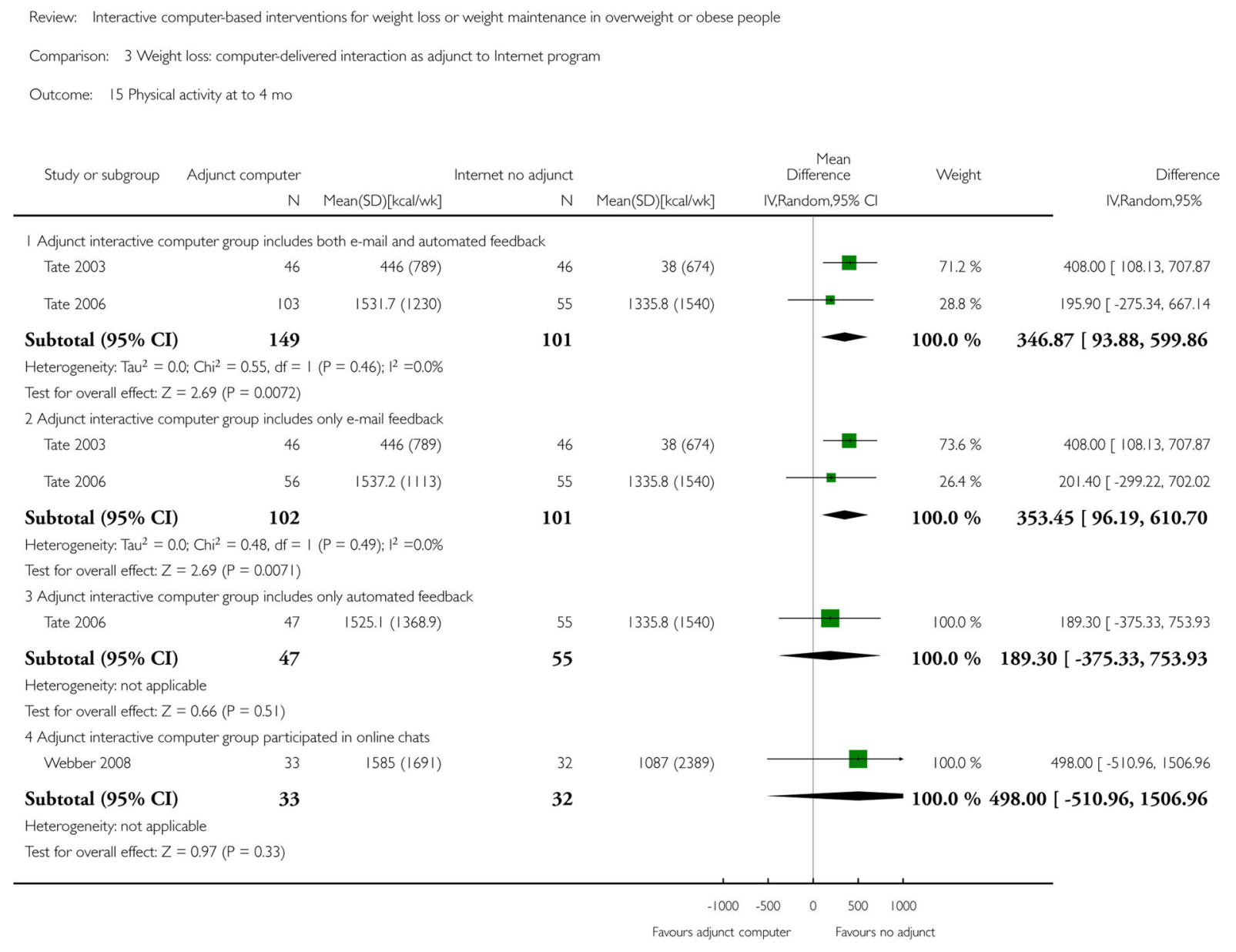

Analysis 3.15.

Comparison 3 Weight loss: computer-delivered interaction as adjunct to Internet program, Outcome 15 Physical activity at to 4 mo. 


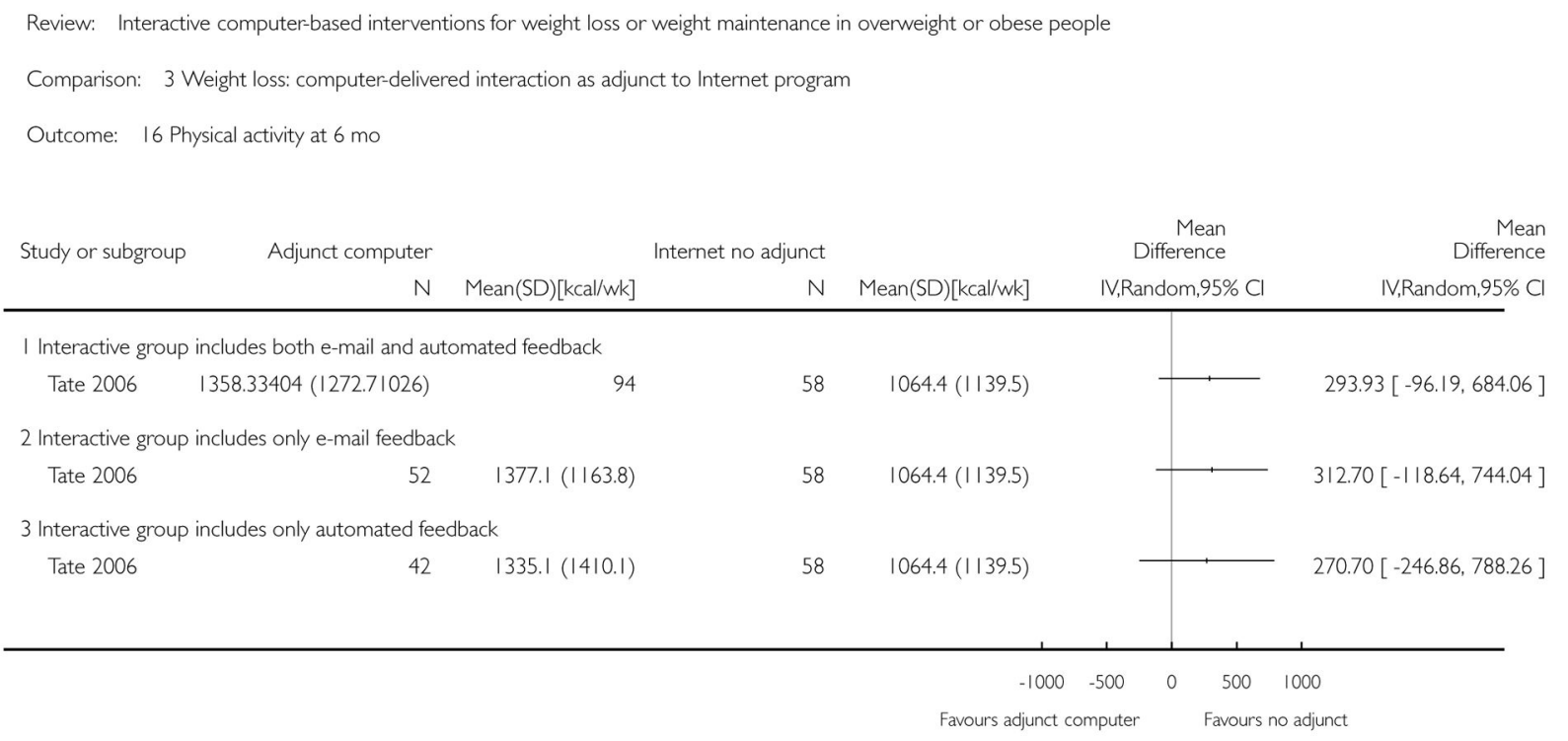

Analysis 3.16.

Comparison 3 Weight loss: computer-delivered interaction as adjunct to Internet program, Outcome 16 Physical activity at 6 mo. 


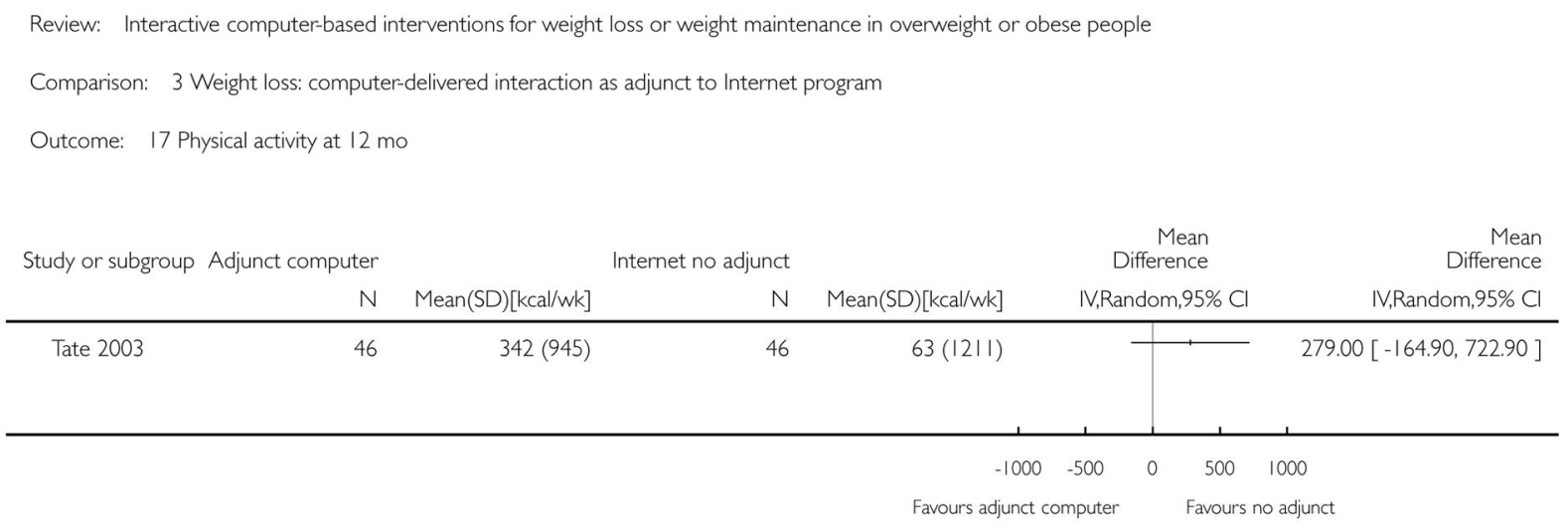

Analysis 3.17.

Comparison 3 Weight loss: computer-delivered interaction as adjunct to Internet program, Outcome 17 Physical activity at 12 mo. 


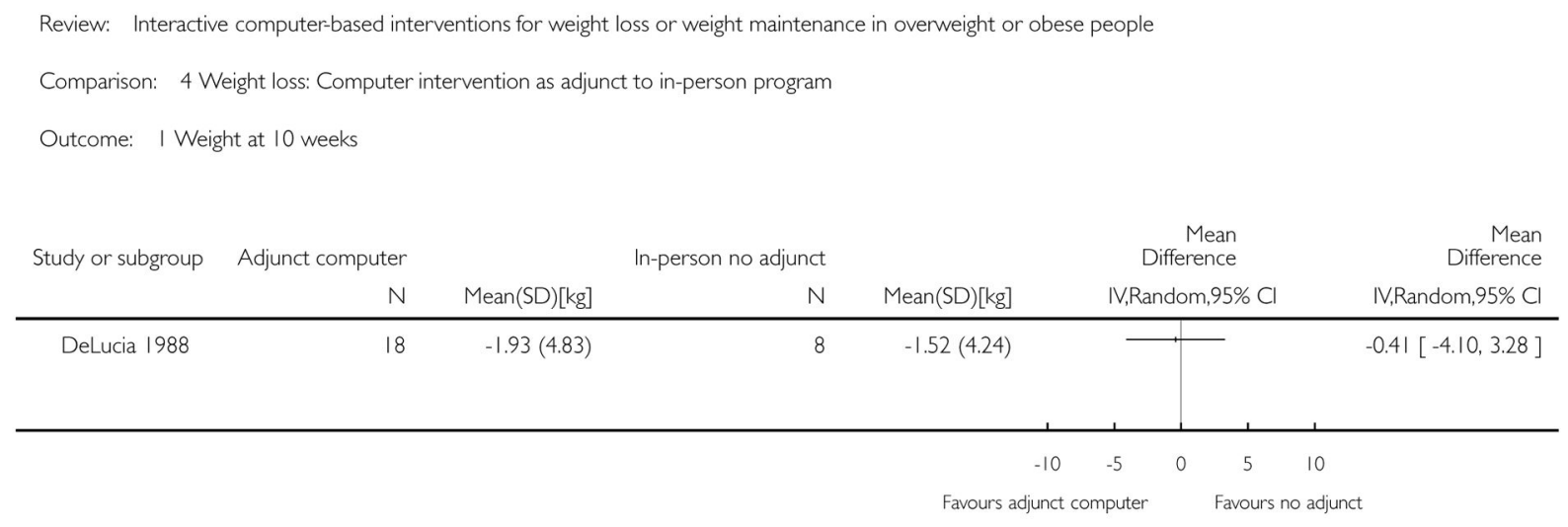

Analysis 4.1.

Comparison 4 Weight loss: Computer intervention as adjunct to in-person program, Outcome 1 Weight at 10 weeks. 


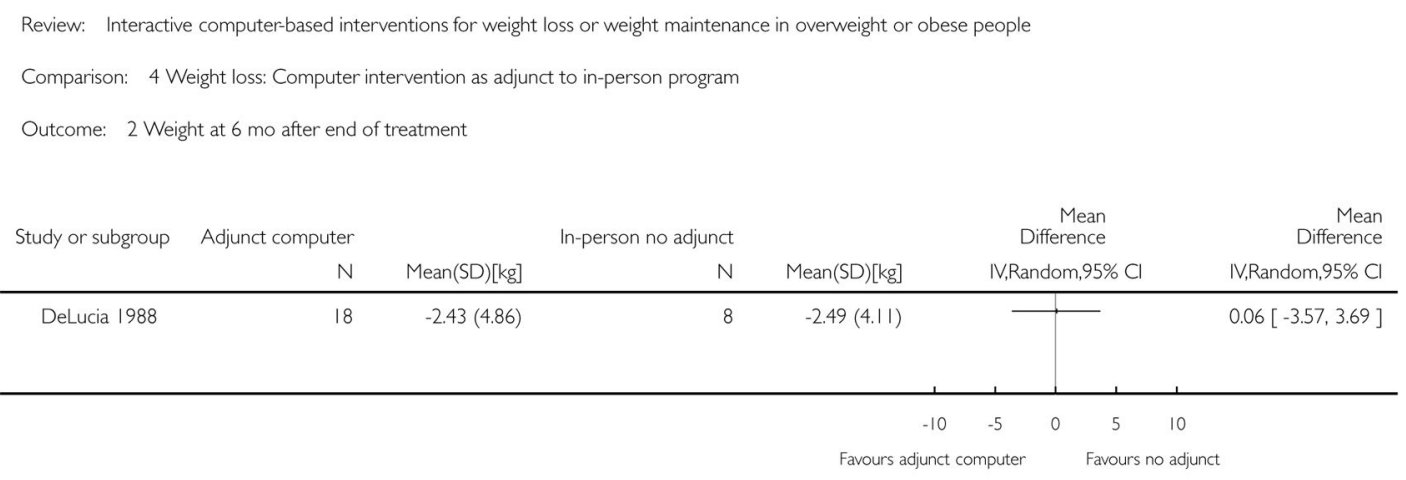

\section{Analysis 4.2.}

Comparison 4 Weight loss: Computer intervention as adjunct to in-person program, Outcome 2 Weight at 6 mo after end of treatment. 


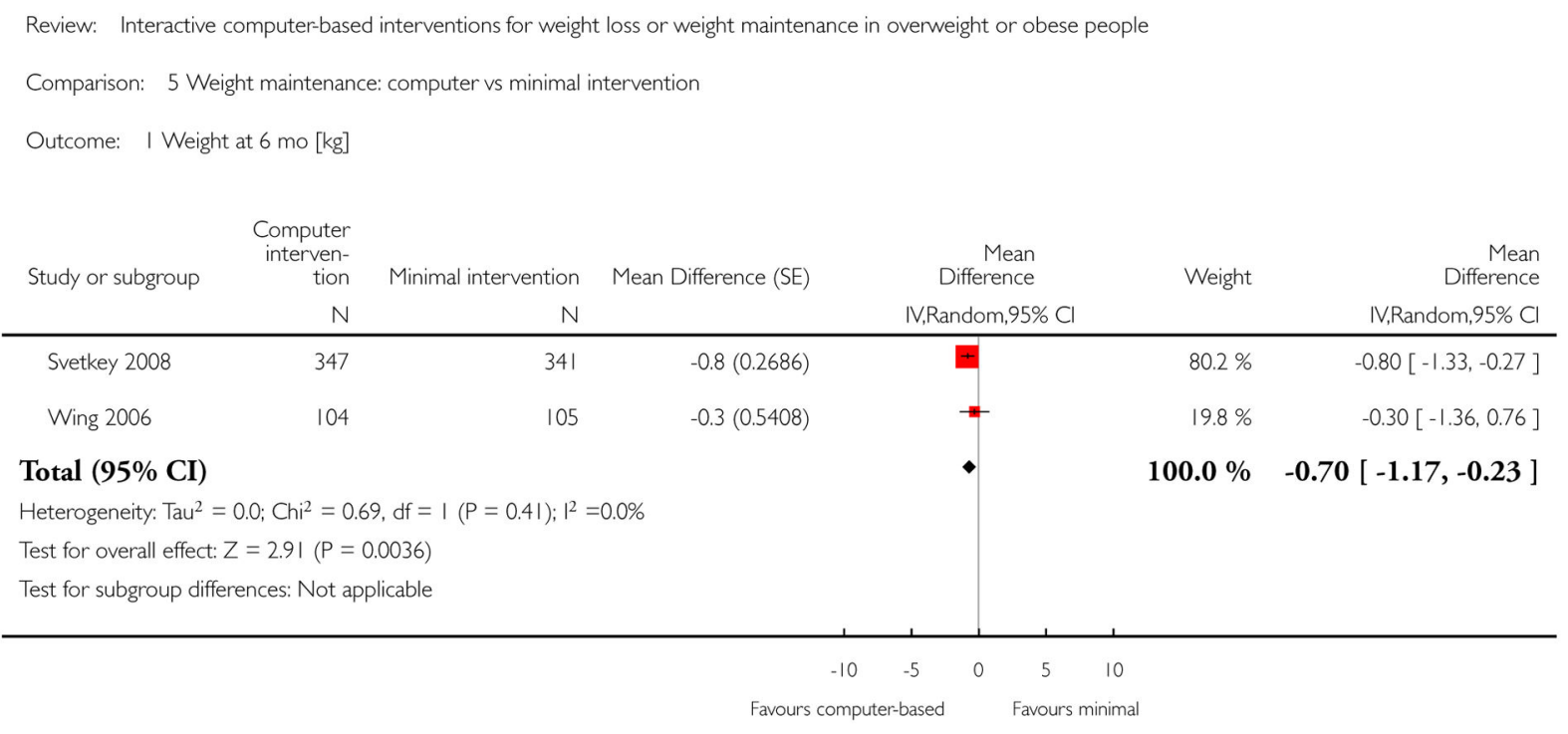

Analysis 5.1.

Comparison 5 Weight maintenance: computer vs minimal intervention, Outcome 1 Weight at 6 mo [kg]. 


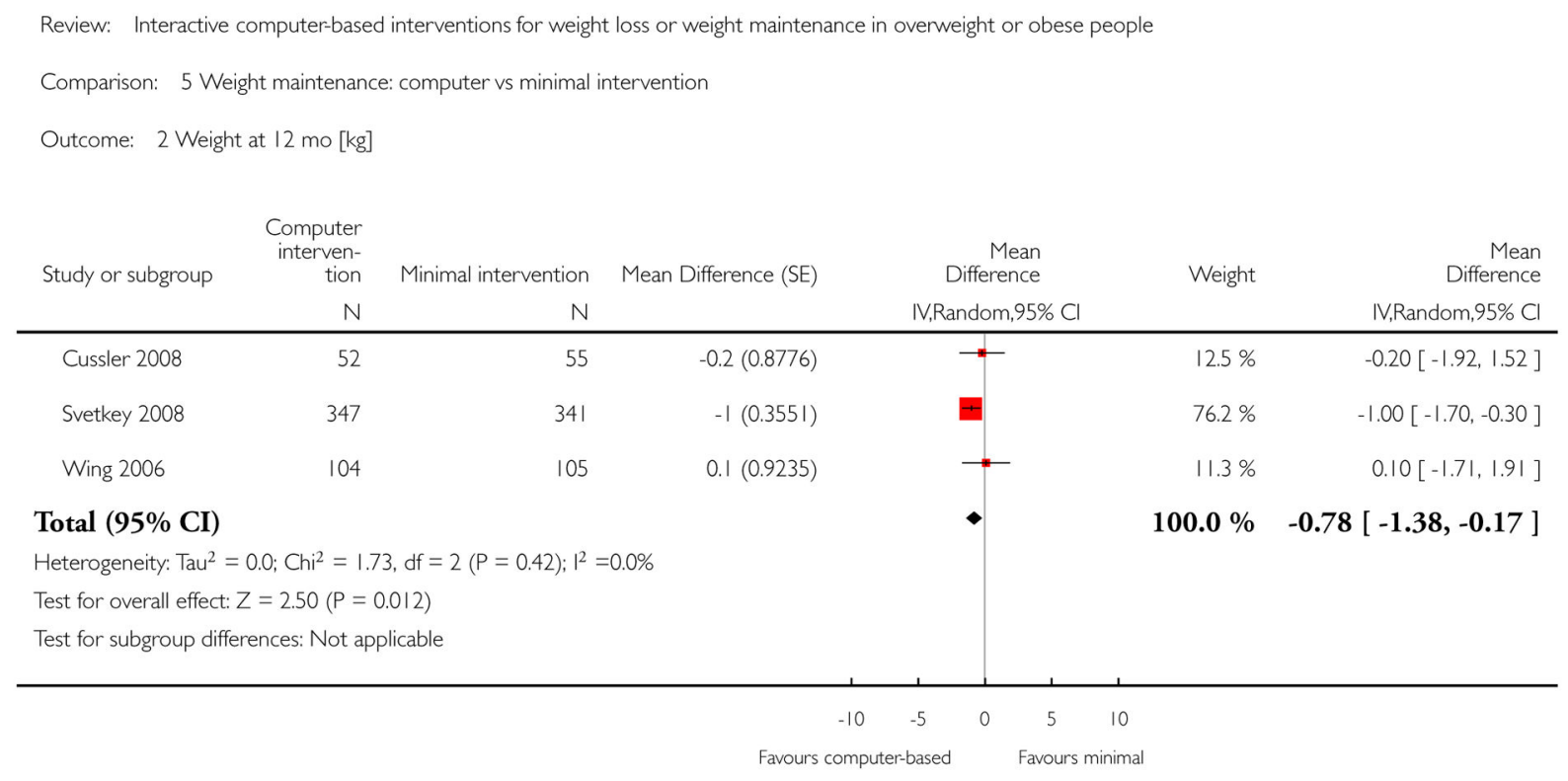

Analysis 5.2.

Comparison 5 Weight maintenance: computer vs minimal intervention, Outcome 2 Weight at $12 \mathrm{mo}[\mathrm{kg}]$. 


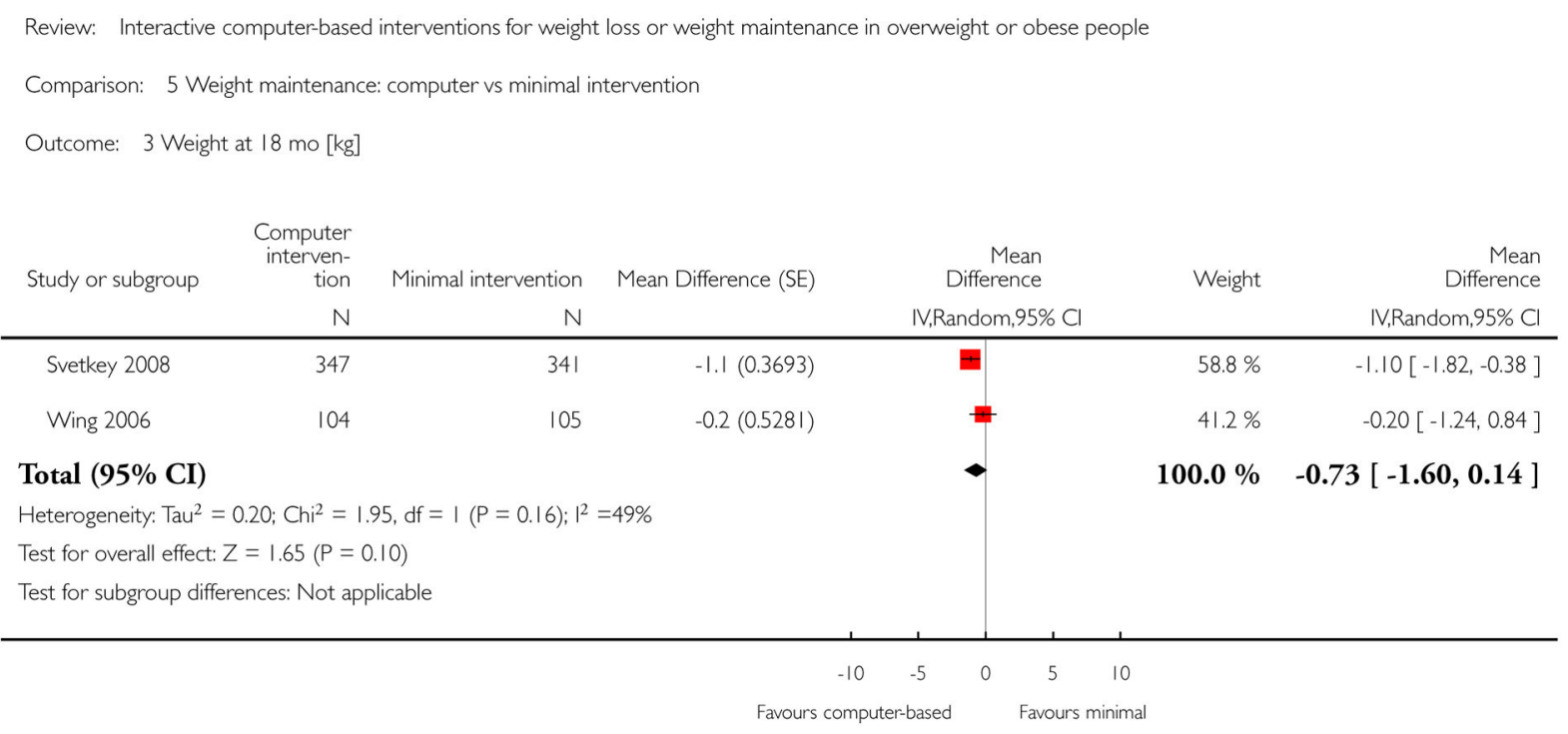

Analysis 5.3.

Comparison 5 Weight maintenance: computer vs minimal intervention, Outcome 3 Weight at $18 \mathrm{mo}$ [kg]. 


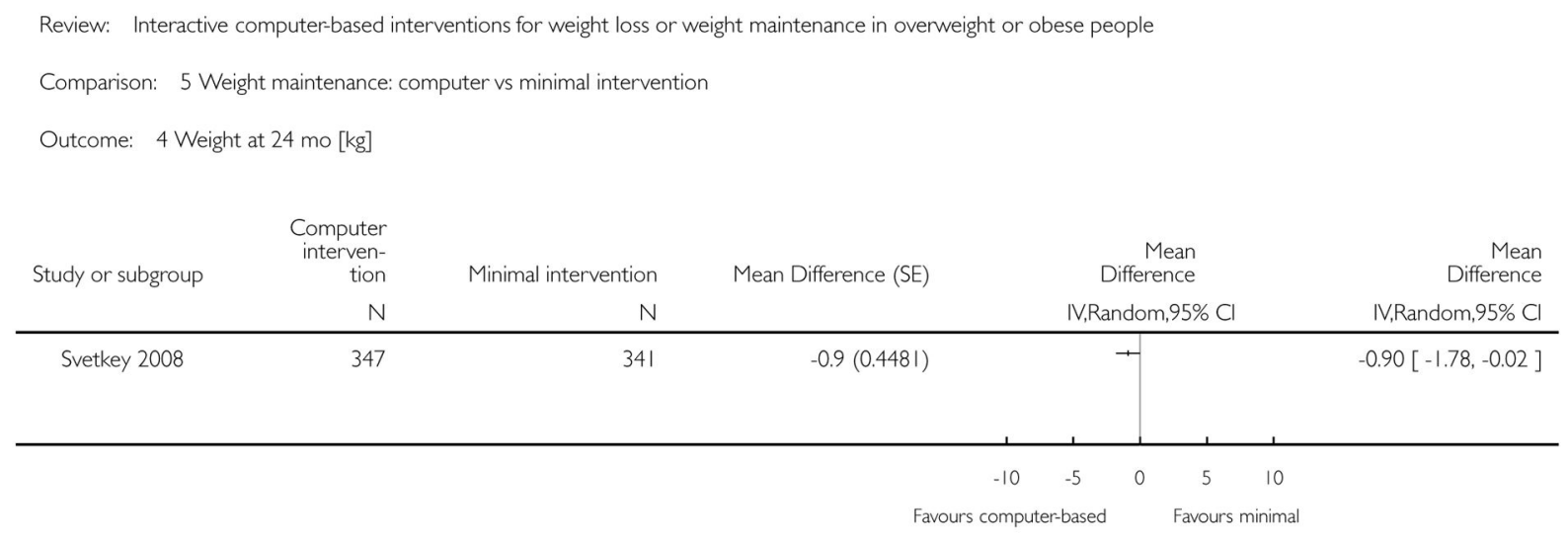

Analysis 5.4.

Comparison 5 Weight maintenance: computer vs minimal intervention, Outcome 4 Weight at 24 mo [kg]. 


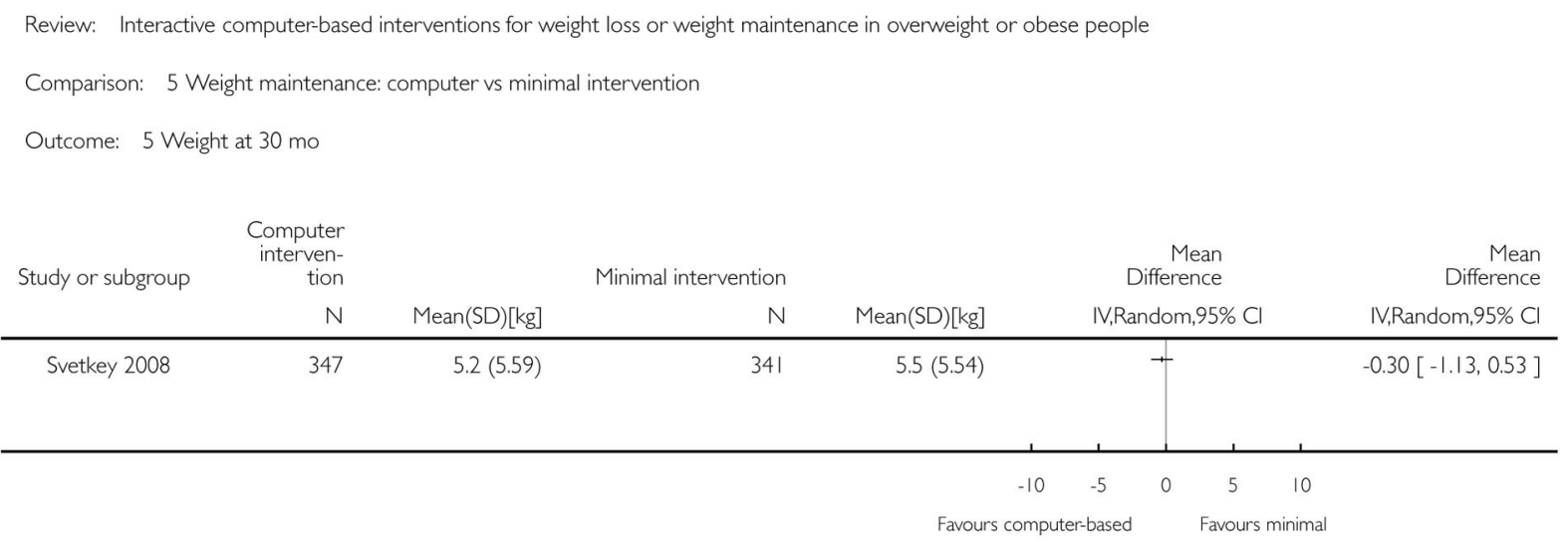

Analysis 5.5.

Comparison 5 Weight maintenance: computer vs minimal intervention, Outcome 5 Weight at 30 mo. 


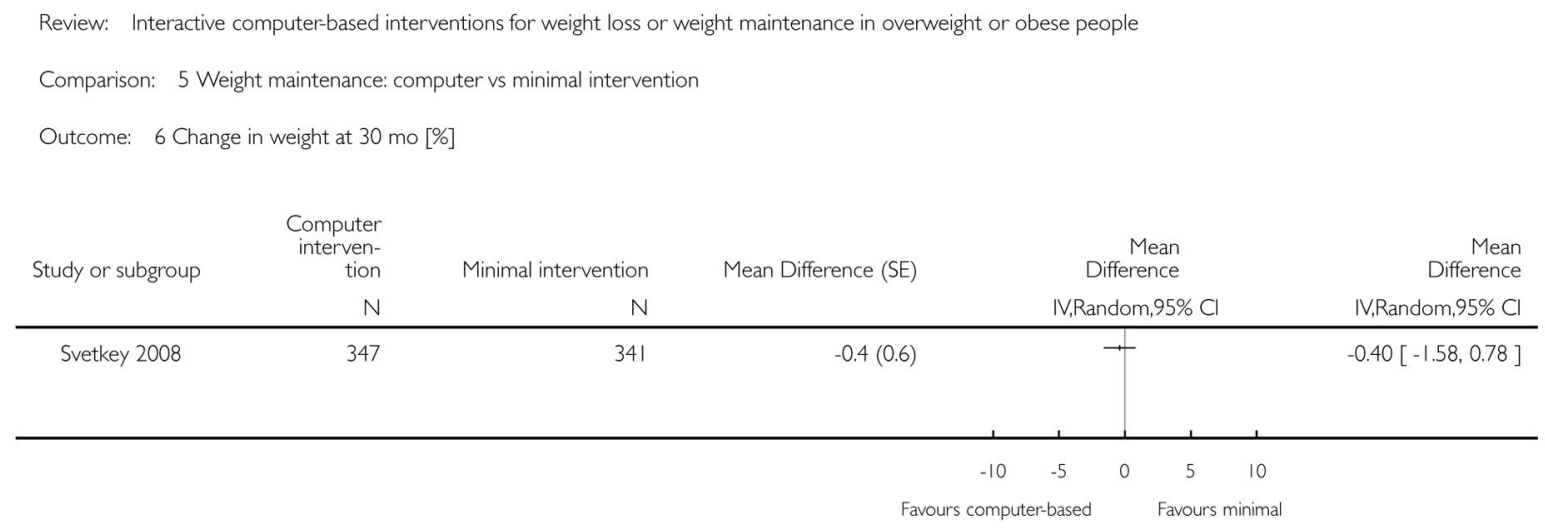

Analysis 5.6.

Comparison 5 Weight maintenance: computer vs minimal intervention, Outcome 6 Change in weight at 30 mo [\%]. 


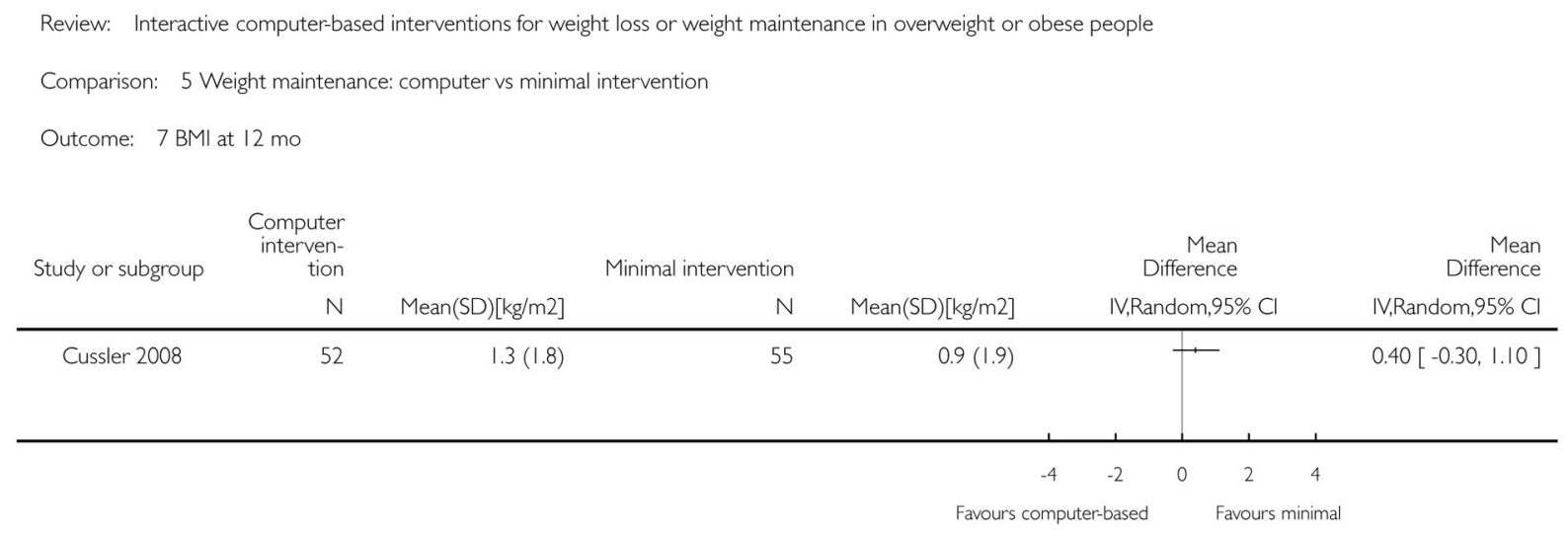

Analysis 5.7.

Comparison 5 Weight maintenance: computer vs minimal intervention, Outcome 7 BMI at 12 mo. 


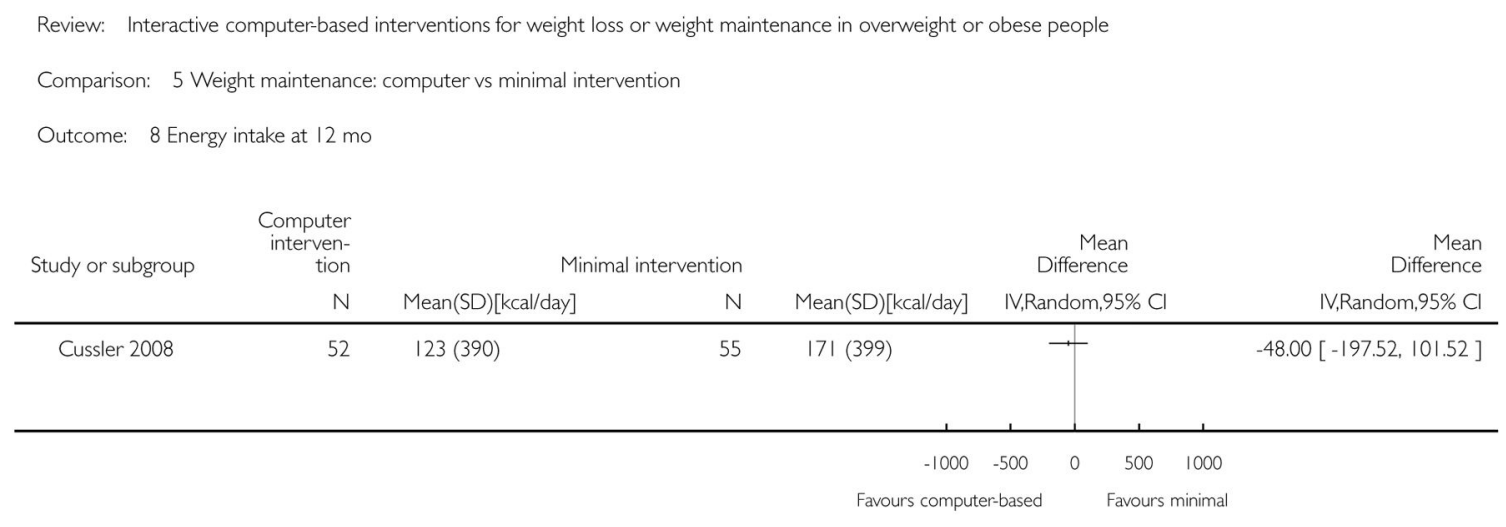

\section{Analysis 5.8.}

Comparison 5 Weight maintenance: computer vs minimal intervention, Outcome 8 Energy intake at 12 mo. 


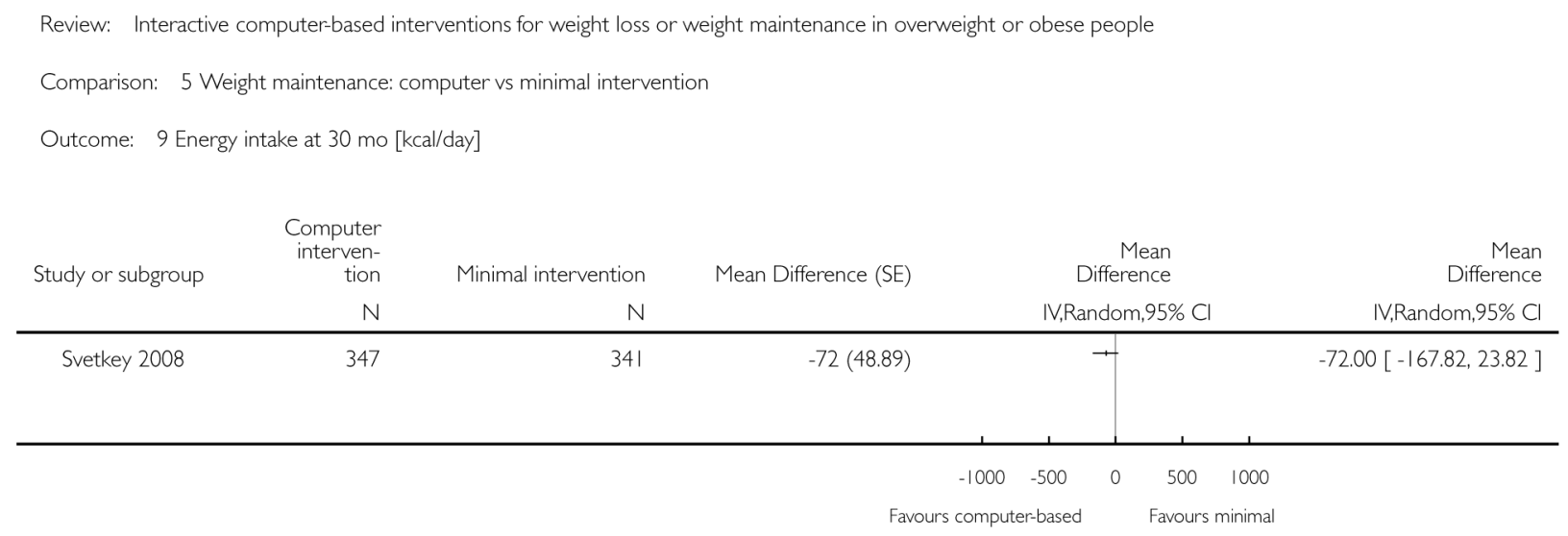

Analysis 5.9.

Comparison 5 Weight maintenance: computer vs minimal intervention, Outcome 9 Energy intake at $30 \mathrm{mo}$ [kcal/day]. 


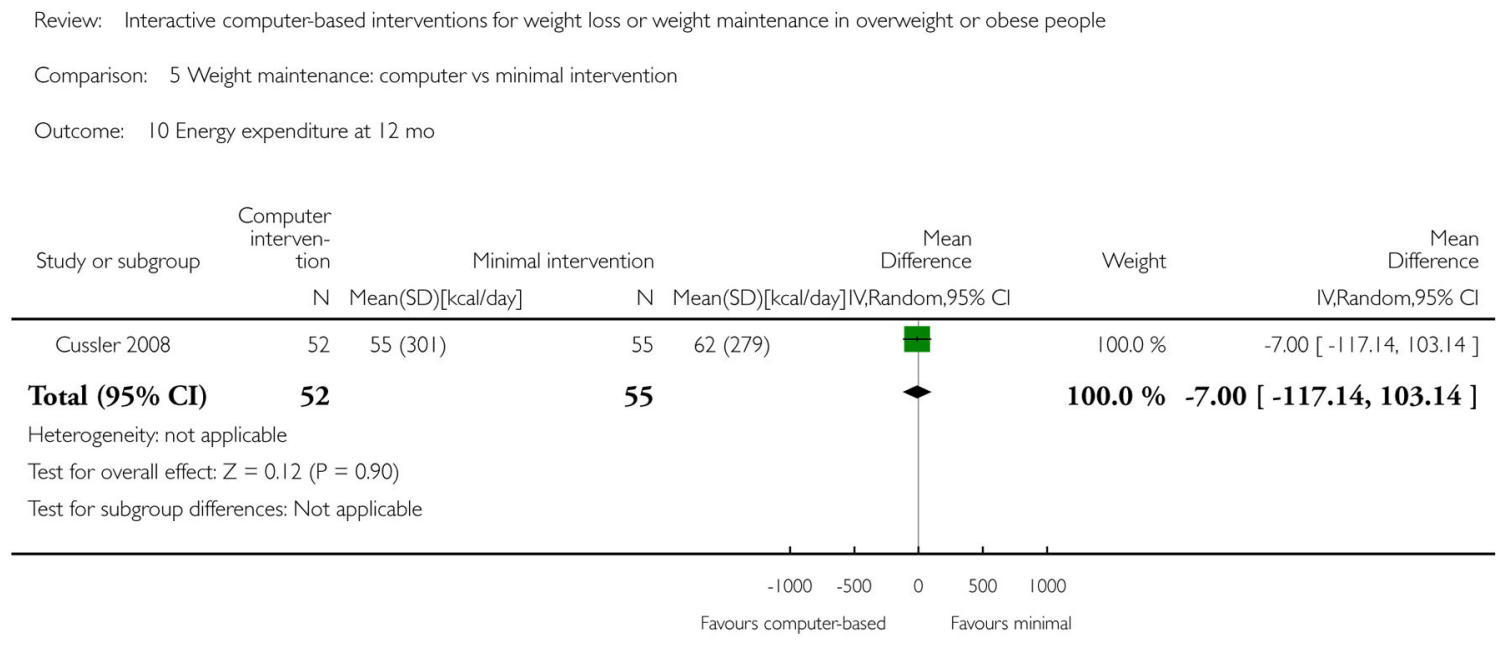

Analysis 5.10.

Comparison 5 Weight maintenance: computer vs minimal intervention, Outcome 10 Energy expenditure at 12 mo. 


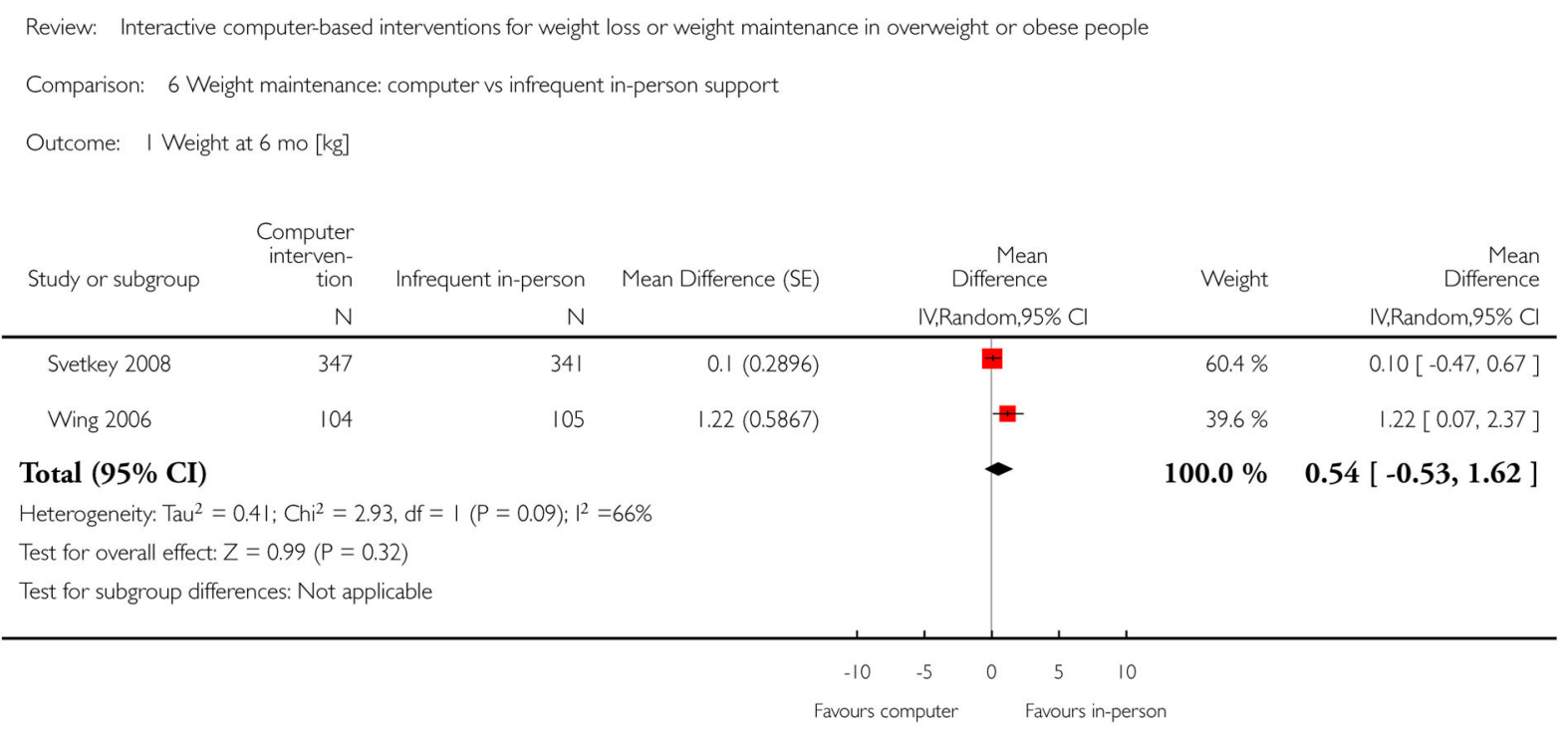

Analysis 6.1.

Comparison 6 Weight maintenance: computer vs infrequent in-person support, Outcome 1 Weight at 6 mo [kg]. 


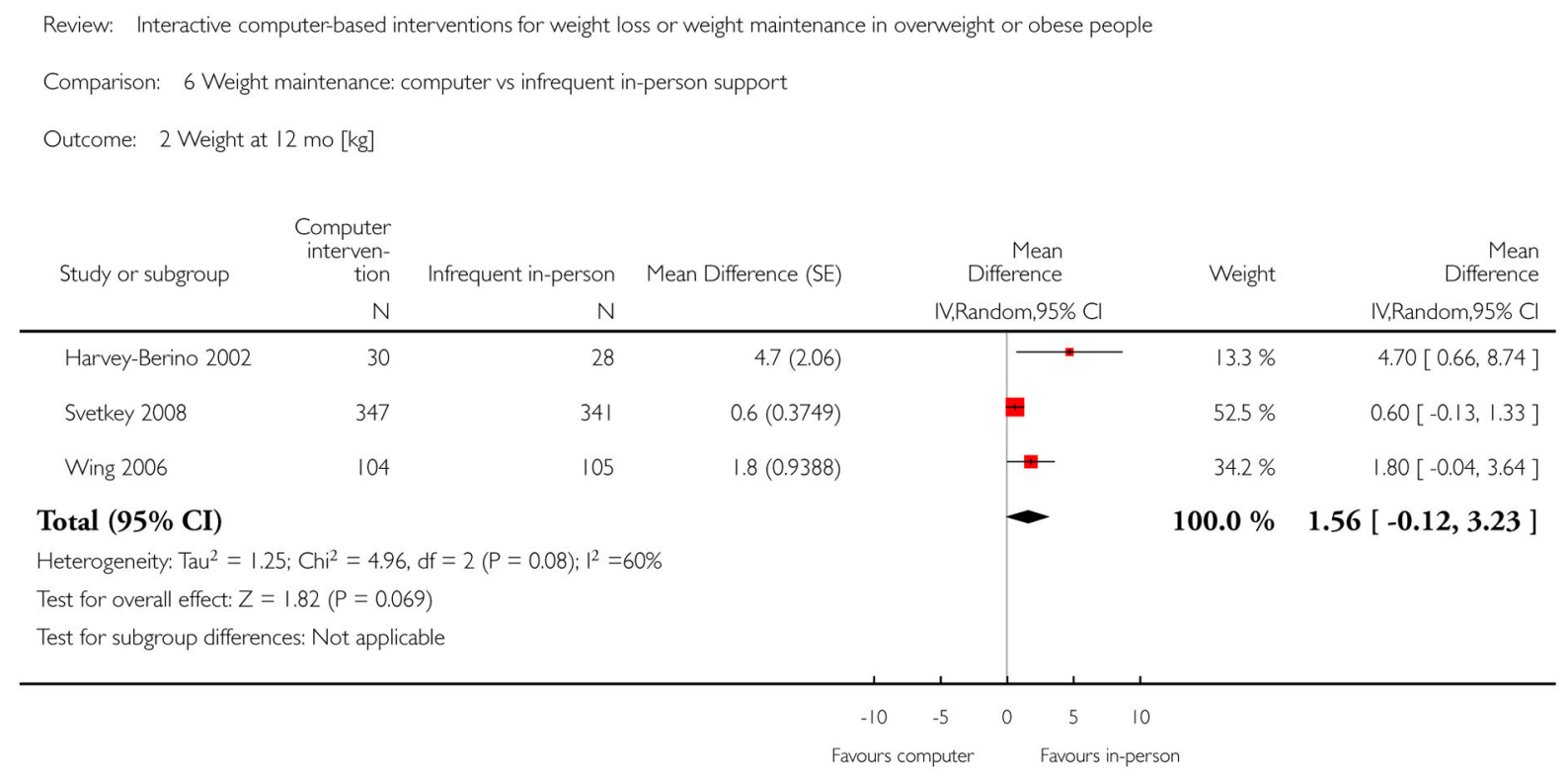

Analysis 6.2.

Comparison 6 Weight maintenance: computer vs infrequent in-person support, Outcome 2 Weight at $12 \mathrm{mo}$ [kg]. 


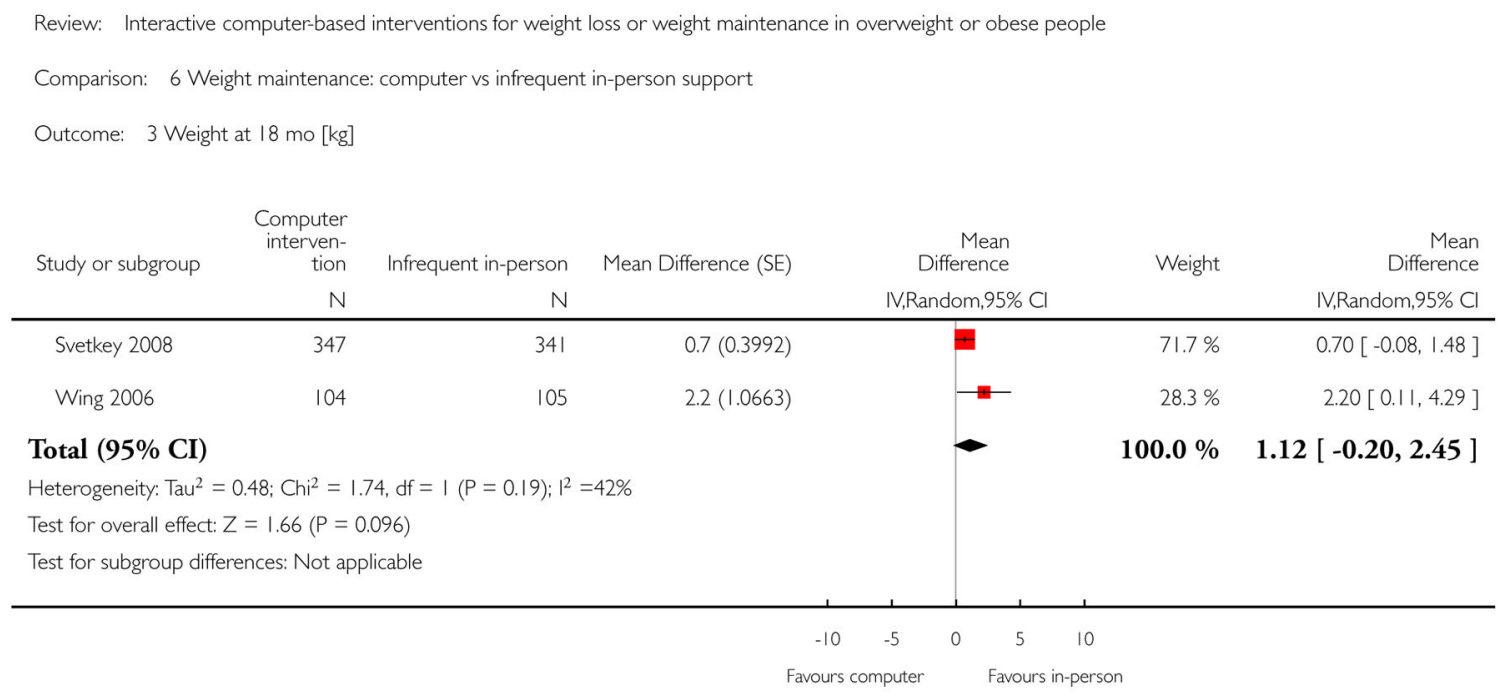

Analysis 6.3.

Comparison 6 Weight maintenance: computer vs infrequent in-person support, Outcome 3 Weight at $18 \mathrm{mo}[\mathrm{kg}]$. 


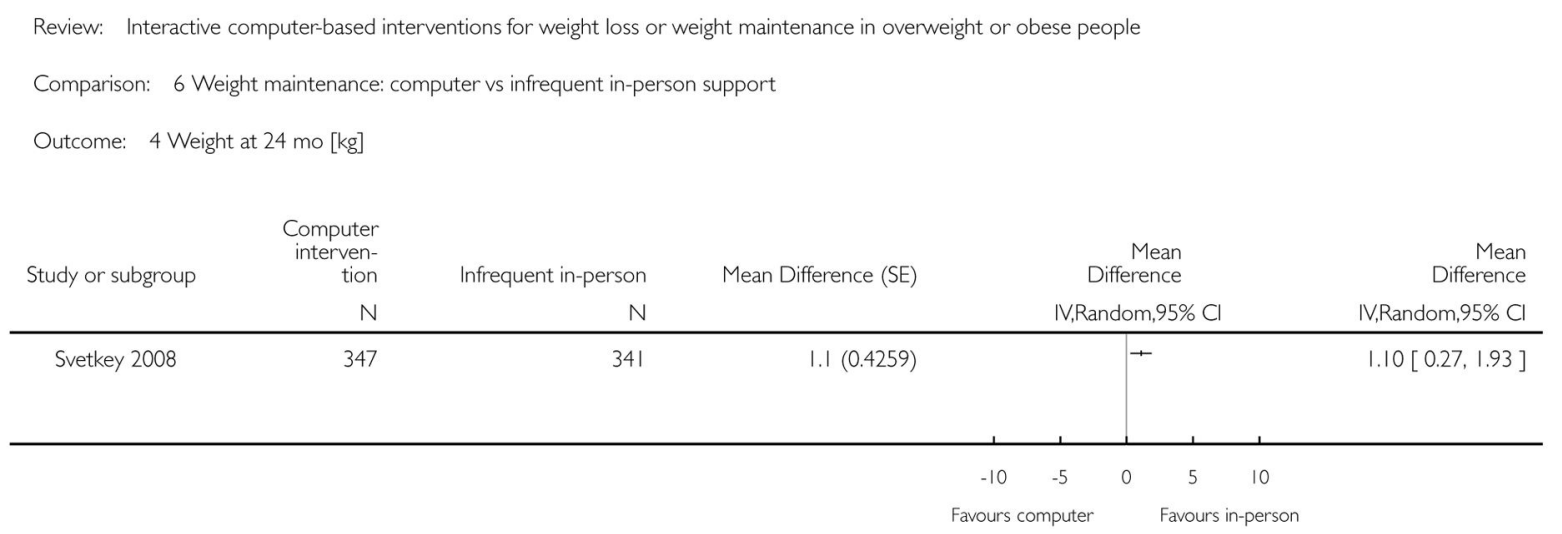

Analysis 6.4.

Comparison 6 Weight maintenance: computer vs infrequent in-person support, Outcome 4 Weight at $24 \mathrm{mo}$ [kg]. 


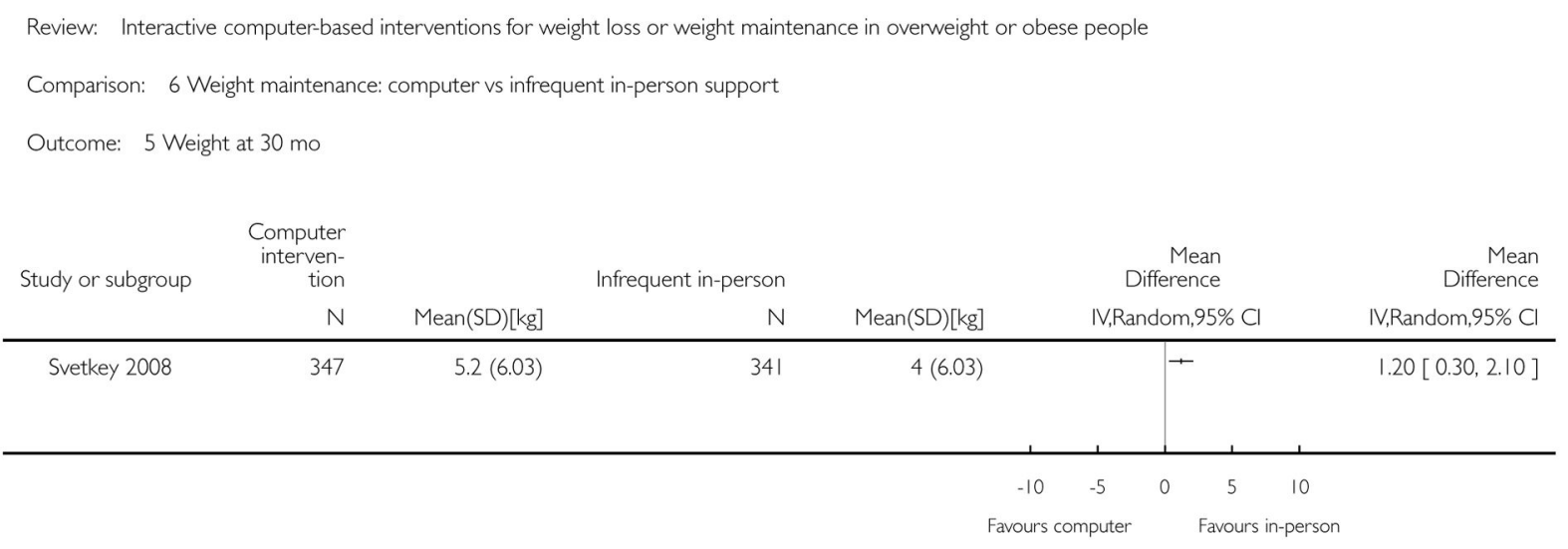

Analysis 6.5.

Comparison 6 Weight maintenance: computer vs infrequent in-person support, Outcome 5 Weight at 30 mo. 


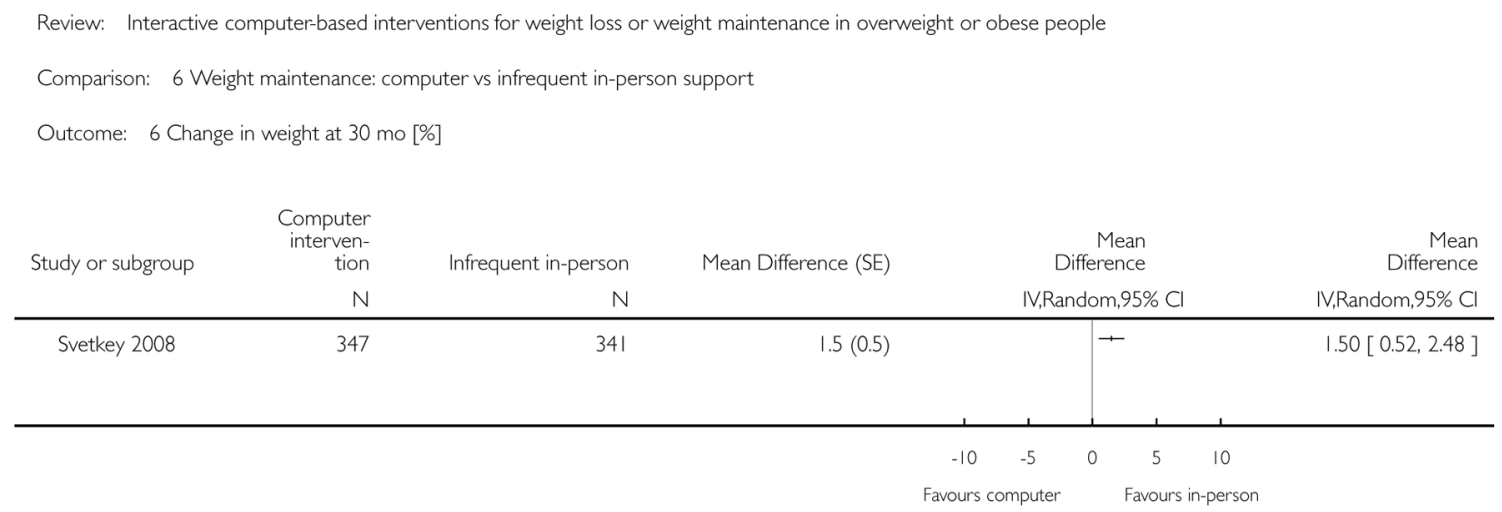

Analysis 6.6.

Comparison 6 Weight maintenance: computer vs infrequent in-person support, Outcome 6 Change in weight at 30 mo [\%]. 


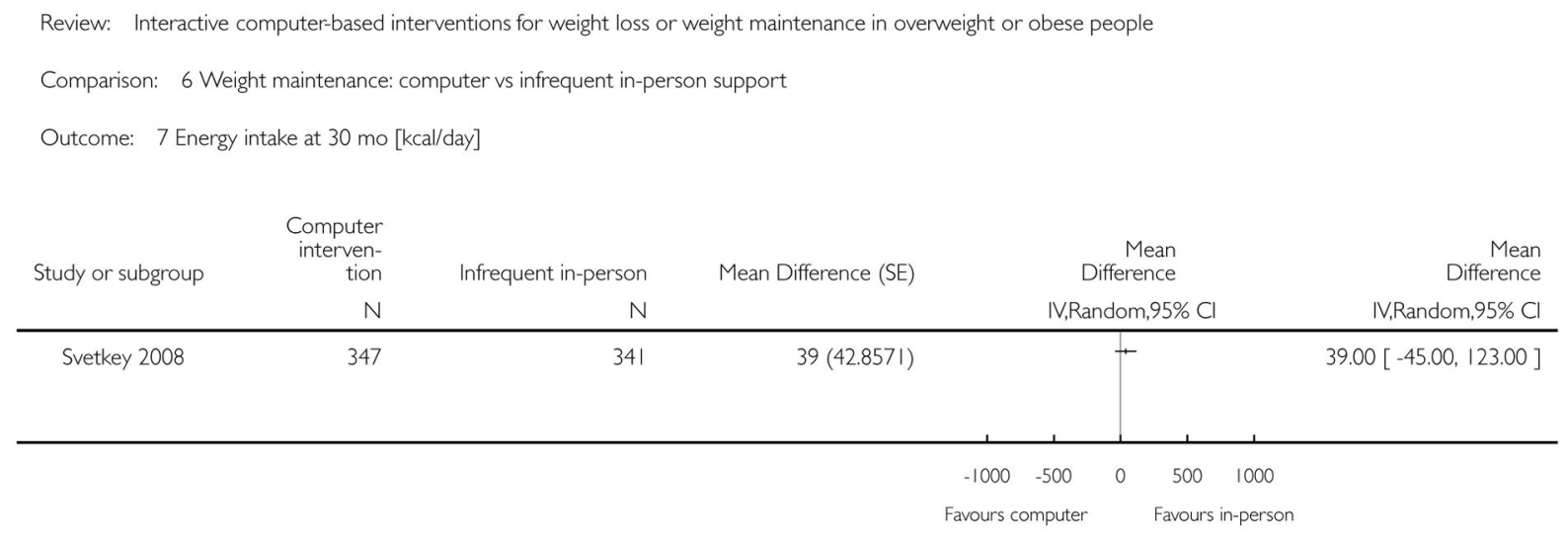

Analysis 6.7.

Comparison 6 Weight maintenance: computer vs infrequent in-person support, Outcome 7 Energy intake at 30 mo [kcal/day]. 


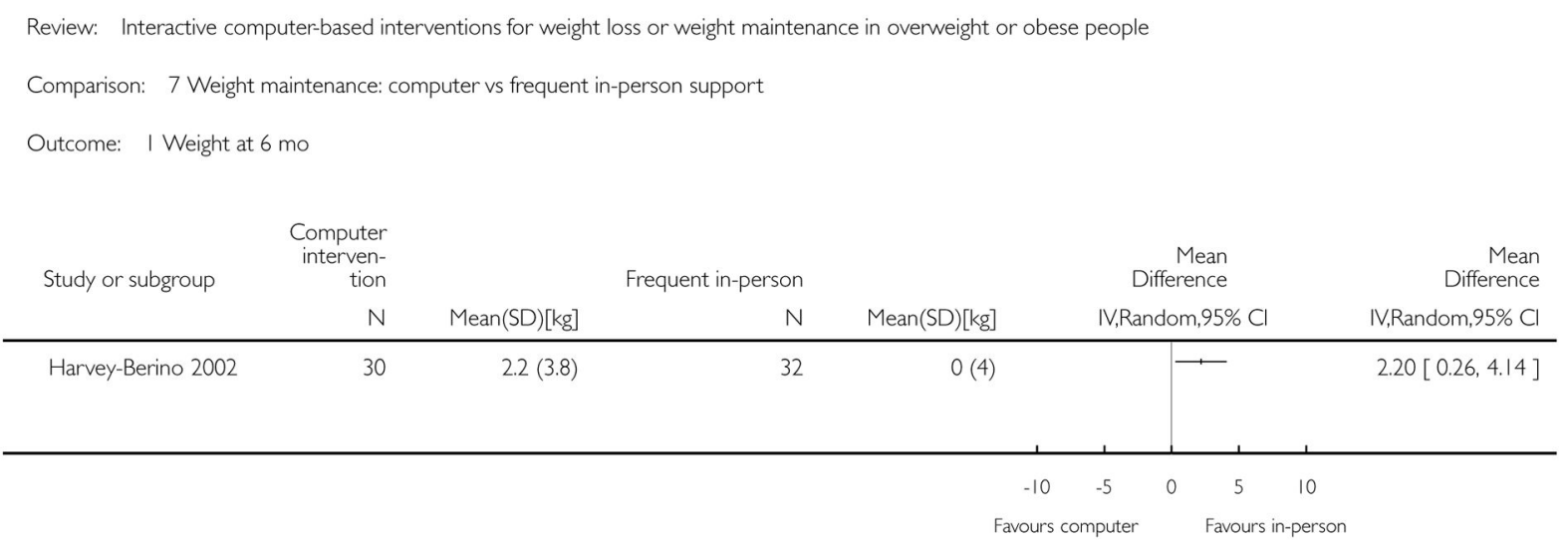

Analysis 7.1.

Comparison 7 Weight maintenance: computer vs frequent in-person support, Outcome 1 Weight at 6 mo. 


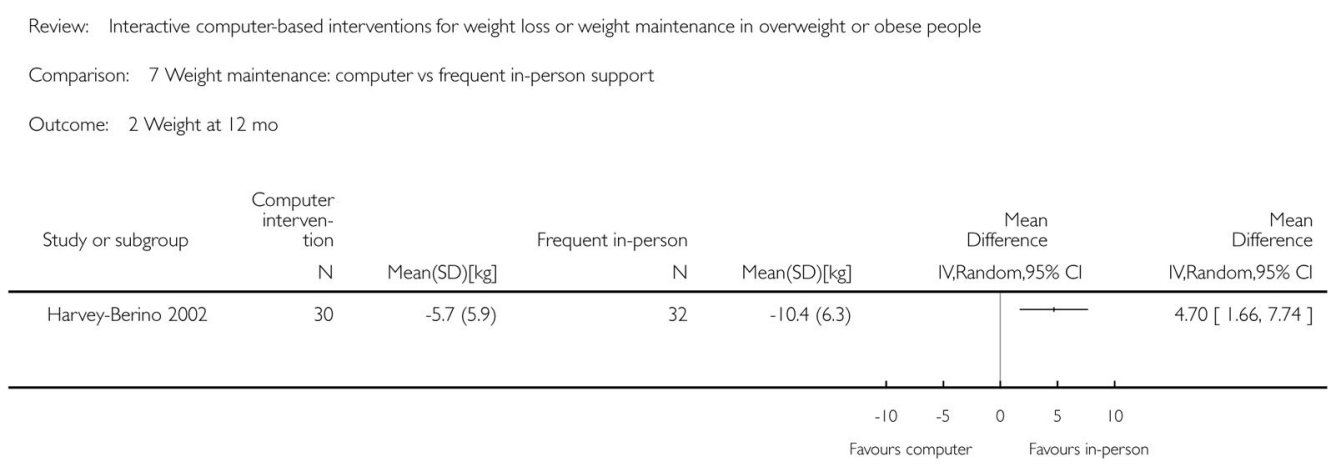

Analysis 7.2.

Comparison 7 Weight maintenance: computer vs frequent in-person support, Outcome 2 Weight at 12 mo. 
Table 1

Overview of study populations

\begin{tabular}{|c|c|c|c|c|c|c|c|}
\hline Characteristic Study ID & $\begin{array}{l}\text { Intervention (s) and } \\
\text { control(s) }\end{array}$ & [n] screened & [n] randomized & [n] safety & {$[\mathbf{n}]$ ITT } & [n] finishing study & $\begin{array}{l}{[\%] \text { of }} \\
\text { randomized } \\
\text { participants } \\
\text { finishing } \\
\text { study }\end{array}$ \\
\hline Bennett 2010 & $\begin{array}{l}\text { I: Internet-based } \\
\text { interactive weight loss } \\
\text { approach; health coach } \\
\text { support }\end{array}$ & \multirow[t]{3}{*}{ Total: 390} & 51 & 51 & 51 & 43 & 84 \\
\hline (weight loss study) & $\begin{array}{l}\text { C: current standard of } \\
\text { outpatient care and } \\
\text { written materials }\end{array}$ & & 50 & 50 & 50 & 42 & 82 \\
\hline \multicolumn{2}{|l|}{ total: } & & 101 & 101 & 101 & 85 & 84 \\
\hline Cussler 2008 & I: Internet-based program & \multirow[t]{3}{*}{ Total: 300} & 66 & 66 & 66 & 52 & 79 \\
\hline (weight maintenance study) & $\begin{array}{l}\mathrm{C} \text { : continue to practice } \\
\text { principles during weight } \\
\text { loss intervention }\end{array}$ & & 69 & 69 & 69 & 59 & 86 \\
\hline \multicolumn{2}{|l|}{ total: } & & 135 & 135 & 135 & 111 & 82 \\
\hline DeLucia 1988 & $\begin{array}{l}\text { I1: Ferguson behavioral } \\
\text { program and nutritional } \\
\text { software 'The Eating } \\
\text { Machine' }\end{array}$ & \multirow[t]{4}{*}{ Not described } & 10 & 10 & Not done & 9 & 90 \\
\hline \multirow[t]{2}{*}{ (weight loss study) } & $\begin{array}{l}\text { I2: Ferguson behavioral } \\
\text { program and nutritional } \\
\text { software 'EATS' }\end{array}$ & & 10 & 10 & & 9 & 90 \\
\hline & C: Ferguson program & & 9 & 9 & & 8 & 89 \\
\hline \multicolumn{2}{|l|}{ total: } & & 29 & 29 & & 26 & 90 \\
\hline Gabriele 2011 & $\begin{array}{l}\text { I1: Internet-based } \\
\text { program and directive e- } \\
\text { coach support }\end{array}$ & Total: 105 & 34 & 34 & 34 & 31 & 91 \\
\hline \multirow[t]{2}{*}{ (weight loss study) } & $\begin{array}{l}\text { I2: Internet-based } \\
\text { program and non- } \\
\text { directive e-coach support }\end{array}$ & & 35 & 35 & 35 & 33 & 94 \\
\hline & $\begin{array}{l}\text { C: Internet-based } \\
\text { program with minimal } \\
\text { support }\end{array}$ & & 35 & 35 & 35 & 32 & 91 \\
\hline \multicolumn{2}{|l|}{ total: } & & 104 & 104 & 104 & 96 & 92 \\
\hline Harvey-Berino 2002 & I: Internet support & \multirow[t]{4}{*}{ Not described } & 40 & 40 & 40 & 30 & 75 \\
\hline \multirow[t]{2}{*}{ (weight maintenance study) } & $\begin{array}{l}\mathrm{C} 1 \text { : continue to practice } \\
\text { principles during weight } \\
\text { loss intervention }\end{array}$ & & 41 & 41 & 41 & 32 & 78 \\
\hline & $\begin{array}{l}\text { C2: minimal in-person } \\
\text { support }\end{array}$ & & 41 & 41 & 41 & 28 & 68 \\
\hline \multicolumn{2}{|l|}{ total: } & & 122 & 122 & 122 & 90 & 74 \\
\hline Harvey-Berino 2010 & $\begin{array}{l}\text { I: online recording and } \\
\text { chat sessions }\end{array}$ & \multirow{3}{*}{$\begin{array}{l}\text { Ineligible: } \\
485 \\
\text { Consented: } \\
658 \\
\text { Total: } 1143\end{array}$} & 161 & 161 & 161 & 159 & 99 \\
\hline \multirow[t]{2}{*}{ (weight loss study) } & $\begin{array}{l}\mathrm{C} 1 \text { : on-line recording } \\
\text { and chat sessions and in- } \\
\text { person meetings }\end{array}$ & & 162 & 162 & 162 & 153 & 94 \\
\hline & $\begin{array}{l}\mathrm{C} 2 \text { : paper recording and } \\
\text { in-person chat sessions }\end{array}$ & & 158 & 158 & 158 & 150 & 95 \\
\hline
\end{tabular}




\begin{tabular}{|c|c|c|c|c|c|c|c|}
\hline Characteristic Study ID & $\begin{array}{l}\text { Intervention (s) and } \\
\text { control(s) }\end{array}$ & {$[n]$ screened } & [n] randomized & [n] safety & [n] ITT & [n] finishing study & $\begin{array}{l}{[\%] \text { of }} \\
\text { randomized } \\
\text { participants } \\
\text { finishing } \\
\text { study }\end{array}$ \\
\hline & total: & & 481 & 481 & 481 & 462 & 96 \\
\hline Hunter $2008^{b}$ & $\begin{array}{l}\text { I: behavioral Internet } \\
\text { treatment }\end{array}$ & \multirow[t]{3}{*}{ Total: 682} & 227 & 227 & 224 & 193 & 85 \\
\hline \multirow[t]{2}{*}{ (weight loss study) } & C: usual care & & 224 & 224 & 222 & 206 & 92 \\
\hline & total: & & 451 & 451 & 446 & 397 & 88 \\
\hline Morgan $2009^{c}$ & $\begin{array}{l}\text { I: Internet weight loss } \\
\text { program; information } \\
\text { session and program } \\
\text { booklet }\end{array}$ & \multirow[t]{3}{*}{ Total: 136} & 34 & 34 & 34 & 28 & 82 \\
\hline (weight loss study) & $\begin{array}{l}\text { C: information session } \\
\text { (modified) and program } \\
\text { booklet }\end{array}$ & & 31 & 31 & 31 & 26 & 84 \\
\hline \multicolumn{2}{|l|}{ total: } & & 65 & 65 & 65 & 54 & 83 \\
\hline Morgan 2011 & $\begin{array}{l}\text { I: Internet weight loss } \\
\text { program; information } \\
\text { session and program } \\
\text { booklet; group-based } \\
\text { financial incentives }\end{array}$ & \multirow[t]{3}{*}{ Total: 127} & 65 & 65 & 65 & 54 & 83 \\
\hline (weight loss study) & C: wait list & & 45 & 45 & 45 & 36 & 80 \\
\hline \multicolumn{2}{|l|}{ total: } & & 110 & 110 & 110 & 89 & 81 \\
\hline Schroder 2010 & $\begin{array}{l}\text { I1: computer-assisted } \\
\text { intervention and } \\
\text { interactive software }\end{array}$ & \multirow[t]{4}{*}{ Total: 94} & 30 & 30 & 30 & 24 & 80 \\
\hline \multirow[t]{2}{*}{ (weight loss study) } & $\begin{array}{l}\text { I2: computer-assisted } \\
\text { intervention and } \\
\text { interactive software; in- } \\
\text { person self management } \\
\text { group training }\end{array}$ & & 31 & 31 & 31 & 26 & 84 \\
\hline & C: wait list & & 30 & 30 & 30 & 26 & 87 \\
\hline \multicolumn{2}{|l|}{ total: } & & 91 & 91 & 91 & 76 & 84 \\
\hline Svetkey 2008 & I1: in-person support & \multirow{4}{*}{$\begin{array}{l}1685 \text { in } \\
\text { weight loss } \\
\text { program } \\
653 \text { excluded } \\
\text { from weight } \\
\text { maintenance } \\
\text { trial } \\
\text { Total: } 1685\end{array}$} & 342 & \multirow[t]{4}{*}{-} & 341 & 320 & 94 \\
\hline \multirow[t]{2}{*}{ (weight maintenance study) } & $\begin{array}{l}\mathrm{C} 1 \text { : continue to practice } \\
\text { principles during weight } \\
\text { loss intervention }\end{array}$ & & 348 & & 347 & 323 & 93 \\
\hline & $\begin{array}{l}\text { C2: printed life-style } \\
\text { guidelines; meeting with } \\
\text { study interventionist }\end{array}$ & & 342 & & 341 & 321 & 94 \\
\hline \multicolumn{2}{|l|}{ total: } & & 1032 & & 1029 & 964 & 93 \\
\hline Tate $2001^{d}$ & $\begin{array}{l}\text { I: Internet behavioral } \\
\text { therapy }\end{array}$ & \multirow[t]{3}{*}{ Total: 114} & 45 & 45 & 45 & 33 & 73 \\
\hline \multirow[t]{2}{*}{ (weight loss study) } & $\begin{array}{l}\text { C: Internet educational } \\
\text { intervention }\end{array}$ & & 46 & 46 & 46 & 32 & 70 \\
\hline & total: & & 91 & 91 & 91 & 65 & 71 \\
\hline Tate 2003 & $\begin{array}{l}\text { I: Internet weight loss } \\
\text { program and weekly e- } \\
\text { mail behavioral } \\
\text { counseling }\end{array}$ & \multirow{2}{*}{$\begin{array}{l}273 \text { screened } \\
92 \text { ineligible } \\
145 \text { invited to } \\
\text { orientation } \\
37 \text { did not } \\
\text { attend } \\
108 \text { attended } \\
16 \text { excluded }\end{array}$} & 46 & 46 & 46 & 38 & 83 \\
\hline (weight loss study) & $\begin{array}{l}\text { C: Internet weight loss } \\
\text { program }\end{array}$ & & 46 & 46 & 46 & 39 & 85 \\
\hline
\end{tabular}




\begin{tabular}{|c|c|c|c|c|c|c|c|}
\hline Characteristic Study ID & $\begin{array}{l}\text { Intervention (s) and } \\
\text { control(s) }\end{array}$ & {$[n]$ screened } & [n] randomized & [n] safety & {$[\mathrm{n}]$ ITT } & [n] finishing study & $\begin{array}{l}{[\%] \text { of }} \\
\text { randomized } \\
\text { participants } \\
\text { finishing } \\
\text { study }\end{array}$ \\
\hline \multicolumn{2}{|l|}{ total: } & Total: 273 & 92 & 92 & 92 & 77 & 84 \\
\hline Tate 2006 & $\begin{array}{l}\text { I1: Internet weight loss } \\
\text { program and weekly e- } \\
\text { mail behavioral } \\
\text { counseling }\end{array}$ & \multirow{4}{*}{$\begin{array}{l}553 \text { screened } \\
239 \text { ineligible } \\
314 \text { invited to } \\
\text { orientation } \\
212 \\
\text { consented } \\
\text { Total: } 553\end{array}$} & 61 & 61 & 61 & 44 & 72 \\
\hline \multirow[t]{2}{*}{ (weight loss study) } & $\begin{array}{l}\text { I2: Internet weight loss } \\
\text { program and weekly } \\
\text { automated computer } \\
\text { feedback }\end{array}$ & & 64 & 64 & 64 & 52 & 81 \\
\hline & $\begin{array}{l}\text { C: Internet weight loss } \\
\text { program }\end{array}$ & & 67 & 67 & 67 & 59 & 88 \\
\hline \multicolumn{2}{|l|}{ total: } & & 192 & 192 & 192 & 155 & 81 \\
\hline Threlfall 1984 & $\begin{array}{l}\text { I: weight loss manual } \\
\text { plus computer-based } \\
\text { lessons }\end{array}$ & \multirow[t]{3}{*}{ Total: 119} & 38 & 38 & \multirow[t]{3}{*}{ not done } & 31 & 82 \\
\hline (weight loss study) & C: weight loss manual & & 38 & 38 & & 32 & 84 \\
\hline \multicolumn{2}{|l|}{ total: } & & 76 & 76 & & 63 & 83 \\
\hline Webber 2008 & $\begin{array}{l}\text { I: Internet weight loss } \\
\text { program and online chat } \\
\text { group sessions }\end{array}$ & \multirow{3}{*}{$\begin{array}{l}145 \text { screened } \\
52 \text { ineligible } \\
93 \text { invited to } \\
\text { orientation } \\
25 \text { did not } \\
\text { attend } \\
68 \text { attended } \\
\text { Total: } 66\end{array}$} & 33 & 33 & 32 & 32 & 97 \\
\hline (weight loss study) & $\begin{array}{l}\text { C: Internet weight loss } \\
\text { program }\end{array}$ & & 33 & 33 & 32 & 32 & 97 \\
\hline \multicolumn{2}{|l|}{ total: } & & 66 & 66 & 64 & 64 & 97 \\
\hline Wing $2006^{e}$ & $\begin{array}{l}\text { I1: Internet weight } \\
\text { maintenance program }\end{array}$ & \multirow[t]{4}{*}{ Total: 648} & 104 & 104 & 104 & 101 & 97 \\
\hline \multirow[t]{2}{*}{ (weight maintenance study) } & $\begin{array}{l}\mathrm{C} 1 \text { : continue to practice } \\
\text { principles during weight } \\
\text { loss intervention }\end{array}$ & & 105 & 105 & 105 & 92 & 88 \\
\hline & C2: quarterly newsletters & & 105 & 105 & 105 & 98 & 93 \\
\hline \multicolumn{2}{|l|}{ total: } & & 314 & 314 & 314 & 291 & 93 \\
\hline Wylie-Rosett 2001 & $\begin{array}{l}\text { I1: computerized weight } \\
\text { loss intervention and } \\
\text { workbook }\end{array}$ & \multirow[t]{4}{*}{ Total: 1041} & 236 & 236 & not done & 183 & 78 \\
\hline \multirow[t]{2}{*}{ (weight loss study) } & $\begin{array}{l}\text { I2: computerized weight } \\
\text { loss intervention, } \\
\text { workbook and staff } \\
\text { consultation }\end{array}$ & & 236 & 236 & & 194 & 82 \\
\hline & C: workbook & & 116 & 116 & & 97 & 84 \\
\hline \multicolumn{2}{|l|}{ total: } & & 588 & 588 & & 588 & 81 \\
\hline \multirow[t]{5}{*}{ Total } & all interventions & & 2452 & & & 2134 & 87 \\
\hline & all controls & & 1688 & & & 1497 & 89 \\
\hline & $\begin{array}{l}\text { all interventions and } \\
\text { controls }\end{array}$ & & 4140 & & & 3631 & 88 \\
\hline & $\begin{array}{l}\text { all weight maintenance } \\
\text { studies: intervention }\end{array}$ & & 552 & & & & \\
\hline & $\begin{array}{l}\text { all weight maintenance } \\
\text { studies: controls }\end{array}$ & & 1051 & & & & \\
\hline
\end{tabular}




\begin{tabular}{l|l|l|l|l|l|l|l}
\hline Characteristic Study ID & $\begin{array}{l}\text { Intervention (s) and } \\
\text { control(s) }\end{array}$ & {$[\mathbf{n}]$ screened } & {$[\mathbf{n}]$ randomized } & [n] safety & {$[\mathbf{n}]$ ITT } & [n] finishing study & $\begin{array}{l}\text { [\%] of } \\
\text { randomized } \\
\text { participants } \\
\text { finishing } \\
\text { study }\end{array}$ \\
\hline & $\begin{array}{l}\text { all weight maintenance } \\
\text { studies: total }\end{array}$ & & 1603 & & & & \\
\hline
\end{tabular}

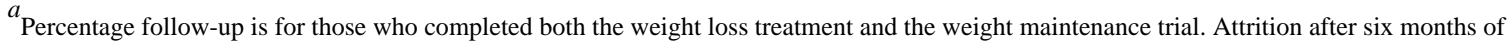
weight loss treatment was $18 \%$ and $24 \%$ over 18 months of weight loss followed by weight maintenance. Therefore the attrition from the weight maintenance segment was less than $20 \%$.

${ }^{b}$ Five participants were excluded from ITT analysis due to pregnancy after randomization.

${ }^{c}$ Participants were followed to 12 months (separate publication). Follow-up at 12 months was $71 \%$ and therefore we did not include the 12 -month data in this review.

$d_{\text {Authr }}$

follow-up, therefore 3-month data were included in the review. 71/91 (78\%) completed baseline and 6-month follow-up, therefore 6-month data were not eligible for inclusion in the review. Data for physical activity and diet at three and six months were only presented for $60 / 91$ (66\%) of participants and therefore were not included in the review.

${ }^{e}$ Follow-up varied across time points. Follow-up was $96 \%$ at six months, $92 \%$ at 12 months, and $93 \%$ at 18 months.

Abbreviations

C: control; I: intervention; ITT: intention-to-treat 